Florida International University FIU Digital Commons

$11-13-2008$

\title{
Successful and Sustained Leadership: A Case Study of a Jesuit High School President
}

Guillermo M. García-Tuñón, S.J.

Florida International University

DOI: $10.25148 /$ etd.FI10022513

Follow this and additional works at: https://digitalcommons.fiu.edu/etd

Part of the Elementary and Middle and Secondary Education Administration Commons

\section{Recommended Citation}

García-Tuñón, S.J., Guillermo M., "Successful and Sustained Leadership: A Case Study of a Jesuit High School President" (2008). FIU Electronic Theses and Dissertations. 284.

https://digitalcommons.fiu.edu/etd/284 


\section{FLORIDA INTERNATIONAL UNIVERSITY}

Miami, Florida

SUCCESSFUL AND SUSTAINED LEADERSHIP:

\section{A CASE STUDY OF A JESUIT HIGH SCHOOL PRESIDENT}

A dissertation submitted in partial fulfillment of the

requirements for the degree of

DOCTOR OF EDUCATION

in

EDUCATIONAL ADMINISTRATION AND SUPERVISION

by

Guillermo M. García-Tuñón, S.J.

2008 
To: Interim Dean Kingsley Banya

College of Education

This dissertation, written by Guillermo M. García-Tuñón, S.J., and entitled Successful and Sustained Leadership: A Case Study of a Jesuit High School President, having been approved in respect to style and intellectual content, is referred to you for judgment.

We have read this dissertation and recommend that it be approved.

$\begin{array}{r}\hline \text { Delia C. García } \\ \hline \text { Tonette S. Rocco } \\ \hline \text { Irma Becerra-Fernández } \\ \hline \text { Peter J. Cistone, Major Professor }\end{array}$

Date of Defense: November 13, 2008

The dissertation of Guillermo M. García-Tuñón, S.J. is approved.

Interim Dean Kingsley Banya
College of Education

Dean George Walker

University Graduate School

Florida International University, 2008 
C Copyright 2008 by Guillermo M. García-Tuñón, S.J.

All rights reserved. 


\section{DEDICATION}

I dedicate this dissertation to my father, Guillermo R. García-Tuñón, whose faith

and hard work have inspired me. I recognize that whatever success I have experienced in my life, be it small or great, is due in large part to his example. 


\section{ACKNOWLEDGMENTS}

I would like to thank and acknowledge the members of my committee for their support and guidance during this study. Dr. Delia García generously accepted sitting on my committee and expressed encouragement throughout the whole process. Dr. Tonette Rocco offered continuous insight into the world of qualitative research that helped solidify the findings of my study and her meticulous reading of my drafts helped improve its content. Dr. Irma Becerra-Fernandez graciously crossed over departments to widen and enrich the perspective of my committee and was a constant support and motivator. And, as chair of my committee and doctoral advisor, I would like to especially acknowledge Dr. Peter Cistone. Dr. Cistone was one of the first professors that I had at FIU and the friendship that ensued has been the catalyst to my enthusiasm for this study.

I would also like to acknowledge Dr. Isadore Newman for his concern and statistical expertise; Dr. Linda Bliss whose class on research that I took years ago helped make this dissertation possible and whose more recent advice gave final definition to what kind of study I would do; and Dr. Boanerges Dominguez, my statistical guru, whose patience, compassion, and generosity made the statistics portion of my work bearable and possibly even a joy. Also, to the members of my family, Belen Jesuit Preparatory School community, and Good Shepherd parish whose prayers were offered and answered.

Finally, I would like to acknowledge my Jesuit brothers at Villa Javier and thank them for their love and support during these years of research and study. I especially thank Fr. Marcelino García who so graciously allowed me to place his work and life under the microscope. Without them this would not have been possible. 


\title{
ABSTRACT OF THE DISSERTATION
}

SUCCESSFUL AND SUSTAINED LEADERSHIP: A CASE STUDY OF A JESUIT HIGH SCHOOL PRESIDENT

\author{
by \\ Guillermo M. García-Tuñón, S.J. \\ Florida International University, 2008 \\ Miami, Florida \\ Professor Peter J. Cistone, Major Professor
}

Fr. Marcelino García, S.J. has been the president of Belen Jesuit Preparatory

School for 25 years. The longevity and success of his tenure is an exemplary case of effective leadership and provided significant insight into what constitutes effective school leadership.

The target population for this case study consisted of the school's 7 administrators, 90 faculty members, 10 English-speaking staff members, and 3 key informants. Data were collected using Bolman and Deal's (1997) Leadership Orientation Survey along with the Jesuit Secondary Education Administration's (1994) Administrative Leadership Profile Survey (ALPS). Data collected from the surveys were analyzed using the SPSS, version 10.

The study also included data collected from focus interviews with Fr. García and six other significant members of the school community. The interviews were approximately 1-hour individual interviews that employed a semi-structured guide.

A concurrent triangulation method was used that directly compared the results from these data collection methods. This was done by looking at the data as a whole and 
in parts. The parts were internal (faculty, administrators, and staff) and external (parents, alumni, and the superior of the Jesuit community) sectors. The comparison of the findings was then examined in terms of each research question.

Analysis of the data revealed that while Fr. García's predominant leadership style reflected the typical Bolman and Deal characteristics associated with the political frame, his leadership demonstrates access to all four frames. Research has found a correlation between multiple frame use and successful leadership. Relatedly, Fr. García's capacity to approach his administration from various perspectives is indicative of success. In addition, from the perspective of Jesuit education, an analysis of Fr. García's leadership indicated recurring themes that contributed to the school's organizational health.

The results of this study provide an extensive analysis of the administration of a unique leader. An analysis of Fr. García's leadership style from two perspectives gives fresh insight into sustained and successful leadership. 


\section{TABLE OF CONTENTS}

CHAPTER

PAGE

I. INTRODUCTION ................................................. 1

Background to the Study ............................................

Leadership in Schools ............................................. 1

Jesuit Leadership .............................................. 2

Jesuit High School Leadership ....................................... 3

A Consummate Example of Jesuit High School Leadership ................. 4

Statement of the Problem ................................................ 5

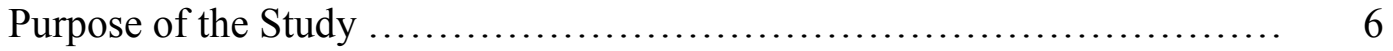

Research Questions .............................................. 6

Conceptual Framework .............................................. 6

Bolman and Deal's Multi-Frame Perspective ........................... 6

Characteristics of Jesuit Education .................................. 8

Relationship Between Conceptual Frameworks ........................... 9

Significance of the Study ............................................ 10

Definition of Terms ................................................... 11

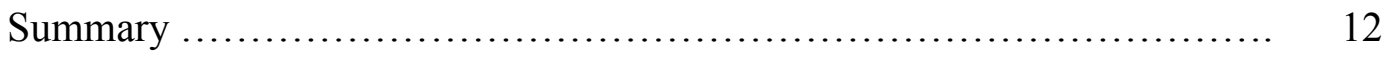

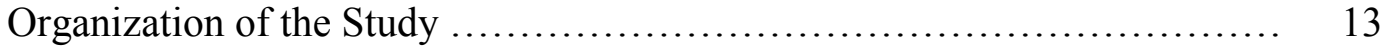

II. LITERATURE REVIEW ............................................... 14

The Nature of Leadership...................................................... 14

The Ability to Influence ........................................... 14

Grounded in Values .............................................. 16

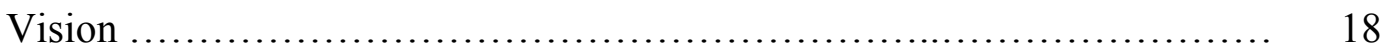

Bolman and Deal Multi-Frame Perspective ............................. 20

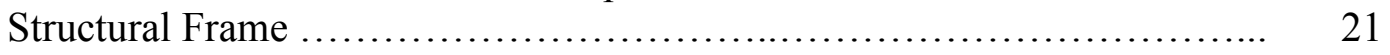

Human Resource Frame ............................................ 23

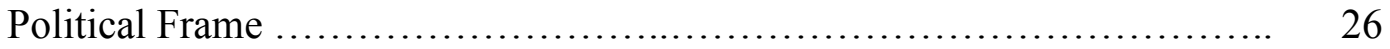

Symbolic Frame ....................................................... 29

Multiple Frames .................................................. 31

The Nature of Jesuit Leadership ...................................... 33

Self-Awareness .................................................... 34

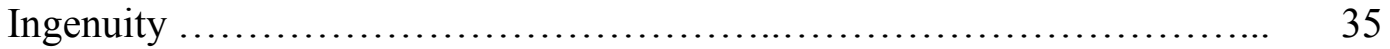

Love ....................................................................... 37

Heroism ........................................................... 40

The Characteristics of Jesuit Education ............................... 41

Brief History of Jesuit Education ..................................... 42

The Twenty-Eight Characteristics .................................... 44

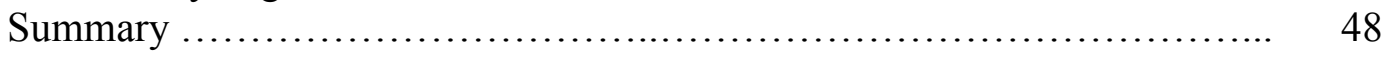

III. METHOD …...................................................... 50

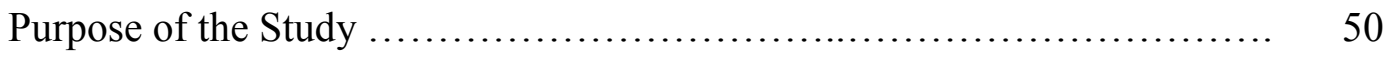

Research Questions ............................................ 50 


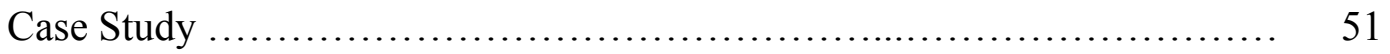

Procedures ........................................................... 52

Exemplary Case Selection ....................................... 52

Data Collection .................................................. 54

Quantitative Data ..................................................... 54

Target Population .................................................. 54

Leadership Orientations Survey .................................... 54

Administrative Leadership Profile Survey (ALPS) ...................... 57

Qualitative Data ................................................. 60

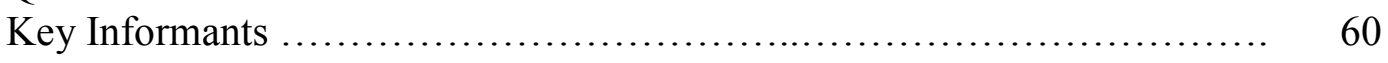

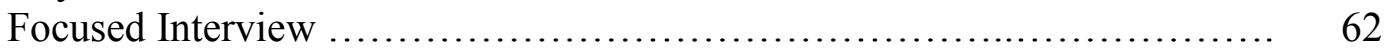

Data Analysis ....................................................... 63

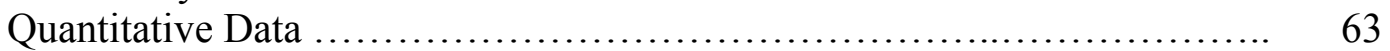

Qualitative Data ..................................................... 64

Concurrent Triangulation .............................................. 66

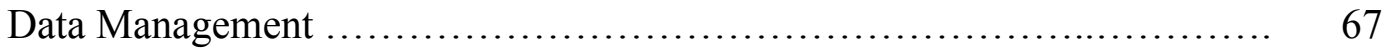

Role of the Researcher ................................................... 67

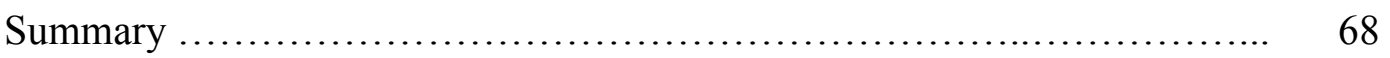

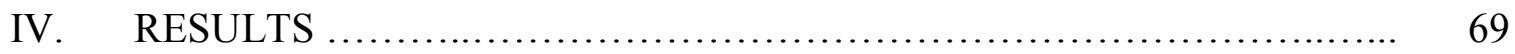

Relationship Between Data Sources ................................. 69

Assessment of Quantitative Data ................................... $\quad 70$

Leadership Orientations Survey Results .............................. $\quad 70$

Analyses of Responses .............................................. $\quad 70$

Section I Results: Leader Behaviors ................................. $\quad 70$

Section II Results: Leadership Style ............................... 72

Multi Frame Use ....................................................... 75

Section III Results: Overall Effectiveness as a Manager and Leader .......... 76

Correlations ....................................................... 76

Administrative Leadership Profile Survey (ALPS) Results .................. 77

Analyses of Responses ............................................ 77

Section I: Goal Importance and Performance of the President ............... 77

Section II: Organizational Health of the School ............................ 78

Section III: Statistical Results ........................................ 78

Assessment of Qualitative Data ....................................... $\quad 90$

Coding Process ........................................................ 91

Key Informants ................................................... 92

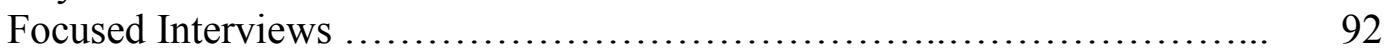

Structural Frame Evidence .......................................... 93

Human Resource Evidence ........................................... 95

Accessibility ............................................................ 95

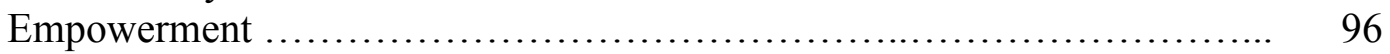

Political Frame Evidence ................................................. 98

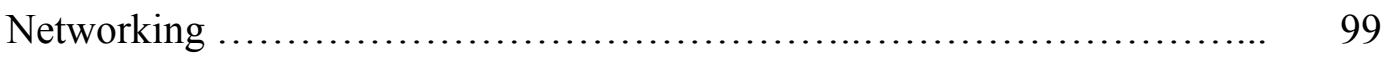

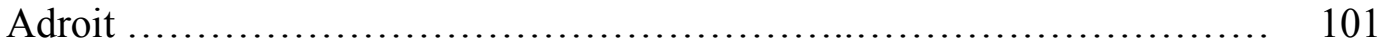

Symbolic Frame Evidence ........................................... 103 
Value-Oriented ....................................................... 103

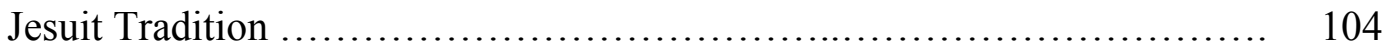

Recurring Themes ................................................ 106

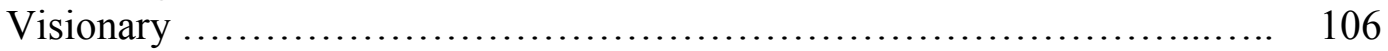

Alumni Association ................................................. 109

Parochial School Conflict .......................................... 111

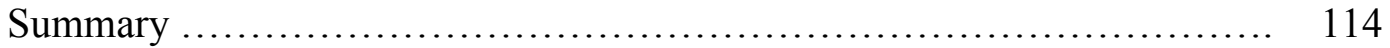

V. ANALYSIS, INTERPRETATION, AND IMPLICATIONS ............... 116

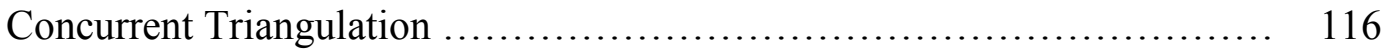

Research Questions ............................................... 116

Predominant Leadership Style ......................................... 117

Frame Use Effectiveness ............................................. 121

Multiple Frame Use ................................................ 126

Effective Jesuit Educational Leadership ............................... 127

Roles and Responsibilities ......................................... 128

Empowerment ........................................................... 129

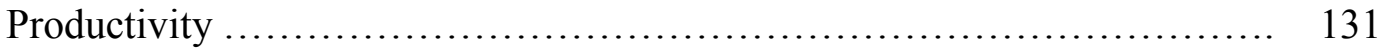

Effective Jesuit Leadership ........................................... 132

Contributing Factors to Jesuit Leadership Effectiveness .................... 132

Entrepreneurial Leadership ......................................... 132

Cura Personalis ............................................................ 135

Ignatian Vision: Value-Oriented ........................................ 139

Implications of Research ......................................... 141

Implications for Future Research .................................. 143

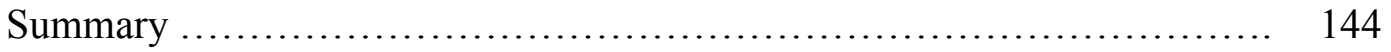

LIST OF REFERENCES ....................................................... 146

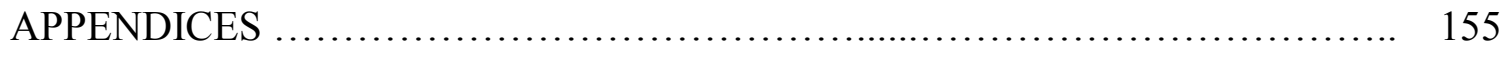

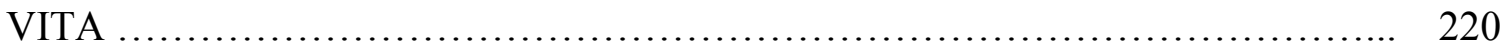




\section{LIST OF TABLES}

TABLE

PAGE

1. Section I - Leader Behaviors Total Mean Scores ........................ 71

2. Section II - Leadership Style Total Mean Scores ......................... 72

3. Section I - Leader Behaviors Results per Item ......................... 74

4. Section II - Leadership Style Rank Order per Item .................... 75

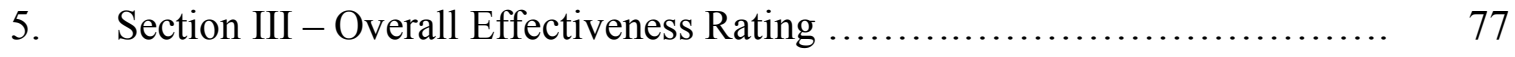

6. Correlations Between Frames ...................................... 78

7. Goal Performance of the President ................................. 80

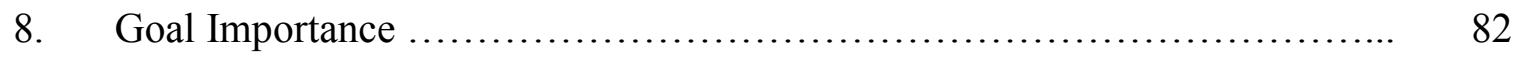

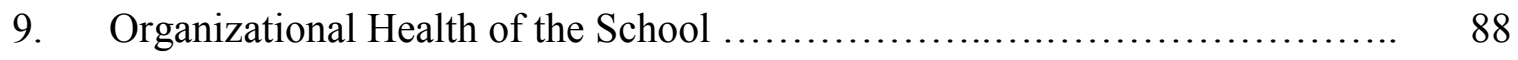

10. Multiple Frame Use ........................................... 122 


\section{CHAPTER I}

\section{INTRODUCTION}

This case study examined the factors and elements that have contributed to the success and longevity of the leadership of Fr. Marcelino García, S.J. in his role as a Jesuit high school president. This chapter presents the background to the study, problem statement, purpose of the study, the research questions guiding the study, the conceptual framework, the significance of the study, and definitions of terms.

\section{Background to the Study}

Fr. García has been the president of Belen Jesuit Preparatory School for 25 years. The longevity and success of his tenure is an exemplary case of effective leadership. As Lyman, Ashby, and Tripses (2005) observed, "a great deal can be learned about how to lead by studying those who do it well" (p. 1), an examination of the leadership of Fr. García provided significant insight into what constitutes effective school leadership.

Research on leadership and leadership effectiveness abounds. The inexhaustibility of the concept seems to reflect the significance of its impact. Salacuse (2006) states that, "Leadership is important, indeed vital, for the success of organizations" (p. 19). And while standard definitions of leadership abound in the literature (Bennis, 2003; Daft, 2008; Pfeffer, \& Sutton, 2006; Salacuse, 2006), it is possible to identify certain basic components that seem to permeate all understandings of what it is to be a leader.

\section{Leadership in Schools}

The role of leadership in schools is vital to school effectiveness and research has demonstrated that its proper exercise is linked to student success (Baker, 2007; Berger, 2002; Mulford, Silins, \& Leithwood, 2004; Sergiovanni, 2001). While definitions may 
have been formulated differently throughout the years about the nature of this leadership, the basic premise tends to remain the same: "maintaining the critical balance between management tasks to conserve the existing culture and leadership initiatives to create new or revised goals, policies, and procedures" (Barr \& Bizar, 2001, p. 4).

Leadership in both the private and public school sector, while influenced and shaped by different factors, strives to create and manage the appropriate environment that will be most conducive to attaining goals that have been agreed upon. Across the board, it seems that the most notable characteristics of educational leadership as found in the research are the ability to influence (Leithwood, Jantzi \& Steinbach, 1999; Lyman, Ashby, \& Tripses, 2005; Pfeffer \& Sutton, 2006; White, 2007; Yukl, 2002), being grounded in personal and professional values (Cohan, 2003; Fowler, 2000; Schumaker \& Sommers, 2001; Short \& Greer, 2002), and having vision (Daft, 2008; Salacuse, 2006; Sergiovanni, 2001; Short \& Greer, 2002; White, 2007).

Jesuit Leadership

The ability to identify and analyze Jesuit leadership is made possible because of the uniqueness of its source, the Spiritual Exercises of St. Ignatius of Loyola (Lowney, 2003; O'Malley, 1993; Wright, 2004). A study of the history of the Society of Jesus and its various contributions to numerous sectors of society viewed through the lens of the Spiritual Exercises can help formulate a definition of Jesuit leadership. Lowney (2003) has identified self-awareness, ingenuity, love, and heroism as the four values or pillars of Jesuit-style leadership that have marked the practices of the Society of Jesus since its foundation and have significantly contributed to its success. 


\section{Jesuit High School Leadership}

After the founding of the first Jesuit school in 1548 in Messina, Italy, the Society of Jesus took off on a path of education that has seen the founding of world-renown institutions of learning such as Georgetown University in 1789 and Japan’s Sophia University in 1913. To date, the Jesuit Secretariat for Education reports that in 68 countries, the Society of Jesus has 202 colleges and universities, 444 high schools (52 in the United States), 123 elementary schools, and 79 technical or professional institutions of learning. In total there are 848 institutions of education where 123,985 laymen and laywomen along with 4,621 Jesuits serve as teachers or administrators (Jesuit USA News, 2006).

What sets apart these institutions of learning from other schools is not only the rich tradition from which they stem, but also the specific characteristics that have been developed throughout the centuries that shape their pedagogy and direct their faculty and administrators making them distinctly Jesuit. At the source of these characteristics are the Spiritual Exercises of St. Ignatius of Loyola, founder of the Society of Jesus (Gray, 2000; ICAJE, 1994; Metts, 1995; Pavur, 2005). According to Newton (1994), this foundational document "can be seen as the spirit which animates and, through the experience it creates, provides the value structure for the Society's more practical educational documents" (p. 99).

The ministerial role of education in the Society of Jesus is very clear and its goals well defined. Father Pedro Arrupe, S.J., Superior General of the Society of Jesus from 1965-1983, clearly stated that,

A Jesuit school should be easily identifiable as such... if it is an authentic Jesuit school - that is to say if our operation of the school flows out of the strengths 
drawn from our own specific charisma, if we emphasize our essential characteristics and our basic options - then the education which our students receive should give them a certain 'Ignacianidad,' if I may use such a term. (1981, p. 257)

The organizational structure of Jesuit high schools has developed throughout the years in order to better meet the demands of a constantly evolving culture of education. Although Jesuit high schools vary in the manner in which they organize their administration, the one administrative position that is common to all Jesuit high schools is that of the president. Uncommon to public high school administration, Jesuit high schools, like many private high schools in the United States, implement the role of the president as its chief administrator (JSEA, 2000).

It is the president that is in charge of all other school administrators and leaders. According to the job description defined by the Jesuit Secondary Education Association (JSEA), the president's primary purpose "is to provide both spiritual and educational leadership for the school's achievement of its mission as a Jesuit high school." More specifically, the president "oversees the operations of the president's office, academics, school finances, development and fund-raising, promotions, public relations, alumni/ae relations, and the care and maintenance of the school's physical facilities" (2000). A Consummate Example of Jesuit High School Leadership

Fr. García has been the president of Belen Jesuit Preparatory School since July 31, 1983. As a president of a Jesuit high school in the United States with 25 years of service, Fr. García is an anomaly. Research indicated that the majority of Jesuit high school presidents have five or fewer years of experience, while only $35 \%$ of current Jesuit high school presidents have served for six years or more. Not only is Fr. García the longest serving active Jesuit high school president in the United States, his closest 
competitor trails by ten years. Furthermore, since the founding of the first Jesuit high school in the United States in 1789 only Fr. Anthony P. Sauer, S.J., president of St. Ignatius College Preparatory School in San Francisco, California from 1979-2006, has had a longer tenure (Jesuit Secondary Education Association, personal communication, September 17, 2007).

Such longevity and success made Fr. García an ideal candidate to study. His uncommonly lengthy tenure as president of a Jesuit high school provided an appropriate venue for analysis of educational leadership effectiveness.

Statement of the Problem

This research focused on the factors and elements that have contributed to the success and longevity of the leadership of Fr. García in his role as a Jesuit high school president. Among presidents in Jesuit high schools, the longevity of the leadership of Fr. García at Belen Jesuit Preparatory School is a rarity. In addition, the extraordinary growth that the school has experienced throughout his 25 year tenure has been significant. These factors warranted an examination of the leadership style that has contributed to such longevity and growth. Can Fr. García's leadership style be identified? Can the various factors and elements that have contributed to his success and longevity be recognized? While ample research has focused on leadership and leadership style of various educational leaders and in several educational contexts, no research has been reported on a Jesuit high school leader. 


\section{Purpose of the Study}

The purpose of this case study was to examine the factors and elements that have contributed to the success and longevity of the leadership of Fr. Marcelino García, S.J. in his role as a Jesuit high school president.

\section{Research Questions}

The main research question of this study was: What are the factors and elements that have contributed to the success and longevity of the leadership of Fr. García in his role as a Jesuit high school president? Additional questions that guided the study were:

1. In reference to Bolman and Deal's (1997) multi-frame perspective, what is the predominant leadership style of Fr. García?

2. In reference to Bolman and Deal's (1997) multi-frame perspective, what factors contribute to the effectiveness of Fr. García's style of leadership?

3. In reference to Jesuit educational leadership, is Fr. García an effective leader?

4. In reference to Jesuit educational leadership, what factors contribute to the effectiveness of Fr. García's style of leadership?

\section{Conceptual Framework}

Bolman and Deal's multi-frame perspective and the characteristics of Jesuit educational leadership are described below. In addition, both frameworks are briefly compared and contrasted.

\section{Bolman and Deal's Multi-Frame Perspective}

The research of Bolman and Deal (1997) identifies four perspectives, which they term frames, that provide a lens through which organizations can be viewed and their leaders think, act, and respond to everyday issues and problems. The first of the four 
frames is the structural frame. Developed from the work of American engineer Fredrick Taylor and German sociologist Max Weber, the structural frame concentrates on viewing the organization as an efficient structure, established with the goal of maximizing productivity.

The second of the four frames is the human resource frame. This frame focuses primarily on the individual and the individual's needs and tries to comply with them for greater effectiveness. According to this perspective, all organizations are composed of symbiotic relationships that are highly interdependent. The third frame is the political frame. It recognizes the human person as well as organizations as requiring political savvy to lead effectively. In this perspective, power and influence are good and necessary components. Finally, the symbolic frame views the organization through its rituals, traditions, and symbols, harnessing their potential to motivate and influence. Drawing its ideas from various sources such as sociology and anthropology, it identifies organizations as cultures that need to be understood and nurtured.

While the research of Bolman and Deal (1997) has identified these four different frames as the lenses through which administrators can possibly view their organizations, it is their conclusion after extensive research that the most effective leaders are those who are able to maintain a multi-frame perspective. Leaders who can apply more than one frame when various situations arise within their organizations will be more effective than those who are limited to one frame. This correlation between leadership effectiveness and the use of multi-frames has been extensively supported by the research literature on the topic (Berger, 2002; Green, 1992; Israel \& Kasper, 2004; Manning, 2001; Thompson, 2000, 2005; Wallace, 2000). 


\section{Characteristics of Jesuit Education}

The conviction of the Society of Jesus and its founders to establish itself in the field of education and the extraordinary growth of Jesuit institutions of education in a fairly short period of time made it necessary for the formulation of its pedagogical purpose and procedure for the sake of guidance and being of one mind (Pavur, 2005). In 1599, after fifty years of collaborated efforts, the Ratio atque Institutio Studiorum Societatis Jesu (Method and System of the Studies of the Society of Jesus) or Ratio Studiorum was produced as a monumental document that synthesized earlier traditions of the classical liberal arts, medieval scholasticism, and Renaissance humanism in the context of Christian ethics and spirituality for the sake of outlining a program of studies and its administration to be applied to all Jesuit schools around the world.

This voluminous work governed Jesuit education around the world for centuries until 1986 when the International Commission on the Apostolate of Jesuit Education of the Society of Jesus (ICAJE) published The Characteristics of Jesuit Education. The significant changes in educational and leadership theory motivated the need to modernize the Society of Jesus's approach to education while remaining faithful to the central precepts of the Society of Jesus and its religious convictions: "Developmental psychology and the social sciences, along with advances in pedagogical theory and education itself, have shed new light on the way young people learn and mature as individuals within a community; this has influenced course content, teaching techniques, and school policies" (ICAJE, 1994, p. 132).

In light of this new document, Jesuit schools began to refocus their pedagogical organizations and modernize their educational and administrative practices in order to 
assure that what they were producing in fact conformed to the modernly defined standards of Jesuit education. More specifically, the need to evaluate their schools and its administrators in light of this new pedagogical perspective became central to the success of implementing the 28 characteristics that the ICAJE now reformulated as epitomizing Jesuit education. These characteristics were divided into nine categories: worldaffirming, openness to growth, value-oriented, religious, committed to justice, in service of the Church, excellence in formation, community-oriented, reflection.

It is for this reason that the Jesuit Secondary Education Association (JSEA) developed the Administrative Leadership Profile Survey (ALPS) as an instrument for the evaluation of Jesuit high school administrators. "The survey results in a profile of the role and performance of the president or principal as viewed by the respondents at a particular time in the tenure of the administrator" (JSEA, 1994, p. 2). This study used the ALPS instrument to help examine the leadership style of Fr. García.

\section{Relationship Between Conceptual Frameworks}

The conceptual frameworks that guided this study are related. Even the most casual of overviews of their various points uncovers several similarities. Characteristics of Jesuit education such as care and concern for others, interest in the total formation of the individual, active life commitment, reliance on a spirit of community, value-oriented, and excellence in formation resonate clearly with both the human resource and structural frames as defined by Bolman and Deal (1997). In addition, while Jesuit education's emphasis on the ability to adapt means and methods to achieve certain goals while working in communion with the network of Jesuit system of schools parallels the 
political frame; its focus on its religious character expressed through its emphasis on prayer and worship and its identity with the Church resonates with the symbolic frame.

More specifically, where the characteristics of Jesuit education set itself apart is in its focus on its association with the Church and particular spirituality. Bolman and Deal's (1997) symbolic frame attests to the necessity of fostering culture and a particular institutional environment, whatever that culture and environment might be. Jesuit education clearly proposes a religious culture that foments a particularly Christian spirituality. The focus of Jesuit education is the promotion of Christian values evidenced mostly by its proposition of Jesus Christ as the model for human life and its declaration of service to the Church. It is this distinctiveness that defines Jesuit education, giving particular shape and flavor to the more general proclamations of Bolman and Deal's frames.

\section{Significance of the Study}

This study examined the factors and elements that have contributed to the success and longevity of the leadership of Fr. García in his role as a Jesuit high school president. Specifically, this study examined Fr. García's leadership applying two frameworks: Bolman and Deal's (1997) multi-frame perspective and the Society of Jesus's characteristics of Jesuit education. The application of both frameworks to the 25 year administration of Fr García contributed to the understanding of educational leadership effectiveness. 


\section{Definition of Terms}

Apostolate refers to all missionary and evangelical activity of the Catholic Church emphasizing that all activity is rooted in the mission of the apostles (Catechism of the Catholic Church, 1994).

Constitutions of the Society of Jesus are the norms formulated by St. Ignatius of Loyola that govern the Society of Jesus.

Cura personalis is a Latin phrase that translates as "care for the person" and refers to the individualized attention to the needs of the other and his or her particular circumstance and concern (ICAJE, 1994).

Ignatian or "Ignacianidad" is a term that refers to things that are directly associated to the spirituality of St. Ignatius of Loyola, founder of the Society of Jesus.

International Commission on the Apostolate of Jesuit Education of the Society of Jesus (ICAJE) was founded in 1980 as an international group composed of Jesuits and laymen and women for the purpose of addressing questions related to secondary education.

Jesuit is a term used to refer to a member of the Society of Jesus or anything directly associated with the Society of Jesus.

Jesuit Secondary Education Association (JSEA) was founded in 1970 in order to care for the particular needs of Jesuit secondary schools in the United States.

Laymen/women or laity are members of the Roman Catholic Church who are not ordained priests or vowed members of religious congregations.

Magis is a Jesuit phrase that in Latin means "the more" and applies to the level of excellence that all things associated with the Society of Jesus should have. 
School leadership has been defined as,

a process of influence leading to the achievement of desired purposes. Successful leaders develop a vision of their schools based on their personal and professional values. They articulate this vision at every opportunity and influence their staff and other stakeholders to share the vision. The philosophy, structures, and activities of the school are geared towards the achievement of this shared vision. (Bush \& Glover, 2003, p. 8)

Society of Jesus (Jesuits) is a missionary religious order of the Catholic Church founded by St. Ignatius of Loyola in 1541.

Spiritual Exercises are a month-long program of meditations, prayers, considerations, and contemplative practices set out in a brief manual written by St. Ignatius of Loyola that helps the Catholic faith to become more fully alive in the everyday life of contemporary people.

Spirituality is defined as an individual's or community's activity intended for the purpose of establishing and deepening a relationship with the sacred as that individual or community understands sacred.

Superior General of the Society of Jesus is the elected individual with "responsibility for the entire body of the Society, a person whose duty is the good government, preservation, and growth of the whole body of the Society" (Constitutions of the Society of Jesus, 1996, p. 356).

Summary

This case study examined the factors and elements that have contributed to the success and longevity of the leadership of Fr. García in his role as a Jesuit high school president. The study surveyed 110 members of the Belen school community using Bolman and Deal's Leadership Orientation (Self) and Leadership Orientation (Other) surveys. In addition, the study used the Jesuit Secondary Education Administration's 
Administrative Leadership Profile Survey (ALPS). The study also included interviews with Fr. García, president of Belen Jesuit Preparatory School; Mr. Leopoldo Nuñez, a longstanding administrator of Belen Jesuit Preparatory School; Mr. Fernando Arán, the president of the Belen Jesuit Alumni Association; Mr. Patrick Collins, a longstanding member of the faculty; Mrs. Carola Calderín, a member of the staff; Mrs. Maria Juncadella, the head of the parents' steering committee; and Fr. Francisco Pérez-Lerena, S.J., the Jesuit superior of the Miami section of the Society of Jesus. This chapter introduced the problem, the purpose of the study, research questions, conceptual framework, and significance of the study.

\section{Organization of the Study}

The next chapter will present the literature that has been reviewed that supports this case study. Included in the review of the literature is the extensive research that has been done on leadership, followed by an analysis of Bolman and Deal's (1997) multiframe theories for effective leadership and organizations and studies that have in the past used the multi-frame theory for investigating leadership effectiveness. In addition, the review of the literature will look at Jesuit leadership in particular along with the history of Jesuit education and its characteristics. Chapter 3 will then introduce and explain the case study research method and the quantitative and qualitative aspects of the study. Chapter 4 follows with the presentation of the data and findings of the study and chapter 5 concludes with the comparison of the data collected, data analysis, and direction for possible future research. 


\section{CHAPTER II}

\section{LITERATURE REVIEW}

In this section a review of the literature pertinent to this study is presented. First, this section presents an overview of the nature of leadership. Then the research involved in the development of Bolman and Deal's multi-frame perspective is addressed together with the literature that supports their perspective. Finally, this section reviews the literature that supports the pedagogical perspective of Jesuit leadership and education.

\section{The Nature of Leadership}

It seems pretty clear that one definition of leadership is very difficult to come by and that the attempt to reduce such a term into a compact statement is to do such a rich and complex concept a grave injustice (Bennis \& Nanus, 1997; Daft, 2008; Pfeffer \& Sutton, 2006; Salacuse, 2006). Various authors estimate that the number of definitions that have been formulated range in the hundreds with one estimate being as high as 850 (Bennis \& Nanus, 1997). Each of these descriptions provides a sliver of insight into the understanding of leadership while remaining incomplete and inadequate. But a study of the literature demonstrates that it is at least possible to identify basic components that seem to permeate all understandings of what it is to be a leader. This study focuses on three basic concepts that seem to be the most significant: the ability to influence, the grounding in values, and the presence of vision.

\section{The Ability to Influence}

Influence and the ability to use it is one of the central themes in the literature on leadership. Hughes, Ginnett, and Curphy (1995) define the term as "the change in a target agent's attitudes, values, beliefs, or behaviors as the result of influence tactics" (p. 339). 
Many researchers use other terms interchangeably such as motivation (Ferris, 2007), manipulation (Ammeter, Douglas, Gardner, Hochwarter, \& Ferris, 2002), or power (Pfeffer \& Sutton, 2006) describing them as "the extent to which the leader can influence subordinates" (Short \& Greer, 2002, p. 61). But whatever the terminology, the ability to get followers to act and perform in order to reach particular goals is a necessary requirement for the exercise of true effective leadership.

The power to influence can take various forms in any organization. Salacuse (2006) refers to this ability to influence specifically as "motivation" claiming that such a term better describes the relationship between leaders and subordinates. "Individuals are not robots... The task of any leader is to find and apply the means that will trigger - that will incite - other persons to take desired action for the benefit of the organization or group. That trigger is generally called 'motivation"' (p. 152).

Here Bolman and Deal (1984) agree and outline the following sources of power that a leader has access to in order to exude influence over others:

1. Authority. The higher an individual's position in an authority hierarchy, the more power the individual typically has.

2. Expertise. Expertise is the power of information and knowledge. People who have important information, people who know how to do things or get things done, can use their expertise as a source of power. Sometimes the expertise may be more symbolic than real - we might not be able to access our lawyer's competence, but we will probably not initiate a lawsuit without legal counsel.

3. Control of rewards. People who can deliver jobs, money, political support, and other valued rewards can be extremely powerful.

4. Coercive power. The union's ability to walk out, the student's ability to sit in, and the air controller's ability to slow down are all examples of coercive power in action.

5. Personal power. Individuals with charisma, political skills, verbal facility, or the capacity to articulate visions are powerful by virtue of personal characteristics, in addition to whatever other power they may have. (p. 116) 
Ultimately, no matter what its source, the use of power or the ability to exercise influence capacitates a leader to guide an organization to move in the right direction. Daft (2008) explains that, "leadership involves the influence of people to bring about change toward a desirable future" (p. 5).

\section{Grounded in Values}

Equally important to any definition of leadership is the determination of a set of values that will drive and give shape to an organization and its leaders. The relationship between the ability of a leader to influence and the establishment of a set of values is essential: "Leaders are at the same time shaped by the culture of their institutions and the shapers of that culture. Influencing institutional culture is an intangible part of leadership that involves using symbolism, articulating values, and setting the tone" (Green, 1992, p. 59).

Research on leadership agrees that leadership effectiveness is dependant on a set of values that help to give structure and direction (Beckner, 2004; Bennis \& Nanus, 1997; Cohan, 2003; Daft, 2008; Deal \& Kennedy, 1982; Fowler, 2000; Kouzes \& Posner, 2002; Morrill, 2007; O’Reilly, Chatman, \& Caldwell, 1991; Short \& Greer, 2002; Schumaker \& Sommers, 2001). More specifically, "a leader needs a philosophy, a set of high standards by which the organization is measured, a set of values about how employees, colleagues, and customers ought to be treated, a set of principles that make the organization unique and distinctive" (Kouzes \& Posner, 2002, p. 187).

This being the case, a leader's values or beliefs have to be clear because they are the standard for others to understand what is important in an organization. Kouzes and Posner (2002) view the role of a leader analogous to the function of a movie projector to 
its audience: "Unless leaders are in focus and clear about their values, their audience is likely to lose interest, become displeased, and channel their energies and resources into some other activity" (p. 195). A leader's values demonstrate not only where the organization needs to go, but also how it is going to get there. Values become the driving force towards the desirable, established goals. Deal and Kennedy (1982) state that, "values provide a sense of common direction for all employees and guidelines for their day-to-day behavior" (p. 21).

Within an organization it becomes critical for a leader to be able to share individual values with subordinates and motivate them to agree with these values. To arrive at a consensus of what is important and how the organization is going to get there becomes a key factor for effectiveness. The research performed by Kouzes and Posner (2002) makes evident the fact that an organization that shares a common set of values produces "tremendous energy." Their research indicates that shared values:

- Foster strong feelings of personal effectiveness.

- Promote high levels of company loyalty.

- Facilitate consensus about key organization goals and stakeholders.

- Encourage ethical behavior.

- Promote strong norms about working hard and caring.

- Reduce levels of job stress and tension. (p. 193)

A leader's individual values are rendered ineffective unless they are shared with subordinates because it is they who, as integral members of the organization, are going to help implement them and ultimately assure effectiveness. O’Reilly, Chatman, \& Caldwell (1991) summarize: "The pervasiveness and importance of values in organizational culture are fundamentally linked to the psychological process of identity formation in which individuals appear to seek social identity that provides meaning and connectedness" (p. 492). 
Vision

The integration and guiding of organizational efforts is made possible by the creation of a vision on the part of a leader. If a vision, or look towards the future, does not exist then the ability to influence others and the formulation of a set of values is essentially not possible. The critical function of leadership becomes the establishment of a common vision for the organization and the ability to communicate that vision to others.

Here the research literature seems to agree and concur with Bennis (2003) who claims that,

The first basic ingredient of leadership is a guiding vision. The leader has an idea of what he wants to do - professionally and personally - and the strength to persist in the face of setback, even failures. Unless you know where you're going, and why, you cannot possibly get there (p. 39).

Kouzes and Posner (2002) refer to four attributes of vision that expand an understanding of what the term implies. First, visions must be future orientated and should therefore be formulated as statements that point to a destination; they become "a point on the horizon" that will one day, at some moment in time be reached. Daft (2008) explains that vision "is an ambitious view of the future that everyone involved can believe in, one that can realistically be achieved, yet one that offers a future that is better in important ways that what now exists" (p. 389).

Second, visions need to "see the future;" that is, they have to be visual. It is interesting to note that the language used by leaders and visionaries always refers to sight, the ability to envision. "When we invent the future, we try to get a mental picture of what things will be like long before we have begun the journey" (Kouzes \& Posner, 2002 , p. 89). This visual formulation of the future helps facilitate the task of sharing the 
vision with others, helping them to see what is expected and desired. "A shared vision of the future suggests measures of effectiveness for the organization and for all its parts. It helps individuals distinguish between what's good and what's bad for the organization, and what it's worthwhile to want to achieve" (Bennis \& Nanus, 1997, p. 84-85). The ability that a leader has to conceptualize the future makes it that much easier to communicate the vision in order to secure commitment among members of the organization.

Third, visions have to communicate the ideal and serve as standards of excellence. No leader can ever expect to be effective if his vision is ordinary and lame. Great leaders have always shot for the moon and have extended their reach far beyond mere probability to extraordinary possibility. As Hammer and Champy (1996) emphasize, "visions have to be powerful" (p. 155). And not simply do the visions themselves have to be grand, but leaders have to be able to communicate them with fervor and conviction. Kouzes and Posner (2002) maintain, "leaders cannot ignite the flame of passion in their followers if they themselves do not express enthusiasm for the compelling vision of the group" (p. $10)$.

Lastly, Kouzes and Posner (2002) highlight that visions have to be unique and therefore set an organization apart from others: "There is no advantage in working for, buying from, or investing in an organization that does exactly the same thing as the one across the street or down the hall" (p. 91). A leader's ability to formulate a distinctive vision for his organization helps to instill pride in what is being done and can act as "the flag around which to rally the troops" (Hammer \& Champy, 1996, p. 154). Such 
uniqueness helps to foster pride among those associated with the organization and booster self-confidence and, eventually, productivity.

\section{Bolman and Deal Multi-Frame Perspective}

Studies of organizations and their leadership throughout history have produced various schools of thought that have spun off theories that have in turn generated plans of action intended to maximize productivity and effectiveness (Argyris, 1990; Ferris, 2007; Malen \& Rice, 2004; Manning, 2001; Pfeffer, 1992; Taylor, 2001; Weber, 2001). These theories, while rooted in their particular historical context, have contributed significantly to modern understandings of organization theory and their influence is still prevalent today.

Bolman and Deal (1997) have gathered the core components of these various theories and have identified four leadership and organizational perspectives, which they labeled frames, which underpin the ways that leaders think, act, and respond to everyday issues and problems. They selected the frames metaphor to conceptualize the understanding of organizations from a variety of perspectives. "Frames are both windows on the world and lenses that bring the world into focus. Frames filter out some things while allowing others to pass through easily. Frames help us order experience and decide what to do" (p. 12).

The research of Bolman and Deal (1997) has had a significant impact on the literature of organizational theory and leadership. Particularly significant has been their findings on multi-framing where they conclude that "the ability to use multiple frames was a consistent correlate of effectiveness" (p. 278). Educational researchers have taken the Bolman and Deal findings and have applied them to a wide variety of educational 
scenarios and settings (Berger, 2002; Green, 1992; Israel \& Kasper, 2004; Manning, 2001; Thompson, 2000, 2005; Wallace, 2000).

\section{Structural Frame}

The extensive research performed by American engineer Fredrick Taylor and German sociologist Max Weber gave eventual rise to the structural constructs of organizations (Bolman \& Deal, 1997). Taylor's scientific management philosophy, also referred to as classical theory, and Weber's bureaucratic model provide the theoretical basis of the structural frame. Division of labor and specialization of tasks were instruments that helped revolutionize the way that organizations operated and met goals. Such ideas have helped bring about a formalization of administration that helps to compartmentalize an organization for maximum efficiency and productivity.

Scientific management applied to the organizational setting elevated efficiency to a very high rank and implied that an organization could be constructed according to a blueprint. Fredrick Taylor (2001) stated that,

The first of the great principles of scientific management, the first of the new burdens which are voluntarily undertaken by those on the management side is the deliberate gathering together of the great mass of traditional knowledge which, in the past, has been in the heads of the workmen, recording it, tabulating it, reducing it in most cases to rules, laws, and in many cases to mathematical formulae, which, with these new laws, are applied to the cooperation of the management to the work of the workmen. This results in an immense increase in the output, we may say, of the two. (p. 65)

This classical theory identified the primary responsibility of a leader as "the needs of the organization, not the needs of the individual" (Hersey, Blanchard, \& Johnson, 1996, p. 96). Leadership became formalized and an administrative hierarchy was defined in order to maintain maximum efficiency. Max Weber (2001) includes this new formulation of leadership in his list of characteristics of bureaucracy, "The principles of 
office hierarchy and of levels of graded authority mean a firmly ordered system of superand subordination in where there is a supervision of the lower offices by the higher ones" (p. 73).

It is from the classical theory of organization and leadership that Bolman and Deal (1997) identified the structural frame. According to Bolman and Deal there are six assumptions that lay the foundation for the structural frame:

1. Organizations exist to achieve established goals and objectives.

2. Organizations work best when rationality prevails over personal preferences and external pressures.

3. Structures must be designed to fit an organization's circumstances (including its goals, technology, and environment).

4. Organizations increase efficiency and enhance performance through specialization and division of labor.

5. Appropriate forms of coordination and control are essential to ensuring that individuals and units work together in the service of organizational goals.

6. Problems and performance gaps arise from structural deficiencies and can be remedied through restructuring. (p. 40)

This mechanistic perspective took hold of educational organizations during the first major growth period of formal systems of education in the United States from the late $19^{\text {th }}$ century to the end of World War I and propelled organizational leadership into a more managerial role. Callahan (1962) discovered that school leaders at the time tended to follow the predominant values of the era emphasizing the necessity to achieve high efficiency and lower costs for the operations of schools.

Bolman and Deal (1992a), in light of the structural frame, gave rise to the metaphor of "the school as a factory" (p. 36). While at first the idea of viewing the schoolhouse as a factory may raise eyebrows because it equates students to products and teachers as factory-workers, the application of this frame signifies the role of the school 
leader as being one of fomenting an environment where clear goals, rationality, efficiency, and accountability are integral characteristics of the organization.

Contemporary school settings still demonstrate many of the principles described above. Included in schools could be found principles such as "division of labor, hierarchy of authority, specified regulations and work procedures, minimal personal relations, and rewards based on technical competence" (Carlson, 1996, p. 21). But while all of these characteristics can be found in modern school settings, the more prominent trace of the structural frame found in schools today is goal-setting and its effects on school effectiveness (McTighe \& O'Connor, 2005; Sergiovanni, 2001; Schumaker \& Sommers, 2001; Szente, 2007).

\section{Human Resource Frame}

The focus of the human resource frame as proposed by Bolman and Deal (1997) is the needs of the individual and draws upon the conclusion that any organization that strives to meet the basic needs of that individual will be successful. The perspective of the human resource frame focuses on a symbiotic relationship between the individual and the organization, understanding that one could not survive without the other. This is a somewhat drastic turn from the perspective of the structural frame that focused on efficiency, rules and regulations.

Bolman and Deal (1997) refer to the following four assumptions as the building blocks for the human resource frame:

1. Organizations exist to serve human needs rather than the reverse.

2. People and organizations need each other: organizations need ideas, energy, and talent; people need careers, salaries, and opportunities.

3. When the fit between individual and system is poor, one or both suffer: individuals will be exploited or will exploit the organization - or both will become victims. 
4. A good fit benefits both: individuals find meaningful and satisfying work, and organizations get the talent and energy they need to succeed. (pp. 102-103)

The rise of this person-centered perspective finds support in the work of American-born psychologist Abraham Maslow (2001) and his studies on human need. If the human resource frame emphasizes the needs of the individual, then what exactly are those needs? Maslow identified a hierarchy of needs that are common to all humans, some being more fundamental than others. He grouped these human needs into five basic categories:

1. Physiological (needs for oxygen, water, food, physical health, and comfort)

2. Safety (to be safe from danger, attack and threat)

3. Belongingness and love (needs for positive and loving relationships with other people)

4. Esteem (to feel valued and to value oneself)

5. Self-actualization (needs to develop to one's fullest, to actualize one's potential)

While these five human needs are universal, it is important to note that Maslow recognizes that there are some that are more important or necessary than others. More specifically, the physiological and safety needs necessarily take precedence over the other needs. Maslow adds though that once these needs are satisfied, humans are inclined to then satisfy the others: "Human needs arrange themselves in hierarchies of prepotency. That is to say, the appearance of one need usually rests on the prior satisfaction of another, more pre-potent need. Man is a perpetually wanting animal” (Maslow, 2001, p. 167). Maslow goes on to claim that the other basic needs fluctuate in importance depending on factors such as an individual's race, culture, and psychological make-up. 
In addition to Maslow's hierarchy of needs, Douglas McGregor's Theory X and Theory Y assumptions have played a vital role in supporting the formulation of the human resource frame. McGregor (1960) argued that managers who adopt a Theory X perspective view their subordinates as lazy, passive, and with little ambition. Managers who adopt a Theory Y perspective assume that their subordinates can be very effective, motivated, and creative if the proper conditions and environment are generated in order to foster it. "The essential task of management is to arrange organizational conditions so that people can achieve their own goals best by directing their efforts toward organizational rewards" (McGregor, 1960, p. 61).

In line with McGregor's assumptions, Argyris (1990) admits that both organizations themselves and the individuals that compose them are complex entities and therefore prone to constant conflict and possible failure. One of the key problems is when the organization's administration does not focus on the individuals under its charge and therefore fails to harness their potential contribution to the realization of the organization's goals. Argyris (1990) insists that organizations are required to "provide opportunities for work in which the individual is able to define his immediate goals, define his own paths to these goals, relate these to the goals of the organization, evaluate his own effectiveness, and constantly increase the degree of challenge at work" (p. 3334).

Schools easily fit the human resource bill because of the frame's emphasis on relationships and creating nurturing environments. School communities have traditionally been characterized as providers of healthy and safe environments of learning for its various stakeholders. To view the school as a "family" (Bolman and Deal, 1992a, p. 38) 
does not require a stretch of the imagination and ample research exists to this expectation (Duttweiler, 1990; Miller \& Rowan, 2006; Sergiovanni, 2001; Seyfarth, 2002). In addition, research also proves that these "familial" environments have an effect on student learning. "Human resource management has a direct impact on school's instructional effectiveness by decisions about recruitment, selection, induction, evaluation, and development of instructional staff members" (Seyfarth, 2002, p. 10).

\section{Political Frame}

Politics have always played an important part in the development and administration of organizations even though it is only more recently that researchers have taken a keen interest in it. Pfeffer (1981) in his landmark book titled Power in Organizations seems to be one of the first to use the term "political skill" in the leadership literature and examine the effects of politics and power in the way organizations are run and how their leaders must act. Mintzberg (2001) defines "political skill" as,

The ability to use the bases of power effectively - to convince those to whom one has access, to use one's resources, information, and technical skills to their fullest in bargaining, to exercise formal power with a sensitivity to the feelings of others, to know where to concentrate one's energies, to sense what is possible, to organize the necessary alliances. (p. 355)

The aforementioned research concurs with the effects of political skills in organizations, "it is assumed that although performance, effectiveness, and career success are determined in part by intelligence and hard work, other factors such as social astuteness, positioning, and savvy also play important roles" (Ferris, Treadway, Perrewé, Brouer, Douglas, Lux, 2007, p. 291). 
This perspective gives rise to the political frame and has Bolman and Deal (1997) describing organizations as "alive and screaming political arenas that host a web of individual and group interests" (p. 163). They list five propositions that characterize the political frame:

1. Organizations are coalitions of various individuals and interest groups.

2. There are enduring differences among coalition members in values, beliefs, information, interests, and perceptions of reality.

3. Most important decisions involve the allocation of scarce resources - who gets what.

4. Scarce resources and enduring differences give conflict a central role in organization dynamics and make power the most important resource.

5. Goals and decisions emerge from bargaining, negotiation, and jockeying for position among different stakeholders. (p. 163)

Numerous researchers have focused on the political character of organizations emphasizing the role of power as necessary for their proper administration (Ammeter et al., 2002; Ferris et al., 2007; Pfeffer, 1981, 1992; Pfeffer \& Fong, 2005; Pfeffer \& Sutton, 2006, Vecchio, 2007). Pfeffer (1992) defines power as "the potential ability to influence behavior, to change the course of events, to overcome resistance, and to get people to do things that they would not otherwise do" (p. 30). Bolman and Deal (1997) put it more simply by claiming that it is "basically the capacity to get things to happen" (p. 165).

In addition to the need for and use of power, Bolman and Deal (1997) also refer to both the struggle for scarce resources and negotiation as underlining factors in the political perspective of organizations. Ammeter et al. (2002) indicates a correlation between politics and the struggle for resources, "research indicates that organizational politics occurs more often at higher organizational levels, which is indicative of the availability of resources and information" (p. 758). Kanter (2005) more powerfully makes reference to both these factors by claiming that, "the effectiveness that power 
brings evolves form two kinds of capacities: first, access to resources, information, and support necessary to carry out a task; and, second, ability to get cooperation in doing what is necessary" (p. 343).

Even though schools are expected to be exempt from "dirty" politics and power struggles, nothing can be farther from the truth. For examples, the financial crisis that hit American schools in the 1970s had schools vying for money, supplies, and even students. Bolman and Deal (1997) refer specifically to the struggle with scarce resources as a major item in the political perspective of schools and their administrators. Wirt and Kirst (2001) explain that even though the public would prefer to think of schools as hallowed institutions of learning, the fact is that schools "act as miniature political systems themselves" (p. 29).

The literature demonstrates the attention that has been given to politics in the school environment (Bolman \& Deal, 1992a, 1997; Howell, 2005; Lyman, Ashby, \& Tripses, 2005; Malen \& Rice, 2004; Marshall \& Scribner, 1991; Wirt \& Kirst, 2001). Marshall and Scribner (1991) argue that the presence of politics in schools is simply because, "Students, teachers, parents, staff members, and administrators within schools have conflicting notions about what should happen in the immediate moment and also over the long term in the life of the school, and how the school should manage or distribute its valued resources" (p. 350). For the school leader this requires an ability to be a politician by influencing "the socioeconomic, legal, political, and cultural contexts of schooling through proactive leadership" (Van Meter \& McMinn, 2001, p. 33). 


\section{Symbolic Frame}

Of the frames presented by Bolman and Deal (1997) it is the symbolic frame that seems to be the most eclectic. The traits identified with this frame are the focus of a variety of more modern sciences such as sociology, anthropology, and symbology. What the symbolic frame encompasses has attracted much attention recently and, with its contribution to understanding organizations as cultures, has created a whole new outlook that has opened new windows of insight. "In the last decade or so it [culture] has been used by some organizational researchers and managers to indicate the climate and practices that organizations develop around their handling of people or to refer to the espoused values and credo of an organization" (Schein, 2001, p. 369).

But the term culture is complex and well-contested, warranting as many definitions as did the concept of leadership. Cook and Yanow (2001) define culture in application to organizations as "a set of values, beliefs, and feelings, together with the artifacts of their expression and transmission (such as myths, symbols, metaphors, rituals), that are created, inherited, shared, and transmitted within one group of people and that, in part, distinguish the group from others" (p. 404). The symbolic frame addresses this reality of organizations understanding that ultimately "what happens" is not as important as "what it means."

For Bolman and Deal (1997) the symbolic frame is composed of the following six assumptions:

1. What is most important about any event is not what happened but what it means.

2. Activity and meaning are loosely coupled: events have multiple meanings because people interpret experience differently.

3. Most of life is ambiguous or uncertain - what happened, why it happened, or what will happen next are all puzzles. 
4. High levels of ambiguity and uncertainty undercut rational analysis, problem solving, and decision-making.

5. In the face of uncertainty and ambiguity, people create symbols to resolve confusion, increase predictability, provide direction, and anchor hope and faith.

6. Many events and processes are more important for what is expressed than what is produced. They form a cultural tapestry of secular myths, rituals, ceremonies, and stories that help people find meaning, purpose, and passion. (pp. 216-217)

It appears that much of what is involved in the symbolic perspective refers to an understanding of the human condition; how individuals are by nature. Researchers have ventured to extend this understanding of the human condition into the corporate world and concluded that the culture of a corporation, with all its particular practices and customs, has a major effect on its success (Cook \& Yanow, 2001; De Pree, 1995; Deal and Kennedy, 1992; Schein, 2001; Trice \& Beyer, 2001). Deal and Kennedy (1992) state plainly that, "Every business has a culture... culture has a powerful influence throughout an organization; it effects practically everything... Because of this impact, we think that culture also has a major effect on the success of the business" (p. 4).

While Bolman and Deal (1992a; 1992b) have led the charge in applying the symbolic frame specifically to school organizations and their leadership, other researchers have also contributed significantly to the importance of identifying the various symbols, myths, and customs that help generate school culture and successful leadership (Manning, 2001; Sergiovanni, 2001; 2005; Short \& Greer, 2002).

It is particularly on the shoulders of a school's leader to foment the school's culture. Short and Greer (2002) state, “the shaping, enhancement, and maintenance of a school's culture are primary responsibilities of the school's leaders" (p. 35). Sergiovanni (2001) especially emphasizes the importance of culture and symbol in the school and 
refers to the school leader as the "high priest" whose responsibility is to "define, strengthen, and articulate those enduring values, beliefs, and cultural strands that give the school its unique identity over time" (p. 105).

\section{Multiple Frames}

The intention of undertaking the development of each of the frames aforementioned is to help provide leaders of organizations insight into understanding their organization's structure, the various possible organizational situations that arise, and even offer an awareness of which frame a leader naturally tends to work with (Bolman and Deal, 1997). As demonstrated above, substantial literature has been written to support the identification of each of these four frames and their ability to empower organizations and their leaders.

But at the same time a wave of research surfaced that supports the conclusions of Bolman and Deal (1997) that claims that leaders who employ multiple frames in their administration of an organization are more effective than leaders who employ only one frame (Berger, 2002; Bush \& Glover, 2003; Israel \& Kasper, 2004; Newmann, 1993; Thompson, 2000, 2005; Wallace, 2000). Their belief is that a multi-frame perspective is a requirement for success because "an increasingly complex and turbulent organizational world demands greater cognitive complexity: effective managers need to understand multiple frames and know how to use them in practice" (Bolman \& Deal, 1991, p. 528).

Bolman and Deal (1992b) examined the relationship between leadership and management for 140 school administrators in the United States and 229 school administrators in Singapore. They did not instruct their respondents on how to distinguish between manager and leader because they wanted to learn how they gave meaning to the 
two terms. The results demonstrated that in both the United States and Singapore the effective school manager is someone oriented toward structure and symbols. The effective school leader in Singapore is oriented to symbols and structure while in the United States the school leader is oriented to symbols, people, and politics.

In one of the first known studies on multi-framing, Bensimon (1989) analyzed the responses of thirty-two college and university presidents that reflected espoused leadership theories in order to identify their use of the cognitive frames. The results demonstrated that new presidents were likely to hold leadership theories with a singleframe orientation in comparison to the multi-frame views of more tenured presidents. Bensimon (1989) concluded that this was more than likely due to older presidents having had more of an opportunity to assimilate the potential complexities of their role and thus being better prepared to shift from one frame to another. He concluded: "espousing a multi-frame theory implies the ability to shift frames in response to situational circumstances" (p. 116).

Studies indicate that the more common practice for leaders is to employ a dualframe perspective, while the use of more than two seems to be more elusive a practice. While the research seems to indicate that the use of the frames depends on factors such as tenure, culture, and context, what does seem to be true across the board is that greater leadership effectiveness depends on the ability to use multiple frames. Bolman and Deal (1997) conclude: "Studies of effective corporations, of individuals in senior management roles, and of public administrators all point to the need for multiple perspectives in developing a holistic picture of complex systems" (p. 279). 


\section{The Nature of Jesuit Leadership}

There is not much research that describes specifically what the nature of Jesuit leadership is. While scores of literature has been written on the history of the Society of Jesus, its various members throughout its 500-year history, its contributions to education and the sciences, and its spirituality, little exists on Jesuit leadership. Jesuits are leaders and traditionally have been in the business of forming leaders. Almost from the beginning of its foundation in 1541, the Society of Jesus has been involved in leadership.

At the core of everything Jesuit are the Spiritual Exercises of St. Ignatius of Loyola. The result of an 11-month hermitage in a secluded cave in the village of Manresa just outside of the city of Barcelona, Ignatius of Loyola composed a four week silent retreat that requires its retreatants to contemplate, meditate, and examine their conscience with the purpose of discovering themselves and the presence of God in their lives (O'Malley, 1993). Wright (2004) refers to the Spiritual Exercises as, "the lodestone of a distinctive Ignatian spirituality - arguably one of the most impressive, enduring Jesuit contributions to the Roman Catholic tradition" (p. 18).

It is from the experience of the Spiritual Exercises that is born the impetus of the Society of Jesus. The retreat becomes the central, formative experience in the life of a Jesuit and sets the standard for his manner of proceeding (O’Malley, 1993). It is also from the Spiritual Exercises that a conceptualization of Jesuit leadership can be developed. A study of the history of the Society of Jesus and its various contributions to numerous sectors of society viewed through the lens of the Spiritual Exercises can help formulate a definition of Jesuit leadership. Lowney (2003) has identified four unique values or pillars of Jesuit-style leadership: self-awareness, ingenuity, love, and heroism. 


\section{Self-Awareness}

One of the key ingredients to the formation of a Jesuit is a process that has been called the examination of conscience. This daily exercise is a process of becoming aware of an individual's strengths and weaknesses, missions and goals, and ultimately his place in the world through an evaluation of his thoughts, words, and actions (de Guibert, 1972). According to Ignatius in the Spiritual Exercises, the purpose is so that the individual can get to know himself so well that he may "perceive the disorder in his actions, in order to detest them, amend himself, and put himself in order" (1992, p. 45).

Ignatius of Loyola suggested that this examination should be done at least three times a day, each time giving the individual the opportunity to go over what has happened and what is to come. Ignatius himself writes: "the individual should make the examination, exacting an account of self with regard to the particular matter decided upon for correction and improvement. He should run through the time, hour by hour or period by period, from the moment of rising, until the present examination" (The Spiritual Exercises of St. Ignatius of Loyola, 1992, p. 33).

Current research in leadership agrees on the importance of self-awareness as a major contributor to effective leadership (Badaracco, 1998; Drucker, 1999; Ruderman \& Ernst, 2004; Taylor-Bianco \& Schermerhorn, 2006; Wildermuth \& Wildermuth, 2006). The ability of a leader to self-examine values, motives, and goals creates the opportunity for personal growth and ultimately the growth of the organization. Ruderman and Ernst (2004) explain that, "the efforts to develop better leaders have traditionally promoted self-knowledge of individual strengths and weaknesses, motivations, management styles, 
and deeply held values. In today's increasingly volatile and complex organizational

environment, it's as important as ever for leaders to understand themselves" (p. 3).

One of the greatest advantages of self-awareness is the opportunity that it presents

for continuous learning and growth. In a constantly changing environment this can

determine the difference between success and failure. Referring to the responsibility of

managers of organizations Badaracco (1998) writes:

They are able to take time out from the chain of managerial tasks that consumes their time and undertake a process of probing self-inquiry - a process that is more often carried out on the run than in quiet seclusion. They are able to dig below the busy surface of their daily lives and refocus on their core values and principles.

Once uncovered, those values and principles renew their sense of purpose at work and act as a springboard for shrewd, pragmatic, politically astute action. By repeating this process again and again throughout their work lives, these executives are able to craft an authentic and strong identity based on their own, rather than someone else's, understanding of what is right. And in this way, they begin to make the transition from being a manager to becoming a leader. (p. 116)

It is obvious that the practice of self-evaluation that leads to self-awareness is not an exercise unique to Ignatius and the Society of Jesus, but it is a practice that has been integral to the formation of Jesuits throughout its long history and a reason for its success. It is exactly this exercise demanded by Ignatius of his followers that led Drucker (1999) to express that "the steadfast focus on performance and results that this habit produces explains why the institution [he founded], the Jesuit order, came to dominate Europe within 30 years" (p. 66).

Ingenuity

Lowney (2003) describes Jesuit ingenuity as, "the ability to innovate, to absorb new perspectives, to respond quickly to opportunities or threats, and to let go of strategies that no longer work in order to embrace new ones" (p. 165). This knack for change when the situation or moment requires it finds its greatest expression in the very life of Ignatius 
of Loyola who in 1521 at the age of thirty was able to bring about the monumental change in his life that would have him leave his home in the Basque region of Northern Spain to explore the world, an opportunity that would present great challenges and opportunities (O’Malley, 1993).

This ability to change and be innovative was so valuable to Ignatius that he made it part of the experience of the Spiritual Exercises in the very first meditation titled the Principle and Foundation. This exercise of prayer challenges the individual to put aside selfish desires and recognize the will of God in his life and to become indifferent to all things (de Guibert, 1972). This Ignatian indifference is not apathy, but a perspective in life that one should not be caught up in or inordinately attached to internal drives, fears, and prejudices that can prevent flexibility and openness; the individual should be unattached. In the mind of Ignatius individuals should make use of things, "to the extent that they help us toward our end, and free ourselves from them to the extent that they hinder us from it" (The Spiritual Exercises of St. Ignatius of Loyola, 1992, p. 23).

The indifference that Ignatius desired and encouraged meant that his charges would be free to tackle whatever challenges the Society of Jesus asked from them in whatever the circumstances may be. Lowney (2003) explains that, "Loyola didn't merely exhort recruits to be adaptable and creative; he ensured through the Exercises that recruits would adopt the demeanor, attitudes, and worldview that make adaptability and creativity possible" (p. 128). This perspective made the Jesuit available for any mission and empowered the Society of Jesus to be effective. Lowney (2003) illustrates,

Jesuits have negotiated change since well before the industrial revolution and continuing through the "e-economy," from a monarchical Europe through a democratic Europe that's seen the birth and death of Communism, from a 
predominantly Catholic world to a predominantly Christian world to a multicreed world to a largely secularized world. (p. 165)

The Jesuit leadership traits of ingenuity, innovation, and creativity have made their way into organizational and leadership theory. Friedman (2006) insists "to be successful in the $21^{\text {st }}$ century, business leaders at all levels must possess three important capacities - authenticity, integrity, and creativity - and enact them at work, in their families, in their communities, and in their personal growth" (p. 1270). His perspective is well shared with leadership and organizational researchers who emphasize the importance of creativity, innovation, and ingenuity (Amabile, 1997; DiLiello \& Houghton, 2006; Kanter, 1983; Pardey, 2007).

Ingenuity is thus critical for the effectiveness of any organization and its leadership. DiLiello and Houghton (2006) state that, "Creative ideas can be used for problem resolution, process improvements and the development of new services and/or products... individual creativity is essential to organizational innovation, which in turn is imperative to long-term organizational survival" (p. 320).

Love

Hoyle and Slater (2001) state that, "One of the most important tasks for educational leadership in America today is to put love at the center of the American educational vision" (p. 790). While love may be acceptable for educational leaders, some may possibly be more cautious in applying the notion of love to other leadership spheres such as business or industry. But Bolman and Deal (2002) disagree and claim that love is one of the main gifts that leaders can bestow upon on their subordinates. They claim that, “one person's care and concern for another is at the heart of teaching and learning. It is 
the social and ethical glue that holds any group or community together" (Bolman \& Deal, 2002, p. 23).

Researchers seem to agree and recognize how love plays an important role in organizational and leadership success (Amabile, 1997; Dennis \& Bocarnea, 2005; Gaskill \& Hamer, 2007; Greenleaf, 1996). They argue that when a leader lovingly encourages, instructs, and, when necessary, corrects, subordinates perform better. Amabile (1997) agrees: "There is abundant evidence that people will be most creative when they are primarily intrinsically motivated, rather than extrinsically motivated by expected evaluation, surveillance, competition with peers, dictates from superiors, or the promise of rewards" (p. 39). She defines "intrinsic motivation" as "the motivation to work on something because it is interesting, involving, exciting, satisfying, or personally challenging” (p. 39).

In both the Spiritual Exercises and the Constitutions Ignatius writes about the fundamental role of love in the life of individuals and his Jesuits. In the Constitutions alone Ignatius of Loyola makes over 50 references to love. He speaks of the love that a Jesuit must have for God, for the Society of Jesus, and for his superiors and/or subordinates. When speaking specifically about the Superior General of the Society of Jesus, Ignatius orders the following:

Very especially helpful, among other qualities, will be his credit and prestige among his subjects, as well as his having and showing love and concern for them, in such a way that the subjects hold the opinion that their superior has the knowledge, desire, and ability to rule them well in the Lord. (Constitutions of the Society of Jesus, 1996, p. 324)

Lowney (2003) explains that, "love was the lens through which individual Jesuits beheld the world around them. It changed not only the way Jesuits looked at others but 
what they saw. Their vision became more acute, their eyes open to talent and potential" (p. 170). Maslow (1970) would agree with this Jesuit vision when he argued that the human need for love is basic and that when satisfied, it leads to the satisfaction of what he calls "esteem needs." Maslow (1970) concludes that, "Satisfaction of the self-esteem need leads to feelings of self-confidence, worth, strength, capability, and adequacy, of being useful and necessary in the world. But thwarting of these needs produces feelings of inferiority, of weakness, and of helplessness" (p. 45).

The manner in which love capacitates makes it a powerful leadership tool that can contribute to the success of any organization. Lowney (2003) explains that,

Love-driven leadership is not urging others forward without concern for their aspirations, well-being, or personal needs. Nor is it being the nice-guy manager who overlooks underperformance that could damage a subordinate's long-term prospects. Instead, love-driven leaders hunger to see latent potential blossom and to help it happen. In more prosaic terms, when do children, students, athletes, or employees achieve their full potential? When they're parented, taught, coached, or managed by those who engender trust, provide support and encouragement, uncover potential, and set high standards. (p. 179)

The desire for continuous learning and improvement is made all the more possible when a leader lovingly admonishes and instructs subordinates. Ignatius himself instituted a practice in the Society of Jesus referred to as "fraternal correction" where superiors were held responsible for the loving correction of his charges. Ignatius writes: "Since the purpose of a manifestation of the defects of others to the superior is both the common good and the spiritual progress of individuals, it should proceed only from the motivation of charity and be done in such a way as to manifest love and charity" (Constitutions of the Society of Jesus, 1996, p. 262).

According to the literature, leadership that is exercised in a loving and caring fashion helps create a nurturing environment that is more conducive to effectiveness. 
"When love-driven leadership takes root on a widespread basis, it energizes performances and creates unique bonds of team unity" (Lowney, 2003, p. 179). This Jesuit characteristic of leadership has found support in organizational and leadership theories such as the Theory Y approach by Douglas McGregor (1960) and the concept of servantleadership by Robert Greenleaf (1996).

\section{Heroism}

Lowney (2003) defines heroic leadership as, "motivating oneself to above-andbeyond performance by focusing on the richest potential of every moment" (p. 209). He further explains that what is heroic about Jesuit leadership is that it focuses the members of the Society of Jesus to passionately adhere to the mission of the order and to always give more of themselves to assure its success. Lowney (2003) points to the Jesuit motto "magis," the restless drive to always do more in every opportunity, as indicative of what is expected of each member of the Society of Jesus. It is for this reason that Ignatius very bluntly and clearly defines the mission of the Society of Jesus at the beginning of the

\section{Constitutions:}

Whoever wishes to serve as a soldier of God beneath the banner of the cross in our Society, which we desire to be designated by the name of Jesus, and to serve the Lord alone and the Church, his spouse, under the Roman pontiff, the vicar of Christ on earth, should, after a solemn vow of perpetual chastity, poverty, and obedience, keep what follows in mind. He is a member of a Society founded chiefly for this purpose: to strive especially for the defense and propagation of the faith and for the progress of souls in Christian life and doctrine.... (1996, pp. 3-4)

The purpose of the Society of Jesus is clear and the vocabulary used to express it inspires a sense of determination that understandably would motivate any young man who would agree with its principles. The clarification of the mission and the determination of what is valuable are not foreign concepts in leadership and 
organizational theories. The importance of values in the literature on leadership is extraordinary and unattested (Beckner, 2004; Bennis \& Nanus, 1997; Daft, 2008; Deal \& Kennedy, 1982; Kouzes \& Posner, 2002; Morrill, 2007; O’Reilly, Chatman, \& Caldwell, 1991; Short \& Greer, 2002).

But what seems to stand out about Jesuit leadership is the passion with which those values are promulgated, embraced, and worked for. Collins and Porras (1995), in their study on the management principles of outstanding companies, elude to this when they conclude that, "Visionary companies do not ask, "What should we value?" They ask, "What do we actually value deep down to our toes" (p. 64)? This same conviction defined the perspective of the Society of Jesus and is evidenced by its claim of having 265 of its members martyred for their struggle to remain resolute to their mission (Tylenda, 1998).

Jesuit heroic leadership resonates well with secular theories of leadership and the effectiveness of its practice in the Society of Jesus is mirrored in leadership practices of organizations around the world. Lowney (2003), using corporate jargon, creatively summarizes the steps of Jesuit heroic leadership as follows:

- First, they invited recruits to turn a corporate aspiration into a personal mission.

- Second, they created a company culture that stressed heroism, modeling the virtue themselves.

- Third, they gave each person an opportunity to enlarge himself by contributing meaningfully to an enterprise greater than his own interests. (p. 205)

\section{The Characteristics of Jesuit Education}

It is impossible to understand the pedagogical aims of the Society of Jesus without understanding the spirit that drives the religious order founded by Ignatius of 
Loyola. The characteristics that determine Jesuit education are deeply rooted in the Spiritual Exercises and it is there that they find their roots (Pavur, 2005).

\section{Brief History of Jesuit Education}

Ignatius of Loyola founded the Society of Jesus for one purpose: "to strive especially for the propagation of the faith and for the progress of souls in Christian life and doctrine" (Constitutions, 1996, p. 4). While the founder gives some indications to how his religious order would perform this task, the founding of schools and their involvement in formal education were never specifically intended (O’Malley, 2000).

Shortly after the founding of his new missionary order, Ignatius became enthused with the possibilities that education offered for the mission. O'Malley (1993) indicates that, "Ignatius was willing to make immense adjustments to accommodate this new ministry and to deal with the many problems and frustrations it entailed" (p. 201). Eventually, in 1548 after the approval of Pope Paul III, ten members of the Society of Jesus opened the Collegio di San Nicolò in Messina in Sicily for the purpose, among other things, to "combat the errors of the Lutherans" (O’Malley, 1993, p. 204).

As schools began to open, the Jesuits who administered and taught in them had to be instructed on pedagogical techniques that could be used in the classroom. After his own studies at the University of Paris, Ignatius was impressed and felt comfortable with the "modus parisiensis" style of education and incorporated the technique into the schools (Codina, 2000). Of this style of education O'Malley (1993) states that, "The 'modus parisiensis' encompassed many things, but what it most broadly gave to the Jesuit system was an organized plan for the progress of the student through increasingly complex 
materials and a codification of pedagogical techniques designed to elicit active response from the learner" (p. 217).

Eventually, the Society of Jesus developed a document that would explicitly state their pedagogical and administrative principles. In 1599, when the Society of Jesus was running over 200 schools in Europe alone, the Ratio atque Institutio Studiorum Societatis Jesu or Ratio Studiorum was produced (Padberg, 2000). This monumental document synthesized the "modus parisiensis" with earlier traditions of the classical liberal arts, medieval scholasticism, and Renaissance humanism in the context of Christian ethics and spirituality for the sake of outlining a program of studies and its administration to be applied to all Jesuit schools around the world (Padberg, 2000).

This voluminous work governed Jesuit education around the world for centuries until 1986 when the International Commission on the Apostolate of Jesuit Education of the Society of Jesus (ICAJE) published The Characteristics of Jesuit Education (1994). The significant changes in educational and leadership theory motivated the need to modernize the Society of Jesus's approach to education while remaining faithful to the central precepts of the Society of Jesus and its religious convictions: "Developmental psychology and the social sciences, along with advances in pedagogical theory and education itself, have shed new light on the way young people learn and mature as individuals within a community; this has influenced course content, teaching techniques, and school policies" (ICAJE, 1994, p. 132).

In light of this new document, Jesuit schools began to refocus their pedagogical organizations and modernize their educational and administrative practices in order to assure that what they were producing in fact conformed to the modernly defined 
standards of Jesuit education. More specifically, the need to evaluate their schools and its administrators in light of this new pedagogical perspective became central to the success of implementing the twenty-eight characteristics that the ICAJE now reformulated as epitomizing Jesuit education.

\section{The Twenty-Eight Characteristics}

When formulating the characteristics of Jesuit education, ICAJE divided the twenty-eight points in nine sections (see Appendix A). Each section encompasses a particular attribute of Ignatian spirituality emphasizing how rooted the pedagogical perspective of Jesuit education is on the spiritual vision of the Society of Jesus and its founder. This spiritual vision finds its ultimate source in the experience of Ignatius of Loyola as expressed in the Spiritual Exercises (Gray, 2000; ICAJE, 1994; Metts, 1995; Newton, 1994).

The purpose of the Spiritual Exercises and thus the purpose of Jesuit education and its characteristics is proclaimed in the first introductory observation of Ignatius of Loyola in the Exercises, "to rid [the person] of all inordinate attachments, and, after their removal, of seeking and finding the will of God in the disposition of our life for the salvation of our soul" (1992, p. 1). All meditations, contemplations, and other methods of prayer found in the Exercises are focused on accomplishing this task (Newton, 1994).

This is why the key to understanding the various characteristics that compose Jesuit education and its institutions of learning is to understand the underlining principles of the Spiritual Exercises. As Newton (1994) indicates,

Jesuit educational institutions were founded on the identical assumption which gave purpose to the Spiritual Exercises. Schools and colleges were not intended to be ends in themselves but instruments to aid Jesuits and their fellowmen to attain the purpose for which they were created, the knowledge, the love and service of 
God. This becomes the ultimate norm for determining the level of success or failure of a Jesuit school or college. (p. 85)

The twenty-eight characteristics of Jesuit education thus become an instrument to obtain the ultimate goal of facilitating for the student a religious experience that will help transform the individual, the individual's community, and ultimately the world. Newton (1994) states that, "the goal of a Jesuit school or college goes beyond humanistic education to an ultimate purpose which is explicitly religious" (p. 85).

It is impossible therefore to remove the religious component from the educational formula of a Jesuit school. Appendix A describes the characteristics, which express the fact that the "religious dimension permeates the entire education," that Jesuit education is "value-oriented," an "apostolic instrument," "proposes Christ as the model of human life," emphasizes "pastoral care" and leads to "prayer and worship."

And while Jesuit schools encourage both students and faculty of various creeds to become integral members of their communities (Commission on Research and Development, 1994a), Jesuit education is Catholic. The Characteristics (1994) clearly state that Jesuit education is "an apostolic instrument on service of the Church," an "education in the service of the faith that does justice," and encourages "active participation in the Church" (see Appendix A).

Terms such as "active participation" and a "faith that does justice" demonstrate that service is a major component of Jesuit education. The Commission on Research and Development (1994b) explains that a graduate of a Jesuit high school "through service of others, is beginning to appreciate the satisfaction of giving of oneself for other people and thereby finding life enriched" (p. 105). The inclination to serve is articulated in several 
characteristics that claim Jesuit education "manifests a particular concern for the poor," is an "active life commitment," and forms "men and women for others" (see Appendix A).

The commitment to serve others that is expected of Jesuit students coincides with the spiritual vision of Ignatius that emphatically confirmed the intrinsic goodness of the world. Ignatius saw the world as created by God and, therefore, "a source of knowledge" (Gray, 2000, p. 3). Because of this perspective, the individual is required to study the world and is encouraged to understand it better. This is why several points of the Characteristics of Jesuit Education (1994) refer to Jesuit education being "world affirming," a "dialogue between faith and culture," "life-long openness to growth," and "a realistic knowledge of the world" (see Appendix A).

The Characteristics of Jesuit Education (1994) incorporate the Ignatian "magis" into its program of studies and calls for "excellence in education" and asks its students to be "witnesses to excellence" (see Appendix A). The Characteristics (1994) claim that, "the pursuit of academic excellence is appropriate in a Jesuit school, but only within the larger context of human excellence" (p. 145). How to study the world and achieve this excellence is also drawn from the spiritual vision of Ignatius. When relating the Spiritual Exercises with the process of education, Metts (1995) states that,

The emphasis placed on the idea of completing a series of exercises that engage not just the mind, but also the body, heart, and soul of the person provide the first important insight into Ignatius's conception of learning. Ignatius believed that learning, especially in the spiritual life, did not occur solely in the mind. Learning for Ignatius requires that the entire person interact with the material and recognizes the fact that God works through the entire person with all types of mental processes. Thus, for something to be learned and understood completely, the body, heart, and soul must accompany any intellectual knowledge about a particular subject matter. (p. 13) 
Ignatian pedagogy therefore involves the whole person in the learning process and removes education from being simply a cerebral exercise. ICAJE (1994) states that in Jesuit education, "particular care is given to the development of the imaginative, the affective, and the creative dimensions of each student in all courses of study" (p. 135). This is the reason why there are elaborated characteristics that claim that Jesuit education involves, "the total formation of each individual in the community," the "care and concern for each individual person," a "realistic knowledge, love, and acceptance of self," the "activity of students in the learning process," and it "adapts means and methods in order to achieve the purposes of Jesuit education" (see Appendix A).

Jesuit education, as expressed in section eight of the Characteristics of Jesuit Education (see Appendix A), also recognizes that learning takes place within a community and that this community plays an essential role in the learning process. The Commission on Research and Development (1994b) states that, "the school community should be created and formed in ways which lay on all its members responsibility for the whole." Furthermore, it suggests that, "broadly based decision-making processes should open channels of communication among the governing body, administrators, faculty, students, parents, and alumni. Each could be invited to assume the appropriate measure of responsibility for the on-going life of the school” (p. 50).

The formulation of the these twenty-eight characteristics of Jesuit education has provided for the Society of Jesus around the world a common vision that helps to focus Jesuit schools and their leadership. In the introductory statement found in Go Forth and Teach (1994), Fr. Peter-Hans Kolvenbach, S.J., current superior general of the Society of Jesus, heralded the promulgation of the characteristics by claiming that they helped 
articulate "our common mission" (p. 130) in education. The Characteristics of Jesuit Education (1994) reminds Jesuit educators and leaders that they belong to "the Jesuit 'system' of schools" and that even though they find themselves all over the world, in varying circumstances and situations, the purposes of Jesuit education remains singular.

\section{Summary}

The review of the literature on leadership seems to indicate that while leaders address their responsibilities from various perspectives depending on the circumstances, certain key elements are common to all leaders. The significance of vision, values, and the ability to influence permeates all concepts of leadership (Bennis \& Nanus, 1997; Daft, 2008; Lyman, Ashby, \& Tripses, 2005; Salacuse, 2006; White, 2007).

More specifically, Jesuit leadership also makes use of these key factors while determining a particular leadership style with the presence of other, more particular, characteristics. Lowney (2003) has identified self-awareness, ingenuity, love, and heroism as being these unique characteristics that give Jesuit leadership its distinctive style. The literature on Jesuit-style leadership, while scarce, recognizes that the source of this Jesuit perspective is the spiritual writings of Ignatius of Loyola and more specifically his Spiritual Exercises (Lowney, 2003; Wright, 2004).

The multiplicity of perspectives among leaders and organizations, central to the research of Bolman and Deal (1997), offers insight to understanding leadership style and effectiveness. Bolman and Deal (1997) have identified four perspectives or frames and argue that leaders who are able to make use of more than one frame when administering their organizations and subordinates are more effective than those who make use of only one. Ample research has been done to support their conclusions (Bensimon, 1989; 
Berger, 2002; Bush \& Glover, 2003; Green, 1992; Newmann, 1993; Thompson, 2000, 2005; Wallace, 2000).

In addition, research on the particular characteristics of Jesuit education was

conducted. The International Commission on the Apostolate of Jesuit Education (1994) has delineated 28 characteristics that define Jesuit education in the modern world. It is these characteristics that help determine the leadership style and effectiveness of Jesuit school leaders. In addition, similar to the findings on Jesuit leadership, researchers identify the Spiritual Exercises as the source of these characteristics (Gray, 2000; ICAJE, 1994; Metts, 1995; Newton, 1994). 


\section{CHAPTER III}

\section{METHOD}

This chapter describes the purpose of this study along with the research questions as delineated in the introduction. It outlines the case study framework that was used in the study and the procedures utilized to conduct the data collection process, analysis, management, and interpretation. The chapter concludes with the role of the researcher in the study.

\section{Purpose of the Study}

The purpose of this case study was to examine the factors and elements which have contributed to the success and longevity of the leadership of Fr. Marcelino García, S.J. in his role as a Jesuit high school president. Fr. García, president of Belen Jesuit Preparatory School, was chosen as the exemplary case to be studied. The study investigated the role of leadership, especially school leadership and Jesuit leadership, and its effectiveness.

\section{Research Questions}

The main research question was: What are the factors and elements that have contributed to the success and longevity of the leadership of Fr. Marcelino García, S.J. in his role as a Jesuit high school president? Subsidiary questions that guided the study were:

1. In reference to Bolman and Deal's (1997) multi-frame perspective, what is the predominant leadership style of Fr. García?

2. In reference to Bolman and Deal's (1997) multi-frame perspective, what factors contribute to the effectiveness of Fr. García's style of leadership? 
3. In reference to Jesuit educational leadership, is Fr. García an effective leader?

4. In reference to Jesuit educational leadership, what factors contribute to the effectiveness of Fr. García's style of leadership?

Case Study

Berg (2007) defines the case study as "a method involving systematically gathering enough information about a particular person, social setting, event, or group to permit the researcher to effectively understand how the subject operates or functions" ( $p$. 283). Creswell (2003) further explains that in a case study the researcher "explores in depth a program, an event, an activity, a process, or one or more individuals. The case(s) are bounded by time and activity, and researchers collect detailed information using a variety of data collection procedures over a sustained period of time" (p. 15).

The idea that case studies are strictly or even more commonly associated with qualitative strategies of data collection is an incorrect determination (Yin, 1981). Yin (1981) confirms that, "case studies can be done with quantitative as well as qualitative data" (p. 99). While scholars still contest some of the basic issues of a mixed methods approach, many researchers hail it as viable and useful (e.g., Creswell, 2003; Morse, 2003; Tashakkori \& Teddlie, 2003). Morse (2003) states that, "by using more than one method within a research program, we are able to obtain a more complete picture of human behavior and experience" (p. 189).

This case study used a parallel/simultaneous mixed methods approach. The data were collected at the same time (i.e., concurrently) by using both quantitative and qualitative methods and analyzed in a complementary manner (Creswell, Clark, 
Gutmann, \& Hanson, 2003; Miller, 2003). The reason for this was to "compare both forms of data to search for congruent findings" (Creswell et al., 2003, p. 217).

\section{Procedures}

The process that was used to perform a single-case study is described below. The first procedure to be addressed is the process for the selection of the particular case that was studied, followed by the data collection methods, data management, analysis, and interpretation. This section concludes with a statement on the role of the researcher.

\section{Exemplary Case Selection}

Two case study designs exist, multiple-case and single-case studies. Yin (2003) justifies the value of a single-case design when the case that is studied represents an "extreme case or unique case" (p. 40). Berg (2007) adds that single-case studies "include studies of unique people" (p. 284). This particular study is about a unique individual in the field of educational leadership; therefore, it is a single-case design.

Fr. Marcelino García, S.J. was selected as the exemplary case because of his 25 year leadership as president of Belen Jesuit Preparatory School. He is unique in that he is the longest serving active Jesuit high school president in the United States and his tenure to date is the second longest in the history of Jesuit high schools in the United States. On average, high school presidents serve for five or six years in Jesuit high schools (Jesuit Secondary Education Association, personal communication, September 17, 2007).

It is not simply longevity that makes Fr. García an exemplary case to study, but also the success and growth that Belen Jesuit Preparatory School has experienced under his leadership. In 1981 the school moved onto the present-day 30-acre campus in South West Miami with only one building that housed classrooms, offices, library, and 
cafeteria. In 1983, the year that Fr. García began his term as president, Belen Jesuit Preparatory School remained the same. Since then, Fr. García's administration has added five buildings along with football and baseball stadiums, a swimming pool, and observatory (Carola Calderín, personal communication, October 12, 2007).

In addition to its structural growth, Belen Jesuit Preparatory School has also experienced an increase in its student population. In 1983, when Fr. García, S.J. began his presidency, the school had 739 students. By 2007, the student population had grown to 1,478 students, an increase of $100 \%$. The school has also increased the number of its faculty from 62 in 1983 to 119 in 2007 . Of these faculty members, 58\% have received their Masters degree in their field of teaching while 12 faculty members have their doctorates. Faculty retention is significant with 25 faculty members having over 20 years of teaching at the school and 30 faculty members with ten years or more (Belen Jesuit Preparatory School, 2007).

Fr. García’s successful leadership cannot only be measured quantitatively, but also qualitatively. In 1983 when Fr. García began his tenure at Belen, the students' ACT mean scores were 22.8 and their SAT mean scores were 470 in verbal and 540 in math. That same year, Belen's curriculum offered three advanced placement courses and no honors courses. Presently, the ACT mean scores has gone up to 25 and SAT mean scores are 602 in verbal and 591 in math. The school's curriculum presently offers 21 Advanced Placement courses and 23 honors courses. In addition and probably most significant is that from 1989 to the present $100 \%$ of Belen graduates have been accepted and have attended college (José Emilio Roca, personal communication, March 17, 2008). 


\section{Data Collection}

This section discusses the target population surveyed, key informants, and the administration of the data collection instruments. Both quantitative and qualitative methods of data collection were concurrently used.

\section{Quantitative Data}

First the target population will be described. Next the three survey instruments will be described.

Target population. The target population consisted of the school's 7 administrators, 90 faculty members, and 10 English-speaking staff members. In addition, because they were interviewed as key informants, the president of the alumni association, the head of the parents' steering committee, and the Jesuit superior of the Miami region of the Society of Jesus were also surveyed. In total, 110 members of the school community were asked to complete each survey.

Leadership Orientations Survey. The Leadership Orientations (Self) Survey and Leadership Orientations (Other) Survey developed by Bolman and Deal (1990) are composed of four sections (see Appendix B \& C). Section I of the surveys measure eight dimensions of leadership by presenting 32 items divided equally among the structural (items 1, 5, 9, 13, 17, 21, 25, 29), human resource (items 2, 6, 10, 14, 18, 22, 26, 30), political (items 3, 7, 11, 15, 19, 23, 27, 31), and symbolic frames (items 4, 8, 12, 16, 20, $24,28,32)$. Within each of the four frames, two leadership dimensions that are associated with each frame are also measured. Respondents were asked to rate each item using a five-point scale where: $1=$ never, $2=$ occasionally, $3=$ sometimes, $4=$ often, and $5=$ always. 
The structural frame encompasses both the analytic (items 1, 9, 17, 25) and organized (items 5, 13, 21, 29) dimensions of leadership. Bolman and Deal (1991) characterize analytic behavior as the ability to think clearly and logically, approaching problems with facts and focused on details. The organized dimension of leadership is characterized as the ability to develop clear goals and policies and hold people accountable for results.

The human resource frame encompasses supportive (items $2,10,18,26$ ) and participative (items $6,14,22,30$ ) dimensions. Leaders that are supportive are concerned about the feelings of their subordinates and are responsive to them. A participative leader "fosters participation and involvement; listens and is open to new ideas" (Bolman \& Deal, 1991, p. 518).

The political frame focuses on the dimensions of being powerful (items 3, 11, 19, 27) and adroit (items $7,15,23,31$ ). Powerful leaders are those that are persuasive, highly successful at mobilizing people and resources, and are able to build alliances and networks. The adroit leader is politically sensitive and skillful, an expert at negotiating in moments of conflict and opposition.

The symbolic frame consists of the inspirational (items 4, 12, 20, 28) and charismatic (items $8,16,24,32$ ) dimensions of leadership. The inspirational leader inspires others to loyalty and enthusiasm and is able to communicate a strong sense of vision. The charismatic leader is defined by Bolman and Deal (1991) as being “imaginative, emphasizes culture and values; is highly charismatic” (p. 518).

Section II of the surveys consists of six forced-choice items. Each of the items has four responses where respondents are asked to rank order each group of four descriptors 
from 1 to 4 using a forced-choice scale. In the Leadership Orientations (Self) Survey "1" is given to "the phrase that is least like you" through " 4 " that is given to "the phrase that best describes you." In the Leadership Orientations (Other) Survey "1" is given to the "phrase that is least like the person" through " 4 " that is given to "the phrase that best describes the person." In each forced-choice item the responses are associated with the four frames: "a" represents the structural frame, "b" represents the human resource frame, "c" represents the political frame, and "d" represents the symbolic frame.

The reason for using both a rating scale and forced-choice items is explained by Bolman and Deal (1992b):

The rating scale and the force-choice measure each has different advantages and liabilities. The rating scale has the advantage of measuring effectiveness in using each frame, but it is subject to a "halo effect." The correlations among the frames tend to be high, producing a collinearity problem in regression analyses. The forced-choice, or ipsative, measure produces sharper differentiation among the frames because it does not permit rating someone high on everything. A linear composite of the two captures some of the strengths of each. (p. 320)

Section III of the surveys has two items that ask respondents to rate effectiveness as a manager and effectiveness as a leader. Bolman and Deal (1991) purposely excluded the definition of management and leadership from the survey. Using an anchored scale requiring the selection of one of five response choices, which have a percentage value, respondents rated overall manager and leadership effectiveness. The criteria were "1" signified "bottom $20 \%$," "2" was the top bottom," "3" was the "middle $20 \%$," "4" was the top middle," and "5" the "top 20\%." While this study addressed Fr. García's leadership effectiveness and not his effectiveness as a manager, this section was included in the survey because according to Bolman and Deal (1990) "expanding the number of 
items to measure effectiveness would be a good way to strengthen the instrument" (pp. 23).

Section IV of the surveys is a demographic addendum composed of several items such as gender and tenure that were not significant for the study.

Bolman and Deal (1991) used factor analysis of responses to the leadership instruments to investigate content validity using both self-ratings and subordinate ratings. Bolman and Deal (1991) claim that, "the analyses consistently produced factors associated with the four frames" (p. 520). The leadership orientation instruments were pilot tested to assess internal reliability. Bolman and Deal (1991) claim that "internal reliability is very high: Cronbach's alpha for the frame measures ranges between .91 and $.93 "$ (p. 518).

Administrative Leadership Profile Survey (ALPS). The ALPS was developed by the Jesuit Secondary Education Association (1994) incorporating various themes relating to the mission of Jesuit education as found in the documents of the Society of Jesus, particularly the International Commission on the Apostolate of Jesuit Education's (1994) document titled Go Forth and Teach: The Characteristics of Jesuit Education. The survey is composed of three sections (see Appendix D).

Part One of the survey is a pencil and paper instrument that looks at the goal performance of the president. This section is comprised of 72 items that are organized into eight themes that profile the president of a Jesuit high school. The eight themes are leadership, open to growth, professional competence, loving and caring, Ignatian vision, in action, communications, and decision-making. 
The JSEA (1994) understands the eight themes as follows. Leadership is the ability to communicate a clear sense of direction calling people to a deeper vision and appreciation of the school's mission. A president who is open to growth is one who has the ability to deal with personal limitations, is flexible and adaptable, and attends to personal, professional, and spiritual development. Professional competence refers to the president's ability to provide for the proficient administration of the school at all levels ensuring its financial well being. The president must also be loving and caring, helping others feel that they are valued members of the school community. The president must also adhere to the Ignatian vision modeling the Ignatian ideals that encourage action, promote service and responsible stewardship. Communication must also be promoted among all the school's stakeholders and the president should draw upon the wisdom and expertise of others in order to make sound decisions.

There are nine items that address each of the eight themes described above. For each item respondents are asked to first indicate the degree of importance they attach to the descriptors as objectives the president of their school should have. Respondents are asked to rate importance by using a three-point scale where: $0=$ not at all important, $1=$ somewhat important, and 2 = definitely important. Respondents are then asked to indicate the extent to which they see the performance of the president meeting the objectives implied by the descriptors. Respondents are asked to rate performance by using a fivepoint scale where: $0=$ never does, $1=$ rarely does, $2=$ sometimes does, $3=$ usually does, and $4=$ consistently does.

Part Two of the survey is also a pencil and paper instrument that looks at the organizational health of the school. The purpose of this section is "meant to set a context 
within which to understand the profile of the president" (JSEA, 1994). This section is comprised of 34 items organized into ten themes: goals (defined and people are committed to), roles (clearly defined), leadership (effective and supportive), efficiency (people get things done), consonance (school's goals are carried into action), proponence (people plan for change), individual synergy (people individually are active), institutional synergy (school as organization sustains energetic, productive decision-making), support (people feel they have the support of those in charge), and attitudinal outlook (people have a realistic attitude about the school).

There are three items for each of the themes listed above with the exception of individual synergy that has four items, institutional synergy that has four items, and attitudinal outlook that has five items. For each item respondents are asked to rate level of agreement using a seven-point scale where: $-3=$ strong disagreement, $-2=$ basic disagreement, $-1=$ some disagreement, $0=$ uncertain,$+1=$ some agreement,$+2=$ basic agreement, $+3=$ strong agreement.

Part Three of the ALPS calls for short written reflections from the respondents for the purpose of helping the president set personal and professional goals for the future. Because of the nature of this study, this section of the survey was not included.

The Jesuit Secondary Education Association developed the ALPS for the internal evaluation of Jesuit high school presidents. Because their results were never meant to be published, the instrument has never been tested for validity or reliability; however the ALPS instrument has been used over 500 times and the results have indicated high levels of validity and reliability (Jesuit Secondary Education Association, personal communication, October 30, 2007). 


\section{Qualitative Data}

First the key informants are described below. This is followed by a discussion of the focused interviews using semi structured interview guides.

Key informants. These individuals were selected purposefully because they are in positions of responsibility within the school, representing the administration, faculty, staff, alumni, parents, and Jesuit community. These key informants work especially closely with Fr. García. Because of their particular insight into his administration, one individual from each of these sectors was interviewed. Below is a brief background for each key informant who agreed to participate in this study.

Leopoldo Nuñez has been a member of the school administration since 1989 and faculty member since 1975 . He served as the executive assistant principal for 16 years until 2004 when he resigned that position in order to become the chair of the humanities department and director of the Ignatian Center for the Arts at the school. Throughout his years as an administrator, Mr. Nuñez served for a time as the director of discipline and taught art history, a role he maintains to the present. Because of his 30 years of work at Belen, 18 years as an administrator, and his close relationship with Fr. García, Mr. Nuñez offered valuable insight into Fr. García’s leadership.

Patrick Collins is a tenured member of the school faculty. He has been teaching U.S. Government and has headed the social studies department since 1971. In addition, he has also been the tennis coach since 1975 and has been running the Close-Up program for over 30 years. Mr. Collins has most recently helped found the Belen Overseas Study Program, a summer program that takes Belen high school students to various countries around the world. His longevity on the faculty made him an invaluable asset to this study. 
Carola Calderín is a member of the school staff. She has served as the president's assistant and business manager of Belen Jesuit Preparatory School for five years. In these roles she has worked closely with Fr. García, the school's administration, the faculty, and staff. Ms. Calderín offered rich insight into the relationship between Fr. García and the school staff.

Fernando Arán, Esq. is the president of the Belen Jesuit Alumni Association. He graduated from Belen Jesuit Preparatory School in 1975 and is currently a managing partner of Arán, Correa, \& Guarch, P.A. in Miami, Florida. In 2005, Fr. García initiated the reformation of the Belen Jesuit Alumni Association and asked Mr. Arán to help institute the reforms. He was eventually elected in 2006 the association's president. His work with Fr. García and relationship with the school's alumni offered valuable insight.

Maria Juncadella is a school parent and is currently the head of the parents' steering committee. Her two children are students at Belen Jesuit Preparatory School, one a senior and the other a sophomore. As the head of the steering committee her responsibility is to work mostly as a liaison between the parents and the school's administration. In addition, Ms. Juncadella is responsible for organizing the parents into the various committees that exist at the school that help run the various events throughout the school year. Her perspective as school and parent liaison was invaluable for this study.

Fr. Francisco Perez-Lerena, S.J. is a member of the Jesuit community and has been the Jesuit superior of the Miami region since September 18, 2003. As superior of the Miami region, Fr. Perez-Lerena is the direct superior of Fr. García as well as the 16 other Jesuit priests and seminarians who live and work in Miami, Florida. In addition, he was 
also Fr. García's predecessor as president of Belen Jesuit Preparatory School. His experience and relationship with Fr. García were invaluable.

Focused interview. Focused interviews (Yin, 2003) were held with Fr. García and six other members of the Belen Jesuit Preparatory School community. These interviews "allow us to enter into the other person's perspective" (Patton, 2002, p. 341). The interviews were individual interviews and employed a semi-structured guide in order to ensure that the same basic lines of inquiry were pursued with each person interviewed and that the questions were focused (Rubin \& Rubin, 2005). The questions were designed to focus the interview and elicit particular information that helped answer the research questions (Rubin \& Rubin, 2005). The respondents were each interviewed for approximately one hour.

Two different interview guides were used; one for Fr. García (see Appendix E) and one for the six key informants (see Appendix F). The two different interview guides followed "a certain set of questions derived from the case study protocol" (Yin, 2003, p. 90). The guide used for Fr. García's interview consisted of three sections. First, the interview began with open-ended questions that focused on his greatest successes as president and how he was able to achieve them and his greatest challenges and how he was able to overcome them. Second, a series of questions based on Bolman and Deal's (1990) Leadership Orientations Survey. Third, a series of questions were included about Jesuit characteristics of education based on the Administrative Leadership Profile Survey (ALPS).

Similar to Fr. García's interview guide, the one used for the six key informants consisted of three sections. The first section included questions designed to elicit 
reflections on the successes and challenges of Fr. García's administration and what the key informant believed Fr. García's role was in each of them. Second, a series of questions based on Bolman and Deal's (1990) Leadership Orientations Survey were asked. The third section was a series of questions that referred to Jesuit characteristics of education based on the Administrative Leadership Profile Survey (ALPS) and how Fr. García embodies them.

\section{Data Analysis}

The analysis of the data had to be sensitive to the design being implemented in a mixed methods study. The analytical procedure used in this study was a direct comparison of the results of both quantitative and qualitative methods (Creswell, Clark, Gutmann, \& Hanson, 2003). Below is a description of each of the procedures used.

\section{Quantitative Data}

Data collection from the surveys was analyzed using SPSS, version10. For the analysis of the Leadership Orientations (Self) Survey, Leadership Orientations (Other) Survey, statistical analysis was used to find the means, standard deviations, and $95 \%$ confidence interval for each frame as indicated by the target population of 110 faculty, staff, and administrative members of Belen Jesuit Preparatory School. Correlations between frames were also determined.

For the Administrative Leadership Profile Survey (ALPS), descriptive statistics and exploratory data analysis (EDA) were used to summarize in three sections the main findings for the two different parts administered in the survey. Frequency distribution along with a series of bar charts and line graphs showing the frequency (percentage) of responses were reported. 
Section I looked at the goal performance of the president and goal importance as determined by Part One of the survey and the results were reported in three ways. First, a series of bar charts showed the frequency (percentage) of responses for each item in terms of the president's performance; second, two bar graphs, one that showed the percentage of responses rating the goal statements as "Definitely Important" and the other that showed the percentage of responses rating the president's performance of those same goals as "Usually Does" or "Consistently Does;" third, a line graph that compared the mean scores on importance and performance.

In Section II, the organizational health of the school as indicated by the results of Part Two of the survey were reported in two ways. First, a series of bar charts that showed the frequency (percentage) of responses for each item on a scale from "Strongly Agree" to "Strongly Disagree," that indicated the respondent's perception or experience of the school from an organizational point of view. Second, a bar graph, that showed the percentage of responses rating the items as "Agree" or "Strongly Agree" was also included.

Section III of the analysis provided for each item in the survey the following statistical information: percentage responses, number of replies, mean (average) score, standard of deviation, mean error for $95 \%$ distribution, and margin error for $95 \%$ distribution.

\section{Qualitative Data}

The analysis of the data collected first started with the transcription of the interviews by a professional transcriber. The transcriber was instructed to transcribe the interviews verbatim (Patton, 2002). All transcripts were reviewed by the researcher while 
listening to the audio recordings in order to assure accuracy and allowed the researcher to become familiarized with the transcripts. Notes were also taken during this step in order to record immediate impressions that contributed to identifying particular themes (Ryan $\&$ Bernard, 2003). In addition, in order to enhance the credibility of the transcriptions, interviewees were shown their own transcript to verify accuracy (Rubin \& Rubin, 2005).

Next was an inductive approach identifying recurring themes and concepts that emerged in the data that were not identified by the a priori codes referred to below (Ryan $\&$ Bernard, 2003). A review of the transcripts and notes provided the opportunity for the researcher to identify and list themes within the descriptions. The themes were then coded. This was done with each interview before comparing the items or themes with the other interviews (Patton, 2002).

The transcripts were then coded by searching for evidence of a priori codes (Ryan $\&$ Bernard, 2003). These a priori codes were identified from the Bolman and Deal (1990) Leadership Orientation Survey and the Jesuit Secondary Education Association (1994) Administrative Leadership Profile Survey (ALPS) and were organized into a coding rubric (see Appendix G). The a priori codes included the structural, human resource, political, and symbolic leadership frames and the Jesuit high school leadership characteristics: leadership, open to growth, professional competence, loving and caring, Ignatian vision, in action, communications, and decision making.

When evidence was discovered of one of the codes, the data analysis code was recorded in the transcript (Rubin \& Rubin, 2005). For example, the code PO, for political leadership frame, was assigned when concepts or themes such as powerful, adroit, persuasive, networking, negotiator, conflict, skillful, and resources were evidenced in the 
data. These terms were identified in the evidence column of the coding rubric (see Appendix G).

Once all the coded sections were sorted, specific passages were found that best illustrated the codes and themes. These passages were used in the following chapters to report the results of the study and draw conclusions. Conclusions that were drawn from the coded transcripts were shared with the interviewees in order to enhance the credibility of the study (Rubin \& Rubin, 2005).

\section{Concurrent Triangulation}

After the quantitative and qualitative data analysis, a concurrent triangulation method was used that directly compared the results. According to Creswell (2003) this method is "selected as the model when a researcher uses two different methods in an attempt to confirm, cross-validate, or corroborate findings within a single study" (p. 217). Evidence collected from each form of data collection was used to support the other. According to Creswell (2003) concurrent triangulation is "advantageous because it is familiar to most researchers and can result in well-validated and substantiated findings" (p. 217).

The data were integrated during the interpretation phase (Creswell, 2003). The findings from the quantitative analysis was compared and contrasted to the qualitative findings. This process was done by looking at the data as a whole and in parts. The parts were internal and external sectors. The internal sector was composed of faculty and staff who work inside the school. The external sector was composed of alumni, parents, and the Jesuit superior who work outside of the school. The comparison of the findings was then examined in terms of each research question. 


\section{Data Management}

All transcriptions and electronic files were stored in a locked file cabinet. As per university policy, the files will be kept for three years from the completion of the study (Florida International University, 2005).

\section{Role of the Researcher}

My interest in this study stemmed from my educational vocation and a more recent interest in school administration and leadership. As a member of the Society of Jesus, I was particularly interested in Jesuit educational leadership and its role in the success of Jesuit education. As a teacher and Jesuit at Belen Jesuit Preparatory School, I experienced firsthand the school's success and, more specifically, the administration of Fr. García. His ability to overcome obstacles and to be a major contributor in the success of Belen Jesuit Preparatory School intrigued me and convinced me that insight into his leadership style can help other school leaders.

As a teacher at Belen Jesuit Preparatory School and fellow member of the Society of Jesus, I was conscious of the possible risks involved in this study. The possibility of revealing certain negative aspects of Fr. García and his leadership concerned me. In addition, I had to admit my admiration for Fr. García and Belen Jesuit Preparatory School and acknowledged this bias as I began my study.

Recognizing these influences on my role as a researcher, I performed extensive research on leadership, school leadership, and Jesuit leadership to better prepare myself for observation of my particular case. Examining both the quantitative and qualitative data from these various viewpoints ensured a valid perspective. Additionally, I was 
always aware of my ethical responsibilities as a researcher and presented the data to the best of my ability.

\section{Summary}

A single case study design was used to study the factors and elements that have contributed to the success and longevity of the leadership of Fr. García in his role as a Jesuit high school president. Using a mixed methods approach, both surveys and interviews gave the researcher access to the successful leadership of Fr. García. The following chapter presents the findings of the study and chapter 5 concludes the study with implications, recommendations for future research, and a summary. 


\section{CHAPTER IV}

\section{RESULTS}

This chapter presents an analysis of both quantitative and qualitative data. First, a brief description of the process used to assess data collected by both quantitative

instruments are presented, followed by analyses of the data. Second, a brief description of the process used to code the data collected from the focus interviews are presented along with a brief description of the key informants and focused interviews, followed by a presentation of the evidence collected.

\section{Relationship Between Data Sources}

Both quantitative and qualitative methods of research were used concurrently to access the leadership style and effectiveness of Fr. García as president of a Jesuit high school. Both methods of research targeted internal and external members of the Jesuit high school community. The internal sector was composed of faculty and staff who work inside the school. The external sector was composed of alumni, parents, and the Jesuit superior who work outside of the school.

In addition, focused interviews used a semi-structured guide that included questions designed from both quantitative instruments to focus the interview and elicit particular information that helped answer the research questions. Finally, the a priori coding rubric designed for analyzing the qualitative data was generated from Bolman and Deal's (1997) four leadership frames and the Jesuit Secondary Education Association's (1994) high school leadership characteristics. 


\section{Assessment of Quantitative Data}

Data collected from the Leadership Orientations Survey were assessed using SPSS, version 10. For the four frames, statistical analysis was used to find the means, standard deviations, and 95\% confidence intervals for each frame. Correlations between frames were also determined. Data collected from the Administrative Leadership Profile Survey (ALPS) were assessed using descriptive statistics and exploratory data analysis (EDA).

\section{Leadership Orientations Survey Results}

The Leadership Orientations Survey was administered to 110 members of the Belen Jesuit Preparatory School community: 90 faculty, 10 staff, 7 administrators, the president of the alumni association, the head of the parents' steering committee, and the superior of the Miami region of the Society of Jesus.

\section{Analyses of Responses}

Total mean scores for responses to Section I of the Leadership Orientations Survey, leader behaviors, are reported in Table 1. Total mean scores for responses to Section II of the survey, leadership style, are reported in Table 2.

Section I results: Leader behaviors. Respondents were asked to rate each item using a five-point scale where: $1=$ never, $2=$ occasionally, $3=$ sometimes, $4=$ often, and $5=$ always. The possible range for each frame was between 8 and 40 . Complete results of mean scores per item are reported in Table 3.

Analyses of responses for items that refer to the structural frame indicated a total mean score of 32.07 and the $95 \%$ confidence interval of 30.87 and 33.28 . The lowest score for items within the structural frame was 13 and the maximum score was 40 . 
Respondents rated Fr. García lowest within the structural frame when asked if he "sets specific, measurable goals and holds people accountable for results" (item 21), with a mean score of $3.78(S D=1.18)$, and rated him best when asked if he "thinks very clearly and logically" (item 1), with a mean score of $4.32(S D=.73)$.

Table 1

Section I-Leader Behaviors Total Mean Scores

\begin{tabular}{lcccc}
\hline Frames & Mean & $S D$ & \multicolumn{2}{c}{$95 \%$ Confidence } \\
\cline { 3 - 5 } & & & Lower Bound & Upper Bound \\
\hline Structural & 32.07 & 6.34 & 30.87 & 33.28 \\
Human Resource & 33.34 & 5.96 & 32.21 & 34.48 \\
Political & 35.16 & 4.49 & 34.30 & 36.02 \\
Symbolic & 33.93 & 5.50 & 32.88 & 34.97 \\
Total & 33.62 & 5.71 & 33.08 & 34.16 \\
\hline
\end{tabular}

Note. Range score between 8 and 40 where higher values indicate positive performance.

Analyses of responses for items that refer to the human resource frame indicated a total mean score of 33.34 and the $95 \%$ confidence interval of 32.21 and 34.48 . The lowest score for items within the human resource frame was 11 and the maximum score was 40. Respondents rated Fr. García lowest within the human resource frame when asked if he "fosters high levels of participation and involvement in decisions" (item 14), with a mean score of $3.75(S D=1.04)$, and rated him best when asked if he "shows high levels of support and concern for others" (item 2), with a mean score of $4.46(S D=.71)$.

Analyses of responses for items that refer to the political frame indicated a total mean score of 35.16 , the highest of all four frames, and the $95 \%$ confidence interval of 34.30 and 36.02. The lowest score for items within the political frame was 22 and the maximum score was 40. Respondents rated Fr. García lowest within the political frame when asked if he "anticipates and deals adroitly with organizational conflict" (item 15) with a mean score of $3.53(S D=1.12)$, the lowest rating for any item in Section I of the 
survey. Respondents rated Fr. García best when asked if he "is very effective in getting support from people with influence and power" (item 19), with a mean score of 4.82 (SD $=.43$ ), the highest rating for any item in Section I of the survey.

Table 2

Section II - Leadership Style Total Mean Scores

\begin{tabular}{lcccc}
\hline Frames & Mean & $S D$ & \multicolumn{2}{c}{$95 \%$ Confidence } \\
\cline { 3 - 5 } & & & Lower Bound & Upper Bound \\
\hline Structural & 12.92 & 3.47 & 12.26 & 13.58 \\
Human Resource & 14.94 & 3.39 & 14.28 & 15.61 \\
Political & 17.67 & 3.77 & 16.95 & 18.39 \\
Symbolic & 14.47 & 3.77 & 13.75 & 15.19 \\
Total & 15.00 & 4.00 & 14.62 & 15.38 \\
\hline
\end{tabular}

Note. Range score between 6 and 24 where higher values indicate positive performance.

Analyses of responses for items that refer to the symbolic frame indicated a total mean score of 33.93 and the $95 \%$ confidence interval of 32.88 and 34.97 . The lowest score for items within the symbolic frame was 16 and the maximum score was 40 . Respondents rated Fr. García lowest within the symbolic frame when asked if he "is highly imaginative and creative" (item 16), with a mean score of $4.00(S D=.94)$, and rated him best when asked if he "communicates a strong and challenging vision and sense of mission" (item 20), with a mean score of $4.57(S D=.66)$.

Section II results: Leadership style. Respondents were asked to rank order each group of four descriptors from 1 to 4 using a forced-choice scale where " 1 " is given to "the phrase that is least like the person" through " 4 " that is given to "the phrase that best describes the person." The possible range for each frame was between 6 and 24 . Complete results of rank order for each item are reported in Table 4.

Analyses of responses indicated a mean score of 12.92 and the $95 \%$ confidence interval of 12.26 and 13.58. The lowest score for items within the structural frame was 6 
and the maximum score was 21. More specifically, $76(69.1 \%)$ respondents indicated that within the structural frame, being a "technical expert" (item 2a) is the phrase that least describes Fr. García, the highest "1" rating for any item in Section II of the survey. Furthermore, within the structural frame, 27 (24.5\%) respondents indicated "makes good decisions" (item 3a) is the phrase that best describes Fr. García.

Analyses of responses indicated a mean score of 14.94 and the $95 \%$ confidence interval of 14.28 and 15.61 . The lowest score for items within the human resource frame was 7 and the maximum score was 21 . More specifically, 47 (42.7\%) respondents indicted that within the human resource frame, what least describes Fr. García is his ability for "coaching and developing people" (item 3b), while 30 (27.3\%) indicated that what best describes him is his "caring and support for others" (item 5b).

Analyses of responses indicated a mean score of 17.67 and the $95 \%$ confidence interval of 16.95 and 18.39 (see Table 2). The lowest score for items within the political frame was 7 and the maximum score was 24 . More specifically, $58(52.7 \%)$ respondents indicated that within the political frame, the phrase that least describes Fr. García is his "toughness and aggressiveness" (item 5c), while 69 (62.7\%) indicated that what best describes him is his ability to "build alliances and a power base" (item 3c), the highest "4" rating of all items in Section II of the survey.

Analyses of responses indicated a mean score of 14.47 and the $95 \%$ confidence interval of 13.75 and 15.19 . The lowest score for items within the symbolic frame was 7 and the maximum score was 23 . More specifically, $48(43.6 \%)$ respondents indicated that within the symbolic frame the phrase that least describes Fr. García is his "ability to 
excite and motivate" (item 1d), while $56(50.9 \%)$ indicated that the phrase that best describes him is as "a visionary" (item 6d).

Table 3

Section I-Leader Behaviors Results per Item

\begin{tabular}{|c|c|c|c|c|c|c|}
\hline Frame & Item No. & Mean & $S D$ & $n$ & Minimum & Maximum \\
\hline \multirow[t]{8}{*}{ Structural } & 1 & 4.32 & 0.73 & 110 & 2.00 & 5.00 \\
\hline & 5 & 3.99 & 0.99 & 110 & 1.00 & 5.00 \\
\hline & 9 & 4.19 & 0.84 & 110 & 2.00 & 5.00 \\
\hline & 13 & 3.87 & 1.01 & 110 & 1.00 & 5.00 \\
\hline & 17 & 4.22 & 0.91 & 109 & 1.00 & 5.00 \\
\hline & 21 & 3.78 & 1.18 & 110 & 1.00 & 5.00 \\
\hline & 25 & 3.93 & 0.83 & 110 & 2.00 & 5.00 \\
\hline & 29 & 3.79 & 1.18 & 110 & 1.00 & 5.00 \\
\hline \multirow[t]{8}{*}{ Human Resource } & 2 & 4.46 & 0.71 & 110 & 2.00 & 5.00 \\
\hline & 6 & 4.09 & 1.05 & 110 & 1.00 & 5.00 \\
\hline & 10 & 4.41 & 0.78 & 110 & 1.00 & 5.00 \\
\hline & 14 & 3.75 & 1.04 & 110 & 1.00 & 5.00 \\
\hline & 18 & 4.39 & 0.78 & 109 & 1.00 & 5.00 \\
\hline & 22 & 4.21 & 0.96 & 109 & 1.00 & 5.00 \\
\hline & 26 & 4.00 & 1.04 & 110 & 1.00 & 5.00 \\
\hline & 30 & 4.01 & 1.06 & 110 & 1.00 & 5.00 \\
\hline \multirow[t]{8}{*}{ Political } & 3 & 4.57 & 0.76 & 109 & 2.00 & 5.00 \\
\hline & 7 & 4.56 & 0.74 & 109 & 2.00 & 5.00 \\
\hline & 11 & 4.41 & 0.69 & 110 & 3.00 & 5.00 \\
\hline & 15 & 3.53 & 1.12 & 108 & 1.00 & 5.00 \\
\hline & 19 & 4.82 & 0.43 & 110 & 3.00 & 5.00 \\
\hline & 23 & 4.51 & 0.78 & 110 & 2.00 & 5.00 \\
\hline & 27 & 4.35 & 0.89 & 110 & 1.00 & 5.00 \\
\hline & 31 & 4.28 & 0.80 & 110 & 2.00 & 5.00 \\
\hline \multirow[t]{8}{*}{ Symbolic } & 4 & 4.25 & 0.89 & 110 & 2.00 & 5.00 \\
\hline & 8 & 4.06 & 1.02 & 110 & 1.00 & 5.00 \\
\hline & 12 & 4.17 & 0.84 & 110 & 1.00 & 5.00 \\
\hline & 16 & 4.00 & 0.94 & 110 & 1.00 & 5.00 \\
\hline & 20 & 4.57 & 0.66 & 109 & 3.00 & 5.00 \\
\hline & 24 & 4.41 & 0.91 & 110 & 1.00 & 5.00 \\
\hline & 28 & 4.25 & 0.88 & 110 & 1.00 & 5.00 \\
\hline & 32 & 4.23 & 0.86 & 110 & 1.00 & 5.00 \\
\hline
\end{tabular}

Note. Each item was rated using a five-point scale where: $1=$ never, $2=$ occasionally, $3=$ sometimes, $4=$ often, and $5=$ always. For specific wording of each item refer to instrument (Appendix B or C). 
Table 4

Section II - Leadership Style Rank Order per Item

\begin{tabular}{|c|c|c|c|c|c|c|}
\hline \multirow[t]{2}{*}{ Frame } & \multirow{2}{*}{$\begin{array}{l}\text { Item } \\
\text { No. }\end{array}$} & \multicolumn{4}{|c|}{ Rank Order } & \multirow[t]{2}{*}{$n$} \\
\hline & & 1 & 2 & 3 & 4 & \\
\hline \multirow[t]{6}{*}{ Structural } & $1 \mathrm{a}$ & $32(29.1 \%)$ & $24(21.8 \%)$ & $36(32.7 \%)$ & $17(15.5 \%)$ & 109 \\
\hline & $2 \mathrm{a}$ & $76(69.1 \%)$ & $11(10.0 \%)$ & $12(10.9 \%)$ & $10(9.1 \%)$ & 109 \\
\hline & $3 a$ & $8(7.3 \%)$ & $27(24.5 \%)$ & $47(42.7 \%)$ & $27(24.5 \%)$ & 109 \\
\hline & $4 a$ & $48(43.6)$ & $33(30.0 \%)$ & $16(14.5 \%)$ & $13(11.8 \%)$ & 110 \\
\hline & $5 a$ & $18(16.4 \%)$ & $36(32.7 \%)$ & $28(25.5 \%)$ & $26(23.6 \%)$ & 108 \\
\hline & $6 a$ & $57(51.8 \%)$ & $31(28.2 \%)$ & $17(15.5 \%)$ & $3(2.7 \%)$ & 108 \\
\hline Human & $1 b$ & $14(12.7 \%)$ & $36(32.7 \%)$ & $29(26.4 \%)$ & $29(26.4 \%)$ & 108 \\
\hline \multirow[t]{5}{*}{ Resource } & $2 b$ & $8(7.3 \%)$ & $44(40.0 \%)$ & $42(38.2 \%)$ & $15(13.6 \%)$ & 109 \\
\hline & $3 b$ & $47(42.7 \%)$ & $44(40.0 \%)$ & $14(12.7 \%)$ & $3(2.7 \%)$ & 108 \\
\hline & $4 b$ & $11(10.0 \%)$ & $28(25.5 \%)$ & $44(40.0 \%)$ & $25(22.7 \%)$ & 108 \\
\hline & $5 b$ & $10(9.1 \%)$ & $35(31.8 \%)$ & $35(31.8 \%)$ & $30(27.3 \%)$ & 110 \\
\hline & $6 b$ & $21(19.1 \%)$ & $37(33.6 \%)$ & $33(30.0 \%)$ & $17(15.5 \%)$ & 108 \\
\hline \multirow[t]{6}{*}{ Political } & $1 \mathrm{c}$ & $14(12.7 \%)$ & $13(11.8 \%)$ & $27(24.5 \%)$ & $55(50.0 \%)$ & 109 \\
\hline & $2 c$ & $4(3.6 \%)$ & $16(14.5 \%)$ & $23(20.9 \%)$ & $65(59.1 \%)$ & 108 \\
\hline & $3 c$ & $11(10.0 \%)$ & $7(6.4 \%)$ & $23(20.9 \%)$ & $69(62.7 \%)$ & 110 \\
\hline & $4 c$ & $9(8.2 \%)$ & $21(19.1 \%)$ & $25(22.7 \%)$ & $53(48.2 \%)$ & 108 \\
\hline & $5 c$ & $58(52.7 \%)$ & $14(12.7 \%)$ & $20(18.2 \%)$ & $16(14.5 \%)$ & 108 \\
\hline & $6 c$ & $21(19.1 \%)$ & $19(17.3 \%)$ & $35(31.8 \%)$ & $34(30.9 \%)$ & 109 \\
\hline \multirow[t]{6}{*}{ Symbolic } & $1 d$ & $48(43.6 \%)$ & $35(31.8 \%)$ & $16(14.5 \%)$ & $9(8.2 \%)$ & 108 \\
\hline & $2 d$ & $20(18.2 \%)$ & $37(33.6 \%)$ & $31(28.2 \%)$ & $20(18.2 \%)$ & 108 \\
\hline & $3 d$ & $42(38.2 \%)$ & $30(27.3 \%)$ & $24(21.8 \%)$ & $12(10.9 \%)$ & 108 \\
\hline & $4 d$ & $40(36.4 \%)$ & $26(23.6 \%)$ & $23(20.9 \%)$ & $19(17.3 \%)$ & 108 \\
\hline & $5 d$ & $22(20.0 \%)$ & $23(20.9 \%)$ & $25(22.7 \%)$ & $38(34.5 \%)$ & 108 \\
\hline & $6 \mathrm{~d}$ & $9(8.2 \%)$ & $21(19.1 \%)$ & $23(20.9 \%)$ & $56(50.9 \%)$ & 109 \\
\hline
\end{tabular}

Note. Respondents were asked to rank order each group of four descriptors from 1 to 4 using a forced-choice scale where " 1 " is given to "the phrase that is least like the person" through " 4 " that is given to "the phrase that best describes the person." For specific wording of each item refer to instrument (Appendix B or C).

Multiple frame use. Using the cut off point provided by Dr. Lee Bolman, frame use was determined by a mean subscale score of 25.92 or greater for Section I responses and 9.6 or greater for Section II responses of the Leadership Orientations Survey. Tabulation of the usable surveys resulted in the mean scores for each of the four frames 
in both sections of the surveys presented in Table 1 and Table 2. Respondents indicated frequent use of all four frames by Fr. García.

Section III results: Overall effectiveness as a manager and leader. Respondents rated overall manager and leadership effectiveness using an anchored scale requiring the selection of one of five response choices, which have a percentage value. The criteria were " 1 " signified "bottom $20 \%$," "2" was the "bottom to middle," "3" was the "middle $20 \%$," "4" was the "middle to top," and " 5 " the "top 20\%." Results are reported in Table 5.

Manager effectiveness scores indicated that 38 (34.5\%) respondents consider Fr. García to be in the middle to top $20 \%$ of managers they have known and $56(50.9 \%)$ consider him in the top $20 \%$. In contrast, 16 (14.5\%) respondents rated him in the middle, bottom to middle, or bottom $20 \%$. If manager effectiveness were measured by the middle to top and top 20\%, $94(85.4 \%)$ respondents agree that Fr. García is an effective manager.

In reference to leader effectiveness, scores indicated that 43 (39.1\%) respondents consider Fr. García to be in the middle to top $20 \%$ of leaders they have known and 49 (44.5\%) consider him in the top $20 \%$. In contrast, $18(16.3 \%)$ respondents rated him in the middle, middle to bottom, or bottom $20 \%$. If leader effectiveness were measured by the middle to top and top 20\%, $92(83.6 \%)$ respondents agree that Fr. García is an effective leader.

Correlations. Correlation between frames is reported in Table 6. Analyses of responses indicated that there were significant negative correlations between the human resource frame and the structural frame, $r=-.43$, and the human resource frame and the political frame, $r=-.47$. There was not a significant correlation between the human 
resource and symbolic frame, $r=-.06$. In addition, there was a significant negative correlation between the structural frame and symbolic frame, $r=-.47$, and between the political frame and symbolic frame, $r=-.51$. There was no significant correlation between the structural and political frames, $r=-.06$.

Table 5

Section III - Overall Effectiveness Rating

\begin{tabular}{lcccccc}
\hline Rate & \multicolumn{2}{c}{$\begin{array}{c}\text { Effectiveness as a } \\
\text { Manager }\end{array}$} & & \multicolumn{2}{c}{$\begin{array}{c}\text { Effectiveness as a } \\
\text { Leader }\end{array}$} \\
\cline { 2 - 3 } \cline { 5 - 6 } \cline { 5 - 6 } & Frequency & Percent & & Frequency & Percent \\
\hline 1 (Bottom 20\%) & 0 & 0 & & 1 & .9 \\
2 (Bottom to Middle 20\%) & 5 & 4.5 & & 2 & 1.8 \\
3 (Middle 20\%) & 11 & 10.0 & & 15 & 13.6 \\
4 (Middle to Top 20\%) & 38 & 34.5 & & 43 & 39.1 \\
5 (Top 20\%) & 56 & 50.9 & & 49 & 44.5 \\
Total & 110 & & & 110 & \\
\hline
\end{tabular}

\section{Administrative Leadership Profile Survey (ALPS) Results}

The Administrative Leadership Profile Survey (ALPS) was administered to 110 members of the Belen Jesuit Preparatory School community: 90 faculty, 10 staff, 7 administrators, the president of the alumni association, the head of the parents' steering committee, and the superior of the Miami region of the Society of Jesus.

Analyses of Responses

Descriptive statistics and exploratory data analysis (EDA) were used to summarize in three sections the main findings for the two different parts administered in the survey.

Section I: Goal importance and performance of the president. Results for Part One of the survey have been reported through the use of a series of bar charts that show the frequency (percentage) of responses for each item in terms of the president's performance (see Appendix H). Two bar graphs, one that shows the percentage of 
responses rating the goal statements as "Definitely Important" and the other that shows the percentage of responses rating the president's performance of those same goals as "Usually Does" or "Consistently Does" have also been included (see Appendix I). Also included is a line graph that compares the mean scores on importance and performance (see Appendix J).

Table 6

Correlations Between Frames

\begin{tabular}{ll}
\hline \multicolumn{1}{c}{ Pairs of Frames } & \multicolumn{1}{c}{$r$} \\
\hline Structural with Human Resource & $-.43^{* * *}$ \\
Structural with Symbolic & $-.47 * * *$ \\
Structural with Political & -.06 \\
Human Resource with Symbolic & -.06 \\
Human Resource with Political & $-.47 * * *$ \\
Symbolic with Political & $-.51 * * *$ \\
\hline Note. ${ }^{* * *} p<.001$. & \\
$n=108$. &
\end{tabular}

Section II: Organizational health of the school. For Part Two, the organizational health of the school, results have been reported through a series of bar charts that show the frequency (percentage) of responses for each item on a scale from "Strongly Agree" to "Strongly Disagree," indicating the respondents' perceptions or experience of the school from an organizational point of view (see Appendix K). Also included is a bar graph that shows the percentage of responses rating the items as "Agree" or "Strongly Agree" (see Appendix L).

Section III: Statistical results. In Part One of the survey respondents were asked to rate the goal performance of Fr. García by using a five-point scale where: $0=$ never does, 1 = rarely does, $2=$ sometimes does, $3=$ usually does, and $4=$ consistently does. Thus, the possible range for each item was between 0 and 4 . The lowest and highest ratings are reported per category below (see Table 7 for complete results). 
In addition, respondents were also asked to rate the degree of importance that they attached to each item by using a thee-point scale where: $0=$ not at all important, $1=$ somewhat important, and 2 = definitely important. The possible value range for each item was between 0 and 3 where the value 0 was given to "no answer." The lowest and highest ratings are reported per category below (see Table 8 for complete results).

Analyses of responses for items that refer to leadership indicated that respondents rated Fr. García lowest when asked if he "collaborates in building and sustaining an effective administrative team" (item 37), with a mean score of $2.82(S D=1.13)$. Respondents rated him best when asked if he "seeks to deepen alumni/ae commitment to the service of others" (item 40$)$, with a mean score of $3.81(S D=.40)$ and "cultivates involvement and support by parents and alumni/ae" (item 59) also with a mean score of $3.81(S D=.46)$.

In reference to the degree of importance attached to the items that refer to leadership, respondents rated "motivates people to do their very best and to work effectively together" (item 35$)$ lowest with a mean score of $1.85(S D=.38)$. Respondents rated "gives people the freedom and authority to do their jobs well" (item 50) highest with a mean score of $1.97(S D=.16)$.

Analyses of responses for items that refer to being open to growth indicated that respondents rated Fr. García lowest when asked if he "invites regular evaluation of the president by the Board of Trustees" (item 34), with a mean score of $3.19(S D=1.17)$. Respondents rated him best when asked if he "takes time out for prayer, reading and reflection" (item 54), with a mean score of $3.78(S D=.46)$. 
Table 7

Goal Performance of the President

\begin{tabular}{|c|c|c|c|c|c|c|}
\hline \multirow[t]{2}{*}{ Theme } & \multirow[t]{2}{*}{ Item No. } & \multirow[t]{2}{*}{ Mean } & \multirow[t]{2}{*}{$S D$} & \multirow[t]{2}{*}{$n$} & \multicolumn{2}{|c|}{$95 \%$ Confidence } \\
\hline & & & & & Lower Bound & Upper Bound \\
\hline \multirow[t]{9}{*}{ Leadership } & 35 & 3.08 & 0.98 & 109 & 2.89 & 3.27 \\
\hline & 36 & 3.32 & 0.82 & 109 & 3.16 & 3.48 \\
\hline & 37 & 2.82 & 1.13 & 109 & 2.60 & 3.04 \\
\hline & 40 & 3.81 & 0.40 & 108 & 3.73 & 3.89 \\
\hline & 41 & 3.75 & 0.53 & 109 & 3.65 & 3.85 \\
\hline & 44 & 3.45 & 0.80 & 110 & 3.30 & 3.60 \\
\hline & 50 & 3.80 & 0.47 & 109 & 3.71 & 3.89 \\
\hline & 57 & 3.35 & 0.87 & 110 & 3.18 & 3.52 \\
\hline & 59 & 3.81 & 0.46 & 110 & 3.72 & 3.90 \\
\hline Open to & 8 & 3.29 & 0.78 & 104 & 3.14 & 3.44 \\
\hline \multirow[t]{8}{*}{ Growth } & 18 & 3.47 & 0.78 & 109 & 3.32 & 3.62 \\
\hline & 20 & 3.71 & 0.55 & 106 & 3.60 & 3.82 \\
\hline & 26 & 3.65 & 0.66 & 109 & 3.52 & 3.78 \\
\hline & 34 & 3.19 & 1.17 & 91 & 2.94 & 3.44 \\
\hline & 45 & 3.52 & 0.78 & 108 & 3.37 & 3.67 \\
\hline & 48 & 3.35 & 0.88 & 92 & 3.17 & 3.53 \\
\hline & 54 & 3.78 & 0.46 & 104 & 3.69 & 3.87 \\
\hline & 72 & 3.36 & 0.84 & 107 & 3.20 & 3.52 \\
\hline Professional & 14 & 3.84 & 0.47 & 109 & 3.75 & 3.93 \\
\hline \multirow[t]{8}{*}{ Competence } & 16 & 3.56 & 0.71 & 108 & 3.42 & 3.69 \\
\hline & 24 & 3.36 & 0.79 & 110 & 3.21 & 3.51 \\
\hline & 30 & 3.72 & 0.56 & 109 & 3.61 & 3.83 \\
\hline & 42 & 3.66 & 0.67 & 99 & 3.53 & 3.79 \\
\hline & 43 & 3.80 & 0.59 & 95 & 3.68 & 3.92 \\
\hline & 46 & 3.28 & 0.91 & 109 & 3.11 & 3.45 \\
\hline & 47 & 3.33 & 0.94 & 109 & 3.15 & 3.51 \\
\hline & 55 & 2.73 & 1.19 & 102 & 2.49 & 2.97 \\
\hline Loving and & 11 & 3.63 & 0.59 & 109 & 3.52 & 3.74 \\
\hline \multirow[t]{8}{*}{ Caring } & 12 & 3.86 & 0.39 & 110 & 3.79 & 3.93 \\
\hline & 19 & 3.77 & 0.54 & 110 & 3.67 & 3.87 \\
\hline & 29 & 3.87 & 0.49 & 109 & 3.78 & 3.96 \\
\hline & 33 & 3.71 & 0.57 & 105 & 3.60 & 3.82 \\
\hline & 58 & 3.49 & 0.85 & 110 & 3.33 & 3.65 \\
\hline & 63 & 3.31 & 0.82 & 109 & 3.15 & 3.47 \\
\hline & 67 & 3.29 & 0.89 & 107 & 3.12 & 3.46 \\
\hline & 70 & 3.62 & 0.72 & 108 & 3.52 & 3.74 \\
\hline
\end{tabular}

(table continues) 
Table 7 (continued)

\begin{tabular}{|c|c|c|c|c|c|c|}
\hline \multirow[t]{2}{*}{ Theme } & \multirow[t]{2}{*}{ Item No. } & \multirow[t]{2}{*}{ Mean } & \multirow[t]{2}{*}{$S D$} & \multirow[t]{2}{*}{$n$} & \multicolumn{2}{|c|}{ 95\% Confidence } \\
\hline & & & & & Lower Bound & Upper Bound \\
\hline \multirow[t]{9}{*}{ Ignatian Vision } & 2 & 3.54 & 0.63 & 110 & 3.42 & 3.66 \\
\hline & 5 & 3.66 & 0.58 & 109 & 3.55 & 3.77 \\
\hline & 13 & 3.53 & 0.76 & 109 & 3.38 & 3.68 \\
\hline & 15 & 3.82 & 0.49 & 108 & 3.73 & 3.91 \\
\hline & 22 & 3.52 & 0.72 & 108 & 3.38 & 3.66 \\
\hline & 38 & 3.60 & 0.70 & 105 & 3.46 & 3.74 \\
\hline & 49 & 3.50 & 0.83 & 101 & 3.33 & 3.67 \\
\hline & 62 & 3.66 & 0.64 & 110 & 3.54 & 3.78 \\
\hline & 68 & 3.43 & 0.80 & 106 & 3.27 & 3.59 \\
\hline \multirow{9}{*}{ In Action } & 6 & 3.05 & 0.94 & 109 & 2.87 & 3.23 \\
\hline & 7 & 3.17 & 0.86 & 109 & 3.01 & 3.33 \\
\hline & 9 & 3.41 & 0.75 & 110 & 3.27 & 3.55 \\
\hline & 10 & 3.71 & 0.60 & 110 & 3.60 & 3.82 \\
\hline & 25 & 3.78 & 0.51 & 98 & 3.68 & 3.88 \\
\hline & 27 & 3.44 & 0.72 & 110 & 3.30 & 3.58 \\
\hline & 51 & 3.49 & 0.75 & 109 & 3.35 & 3.63 \\
\hline & 65 & 3.41 & 0.81 & 107 & 3.25 & 3.57 \\
\hline & 69 & 3.48 & 0.76 & 92 & 3.32 & 3.64 \\
\hline \multirow[t]{9}{*}{ Communications } & 1 & 3.67 & 0.55 & 109 & 3.56 & 3.78 \\
\hline & 4 & 2.75 & 0.97 & 109 & 2.56 & 2.94 \\
\hline & 17 & 3.76 & 0.57 & 100 & 3.64 & 3.87 \\
\hline & 21 & 3.73 & 0.57 & 108 & 3.62 & 3.84 \\
\hline & 28 & 3.35 & 0.85 & 110 & 3.19 & 3.51 \\
\hline & 31 & 3.47 & 0.81 & 109 & 3.31 & 3.63 \\
\hline & 39 & 3.80 & 0.45 & 108 & 3.71 & 3.89 \\
\hline & 52 & 3.02 & 1.03 & 106 & 2.82 & 3.22 \\
\hline & 71 & 3.63 & 0.64 & 107 & 3.79 & 3.93 \\
\hline \multirow[t]{9}{*}{ Decision Making } & 3 & 3.12 & 0.75 & 109 & 2.98 & 3.26 \\
\hline & 10 & 3.54 & 0.81 & 110 & 3.39 & 3.69 \\
\hline & 23 & 3.08 & 0.90 & 110 & 2.91 & 3.25 \\
\hline & 32 & 3.14 & 0.98 & 109 & 2.95 & 3.33 \\
\hline & 53 & 3.40 & 0.79 & 109 & 3.25 & 3.55 \\
\hline & 56 & 3.07 & 1.06 & 95 & 2.85 & 3.29 \\
\hline & 61 & 3.65 & 0.63 & 110 & 3.53 & 3.77 \\
\hline & 64 & 3.11 & 0.99 & 102 & 2.91 & 3.31 \\
\hline & 66 & 3.29 & 0.75 & 109 & 3.15 & 3.43 \\
\hline
\end{tabular}

Note. Possible range for each item was between 0 and 4 . For specific wording of each item refer to instrument (Appendix D). 
Table 8

Goal Importance

\begin{tabular}{|c|c|c|c|c|c|c|}
\hline Theme & Item No. & Mean & $S D$ & $n$ & Minimum & Maximum \\
\hline \multirow[t]{9}{*}{ Leadership } & 35 & 1.85 & 0.38 & 110 & 0.00 & 2.00 \\
\hline & 36 & 1.92 & 0.28 & 110 & 1.00 & 2.00 \\
\hline & 37 & 1.86 & 0.37 & 110 & 0.00 & 2.00 \\
\hline & 40 & 1.84 & 0.39 & 108 & 0.00 & 2.00 \\
\hline & 41 & 1.89 & 0.31 & 109 & 1.00 & 2.00 \\
\hline & 44 & 1.88 & 0.33 & 109 & 1.00 & 2.00 \\
\hline & 50 & 1.97 & 0.16 & 109 & 1.00 & 2.00 \\
\hline & 57 & 1.88 & 0.33 & 109 & 1.00 & 2.00 \\
\hline & 59 & 1.90 & 0.30 & 110 & 1.00 & 2.00 \\
\hline \multirow[t]{9}{*}{ Open to Growth } & 8 & 1.72 & 0.45 & 103 & 1.00 & 2.00 \\
\hline & 18 & 1.80 & 0.43 & 109 & 0.00 & 2.00 \\
\hline & 20 & 1.92 & 0.28 & 108 & 1.00 & 2.00 \\
\hline & 26 & 1.96 & 0.19 & 110 & 1.00 & 2.00 \\
\hline & 34 & 1.76 & 0.48 & 94 & 0.00 & 2.00 \\
\hline & 45 & 1.85 & 0.38 & 108 & 0.00 & 2.00 \\
\hline & 48 & 1.72 & 0.49 & 97 & 0.00 & 2.00 \\
\hline & 54 & 1.91 & 0.32 & 108 & 0.00 & 2.00 \\
\hline & 72 & 2.91 & 0.32 & 107 & 1.00 & 3.00 \\
\hline Professional & 14 & 1.92 & 0.28 & 108 & 1.00 & 2.00 \\
\hline \multirow[t]{8}{*}{ Competence } & 16 & 1.91 & 0.29 & 108 & 1.00 & 2.00 \\
\hline & 24 & 2.91 & 0.29 & 110 & 2.00 & 3.00 \\
\hline & 30 & 1.98 & 0.13 & 110 & 1.00 & 2.00 \\
\hline & 42 & 1.89 & 0.31 & 101 & 1.00 & 2.00 \\
\hline & 43 & 1.94 & 0.32 & 95 & 0.00 & 2.00 \\
\hline & 46 & 1.90 & 0.33 & 109 & 0.00 & 2.00 \\
\hline & 47 & 1.83 & 0.40 & 110 & 0.00 & 2.00 \\
\hline & 55 & 1.76 & 0.49 & 104 & 0.00 & 2.00 \\
\hline Loving and & 11 & 1.92 & 0.28 & 109 & 1.00 & 2.00 \\
\hline \multirow[t]{8}{*}{ Caring } & 12 & 1.83 & 0.38 & 109 & 1.00 & 2.00 \\
\hline & 19 & 1.90 & 0.30 & 110 & 1.00 & 2.00 \\
\hline & 29 & 1.91 & 0.32 & 110 & 0.00 & 2.00 \\
\hline & 33 & 1.82 & 0.41 & 106 & 0.00 & 2.00 \\
\hline & 58 & 1.90 & 0.30 & 110 & 1.00 & 2.00 \\
\hline & 63 & 1.85 & 0.35 & 110 & 1.00 & 2.00 \\
\hline & 67 & 1.84 & 0.39 & 107 & 0.00 & 2.00 \\
\hline & 70 & 1.93 & 0.30 & 108 & 0.00 & 2.00 \\
\hline
\end{tabular}

(table continues) 
Table 8 (continued)

\begin{tabular}{|c|c|c|c|c|c|c|}
\hline Theme & Item No. & Mean & $S D$ & $n$ & Minimum & Maximum \\
\hline \multirow[t]{9}{*}{ Ignatian Vision } & 2 & 1.97 & 0.16 & 110 & 1.00 & 2.00 \\
\hline & 5 & 1.96 & 0.19 & 109 & 1.00 & 2.00 \\
\hline & 13 & 1.81 & 0.39 & 108 & 1.00 & 2.00 \\
\hline & 15 & 1.86 & 0.35 & 108 & 1.00 & 2.00 \\
\hline & 22 & 1.87 & 0.36 & 109 & 0.00 & 2.00 \\
\hline & 38 & 1.89 & 0.35 & 106 & 0.00 & 2.00 \\
\hline & 49 & 1.73 & 0.49 & 104 & 0.00 & 2.00 \\
\hline & 62 & 1.97 & 0.16 & 110 & 1.00 & 2.00 \\
\hline & 68 & 1.86 & 0.40 & 107 & 0.00 & 2.00 \\
\hline \multirow[t]{9}{*}{ In Action } & 6 & 1.90 & 0.30 & 110 & 1.00 & 2.00 \\
\hline & 7 & 1.84 & 0.37 & 110 & 1.00 & 2.00 \\
\hline & 9 & 1.89 & 0.31 & 109 & 1.00 & 2.00 \\
\hline & 10 & 1.94 & 0.28 & 109 & 0.00 & 2.00 \\
\hline & 25 & 1.96 & 0.24 & 99 & 0.00 & 2.00 \\
\hline & 27 & 1.92 & 0.28 & 109 & 1.00 & 2.00 \\
\hline & 51 & 1.94 & 0.23 & 109 & 1.00 & 2.00 \\
\hline & 65 & 1.91 & 0.32 & 107 & 0.00 & 2.00 \\
\hline & 69 & 1.81 & 0.40 & 94 & 1.00 & 2.00 \\
\hline \multirow[t]{9}{*}{ Communications } & 1 & 1.83 & 0.38 & 110 & 1.00 & 2.00 \\
\hline & 4 & 1.60 & 0.53 & 108 & 0.00 & 2.00 \\
\hline & 17 & 1.83 & 0.37 & 103 & 1.00 & 2.00 \\
\hline & 21 & 2.90 & 0.33 & 109 & 1.00 & 3.00 \\
\hline & 28 & 1.90 & 0.30 & 110 & 1.00 & 2.00 \\
\hline & 31 & 1.90 & 0.33 & 110 & 0.00 & 2.00 \\
\hline & 39 & 1.81 & 0.42 & 109 & 0.00 & 2.00 \\
\hline & 52 & 1.85 & 0.38 & 108 & 0.00 & 2.00 \\
\hline & 71 & 1.94 & 0.23 & 106 & 1.00 & 2.00 \\
\hline Decision & 3 & 1.85 & 0.35 & 110 & 1.00 & 2.00 \\
\hline \multirow[t]{8}{*}{ Making } & 10 & 1.94 & 0.28 & 109 & 0.00 & 2.00 \\
\hline & 23 & 1.86 & 0.34 & 110 & 1.00 & 2.00 \\
\hline & 32 & 1.83 & 0.43 & 110 & 0.00 & 2.00 \\
\hline & 53 & 1.88 & 0.35 & 110 & 0.00 & 2.00 \\
\hline & 56 & 1.68 & 0.53 & 98 & 0.00 & 2.00 \\
\hline & 61 & 1.96 & 0.19 & 110 & 1.00 & 2.00 \\
\hline & 64 & 1.73 & 0.49 & 102 & 0.00 & 2.00 \\
\hline & 66 & 1.88 & 0.33 & 108 & 1.00 & 2.00 \\
\hline
\end{tabular}

Note. Possible range for each item was between 0 and 3 where a 0 value was given to a "no answer." For specific wording of each item refer to instrument (Appendix D). 
In reference to the degree of importance attached to the items that refer to being open to growth, respondents rated "knows personal limitations and deals effectively with them" (item 8) lowest with a mean score of $1.72(S D=.45)$ as well as "sees to the continued education and development of the Board of Trustees" (item 48) with a mean score of $1.72(S D=.49)$. Respondents rated "sees that the school regularly evaluates how it's fulfilling its mission" (item 72) highest with a mean score of $2.91(S D=.32)$, the highest rating of importance among all items.

Analyses of responses for items that refer to professional competence indicated that respondents rated Fr. García lowest when asked if he "evaluates the performance of the administration on a systematic basis" (item 55), with a mean score of $2.73(S D=$ 1.19), the lowest rating for any item in part one of the survey. Furthermore, this item was also considered least important among this particular category $(M=1.76, S D=.49)$. On the other hand, Fr. García received the highest rating within this category when asked if he "oversees a program for maintaining and improving the school's facilities" (item 14), with a mean score of $3.84(S D=.47)$. Respondents rated "keeps on top of significant school issues" (item 24) highest with a mean score of $2.91(S D=.29)$, which along with item 72 was the highest rating of importance among all items.

Analyses of responses for items that refer to being loving and caring indicated that respondents rated Fr. García lowest when asked if he "delegates responsibilities according to people's talents and interests" (item 67), with a mean score of $3.29(S D=$ .89). Respondents rated him best when asked if he "solicits contributions on behalf of the school with grace and conviction" (item 29), with a mean score of $3.87(S D=.49)$, the highest rating for any item in part one of the survey. 
In reference to the degree of importance attached to the items that refer to being loving and caring, respondents rated "spends time with people for whom the school has special meaning" (item 33) lowest with a mean score of $1.82(S D=.41)$. Respondents rated "is visible and available to constituencies inside and outside the school" (item 70) highest with a mean score of $1.93(S D=.30)$.

Analyses of responses for items that refer to Ignatian vision indicated that respondents rated Fr. García lowest when asked if he "models a leadership style of apostolic service" (item 68$)$, with a mean score of $3.43(S D=.80)$. Respondents rated him best when asked if he "encourages Jesuits to invest in the school as an apostolic work" (item 15), with a mean score of $3.82(S D=.49)$.

When referring to the degree of importance attached to the items that refer to Ignatian vision, respondents rated "promotes participation in the programs of JSEA" (item 49) lowest with a mean score of $1.73(S D=.49)$. Respondents rated both "calls the school to excellence in carrying out its education mission" (item 2) and "shows genuine interest in the spiritual growth of the school community" (item 62) highest with a mean score of $1.97(S D=.16)$.

Analyses of responses for items that refer to being in action indicated that respondents rated Fr. García lowest when asked if he "maintains high standards of performance and conduct for all personnel" (item 6), with a mean score of $3.05(S D=$ .94). Least important for respondents was whether he "promotes responsible stewardship of the school by the Board of Trustees" (item 69), with a mean score of $1.81(S D=.40)$. Respondents rated Fr. García best when asked if he "encourages and supports the 
principal" (item 25$)$, with a mean score of $3.78(S D=.51)$, item that was also considered to be the most important within the category $(M=1.96, S D=.24)$.

Analyses of responses for items that refer to communications indicated that respondents rated Fr. García lowest when asked if he "ensures good communication between administrative offices of the school" (item 52), with a mean score of 3.02 (SD= 1.03). Respondents rated him best when asked if he "keeps alumni/ae informed about each other and the school" (item 39$)$, with a mean score of $3.80(S D=.45)$. In reference to the degree of importance, respondents rated "maintains effective lines of communication with students" (item 4) lowest with a mean score of $1.60(S D=.53)$, the lowest rating of importance among all items, and rated "maintains good relations with the Jesuit community" (item 21) highest with a mean score of $2.90(S D=.33)$.

Analyses of responses for items that refer to decision making indicated that respondents rated Fr. García lowest when asked if he "entrusts the Board of Trustees with broad policy making" (item 56$)$, with a mean score of $3.07(S D=1.06)$. Respondents also indicated this item to be the least important within the category $(M=1.68, S D=.53)$. Fr. García's performance was rated highest when asked if he "makes decisions that advance the mission and philosophy of the school" (item 61$)$, with a mean score of $3.65(S D=$ $.63)$, item that was considered to be the most important within the category $(M=1.96, S D$ $=.19)$.

In Part Two of the survey respondents were asked to rate the organizational health of the school. For each item respondents were asked to rate level of agreement using a seven-point scale where: $-3=$ strong disagreement, $-2=$ basic disagreement, $-1=$ some disagreement, $0=$ uncertain,$+1=$ some agreement,$+2=$ basic agreement,$+3=$ strong 
agreement. Thus, the possible range for each item was between -3 and 3 . Lowest and highest ratings are reported per category below (see Table 9 for complete results).

Analyses of responses for items that refer to goals indicated that respondents perceived Belen to be lowest when asked if "we have definite goals as a school" (item $27)$, with a mean score of $1.90(S D=1.33)$, and rated Belen best when asked if "we have school goals that we believe in and are committed to" (item 29), with a mean score of $2.07(S D=1.08)$

Analyses of responses for items that refer to roles indicated that respondents perceived Belen to be lowest when asked if "roles and responsibilities are clearly communicated at our school" (item 16), with a mean score of $1.37(S D=1.49)$, and rated Belen best when asked if "I am comfortable with my role in the school" (item 1), with a mean score of $2.39(S D=1.00)$.

Analyses of responses for items that refer to leadership indicated that respondents perceived Belen to be lowest when asked if "our administrators know what people are doing and how they are feeling" (item 20$)$, with a mean score of $0.89(S D=1.33)$. In addition, this particular item, along with item 31, scored lowest of all 34 items in part two of the survey. Respondents rated their perception of Belen best in reference to leadership when asked if "administrators at our school are comfortable exercising leadership" (item $10)$, with a mean score of $1.97(S D=1.30)$.

Analyses of responses for items that refer to efficiency indicated that respondents perceived Belen to be lowest when asked if "internal communication in our school is good" (item 31), with a mean score of $0.89(S D=1.85)$. As indicated above, this item along with item 20 scored lowest of all 34 items in part two of the survey. Respondents 
rated their perception of Belen best in reference to efficiency when asked if "people in our school get things done" (item 2), with a mean score of $1.90(S D=1.01)$.

Table 9

\begin{tabular}{|c|c|c|c|c|c|c|}
\hline \multirow{3}{*}{ Theme } & \multirow{3}{*}{ Item No. } & \multirow{3}{*}{ Mean } & \multirow{3}{*}{$S D$} & \multirow{3}{*}{$n$} & \multicolumn{2}{|c|}{ 95\% Confidence } \\
\hline & & & & & & \\
\hline & & & & & Lower Bound & Upper Bound \\
\hline \multirow[t]{3}{*}{ Goals } & 17 & 1.92 & 1.07 & 108 & 1.71 & 2.13 \\
\hline & 27 & 1.90 & 1.33 & 109 & 1.65 & 2.15 \\
\hline & 29 & 2.07 & 1.08 & 109 & 1.86 & 2.28 \\
\hline \multirow[t]{3}{*}{ Roles } & 1 & 2.39 & 1.00 & 110 & 2.20 & 2.58 \\
\hline & 16 & 1.37 & 1.49 & 109 & 1.08 & 1.66 \\
\hline & 32 & 1.82 & 1.21 & 110 & 1.59 & 2.05 \\
\hline \multirow[t]{3}{*}{ Leadership } & 5 & 1.45 & 1.32 & 110 & 1.20 & 1.70 \\
\hline & 10 & 1.97 & 1.30 & 110 & 1.72 & 2.22 \\
\hline & 20 & 0.89 & 1.52 & 107 & 0.60 & 1.18 \\
\hline \multirow[t]{3}{*}{ Efficiency } & 2 & 1.90 & 1.01 & 110 & 1.71 & 2.09 \\
\hline & 31 & 0.89 & 1.85 & 110 & 0.54 & 1.24 \\
\hline & 33 & 1.63 & 1.47 & 109 & 1.35 & 1.91 \\
\hline \multirow[t]{3}{*}{ Consonance } & 11 & 2.24 & 1.16 & 110 & 2.02 & 2.46 \\
\hline & 23 & 1.85 & 1.04 & 110 & 1.65 & 2.05 \\
\hline & 34 & 2.06 & 1.03 & 109 & 1.86 & 2.26 \\
\hline \multirow[t]{3}{*}{ Proponence } & 3 & 1.88 & 1.15 & 110 & 1.66 & 2.10 \\
\hline & 9 & 2.70 & 0.63 & 109 & 2.58 & 2.82 \\
\hline & 14 & 1.31 & 1.64 & 110 & 1.00 & 1.62 \\
\hline Individual & 8 & 1.92 & 1.17 & 110 & 1.70 & 2.14 \\
\hline Synergy in & 13 & 1.79 & 1.17 & 110 & 1.57 & 2.01 \\
\hline Decision & 21 & 1.62 & 1.20 & 110 & 1.39 & 1.85 \\
\hline Making & 26 & 1.09 & 1.49 & 110 & 0.81 & 1.37 \\
\hline Institutional & 7 & 1.56 & 1.40 & 108 & 1.29 & 1.83 \\
\hline Synergy in & 12 & 1.64 & 1.34 & 110 & 1.38 & 1.90 \\
\hline Decision & 28 & 1.57 & 1.28 & 107 & 1.32 & 1.82 \\
\hline Making & 30 & 1.24 & 1.49 & 110 & 0.96 & 1.52 \\
\hline
\end{tabular}

(table continues) 
Table 9 (continued)

\begin{tabular}{lrrrrrr}
\hline Theme & Item No. & Mean & $S D$ & $n$ & \multicolumn{2}{c}{$95 \%$ Confidence } \\
\cline { 6 - 7 } & & & & & Lower Bound & Upper Bound \\
\hline Support & 6 & 1.58 & 1.34 & 110 & 1.32 & 1.84 \\
& 15 & 1.55 & 1.41 & 110 & 1.28 & 1.82 \\
& 25 & 2.11 & 1.10 & 110 & 1.90 & 2.32 \\
Attitudinal & 4 & -2.05 & 1.53 & 110 & -2.34 & -1.76 \\
Outlook & 18 & -1.35 & 1.97 & 110 & -1.73 & -0.97 \\
& 19 & -0.86 & 1.85 & 110 & -1.21 & -0.50 \\
& 22 & -1.55 & 1.57 & 110 & -1.85 & -1.25 \\
& 24 & -1.78 & 1.57 & 109 & -2.08 & -1.48 \\
\hline
\end{tabular}

Note. Possible range for each item was between -3 and 3. In the attitudinal outlook theme, negative responses were preferred. For specific wording of each item refer to instrument (Appendix D).

Analyses of responses for items that refer to consonance indicated that respondents perceived Belen to be lowest when asked if "as a school we direct our energies and resources to achieving our goals" (item 23), with a mean score of 1.85 ( $S D=$ 1.04), and rated Belen best when asked if "our school remains true to the best of its traditions" (item 11), with a mean score of $2.24(S D=1.16)$.

Analyses of responses for items that refer to proponence indicated that respondents perceived Belen to be lowest when asked if "as a school we plan for change, instead of simply reacting to it" (item 14$)$, with a mean score of $1.31(S D=1.64)$. Respondents rated their perception of Belen best when asked if "we believe we make a difference in our students' lives" (item 9), with a mean score of $2.70(S D=0.63)$, the highest score of all 34 items in part two of the survey.

Analyses of responses for items that refer to individual energy in decision making indicated that respondents perceived Belen to be lowest when asked if "people at our school regularly evaluate their own work and performance" (item 26), with a mean score of $1.09(S D=1.49)$, and rated Belen best when asked if "people at our school feel 
authorized to make decisions in their work" (item 8), with a mean score of $1.92(S D=$ 1.17).

Analyses of responses for items that refer to institutional synergy in decision making indicated that respondents perceived Belen to be lowest when asked if "decisions are promptly translated into effective action at our school" (item 30), with a mean score of 1.24 ( $S D=1.49)$, and rated Belen best when asked if "options are carefully considered in making major decisions at our school" (item 12), with a mean score of $1.64(S D=$ 1.34).

Analyses of responses for items that refer to support indicated that respondents perceived Belen to be lowest when asked if "people are recognized for a job well done at our school" (item 15), with a mean score of $1.55(S D=1.41)$, and rated Belen best when asked if "people at our school have the authority and resources to do their jobs" (item $25)$, with a mean score of $2.11(S D=1.10)$.

Analyses of responses for items that refer to attitudinal outlook indicated that respondents perceived Belen to be lowest when asked if "people who try to change things at our school often get in trouble" (item 19), with a mean score of -0.86 $(S D=1.85)$, and rated Belen best when asked if "our school is in serious trouble" (item 4), with a mean score of $-2.05(S D=1.53)$. It is important to note that in this particular category negative responses were preferred.

\section{Assessment of Qualitative Data}

Data collected from the seven focused interviews were assessed using the a priori coding rubric generated from Bolman and Deal's (1997) four leadership frames and the Jesuit Secondary Education Association's (1994) high school leadership characteristics 
(see Appendix G). In addition, three recurrent themes were identified and coded: vision, alumni, and parochial schools.

\section{Coding Process}

Data collected from the interviews started with the verbatim transcription of the interviews by a professional transcriber. All transcripts were reviewed by the researcher while listening to the audio recordings in order to assure accuracy and allowed the researcher to become familiarized with the transcripts. Notes were also taken during this step in order to record immediate impressions that contributed to identifying particular themes (Ryan \& Bernard, 2003). In addition, in order to enhance the credibility of the transcriptions, interviewees were shown the transcript to verify its accuracy (Rubin \& Rubin, 2005).

The next step involved identifying recurring themes that emerged in the data that were not identified by the a priori codes referred to below. A review of the transcripts and notes provided the opportunity for the researcher to identify and list themes within the descriptions. The themes were then coded. This was done with each interview before comparing the items or themes with the other interviews.

The transcripts were then coded by searching for evidence of a priori codes. These a priori codes were identified from the Bolman and Deal (1990) Leadership Orientation Survey and the Jesuit Secondary Education Association (1994) Administrative Leadership Profile Survey (ALPS) and were organized into a coding rubric (see Appendix G). The a priori codes included the structural, human resource, political, and symbolic leadership frames and the Jesuit high school leadership characteristics: leadership, open to growth, professional competence, loving and caring, Ignatian vision, in action, communications, 
and decision making. When evidence was discovered of one of the codes, the data analysis code was recorded in the transcript.

Once all the coded sections were sorted, specific passages were found that best expressed the codes and themes. These passages were used to report the results of the study and draw conclusions. Conclusions that were drawn from the coded transcripts were shared with the interviewees in order to enhance the credibility of the study (Rubin \& Rubin, 2005).

\section{Key Informants}

In addition to Fr. García, six individuals were selected purposefully as key informants because they are in positions of responsibility within the school and provide particular insight into Fr. García's administration. Each informant represents a particular sector of the school community: Leopoldo Nuñez represented the administration, Patrick Collins represented the faculty, Carola Calderín represented the staff, Fernando Arán represented the alumni, Maria Juncadella represented the parents, and Fr. Francisco Perez-Lerena, S.J. represented the Jesuit community.

\section{Focused Interviews}

Individual, focused interviews were held using a semi-structured guide in order to ensure that the same basic lines of inquiry were pursued with each person interviewed and that the questions were focused (Rubin \& Rubin, 2005). Two different interview guides were used; one for Fr. García (see Appendix E) and one for the six key informants (see Appendix F). The key informants were interviewed for approximately 1 hour. 


\section{Structural Frame Evidence}

Evidence of the structural frame is present in the interviews but not all of it is necessarily positive. The specialization of labor, which is typical of the structural frame, is present in Fr. García's administration evidenced by the presence of several assistant principals, each one responsible for a particular area of school administration.

Interviewees expressed that the growth of the school in so many areas has generated a complex and, oftentimes, congested administration. Such a complicated organizational structure, while addressing the multifaceted school curriculum, has opened the door to confusion of roles, decision-making, and unaccountability. Leopoldo Nuñez, school administrator, stated: "it seems to me that there is an overabundance of chiefs and, when that happens, you overlap and when you overlap, people get bothered and I think when that happens, then it's very hard to achieve consensus."

Carola Calderín, business manager of the school, addressed this point and added that because of the complexity of the administration, their position and responsibilities, there has seeped in a level of unaccountability that has made several administrators untouchable. She stated:

You cannot touch certain people that are not doing their work. We have people that have conflict of interests and they have not been told that they could not be doing what they are doing and to me that is a problem because what happens is that people get demoralized.

Interviewees associated unaccountability with administrators' resistance to having their work evaluated and, if necessary, criticized. The administrators' high levels of responsibility delegated by Fr. García in their particular areas have rendered them untouchable status. It is in this area that Mr. Nuñez stated could be found Fr. García's greatest weakness. He explained: 
If there is a weakness, if there is something that Fr. Marcelino [García] needs to be challenged with, it is the process of what we would call or in administration is called accountability. Uh, it becomes very difficult for Fr. Marcelino [García] to hold people accountable. Ah... and to do it in those terms, to have the people that work with him be keenly aware that they are accountable and in as much as we get many rewards for our successes, we ought to be, or should be, or should be better or more accountable for the things that we don't do so well and if we are adults and we are professionals and we are mature, we ought to be able to expect that sort of thing as well. Rewards and accountability and also calling people's attention for things that are not working out. That is his job.

Even though he does not have the same access to the inside workings of Belen as does Mr. Nuñez or Ms. Calderín, Fernando Arán, president of the alumni association, also shares this opinion. Mr. Arán expressed that certain members of Fr. García’s administration resist any kind of intervention. Administrators have grown accustomed to having a lot of independence in the administration of their particular area and are apprehensive to accepting outside suggestions and opinion. He stated: "I think the problem is it's extremely difficult to do anything that interferes with the authority of people who have claimed, named, and titled their little area."

Although evidence demonstrates that there are complaints about accountability and that administrators have become resistant to evaluation and criticism, Fr. García emphasized that he found constant evaluation important. He stated:

I could say that the main verb that we should use as a president is to evaluate. Constantly evaluating the running of the school in order to make corrections and to develop the school, but evaluation is a very good step. It is the last step of the Ignatian Paradigm and it is used outside also. It is not only proper for the Society of Jesus or for the Ignatian Paradigm. Other methods of education, other methods of directing and management, they use evaluation, but for us it is very important. It is indispensable, the use of the evaluation.

Maria Juncadella, head of the parents' steering committee, corroborated Fr. García's claim when she mentioned that what always impressed her was Fr. García's ability to examine and reexamine his work. In the years that she has been involved with 
the school she has identified this practice of being part of the secret to Fr. García's success. She claimed: "That is why I say that, you know, in 10 years, that constant process of re-examination will eliminate the things in Belen that will not work and will leave just the solid things because I think he does that, he re-evaluates."

\section{Human Resource Evidence}

Most of the evidence coded in the interviews pointed to Fr. García's ability to be supportive and accessible to his various stakeholders. All those that were interviewed made reference to Fr. García as being an administrator that encompassed the Jesuit characteristics of being loving and caring, open to growth, and a communicator, characteristics that fall perfectly within the human resource frame. In addition, his ability to empower individuals was also duly noted.

Accessibility. One of the points that permeated most of the interviews was Fr.

García's accessibility. The various interviewees mentioned that it was easy for them to contact Fr. García when they needed him because he always made himself available to them. Ms. Juncadella stated that:

He is always accessible. He has always been an accessible president. I have never come into the office where he doesn't recognize me and asks me to come in and without an appointment. His door is always open. Uh, you know, that has been my perception. I have sent parents to him with serious problems that I have, you know, don't have the, uh, the authority to even get involved in and I said: "Go straight to him" and he is always open.

The faculty shares Ms. Juncadella's sentiment as well. Patrick Collins, longstanding member of the faculty, added that Fr. García's accessibility has given him, and the faculty, the opportunity to express his opinion and thoughts about the school, its curriculum, and administration. Mr. Collins claimed that: 
I can think of time and time again where Fr. García has listened attentively and actually deferred to suggestions of the faculty and I think the faculty maybe, if not spoken to in group, but certainly individually, would have to admit that this is a person, Fr. García, who holds teachers in the highest regard and so I would say that one of the reasons why it's been so gratifying for me to work here is because I've always felt that if I needed to convey something to him, if I didn't get my way, it would at least be considered by him in a serious way.

Mr. Nuñez added that access to Fr. García is not simply a personal trait of the president, but a requirement for his administrators:

The policy of Fr. García and of the assistant principals has always been open door and so any member of the faculty at anytime, unless there is a very private meeting going on, has absolute access, not only to assistant principals, but also to the president of the school and that is an absolute.

Fr. García's open-door policy is evidence of his human resource perspective on administration. Similarly, such a practice points to the loving and caring characteristic of Jesuit education. His supportive and attentive nature has helped to nurture an environment that has given the school community a sense of comfort and trust. Fr. García explained:

I never close my door, even when I am discussing something very serious, I like to have my door open, but another way to maintain communication with the faculty is to praise anything that they do personally in the institution or condemn anything wrong that they do, even if we do it in a sweet way or a very respective way, but, and in a constructive way, but to maintain these two aspects for praising and condemning, that is good.

Also at the same time, to be just, to be just with them, trying to defend their rights in front of the parents, in front of the other people, people from other sides, giving confidence. They know that I have faith in them even if they can make mistakes as any one of us can and have, empowering them to do what they, they have to do to let others work and be creative and sometimes we should set the goals, they have to be created by all of us, the goals of the faculty and administration.

Empowerment. Another characteristic of Fr. Garcia's leadership style that emerged in the interviews is his ability to listen and empower his charges and the various school stakeholders. Those interviewed mentioned that Fr. García always expresses a 
genuine interest in their concerns. In addition, he understands the individual's potential to overcome obstacles, to be innovative, and to take part in the fulfillment of the school's mission. Fr. García encourages those around him to use their talent and creativity for the good of the school community.

The freedom that Fr. García refers to is highly appreciated by his faculty, administration, and staff. They seem to feel that they have always had the opportunity to explore new things both in and out of the classroom. Mr. Collins claimed:

Father is such a great believer in learning outside the classroom that I've been amazed how not only agreeable he is, but how he initiates programs that have students learn outside the classroom. In the Social Studies area where I am at, when he was approached about "What are your feelings about a weeklong seminar with the Close-Up foundation in Washington?" "What do you think about taking students on the overseas study program to Europe or to China and this summer to Japan?"

Whether or not there should be a model United Nations team that takes students to college campuses that provide high school model United Nations tournaments; whether the modern language department wants to go to South America or to Europe or the missions that go to the Dominican Republic. The point is, so many principals or presidents would say, "Hey listen, the lawyers are advising against this. There is just too much liability here." Or "there is too much worry about just the financing of these programs." Marcelino [Fr. García] has always been an advocate of these programs and I think that is one of the distinctive marks of the school that we offer such opportunities for students to learn beyond what we have here.

Fr. García's knack for empowering others applies also to the stakeholders outside the classroom. Mr. Arán referred to this very detail when remarking on the restructuring of the alumni association that took place in 2005. Mr. Arán stated that while the idea of revamping the association came from Fr. García, he rarely interfered with the process allowing the alumni to take charge and use their creativity. The alumni president commented: "No doubt that he had a lot of good ideas that we followed, but he truly 
allowed us to really structure it and to really focus on what we wanted it to be like... he never interfered with any of it."

The positive result of Fr. García's ability to empower is reflected in the response that he receives from others for the various projects that the school decides to adopt. Ms. Juncadella pointed out:

People are willing to jump on the boat with him, even if it means extra hours, extra students, uh, you know, taking a class in the middle of a semester that wasn't there. I mean, people are willing to go with him, you know, the extra mile. Anywhere from a parents' club point of view, I have, you know, seen those that are selling hot dogs at the school carnival, you know, knee deep in dirt and selling food they would never eat themselves because they're probably vegan or something, but... but he just has a way of getting people on board and I think that's a great success on his part.

This participative form of leadership resonates with the human resource frame and similarly encompasses characteristics of Jesuit education such as loving and caring, leadership, and communication. Fr. García emphasized:

As a president I have to have confidence in the assistants, in the systems, have confidence in them. Most of them have been very creative. For instance, the person in charge of admissions has created a very nice project of how to admit people at Belen, how to increase the numbers of our students coming. The person in charge of technology, the person in charge of... different areas of Belen, another area is activities. We have so many clubs, so many activities that we promote at Belen that I think is another great asset for the school. But, eh, that has been possible because of the... allowing the assistants to be creative and to have freedom even if they know that freedom is going to be supervised, but they feel free to create great projects.

\section{Political Frame Evidence}

Second only to evidence that referred to the human resource frame, the evidence of characteristics typical of the political frame emerged. The ability to network and deal with conflict stood out as consistent themes. In addition, Jesuit characteristics such as 
professional competence, communications, and decision making, characteristics that resound with the political frame may clearly be identified in Fr. García's administration.

Networking. One of the key elements to Fr. García's administration has been his ability to work with so many different members of the school and local community. His contact with the world outside of Belen has given him access to several possibilities that have benefited the school both academically and financially. Mr. Collins stated:

I think Fr. García's contact in the community has been able to make things happen. If there was a leader who was less willing to engage in the community, whether it be the Hispanic community or the Anglo community, the Jesuit community of other Jesuit high schools in the province, if he had been resistant to becoming part of those groups, I think there would have been much less success than we have to this point. So his willingness to become engaged in the community, I think, is part of the explanation for the success of Belen.

Ms. Juncadella agreed that Fr. García does not limit his sphere of influence to Belen, but that his venturing spirit and driven personality has given him access to many sectors of society that benefit his administration. She stated:

He is a person very much driven by, I think, creativity. I think, uh, you know, I think he is a very sophisticated person, uh, intellectually and has a drive, a lot of energy, uh, and I think he, uh, he continuously... he is very knowledgeable about what is going on in the community worldwide and that is how he begins his meetings with us.

He begins from the universal and the Americas and then down to what is going on here with, uh, the Jesuits of the region and then Belen. So he gives us first a global perspective: "These are the trends. This is what's happening out there in the Jesuit schools and this is what we can adapt from that larger model", and so, he's excited. He gets excited about those global movements.

Like when they were picking the new general for the Jesuits, he had us abreast of all the changes and we almost knew who was going to be selected, but it turned out that it was done differently, but he explained it all and he is very excited about change. And I think he, he... he gets people excited even though there is a tendency to not change things because if it is working, you know, why change? And Belen seems to be working, but he always has other goals that he is setting. 
Fr. García's contact with the community and especially with powerful and

influential individuals has made the growth of Belen a reality. Ms. Calderín expressed:

I think he is wonderful for that. He knows how to do that perfectly... When he started here, the school was almost bankrupt and he was able to get ahead and bring it up to the position that we are now and he used some of the alumni to visit the people that were able to donate.

In Jesuit education, the characteristic labeled professional competence is defined

as the ability to secure the wellbeing of the school and in particular the financial

wellbeing. Along with the ability to communicate, the president of a Jesuit high school is called to maintain institutional integrity while being the public face of the school. Fr.

Garcia's networking skills have contributed to the fulfillment of this responsibility. Mr.

Nuñez explained:

Fr. García is a workhorse in that he has, I've always had a sense that he is somewhat hyper, so he has an enormous amount of energy, I think. So he will have meetings and he will go out to lunch with some major donor and he will have a meeting of the alumni that evening and so I see him with an enormous ability to move and to be there.

I sometimes also sense that he is extremely tired and he ought to be because the school has grown phenomenally and there are many, many elements of the school that were not here just a few years ago. The office of development operates in a house adjacent to the school. It has its own personnel. It has its own leader, but what is the... how does that relationship work? How do they report? How are they supervised? I haven't the vaguest idea. The alumni association is very strong, very, very, very strong, but they have their own independence and they have their own particular leadership. How that interaction occurs with the office of the president? I do not know, I do not know. Is that a fault? Well, maybe, but on the other hand, you know, development is development, and alumni is alumni and I am in academics and I am inside a building of the school. What do I know of how things are being done?

There is one element that is fundamental and I know he handles it as well, which is the relationship with the Archdiocese of Miami and that is vital. So he attends meetings with other presidents and principals of schools in the Archdiocese and that too is very important for the school and both for the future of the school. 
Adroit. Such a large and complex organization as Belen necessarily sees its fair share of conflict. Too often encouragement to be creative and adventurous can lead to disagreements, differences, and discord. In addition, the promoted involvement of so many varying sectors of the school community vying for limited school resources leaves open the door for conflict (Ammeter et al., 2002; Kanter, 2005). Essential to successful leadership becomes the ability to expertly negotiate during these difficult situations.

Those who were interviewed saw this ability to navigate through conflictive situations as one of the reasons why Fr. García has lasted so long as president. Mr. Collins remarked:

When Dwight Eisenhower was elected President, his predecessor Harry Truman worried mightily that a person who was experienced in the military would assume that when he became President that he could resolve conflict, fix things, get things started in the military way, Ike would say: "Do this" and "do that" and Truman worried that nothing would get done because Truman knew that the way you get things done in the Presidency, whether it's of the U.S. or here, was by the art of persuasion and Fr. García has mastered the art of persuasion because he doesn't take that clenched fist attitude, "It's either my way or no way," and he has developed to an art form the ability to take warring sides of an issue and finding a way to resolve them.

Fr. García seems to use conflict, especially the conflict that arises between his administrators, to his advantage. Reaping the benefits of the energy created by the friction often times experienced in administration meetings, he uses the new and clever ideas in order to advance the school's goals. He stated:

I think without noticing, we have created the, eh... a way to manage the institution. The first thing was when we created the, the administration, meaning the assistant principals. We have seven assistant principals, or seven persons working in administration that, eh, have become the best persons in the institute. Any one of them could be a president, could be a principal of the institution. I think the creation of a good group of assistants in the present is very important. Even if they don't have and maintain a good relation between them and this is our case, they are very creative and they try to respect the children in the job that they have and they are very creative, I could say that. 
After over 25 years as an administrator of the school, Mr. Nuñez verified that at

the administrative level conflict and friction are commonplace, but that it has always been exceptionally clear that any decision ultimately is reserved for Fr. García. Mr. Nuñez explained:

When you have an administration with four, five, six assistant principals in a relatively small school because 1400 students is not really a large school, you got to keep in touch with those people and you have to have those people meet and share and compare. They used to meet a little bit more regularly than they do now, but certainly there's a lot of dialogue. There's a lot of opinion and Fr. García seldom participates in terms of the discussion.

He reserves to himself the right of the responsibility, which he has, which is to be the decision-maker ultimately. The responsibility is his and he makes the decision himself. So I think that it's a collegiality. There is commonality in the administration of discussion, of dialogue, of agreement, disagreement very open in the meetings of the administration and then on the basis of some of those discussions or many of these discussions, Father eventually makes a decision that stands and I think that has been a pattern in the past 25 years since he has been president.

Fr. García's adroit style when working with his administration is common

knowledge and not a phenomenon that remains secretively kept behind closed conference

doors. Mr. Collins expressed that the faculty is aware of this particular characteristic of

Fr. García's leadership. He stated:

I think Father takes the position, to make another reference to an American president, the way that FDR would handle his administrations. When conflicting reports came in, FDR would, figuratively, lock two people in a closet and say you don't come out until you've resolved your differences. Well I'm not sure that Marcelino [Fr. García] goes to that point, but I think he rather benefits from sparks within the administration until some of those sparks might be initiated by some idea from an assistant who lets up a trial balloon and see what kind of reaction it gets and if it doesn't go well, well, Marcelino [Fr. García] knows that was probably an unwise path to take and he plays this chess game of others wanting to either dominate him or have it... or at least be his principal advisor and I think he plays off all of them to the point where he then is sure that whatever decision is finally made, that he ultimately has to make, will be after all sides have been duly considered. 


\section{Symbolic Frame Evidence}

Evidence of leadership typical of the symbolic frame is prevalent in the comments made by the various interviewees. Continuous references made to the presence and importance of tradition, values, and religious identity demonstrate that Fr. García's leadership has helped create an environment that has contributed to his and the school's success. Furthermore, Jesuit education's characteristics of being loving and caring, Ignatian vision, and leadership, characteristics that resound with the symbolic frame, are clearly present.

Value-oriented. Belen's Catholic identity necessitates that its education be valuebased and, more specifically, rooted in Christian values. Such clarity has been beneficial for the school because of the particular vision that it helps generate. Fr. García explained:

I don't see that public education or some private education has the characteristic that we have. Jesuit leadership has a vision. We know where we go and we know why we fight for education. We have clear methods in Jesuit pedagogy. We don't have to go outside to get methods even if we should be objective in order to receive from outside the best of what they produce, but Jesuit leadership has a vision and clear methods to follow that vision. That's very important.

The religious dimension that the private education doesn't have or public education doesn't have religious dimension. They are losing a very important factor in the personality of the person because religious dimension is one of the aspects of our personality and we are... we are feeling that dimension of the person. The religious dimension and the Christian values, other projects in the public realm or in the private realm, they don't follow Christian values. Christian values have succeeded in the 2000 years of Christianity and we are following that tradition. And those specifications, to be a Christian institution allow us to become a tremendous institution because we are following a vision.

We have clear methods and at the same time, we are a religious institution. We are feeling that dimension of the person, but at the same time we are following values that are Christian and proper specifications of the Christian project.

Fr. García understands that the Catholic vision that fuels the educational process

at Belen, a vision rooted in clear Christian values, values that are part of his conviction as 
a priest, is one of the main reasons why parents are attracted to the school. He emphatically stated that it is these values that he has to secure, "values that have been showing success in life, success in the Christian model of creating a Christian man and that's something that the people outside, the parents and the society evaluate and like." Mr. Arán, who along with being the president of the alumni association is also a Belen parent, agreed:

I think that's what separates you from a Gulliver or a Palmer Trinity or, you know, or any of these other fine schools... And I think that's kind of what ends up creating the brotherhood. I mean, as a Belen graduate, you know, I went to an event last night, a scouting event last night and it's similar to what Eagle Scouts, you know, feel. When you go through Belen you have to sacrifice, you have to study hard, you have to work hard, okay, and then you earn this Belen diploma. In the process you experience brotherhood in many different ways. You explain it. You did it in class. You did it by participating in the mass.

The Christian values help create a particular environment in the school, an environment that is conducive to success because of its clarity, sense of security, and spirit of fraternity. Mr. Nuñez referred to this environment as "a beautiful place," but admitted that it does present a problem. He explained:

I think the great challenge for any Catholic institution, and Belen in particular, and this is a fear; a fear that I have often talked about. Belen is a beautiful place. But there is a world out there for these same kids that is diametrically opposite of what Belen is, ah... consumerism, cease the day, etc., etc., etc., and I sometimes question whether we inside Belen, which live very privileged lives in the sense of having this wonderful community of lay people and priests, which care for each other, which love each other, which enjoy each other's company and which basically are colleagues and friends, how real is this as compared to the nittygritty world in which these kids are living not only in terms of all these consumers, marketing and whatever, but in terms of sensuality, eroticism, of broken parents, separations and how well do we handle that inside of this wonderful world of ours?

Jesuit tradition. As Mr. Arán mentioned, the allure of Belen is not simply an educational environment rooted in solid Christina values, but an environment seeped 
specifically in the Jesuit tradition. The Society of Jesus's experience of over 500 years in education and Belen's subsequent involvement in education for over 150 years clarifies that the Jesuit tradition plays a major role in the school's administration.

Fr. García cannot fathom Belen without the presence of this tradition and is very clear that the tradition is there because of the presence of Jesuits in the school. He explained:

I don't believe that we can have something; maybe other Jesuits don't agree with me, we cannot have a Jesuit school without Jesuits. I know that the Jesuits in America have created a document of how you can raise and create a school without Jesuits and that school having Ignatian spirituality. I don't see that. I think the Jesuits are the soul of the school and the relation of and the number of Jesuits and the quality of Jesuits and the number of young people being Jesuits that work in the school is a most important factor to transmit the spirit... to transmit the Spiritual Exercises, to transmit the spirit that is behind the Spiritual Exercises that is Ignatian pedagogy. I don't see that we can run schools without Jesuits.

Mr. Collins agreed that the essence of Fr. García's administration has been the

Jesuit character of his leadership style and recognizes that leadership in the Jesuit tradition is not only unique, but also highly effective. Mr. Collins stated:

What I admire most about Jesuit leadership is that Jesuits don't talk about leadership. They prefer to live it. It's always been since Ignatius's time the idea that you set yourself up and make a leader of yourself first. Not by talking about it, but by living it through your actions, through who you are. So what I most admire about Jesuit leadership is that they don't subscribe to the great man theory of history or the top down theory of leadership where there will be one person who is so enriched and so enlightened that he will tell the rest of us peons what to do and how to live.

The Jesuits believe that every single person has the potential of being a leader. Now that may sound rather Utopian or "Disneyesque," but in fact if you define leadership as describing and being a good person rather than, "What have I accomplished" then the Jesuits are trying to have in the end students who are good people. Students who are going to make it to heaven and the way you do that is to lead the life and that life is of a good person who's considered in, say, western civilization as being a great leader. 
The Ignatian vision that is characteristic of Jesuit education has been

communicated effectively to the Belen community. When asked to comment about the Jesuit character of the school, Mr. Nuñez described that after so many years of working at Belen he feels the spirit of St. Ignatius, founder of the Society of Jesus, present. He explained:

A Jesuit leader to me is a man who, first and above everything else, of course, is Christ centered, but is a man of knowledge, is a man of conviction, is a man of daring. Ah, Saint Ignatius has a wonderful comment in his autobiography where he said that he would not mind at all being tarred and feathered for the greater glory of God and although I would not suggest that the modern leader should think along the same lines, but I do think that there has to be a mixture of these attitudes and an enormous amount of integrity.

We live in a world of failure. We live in a world of double-dealing. We live in a world in which constantly we are exposed to leaders that fail and fail in the most human, but the most frail and situations that indicate a tremendous lack of strength of gumption, of internal fortitude, if you will, so a Jesuit leader to me is Christ centered, is a man of integrity, a man that has to have a sense of justice, but also has to have an enormous amount of courage and daring to pursue, to be, in fact a mini Saint Ignatius.

\section{Recurring Themes}

Three recurring themes seemed to predominate all seven interviews and incorporate several elements identified in the coding rubric created for the analysis of data. These themes point to Fr. García as a visionary, his work with the alumni association, and the conflict with the parochial schools of the Archdiocese of Miami.

Visionary. To have a sense of direction and to be able to communicate it is one of the most basic components of leadership (Daft, 2008; Salacuse, 2006; Sergiovanni, 2001; Short \& Greer, 2002; White, 2007). Such is the case that in Jesuit education the characteristic of leadership necessitates vision and the ability to motivate others to adhere to it. Similarly, Bolman and Deal's (1997) symbolic frame encompasses the quality of 
looking ahead, determining goals, communicating them, and inspiring commitment.

These are the qualities of a visionary.

Part of Fr. García's understanding of his role as president is the need to not simply determine clear goals, but to communicate them and enthuse others so that they will commit to them. This is no small task when considering the various individuals involved in the school community. But from the beginning of his tenure, Fr. García saw this one aspect of his mission as being essential. He explained:

Our goal is to be special. We wanted to be the best and always we had in mind these 25 years how we could become the best school in the county and the country and be among the 47 Jesuit high schools in the country, I think that was another purpose that we had.

Patrick Collins identified Fr. García as a visionary and expressed this by referring to several aspects of Fr. García's administration. One of the points that he addresses is how a school in exile adopted an understanding of its role and its future in Miami. Mr. Collins not only credits this understanding to the members of the Society of Jesus who opted to re-found the school in Miami, but specifically to Fr. García:

Fr. Marcelino [García] came into Belen at a time when the future of Belen was uncertain to the extent that it hadn't quite been decided whether or not Belen in Miami was a school in waiting or whether or not there was going to be a permanent Belen in Miami and to his credit, to their credit, they decided that no matter what the political circumstances were in Cuba, Belen was going to have a place and a history in Miami. They had been a two-campus school, but when Fr. Garcia decided that this was going to be our home, from then all the additions, the growth, the new programs in the school were made possible because he was the person that said: "We are going to remain here and move forward. We are not going to be on hold."

As indicated by Mr. Collins's remarks, Belen's unique history has helped to create the opportunity for vision to be a necessary standard for success. Mr. Nuñez reiterated this sentiment: 
Belen has a very unique situation, but probably in the world of the Society of Jesus. Here is a school that is founded in the United States, but originally comes from Cuba, who has this, almost daring attitude of saying "We are expelled from Cuba. We arrived in the United States in 1961. We opened in September of 1961," again, and there is this continued education of Belen school, nonstop, noninterrupted after being kicked out of your country and starting again from scratch in, you know, that is an extraordinary story.

The vision of a permanent home in Miami for Belen was solidified by both the physical and pedagogical development of the school. This permanence was evidenced through the acquisition in 1981 of 30 acres of land in southwest Miami and the subsequent construction of a school building. In 1983, when Fr. García began his tenure at Belen, he envisioned the growth of Belen and understood that it was crucial for success. Of the schools physical growth Fr. García stated:

Because now when you see the school and in one or two years more when the whole project has been finished, it's going to look like what we had in Cuba, the Palace of Education. It is going to look like a tremendous school with so many facilities, with so many, eh, positive things about the education and really the kids love to stay in the school because they see the school as the second home, no? And that was made with perseverance having in mind the vision and mission. We knew that we had to make our school complex and in order to bring so many facilities and so many great things to the school.

Mr. Arán agreed that success is tied to the physical development of the school. He expressed that Fr. García's vision is what has contributed to the Belen's growth:

I think that, you know, Belen finally got put on the map because it wasn't on the map in 1970 or in '74 or in '75, but, you know, when you look at the aerial photo of Belen, which I have here, and I've had it laying here for a couple days. Anybody that comes and sees this goes, "This is a college campus. This is a small college campus." You know? And one of my associates, Edgar, says, "You know, my son goes to Palmer Trinity. We have three times the land and one-third the facilities." You know what I mean? Ah, so, I mean this a testament to how he can plan things and how he can develop things and how he, he, his vision of how something should be and then the implementation of a plan to realize that vision is his strongest point and he could do that very well, very, very well. 
The physical development of the school is not the only standard that individuals use to recognize Fr. García as a visionary. The development of the pedagogical component of the school and its nuances seem to also reflect this visionary component. The increase of honors and advanced placement classes, the school's 100\% college acceptance rate, and increasing GPA, ACT, and SAT scores indicate the school's academic success (José Emilio Roca, personal communication, March 17, 2008). In addition, the school's advancement in technology is evidence of Fr. Garcia's character of seeing ahead. Mr. Collins claimed:

It would be remiss not to mention the advances in technology as a success story at Belen. I think if you ask outsiders: "Do you think a school that came from..." and I say this tongue-in-cheek, "...from a little island nation in the Caribbean is going to be one of the great technological, innovative leaders in Miami?" They'd say, "Not likely." Marcelino [Fr. García] has embraced, whether it's the equipment for the smart boards, whether it's the training for the teachers, whether it's attending conferences, he's been the driving force behind that.

Fr. García credits the clarity of vision to the Ignatian perspective that permeates

Jesuit education. He expressed Belen's conviction to remain faithful to that vision:

The clear vision is the vision that Saint Ignatius had for the world and it had been instilled in us through the Spiritual Exercises, through the Ignatian spirituality. That's a vision of what is a world, what is the end of man, and what should be a religious person, all those things that are inside the Ignatian spirituality and the Ignatian vision of society. We bought that vision. Since the beginning, we don't have to go outside to get that vision. We have the vision and we have the methods to conquer and to obtain that vision.

Alumni association. One of the apparent successes of Fr. García's administration has been his work with the school's alumni association. Fr. García spearheaded the revamping of this organization in 2005 with the intention of being able to better involve this sector of the school community and give it a more official structure with the establishment of an elected governing body. Fr. García explained what inspired him: 
Through a process of discovering leaders among the alumni board, we created in the year 2004 and 2005 the group that could create bylaws for the association following the recommendation of the Father General of the Society of Jesus, how to have an alumni association and they have been cooperating with ideas, with financial help and also working on different projects of the school. That friendship and that love that is created among the students in the school is followed through the association and in activities outside in order to promote social justice, to work in charities and so forth and they have been very instrumental.

Fr. García went on to explain that one of the purposes of Jesuit education is to develop students who are influential in society and are able to affect the world around them. But he recognized that this ability to influence "should be cultivated inside the classrooms, but also after they graduate, it should be cultivated among the members of the alumni association."

Ms. Calderín insisted that the alumni association and Fr. García's relationship with them is one of the highlights of his administration. Ms. Calderín stated:

The development of the alumni is a success that he [Fr. García] had because, as you know, the association did not have a very strong presence in the school and he wanted that to be accomplished and we have accomplished it and he brought the right person to do that.

The "right person" that Ms. Calderín referred to was Fernando Arán. Mr. Arán is a Belen graduate from the class of 1975 and was recruited by Fr. García in order to revamp the association. An alumni congress was held in 2005 with the intention of creating the foundation for a newer, more effective association. Mr. Arán recalled:

We had to create the environment for there to be an Alumni Association and that's how I started to work more closely with Fr. Marcelino [García]. I want to say four years before that, ah, Fr. Marcelino [García] asked me to help him to do a $150^{\text {th }}$ celebration and do a congress of all of the alumni. Call them to the school and then, ah, we spent, gosh, the better part of a year and a half planning that congress and the idea of the congress and this is where Fr. García was very bright because he really, he sees how to develop something and then he plans it longrange and understands that even though it's going to take a long time, you need to be planning all the stages through it. 
So we, in essence, the alumni association as we know it today started, you know, six years ago. You know, two years putting together the alumni congress. From the alumni congress came a vote of confidence from the members that attended that congress that, yes, we should have an Alumni Association with an elected board, with delegates and things of that nature.

How the new alumni administration was organized and its first few steps are indicative of Fr. García's style of leadership. When asked about how involved Fr. García was in the whole process of establishing the association and its governing board, Mr.

Arán stated:

His involvement was constant; $100 \%$ on it, but at times you didn't realize he was there. Ah, it was done, ah, we were, we meaning the board, after having two years of time to reflect, ah, we've been, ah, amazed about how much he truly allowed us to do in the formation of the board, in the implementation of the board, ah, as a, as a body, a governing body. Ah, but yet you know he attended the meetings, ah, he would talk to me. Ah, you know whatever he thought that something was worth discussing.

Ms. Juncadella credited Fr. García's success with the alumni and the association

to his personality and unique perspective:

I think he, uh, encompasses a type of man or a type of Jesuit in particular that can relate to the old order of things and at the same time is open to new ideas and I think he is a bridge between the Belen in Cuba and the Belen in Miami. And I don't know if it is also the fact of his age that he can both, relate very well to, to the alumni and, and his mind set and, uh... and that, you know, type of Jesuit thought and at the same time he is very open to what is going on today in Miami, in the society that we live in. So I think there are very few individuals, you know, younger Jesuits are probably not going to be able to relate that well with the older generation. And an older Jesuit might not really have a clue of how far things have come in society. So I think he is just, you know, that perfect bridge between the Cuba and the Belen that people loved in Cuba and that survived the Cuban revolution and the excitement of what is going on today.

Parochial school conflict. While all interviewees made reference to several positive elements about Fr. García’s administration, a particular conflict between Belen and several pastors of the Archdiocese of Miami was continuously referred to when 
asked about challenges that Fr. García and his administration have had to address. This conflict refers to an agreement signed by several pastors of parochial schools and Fr. García. The pastors wanted to curtail the exodus of their middle school students to Belen in the sixth grade. A quota system was devised that limited the number of students that could leave the parochial school to go to Belen.

Fr. García was placed in a very delicate situation. On the one hand he had to maintain good relations with the pastors and the Archdiocese of Miami and on the other he had to ensure the rights and respect the desires of parents, most of them alumni. What the conflict provided was an opportunity for Fr. García to exercise his ability to maneuver through a power struggle. Mr. Nuñez summarized the difficult situation:

There is no way of handling that [parochial school conflict] effectively and there is no way of pleasing all the parts. So Marcelino [Fr. García] has a major problem on his hands and it is a problem that I do not think will ever have a real solution. There will be diplomatic solutions and there will be solutions that are perhaps politically correct, but there is a reality and the reality, I think, is very simple and it is a reality that we have to understand that the pastors cannot cope with well.

So that when the messes started, oh God, a good 20 years ago, and we were taking students away from their elementary schools, why on earth was this happening? It was happening because the parents were thinking in terms of what is best for my kid and Belen offers a product that to them, maybe it was not perceived correctly, but to them it was a better product and they were losing kids.

And it is a source of annoyance and rightfully so. I would be annoyed too because the kids that were coming to Belen were the best and the brightest in many, many cases and no principal wants to lose kids that are best and bright. What is the solution? There is no solution. We have quotas and that does not make us happy. It makes them happy. They have the power. Of course they have the power. It would be silly to say that we hold any kind of power. We are here by the grace of the Lord and of the Bishop, who ultimately is the Lord of Miami and that is the way the cannonball functions. So we are always going to be somewhat under a, perhaps, occasional fear, occasional threats and occasional moments of very pleasant and very positive relations and they will go up and down and left and right as the years go by. 
The greatest challenge for Fr. García in the midst of this conflict was appeasing the school's powerful alumni association that was pulling vigorously in a direction opposite of that of the pastors of the Archdiocese. The concern of the alumni was that their right to have their children educated where they desired was not being respected. While Fr. García agreed with this and felt obligated to support them, he had to also respect the concerns of the pastors and maintain good relations with the Archdiocese. $\mathrm{Mr}$. Arán recalled:

We as an alumni association were, ah, interviewing public relation firms. We had people committed to donating funds to hire that public relation firm and to, in essence, in a very professional way with the assistance of professionals, ah, put out the word that this policy was the wrong policy and, ah, try to set the record straight as to what happened leading up to it and Fr. Marcelino [García] made a plea to us, ah, not to continue doing that, to just let it be and that this would resolve itself over time and by then the board had already been in place, the board was already a duly elected board, by now it's past February and we felt that, you know, since we were doing this for the betterment in part of the school, not just the overall Catholic community, that we would sit back and wait a while and see if in fact this would be resolved.

At first, Fr. García had allowed the alumni association to vent their displeasure and anger. He made it a point to inform them of what had happened and the possible reasons for why such actions were being taken. He met with alumni frequently and answered their questions. Fr. García knew of meetings that the alumni had to address the issue and even permitted the space at Belen for these meetings to take place. But eventually, after months of haggling back and forth, Fr. Garcia began to take a more proactive approach to softening the environment and asked the alumni association to put the matter to rest and refocus their efforts. Mr. Arán seemed to agree with Fr. García’s approach:

At the end of the day we figured, "you know what? Fr. Marcelino [García] is a very smart guy; he has his reasons I'm sure for telling us to lay back. Let's lay 
back." You know? And to a certain extent we had almost been exclusively focusing our efforts on this issue when we yet had to pay any attention to the overall mission of the Alumni Association.

In the end there has been established a level of respect that has allowed Fr. García and Belen to ultimately remain in a favorable light with the Archdiocese of Miami. While the subject still remains conflictive, Fr. García's political savvy has helped to somewhat quell the animosity. Ms. Juncadella explained:

Well, I think there is respect. There is mutual respect, but uh, it is a difficult, uh, relationship I imagine. He's [Fr. García] just very bright and so, uh, he knows how to navigate it, but I, uh, you know, it has to be extremely difficult for both, Favalora, who is our Archbishop, uh, to report to his pastors and for Fr. Marcelino [García] to navigate that carefully. So I think he has changed tones and positions as the situation changed. I think that he has been a chameleon in that sense. Sometimes he stays back and he is quiet about it, other times, you know, he doe not. He has been obedient, but at the same time there is nothing that they can do because people want to come [to Belen] and people have the right to choose, like I did.

\section{Summary}

Results of the Leadership Orientations Survey and the Administrative Leadership

Profile Survey (ALPS) were presented in chapter 4. Results from Bolman and Deal's (1990) instrument indicated multi-frame use by Fr. García while identifying the political frame as his most characteristic frame. Results from the Jesuit Secondary Education Association's instrument indicated Fr. García's goal performance in reference to the characteristics of Jesuit education, identifying his most notable characteristics as those associated with being loving and caring. In addition, goal importance was also reported along with the organizational health of the school.

Chapter 4 also presented the evidence identified from the seven focused interviews. Analysis of the interviews identified evidence that was coded using the coding rubrics and also indicated three recurring themes that were duly coded. While 
evidence of the human resource, political, and symbolic frames were identified; evidence of the structural frame was mostly negative.

A concurrent triangulation method is used in chapter 5 that directly compares the results of the quantitative and qualitative data (Creswell, 2003). Quantitative and qualitative data are used to support each other. The comparison of the findings is then examined in terms of each research question. Chapter 5 concludes with the implications of the research and implications for future research. 


\section{CHAPTER V}

\section{ANALYSIS, INTERPRETATION, AND IMPLICATIONS}

This chapter presents findings from the concurrent triangulation approach that was used to compare the results of the quantitative and qualitative methods of research (Creswell, 2003). The findings were examined and presented in terms of the research questions that guided the study. The chapter concludes with implications of the research and questions for further research.

\section{Concurrent Triangulation}

Data reported in chapter 4 were integrated by comparing the findings provided by the quantitative and qualitative research methods. This process was done by looking at the data as a whole and in parts. The parts were internal and external sectors. The internal sector was composed of faculty and staff who work inside the school. The external sector was composed of alumni, parents, and the Jesuit superior who work outside of the school. The comparison of the findings was then examined in terms of each research question.

\section{Research Questions}

The main research question was: What were the factors and elements that have contributed to the success and longevity of the leadership of Fr. Marcelino García, S.J. in his role as a Jesuit high school president? Subsidiary questions that guided the study were:

1. In reference to Bolman and Deal's (1997) multi-frame perspective, what is the predominant leadership style of Fr. García?

2. In reference to Bolman and Deal's (1997) multi-frame perspective, what factors contribute to the effectiveness of Fr. García's style of leadership? 
3. In reference to Jesuit educational leadership, is Fr. García an effective leader?

4. In reference to Jesuit educational leadership, what factors contribute to the effectiveness of Fr. García's style of leadership?

\section{Predominant Leadership Style}

The data concurred that Fr. García's leadership style mostly reflected the characteristics associated with the political frame. Results of the Leadership Orientations Survey indicated for this frame a mean score of $35.16(S D=4.49)$ in Section I and 17.67 $(S D=3.77)$ in Section II, both scores being the highest mean scores among all four frames. More specifically, in Section I of the survey the highest overall scoring item with a mean score of $4.82(S D=.43)$ asked if Fr. García "is very effective in getting support from people with influence and power" (item 19); an attribute of the political frame (Ammeter et al., 2002; Ferris et al., 2007; Pfeffer \& Fong, 2005; Pfeffer \& Sutton, 2006; Vecchio, 2007).

In addition, the highest overall ranking given to describe Fr. García in Section II was that he was able to "build strong alliances and a power base" (item 3c) with 69 (62.7\%) respondents indicating that it was "the phrase that best describes the person." Not far behind was the descriptor of Fr. García as a "skilled negotiator" (item 2c) with 65 (59.1\%) respondents ranking him highest.

Results from the survey are confirmed by what interviewees indicated as significant of Fr. García's administration. When asked about effective leadership Mr. Collins expressed that it is this ability to network with the community and to gain their support that allows Fr. García the ability to administer successfully. Mr. Nuñez added to this by describing Fr. García's workload. He expressed how impressed he was with his 
ability to meet with major donors for lunch and then meet with the alumni for dinner, always moving around and establishing the right contacts.

Exceptionally high was also the rating that respondents gave Fr. García on item 3 in Section I when asked if he "shows exceptional ability to mobilize people and resources to get things done" $(M=4.57, S D=0.76)$. Ms. Calderín referred to this when reflecting on the school's physical growth under Fr. García's administration:

All the buildings that he has been able to construct, the relationships with people that have been able to donate to the school... the school was almost bankrupt and he was able to get ahead and bring it up to the position that we are now.

Although Fr. García scored exceptionally high in the political frame, within these particular items he scored uncharacteristically low in Section I on item 15 that asked if he "anticipates and deals adroitly with organizational conflict" $(M=3.53, S D=1.12)$. The ability to deal effectively with conflict and even use it to an organization's advantage is one of the more common traits of the political frame (Ammeter et al., 2002; Bolman \& Deal, 1997; Kanter, 2005) and yet respondents indicated that Fr. García only sometimes dealt with it properly.

On the other hand, analyses of responses pertaining to items that refer to conflict in Section II present a slightly different perspective. When asked, "what people are most likely to notice about this person," $53(48.2 \%)$ respondents indicated that Fr. García’s "ability to succeed, in the face of conflict and opposition" (item 4c) was "the phrase that best describes the person" and $25(22.7 \%)$ respondents indicated that it was "the next best phrase that describes the person;" in total, 78 (70.9\%) respondents rated Fr. García favorably. How can the discrepancy be understood? 
The difference possibly lies in the distinction that can be made between internal and external conflict as inferred by the items in the survey. In item 15 of Section I, where Fr. García scored lowest, the question specifically asks respondents to address how Fr. García deals with conflict within the organization. A look at the responses of interviewees in reference to organizational conflict supports this difference. For example, when Ms. Calderín referred to the school's growth under Fr. García's administration she added that, "he could take it to the next level if he would not be afraid of confrontations and to tell people things the way that they are." The "people" that Ms. Calderín referred to are the school's administrators and members of the faculty.

Mr. Nuñez as well referred to this internal conflict that is not often confronted effectively when he stated that he felt there was an overabundance of chiefs and that they often seemed to interfere with each others work making it hard at times to achieve consensus. From the perspective of the faculty, Mr. Collins expressed that, "within the administration, we the teachers, hear that there are some struggles between the opinions of different administrators and I would have thought that at some point some heads were going to roll."

Fr. García's non-confrontational approach to internal conflict helps explain the reason why in Section II when asked about his "most important leadership trait" (item 5), $58(52.7 \%)$ respondents indicated that "the phrase that is least like the person" was his "toughness and aggressiveness" (item 5c); a leadership trait that falls within the category of the political frame.

So what of his capacity to deal with external conflict? Respondents' recognition of an ability to succeed in the face of conflict and opposition as indicated in Section II of 
the surveys is supported by all six interviewees who made specific reference to conflicts such as the confrontation with the parochial schools of the Archdiocese of Miami and the various challenges that Belen had to face when first establishing itself in the city.

In reference to the parochial school situation, Ms. Juncadella recognized that Fr. García was very bright and knew how to navigate through very difficult situations. She expressed that Fr. García appreciated the difficulty that the archbishop was in when having to stand between the school and the pastors and so he helped resolve the conflict without creating an overly uncomfortable situation for the archbishop. Mr. Nuñez added that, "There is one element that is fundamental and I know he handles it as well, which is the relationships with the Archdiocese of Miami and that is vital."

Mr. Nuñez's comments about the relationship between Fr. García and the archdiocese should be understood to include not only the parochial school conflict but also the unavoidable clashes that occur when establishing and running a school in a city whose archdiocese for years has been educating the children of its Catholic population. Permissions from the archbishop for construction and expansion, justification for such growth, competition with other already established Catholic high schools for students, competition for limited financial and professional resources; Fr. García has addressed all these issues successfully. Mr. Nuñez stated,

This is a private school, which is reasonably priced, extremely successful, with very modern facilities, which continues to grow, with a very powerful alumni and there are schools, a vast majority of the schools, that cannot compete with something like this and that does not make them happy and they have no reason to be happy. 
Mr. Collins reminisced of the first years of the school on the new campus when Fr. García first arrived and how difficult it was to convince the local community of the good that the school would do for the local community. He stated,

One of García's hidden secrets of getting to the results that he wants is to be patient enough to wait for people to finally come around and realize that maybe their original stance was too adamant and through either that patience or divine intervention, he's been able to resolve conflicts in a way that's been able to maintain him on the job for all these years and to Belen to be as successful as it is.

Evidence has attested to the fact that the various factors that comprise the political frame are the predominant characteristics of Fr. García's leadership style. This, on its own, can be an explanation for Fr. García’s success. Bolman and Deal (1997) might agree: "Despite the low image of organizational politics in the minds of most managers, the political frame appears to be the primary determinant of success" (p. 278). It can be concluded that access to this frame has contributed significantly to the longevity and success of Fr. García’s administration.

\section{Frame Use Effectiveness}

While the data indicated that Fr. García's predominant leadership style resonated most with the characteristics particular to the political frame, it also indicated that characteristics of the other three frames were clearly present as well. Table 10 shows that total mean scores for both Section I and Section II of the Leadership Orientations Survey indicated multiple frame use. Evidence in the interviews strongly supports these results. Thus, it can be concluded that while Fr. García's leadership style is strongly political, it could not simply be reduced to one particular frame.

For example, when asked if Fr. García "communicates a strong and challenging vision and sense of mission" (item 20), a characteristic associated with the symbolic 
frame, respondents rated him highly with a mean score of $4.57(S D=0.66)$, the second highest score for any item in the survey. In addition, Fr. García was rated highly ( $M=$ $4.41, S D=0.91)$ when asked if he "sees beyond current realities to create exciting new opportunities." This was also the case in Section II where 56 (50.9\%) respondents indicated that being "a visionary" (item 6d) was "the phrase that best describes this person" and $23(20.9 \%)$ respondents indicated that it was the phrase "that is next best." Table 10

\begin{tabular}{lccccc}
\multicolumn{2}{l}{ Multiple Frame Use } & \multicolumn{2}{l}{} & & \multicolumn{2}{l}{} \\
\cline { 1 - 3 } \cline { 5 - 6 } Frames & \multicolumn{2}{l}{ Leader Behaviors } & & \multicolumn{2}{c}{ Leadership Style } \\
\cline { 2 - 3 } \cline { 5 - 6 } & Mean & $S D$ & & Mean & $S D$ \\
\hline Structural & 32.07 & 6.34 & & 12.92 & 3.47 \\
Human Resource & 33.34 & 5.96 & & 14.94 & 3.39 \\
Political & 35.16 & 4.49 & & 17.67 & 3.77 \\
Symbolic & 33.93 & 5.50 & & 14.47 & 3.77 \\
Total & 33.62 & 5.71 & & 15.00 & 4.00 \\
\hline
\end{tabular}

Note. Cut off point for multiple frame use was determined by a mean subscale score of 25.92 or greater for Leader Behaviors (Section I) responses and 9.6 or greater for Leadership Style (Section II) responses.

The research literature identifies vision as one of the most fundamental characteristics of successful leadership (Bennis, 2003; Bennis \& Nanus, 1997; Daft, 2008; Hammer and Champy, 1996; Kouzes and Posner, 2002). Bennis (2003) even goes as far as to claim that it is "the first basic ingredient of leadership" (p. 39). In accordance with this, every interviewee made reference to Fr. García's visionary quality and his ability to communicate it to the school community. A particular example of this can be taken from Mr. Collins's interview when referring to the beginnings of Fr. García's administration and the first steps of the school in Miami. Mr. Collins explained that Fr. García came to the school when its future was uncertain and credits him for affirming 
that the school would have a future in Miami and that they were not going to be kept on hold.

Fr. García himself was very clear in his understanding of what he saw as his vision for Belen. He stated that, "Our goal is to be special. We wanted to be the best and always we had in mind these 25 years how we could become the best school in the county and the country." This desire to be the best resounded in the words of the other interviewees who shared Fr. García’s vision.

Another characteristic of the symbolic frame that was evidenced in the data was recognition on the part of respondents and interviewees that Fr. García’s style of leadership is value-oriented. Research emphasizes the importance of values and their successful articulation and communication as one of the more essential traits of a successful leader (Beckner, 2004; Bennis \& Nanus, 1997; Cohan, 2003; Daft, 2008; Fowler, 2000; Kouzes \& Posner, 2002; Morrill, 2007; O’Reilly, Chatman, \& Caldwell, 1991; Short \& Greer, 2002; Schumaker \& Sommers, 2001).

When asked, for example, in Section I if Fr. García "serves as an influential model of organizational aspirations and values" (item 32), respondents rated him favorably with a mean score of $4.23(S D=0.86)$. This ability to model and inspire these values inspired Mr. Arán to state, "my kids go to Belen because they were going to get a Catholic education and a Jesuit Catholic education and they were going to go to a prep school and they were going to go to school with tradition that I learned and that I felt." It is clear that the values that are experienced within the school community and espoused by Fr. García are the Christian-Catholic values that makeup the identity of the school. Mr. Nuñez added, 
Belen is a place in which you come in, in the morning, and I do not mean only the students, faculty as well, and we are challenged and we contribute and we make dreams come true and we have friends and we laugh and we sing sometimes and we go to mass and this enormous camaraderie, which is based and is centered on something that is fundamental, which is engaged in spirituality and of course the presence of Christ.

Fr. García also scored favorably when respondents answered items that referred to the human resource frame. When asked in Section I if he "shows high levels of support and concern for others" (item 2) respondents rated him highly with a mean score of 4.46 $(S D=0.71)$ and with a mean score of $4.41(S D=0.78)$ when asked if he "shows high sensitivity and concern for others' needs and feelings" (item 10). In Section II, when asked what people are most likely to notice about him, 25 (22.7\%) respondents indicated that it was his "concern for people" (item $4 b)$ that best described him and $44(40.0 \%)$ respondents indicated that it was the next best phrase that described him.

Fr. García's concern for individuals is also very clearly evidenced in the responses given by all the interviewees. Ms. Juncadella praised his way of being always accessible and experienced various occurrences when she was invited into his office, even without an appointment. Mr. Collins agreed, "I would say that one of the reasons why it's been so gratifying for me to work here is because I've always felt that if I needed to convey something to him, if I didn't get my way, it would at least be considered by him in a serious way."

Mr. Collins's claim resounded with what respondents indicated in Section I when they agreed in item 22 that Fr. García "listens well and is unusually receptive to other people's ideas and input" $(M=4.21, S D=0.96)$. Also highly favorable were respondents" opinion on Fr. García in item 18 that asked if he "is consistently helpful and responsive to others" $(M=4.39, S D=0.78)$. 
Faculty and administration interpret this receptive and responsive quality as Fr. García's way of empowering them. When referring to his relationship with the faculty and administration, Fr. García stated, "The best verb that we can apply to them is to empower any person in the school, the staff, the administrator, the teacher and give freedom to develop what they have in mind if that thing fits in our mission." Clearly Fr. García's perspective agrees with Bolman and Deal's (1997) suggestion that, "investing in people on the premise that a highly motivated and skilled workforce is a powerful competitive advantage" (p. 119).

While the total mean score for items that referred to the structural frame were the lowest of all four frames, respondents still scored Fr. García favorably. In Section I, respondents indicated that Fr. García "thinks very clearly and logically" (item 1) with a mean score of $4.32(S D=0.73)$, that he "approaches problems with facts and logic" (item $17)$ with a mean score of $4.22(S D=0.91)$, and that he "approaches problems through logical analysis and careful thinking" (item 9) with a mean score of $4.19(S D=0.84)$. In Section II, 27 (24.5\%) respondents indicated that what Fr. García did best was to "make good decisions" (item 3a) and $47(42.7 \%)$ respondents claimed that it was the next best thing that he did; in total, $74(67.2 \%)$ respondents rated him favorably.

Positive traces of these aspects of the structural frame can be found in the interviews. The ability to think clearly and to approach problems with logical analysis is evidenced by what some of the interviewees mentioned of Fr. García. Ms. Juncadella, for example, was impressed with how Fr. García addresses the multiple problems that arise within the school. She stated that he believes that "every problem that everybody brings 
will have a solution, and it might be counter to what he has planned, but I think he surrounds himself with very capable individuals and he listens."

But most notable are the results of other items that refer to the structural frame in both Section I and II where Fr. García scored among the lowest. When asked in Section I if Fr. García "sets specific, measurable goals, and holds people accountable for results" (item 21), respondents rated him with a mean score of $3.78(S D=1.18)$. When further asked if he "strongly believes in clear structure and a chain of command" (item 29), respondents rated him with a mean score of $3.79(S D=1.18)$. In Section II when asked if the best way to describe him was as a "technical expert" (item 2a), an overwhelming 76 $(69.1 \%)$ respondents indicated that it was the phrase that was least like him, the largest single response for any item in Section II.

The evidence found in the interviews also supported this weakness in traits pertaining to the structural frame. Mr. Nuñez clearly sated that, "if there is a weakness, if there is something that Fr. Marcelino [García] needs to be challenged with, it is the process of what we would call or in administration is called accountability." Ms. Calderín agreed: "We have people that have conflict of interests and they have not been told that they could not be doing what they are doing and to me that is a problem because what happens is that people get demoralized."

\section{Multiple Frame Use}

Evidence from responses to Sections I and II of the survey clearly indicated that Fr. García was recognized as a successful leader. In support of this, results from Section III of the survey demonstrated that $92(83.6 \%)$ respondents identified Fr. García as being in the "middle to top" to "top 20\%" of effective leaders that they knew. Moreover, 94 
(85.4\%) respondents identified him as being in the "middle to top" to "top $20 \%$ " of effective managers that they knew. The evidence found in all the interviews lent support to these findings.

In addition, evidence not only demonstrated the use of multiple frames, but also indicated negative correlations between some of these frames (see Table 6). These negative correlations are consistent with the nature of the characteristics associated with each frame that often conflict with each other. For example, a significant negative correlation between the human resource frame and the structural frame, $r=-.43$, might be explained because the human resource perspective represents a position that the "organization exist to serve human needs" (Bolman \& Deal, 1997, p. 102) while the structural perspective represents a position that the "organization exists to achieve established goals and objectives" (Bolman \& Deal, 1997, p. 40). One can see why scores for these frames would be negatively correlated.

Fr. García's ability to use more than one frame in his administration resonated clearly with what researchers have proposed as the key factor to successful leadership. It should be duly emphasized that while studies indicated that the more common practice for leaders was to employ a dual-frame perspective and a much more elusive practice was the use of more than two frames (Berger, 2002; Bolman \& Deal, 1997; Bush \& Glover, 2003; Israel \& Kasper, 2004; Newmann, 1993; Thompson, 2000, 2005; Wallace, 2000), Fr. García's access to all four frames classified him as a unique and successful leader.

\section{Effective Jesuit Educational Leadership}

According to the president's job description as formulated by the JSEA (2000), the president "works to lead all members of the school community to do their very best in 
carrying out the mission and philosophy of the school" (p. 1). Part Two of the

Administrative Leadership Profile Survey assessed the overall organizational health of the school demonstrating the effectiveness of the president. Evidence collected from both Part Two of the survey and the interviews demonstrated that Belen is a very healthy school.

\section{Roles and Responsibilities}

Responses to Part Two of the survey indicated that respondents are very satisfied with their roles and responsibilities within the school community. When asked if they agreed that they were "comfortable with my role in the school" (item 1), 90.0\% of respondents indicated that they either agreed or strongly agreed $(M=2.39, S D=1.00)$. In addition, when gauging the school's health, $56.9 \%$ of respondents agreed or strongly agreed that "roles and responsibilities are clearly communicated at our school" (item 16) and $72.7 \%$ agreed or strongly agreed "people at our school know what is expected of them" (item 32). Fr. García understands the advantages to this kind of an environment. Of the faculty and administration he stated,

We have the best faculty and assistant principals who work very hard and are very creative in the work that they do. If they feel that I can support them and sell to them that they are the best and in the best school, then they feel very proud of that and they have to work to maintain the standard of the best or one of the best schools of the country.

The Jesuit high school president's job description formulated by the JSEA (2000) emphasizes that the responsibility to generate this particular environment belongs most especially to the president. In agreement, Mr. Nuñez points out that the president must "be a man that also has to create a certain atmosphere, ah, of certain... an atmosphere of... of comfort, that people feel good working here." 
The atmosphere that has helped create job or role satisfaction is further clearly evidenced by the perception that respondents have of truly making a difference in the students' lives (item 9). When asked specifically about this positive influence $97.2 \%$ of respondents emphatically indicated that they either agreed or strongly agreed $(M=2.70$, $S D=.63$ ), the highest percentage and mean score of any item in this part of the survey. Mr. Collins's perspective agreed:

At Belen, a great leader might be a holy priest, it might be the track and field coach because the influence those two will have on the people they deal with is equally important and that's rather untypical of corporate America and why this place is the place that I feel so comfortable around because they recognize, say, the talents of, say, the ordinary folks here as potential leaders or other saints.

\section{Empowerment}

Data collected also expressed that individuals agreed that Belen's environment was not only conducive to understanding their roles and responsibilities, but to fulfilling them. Respondents indicated a sense of empowerment that helped create a healthy school. When asked about his faculty, administration, and staff, Fr. García explained that his outlook was to empower any person in the school, the staff, administrator, or faculty member and give them the freedom to develop what they had in mind as long as it fit with the school's mission.

Fr. García's empowerment perspective is typical of Jesuit leadership. Mr. Collins explained,

What I most admire about Jesuit leadership is that they don't subscribe to the great man theory of history or the top down theory of leadership where there will be one person who is so enriched and so enlightened that he will tell the rest of us peons what to do and how to live. The Jesuits believe that every single person has the potential of being a leader. 
A study of the descriptions set out by the JSEA of the role of the president in a Jesuit high school reveals that empowerment, allowing others to work and encouraging creativity, are integral to the president's responsibilities. The JSEA (2008) states that,

By communicating the mission and vision of the school clearly and enthusiastically, by delegating responsibility and authority appropriately to others and calling them to accountability, and particularly through prudent strategic planning and decision making, the president works to lead all members of the school community to do their very best in carrying out the mission and philosophy of the school. (p. 1)

Respondents indicated that Fr. García fulfills this role of the president well. When asked if they agreed that "people at our school have the authority and resources to do their jobs" (item 25), 80\% indicated that they either agreed or strongly agreed with the statement $(M=2.11, S D=1.10)$. Moreover, in item $8,72.7 \%$ of respondents agreed or strongly agreed "people at our school feel authorized to make decisions in their work" ( $M$ $=1.92, S D=1.17)$.

Evidence of an environment of empowerment was also present in comments made by interviewees when asked to talk about their experience at Belen. Ms. Juncadella, for example, explained how Fr. García involves parents in formulating goals and policies at the school:

At the meetings that we have once a month, and I have been having them for seven years, you know, he proposes a plan and first of all I guess he tests the waters with his inner circle and that may include to some extent the parent club and he sees what kind of reception these things have and then if it works and he thinks that he has some positive feedback, he runs with it and he is a very good delegator and he trusts the people that he works with. Sometimes I worry (laughs) that he trusts us too much, you know, uh, that, uh, he has a natural trust for people that are in place. I guess he selects them well in the first place, but you know his Theology Department is in the hands of a lay person and so, you know... but then he lets people act and work and so he is a good delegator. 
Mr. Nuñez, speaking on behalf of the administrators, stated about Fr. García that, "he has a great ability to bear the weight of this rather large administration, of the individuals and the individuals with their ideas, their hopes, their tasks, their plans." The need and ability to "bear the weight" of his administration is a result of Fr. García's openness to their new ideas and initiatives. Respondents attested to this. When asked if "administrators at our school are comfortable exercising leadership" (item 10), 74.5\% indicated that they agreed or strongly agreed $(M=1.97, S D=1.30)$.

\section{Productivity}

Apparent in the evidence was the fact that the school environment was conducive to getting things done. The way that Fr. García administers the school permits individuals to do their job. When working to revamp the alumni association Mr. Arán experienced this firsthand. He stated, "we were, we meaning the board, after having two years of time to reflect, we've been amazed about how much he truly allowed us to do in the formation of the board, in the implementation of the board, and as a governing body."

Survey responses for part two also reflected this reality. When respondents were asked if they agreed that "people in our school get things done" (item 2), 75.5\% agreed or strongly agreed $(M=1.90, S D=1.01)$. When asked if they agreed that "people in our school do their jobs well" (item 13), 72.7\% agreed or strongly agreed $(M=1.79, S D=$ 1.17). In addition, $78.9 \%$ of respondents indicated in item 34 that they either agreed or strongly agreed "our deepest values get translated into action at our school" $(M=2.06$, $S D=1.03)$ 


\section{Effective Jesuit Leadership}

The survey evaluation of the organizational health of Belen demonstrated that $79.4 \%$ of respondents agreed or strongly agreed that the school was functioning well, that the school was healthy. When at one point respondents were asked if they felt that the school was in serious trouble (item 4), 79.1\% indicated that they disagreed or strongly disagreed $(M=-2.05, S D=1.53)$. If the school's vitality is indicative of the president's effectiveness, then respondents recognized Fr. García as an effective Jesuit leader.

\section{Contributing Factors to Jesuit Leadership Effectiveness}

Part One of the ALPS assessed Fr. García's performance in light of the various factors that constitute Jesuit educational leadership. Results demonstrated several areas of strength in Fr. García's leadership reflective of Jesuit education and included the importance that respondents attributed to each one of them. The evidence gathered from the interviews further supported these results and helped identify three recurring themes.

\section{Entrepreneurial Leadership}

Among the characteristics of Jesuit education is the need to "adapt means and methods in order to achieve the purposes of Jesuit education" (ICAJE, 1994, p. 150). It is precisely for this reason that the JSEA (2000) stated in its job description for the president that he "oversees the operations of the president's office, academics, school finances, development and fund-raising, promotions, public relations, alumni/ae relations, and the care and maintenance of the school's physical facilities" (p. 1).

One of the more evident aspects of Fr. García's tenure at Belen has been the financial stability and physical growth of the school. All interviewees spoke about these particular aspects when asked to comment on Fr. García's achievements. Fr. Perez- 
Lerena described this factor of his work: "Well, I think that Fr. Marcelino [García] has done good work as a president of the Belen Jesuit High School. He has handled the fundraising issue, as a president of the high school; he has accomplished it in an excellent way."

Fr. García recognized how significant this responsibility of his presidency was in order to expand the school's facilities and assure its success. Of the various constructions he initiated throughout his tenure he explained, "these were things that were attractions for the parents and attractions for the kids and at the same time was a tremendous temptation and invitation for the teachers to develop their abilities in order to make great contributions to education." There is no question that the school community agreed with him. When items in the survey asked about school facilities, fundraising, and financial stability (items 14, 16, 29, 30 respectively), respondents recognized them as highly important.

Fr. García's success in this area of school leadership was evident. Mr. Collins claimed that, "Fr. Garcia has never been satisfied with the status quo and as a result, we've gone from this, I would say, shoebox campus, shoebox might be too flattering, a matchbox of a campus, to this magnificent facility that we have now with all of the programs and services that are provided." In addition, when respondents were asked in the survey if Fr. García “oversees a program, for maintaining and improving the school's facilities" (item 14), they indicated that he consistently did $(M=3.84, S D=0.47)$.

Working toward the construction of an educational facility that can assure the excellence characteristic of a Jesuit school is the president's concern. The school 
community recognizes that this expansion is the result of Fr. García's financial savvy.

Mr. Nuñez indicated that,

The results, of course, have been the enormous growth of the school, the new buildings, new facilities, the tremendous, in fact, the introduction and the development of the technology aspect of the school, which is, I wouldn't say limitless, but certainly is up to date, year after year after year, and he creates this environment of enjoying and reaching new heights, constantly, all the time.

About Fr. García's ability to raise funds and secure the financial needs of the school, respondents were asked if he "maintains the financial security and integrity of the school” (item 30). To this question respondents answered that he consistently $\operatorname{did}(M=$ $3.72, S D=.56)$. Moreover, when asked if he "supervises the efficient and equitable budgeting of the school's resources" (item 16), respondents also indicated that he consistently did $(M=3.56, S D=.71)$.

Respondents explained that behind Fr. García's success in securing the financial stability and growth of the school is his contact and rapport with both the school and local communities. When asked if he "solicits contributions on behalf of the school with grace and conviction" (item 29), respondents recognized that he consistently did with a mean score of $3.87(S D=0.49)$, the highest mean score for any single item in the survey. Ms. Calderín stated that, "all the buildings that he has been able to construct, the relationships with people that have been able to donate to the school like the Goizuetas and the Rocas and the Rodriguezs. I think he is wonderful for that. He knows how to do that perfectly." Ms. Juncadella stated,

He [Fr. García] has the ability to convince people that it's worth the extra toil to make it happen, you know, the most obvious example is the development side, which is physically obvious how the school has grown in numbers as well as buildings and that is just a reflection of everything that he does with the programs too. 


\section{Cura Personalis}

One of the major recurring themes identified in the interviews was Fr. García's concern for others. Jesuit education refers to this particular trait with the term cura personalis and constitutes one of the more important characteristics of education, "affecting the curriculum and the entire life of the institution" (ICAJE, 1994, p. 138).

Items that referred to the categories of being loving and caring and communications in part one of the survey were associated to the cura personalis and scored consistently high. When asked, for example, if Fr. García "shows a loving care and concern for the individual person" (item 11) and "relates and works well with others" (item 71), respondents indicated that he consistently did $(M=3.63, S D=.59 ; M=3.63$, $S D=.64$ respectively). Such favorable responses were significant considering that respondents also rated these particular items as important $(M=1.92, S D=.28 ; M=1.94$, $S D=.23$ respectively)

Interviews also demonstrated that this particular characteristic was clearly observable in Fr. García's leadership. Ms. Juncadella referred to it: "his door is always open. Uh, that has been my perception. I have sent parents to him with serious problems that I have, you know, don't have the authority to even get involved in and I said: 'Go straight to him' and he is always open."

Ms. Juncadella's comment was confirmed by respondents who indicated that Fr. García "is attuned to the interests and concerns of parents" (item 1), with a mean score of $3.67(S D=.55)$ and that he "makes parents and benefactors feel they are valued by the school" (item 19) with a mean score of $3.77(S D=.54)$. Both these items were identified 
as being important for respondents with means of 1.83 and $1.90(S D \mathrm{~s}=.38$ and .30 ,

respectively).

The cura personalis extends itself to all members of the educational community.

After so many years of teaching at Belen, Mr. Collins commented about Fr. García that:

He maintains a relationship with people, myself especially, of being so cordial, accommodating. I have had personal experiences where I have asked him something sort of off the record about a personal favor having to do with scheduling for example and it was never "Well, okay, I'll consider doing this, but I expect to extract a price from you". It was always: "Well is that all your asking for?" and always made me feel even after asking him a favor that it was not to be considered a debt, that he was glad to do that. This is not to be taken for granted. This is a great characteristic of his leadership skills.

The attention and concern that Fr. García has for the individual was also evident

in the way respondents expressed that they were encouraged to be creative and involved.

Respondents expressed a sense of being empowered by Fr. García. Mr. Collins stated:

He [Fr. García] strongly believes in bringing in various groups and trying to encourage them to express what they believe and what they think should happen. He listens to them and always gives the impression of being a consensus builder. I am sure that oftentimes people may walk away with the impression that he caters to too many people, but I think that it is because he really cares for all the members of the school community and wants them to feel a part of what happens here.

Evidence from the survey also indicated that same sense of empowerment. When asked if Fr. García "gives people the freedom and authority to do their jobs well" (item $50)$, respondents indicated that he did so consistently $(M=3.80, S D=.47)$. Mr. Nuñez attributed this ability to Fr. García's awareness that it provides positive results. He explained:

Fr. García is a people-person. He knows his audience, if you will, very, very well. I am convinced that he's got a lot of savvy in terms of psychology, human psychology and so I think he's very successful in making people serve, produce, whatever the term is, and be content in what they're doing and how they're doing it. He almost, by definition, has a tremendous ability to balance the giving of 
freedom to people and have them act freely and produce, and at the same time has an ability to control and not always successful, but the ability certainly is there and that ability can only be the product of knowing your people, each people, each person that works for you, you know him very, very well.

Respondents further indicated that Fr. García has a genuine concern for others when they claimed that he consistently "spends time with people for whom the school has special meaning" (item 33), with a mean score of $3.71(S D=.57)$ and "cultivates involvement and support by parents and alumni/ae" (item 59), with a mean score of 3.81 $(S D=.46)$, one of the highest mean scores for all items in part one of the survey.

Both the survey and interviews showed that Fr. García was recognized as having a particular concern for the school's alumni. When asked if he "encourages alumni/ae loyalty and dedication to the school (item 12), respondents indicated that he consistently $\operatorname{did}(M=3.86, S D=.39)$, the second highest mean score for all items in part one of the survey. Moreover, when asked if he "keeps alumni/ae informed about each other and the school" (item 39) they indicated that he consistently did $(M=3.80, S D=.45)$.

Based on his experience in the reshaping of the school's alumni association, Mr.

Arán expressed his contentment with the role that Fr. García played in it:

He was $100 \%$ supportive, yet he did not mandate to us what we had to do. No doubt that he had especially at the beginning a lot of good ideas, ah, that we followed, but he truly allowed us to through the thought process that we did by meeting very often, ah, to really structure it and to really focus on what we wanted it to be like and how we wanted it to be governed. Ah, never interfered with any of it. Was there, he attended the meetings, but really allowed us to let it take shape and let it be an independent body.

Fr. García referred to the alumni association very favorably: "the alumni, they have been a tremendous input in the school. I could say with humility that I don't see a better alumni association in... among the Jesuit schools in the world, like the one that we 
have." This focus on the school's former students is very much a characteristic of Jesuit education. The ICAJE (1994) writes that:

Former students are members of the community working in service of the kingdom; a Jesuit school has a special responsibility to them. As far as resources permit, the school will offer guidance and ongoing formation into so that those who received their basic formation in the school can be more effective in putting this formation into practice in adult life and can continue to deepen their dedication to the service of others. (p. 149)

Jesuit education's call to continuous service and formation of the alumni was addressed. In item 40, when respondents were asked whether Fr. García "seeks to deepen alumni/ae commitment to the service of others," they indicated that he consistently did $(M=3.81, S D=.40)$. Fr. García recognized that this was one of the most important goals of the newly ordered alumni association, the continuous formation of school graduates as men in the service of others. He stated that,

The friendship and the love that is created among the students in the school is followed through in the association and in activities outside in order to promote social justice, to work in charities and so forth and they have been very instrumental.

Finally, in reference to being concerned for others, respondents indicated that "maintaining good relations with the Jesuit community" (item 21) was one of the most important responsibilities that Fr. García had with a mean score of $2.90(S D=.33)$, the third highest scoring item. When asked about his relationship with the Jesuits and their presence at the school Fr. García acknowledged how important the presence of his fellow Jesuits was for the proper administration of the school. He expressed disagreement with the opinion of many Jesuits, especially in the United States, that claimed that Jesuit schools could be run without the presence of Jesuits. 
When responding to item 21, respondents indicated that Fr. García consistently maintained good relations with his fellow Jesuits $(M=3.73, S D=.57)$ and additionally agreed that he consistently encouraged them to invest in the school as an apostolic work (item 15$)$, with a mean score of $3.82(S D=.49)$, one of the highest scoring items in the survey. Mr. Collins explained that he understood Fr. García's relationship with the Jesuit community as one of the secrets to his success. He stated that, "If there was a leader who was less willing to engage with the Jesuit community, if he had been resistant to working with this group, I think there would have been much less success than we have to this point."

Ignatian Vision: Value-Oriented

The evidence of Fr. García's good relationship with the Jesuit community exposed another important factor in the success of his leadership. His expressed conviction of the importance of the Jesuits in the school, the continuous references to the Spiritual Exercises and the worldwide Jesuit community of schools, demonstrated that his vision was clearly Ignatian.

Educational research attests to the importance of clarity of vision as a fundamental precept for successful leadership (Daft, 2008; Salacuse, 2006; Sergiovanni, 2001; Short \& Greer, 2002; White, 2007). In accordance with this, reference to the president's job description as detailed by the JSEA states that,

As director of the apostolate, the president leads others to ensure the Jesuit character and Ignatian vision of the school as articulated by the Society of Jesus. The president is the overall spiritual leader of the community of faith and promotes the integration of faith and culture within the school. (JSEA, 2000, p. 1)

The "Jesuit character and Ignatian vision" that the president's job description refers to is solidly rooted in Christian values. As stated by the ICAJE (1994): "Jesuit 
education includes formation in values, in attitudes, and in the ability to evaluate criteria" (p. 139). More specifically, these values are identified as Christian values and all members of the school community are encouraged to strive towards them. The ICAJE (1994) further explains that, "members of various faiths and cultures are a part of the educational community in Jesuit schools today; to all, whatever their beliefs, Christ is proposed as the model of human life" (p. 140).

Respondents considered this particular characteristic of Jesuit education important to the success of the school. Survey items that referred to Ignatian vision were consistently high. When, for example, respondents were asked how important it was for Fr. García to "show genuine interest in the spiritual growth of the school community" (item 62), they responded with the fifth highest mean score among all items $(M=1.97$, $S D=.16)$. When they were asked how important it was for him to "take time out for prayer, reading, and reflection" (item 54), they responded with a mean score of 1.91 (SD $=.32$ ).

Fr. García's performance also reflected the significance of Christian values as a major player in his administration. Mr. Nuñez stated that, "Belen is a place that is based and is centered on something that is fundamental, which is engaged in spirituality and of course the presence of Christ.” Mr. Collins added,

I'd be hard-pressed to find an example where anything that he [Fr. García] envisions is not rooted in growing, whether ideas in the pedagogical area of teaching where he would like to initiate a new emphasis, whether it's on reading or whether it's on class size or whether to develop new programs spiritually. The recent addition of the office of Social Justice, of course, that had to be rooted in our Catholic, Jesuit tradition.

Analyses of responses to the survey concurred. When asked if Fr. García "contributes by word and example to the Christian atmosphere of the school" (item 5) or 
if he "shows genuine interest in the spiritual growth of the school community" (item 62), respondents indicated that he consistently $\operatorname{did}(M=3.66, S D=.58 ; M=3.66, S D=.64$ respectively). In addition, when asked if Fr. García "models for others a contemporary living out of Ignatian ideals" (item 38), respondents agreed that he did with a mean score of $3.60(S D=.70)$.

Respondents recognized Fr. García as being a leader whose personal life reflects the Christian values that are integral to the school's vision. When asked if he "seeks personal, professional, and spiritual enrichment" (item 20), respondents indicated that he consistently did $(M=3.71, S D=.55)$. When asked if he "takes time out for prayer, reading, and reflection" (item 54), they responded with a mean score of $3.78(\mathrm{SD}=.46)$. Fr. García gives evidence of this concern for fomenting these Christian values when he described how he leads Belen:

I could say that the best method of governing and creating an institution is to function asking ourselves what we have to do and how we are going to resolve a different situation that we need during our lives, always new ways, not repeated, make our members of the project to love the project as the best project of the world, teaching the group to discern and find the will of God, teaching the members of your institution how to find what should be done among us and great respect for the companions in this project.

\section{Implications of Research}

Both quantitative and qualitative evidence have helped explain the success and longevity of the leadership of Fr. García. Results of the Leadership Orientations Survey indicated average mean scores higher than the cut off points provided by Dr. Lee Bolman that indicate frame use (25.92 or greater for Section I responses and 9.6 or greater for Section II responses). This evidence, along with evidence of the organizational health of the school, has helped paint a picture of this extraordinary leader that resonates with four 
particular outstanding leadership qualities: being a visionary, goal oriented, accessible, and adroit. These four qualities are identified by both Bolman and Deal and the Jesuit Secondary Educational Association as essential to successful leadership.

In reference to vision, Fr. García's 25 year tenure has been characterized by extensive growth, both physically and academically, from when he first began in 1983 . Fr. García's ability to see the enormous possibilities and opportunities for growth and success has enabled the school community to progress. The evidence further demonstrates that the key to his success is not simply having the vision, but his ability to communicate it to all stakeholders of the school community. This vision seems to be the driving force behind the enthusiasm and motivation of faculty, administration, staff, and alumni that elevate Belen School to its proven success.

Clearly the vision of Fr. García is strongly grounded in well-established, welldefined goals. The Ignatian charisma permeates the various sectors of the school community and helps establish a clear identity that is modern, while part of a long history and tradition. Such an identity has established a culture within the school that parents, faculty, and alumni feel very comfortable with.

In addition, Fr. García has made it a point to reach out to all members of the school community allowing himself to be very accessible. His "open door policy," experienced by faculty and parents alike, continuously expresses his genuine interest in the welfare of the individuals of the school's community and has helped generate the sense of empowerment that they feel.

It is possibly Fr. García's ability to communicate this sense of interest for the individual that most resonates with the school community. He is charming and 
personable, which in turn has made it possible for him to be so influential and, in turn, successful. He adroitly has been able to handle the various challenges that have presented themselves throughout the 25 years of his administration, not allowing them to impede the school's progress and development. His influence both outside and inside the school community is clear.

Educational leaders should be quick to note from the example of Fr. García's administration that their role as administrators is multifaceted. To address the various sectors of the school community with its various challenges requires that the successful leader access various resources. An analysis of Fr. García's role as president throughout his 25 years has provided evidence of the need for administrators to identify their particular leadership qualities in order to take full advantage of them and, likewise, identify their leadership deficiencies in order to improve them.

\section{Implications for Future Research}

Research indicates that access to multiple frames implies the ability to shift frames or reframe in response to situational circumstances (Achinstein \& Barrett, 2004; Burke \& Costello, 2005). This being the case, further research could investigate what particular frames Fr. García would employ when presented with particular circumstances. In addition, further research could investigate the results of the Leadership Orientations (Other) Survey that was administered to the specified target population and compare them with the results of the Leadership Orientations (Self) Survey administered to Fr. García. Such a comparison can reveal the similarities and differences between the perception of others and self-perception. 
Furthermore, to broaden the scope of this study, further research could expand both the target population and key informants to include a wider representation of certain stakeholders of the school community. Those members of the school community, more specifically, could be a larger representation of parents and alumni in addition to students who were not included in this study.

It has been demonstrated that the conceptual frameworks that guided this study are related. The twenty-eight characteristics of Jesuit education resonate with the characteristics associated with the four frames identified by Bolman and Deal (1997). In addition, regression analysis can be done using the four frames and the eight themes of the characteristics of Jesuit education to identify variables that determine an effective leader or manager. This research could further investigate more profoundly the association between these frameworks and offer insight to both secular and Jesuit school leaders.

\section{Summary}

Chapter 5 concluded the study by comparing the data provided by the quantitative and qualitative methods of research employing a concurrent triangulation process. In reference to the multi-frame perspective of Bolman and Deal (1997), results of the study indicated that the political frame predominantly characterized Fr. García's leadership style. In addition, the study also indicated that characteristics typical of the other three frames were significantly evident. Thus, Fr. García's access to all four frames in his administration of Belen School has contributed to his successful leadership.

Additionally, studying Fr. García's effectiveness in reference to Jesuit educational leadership, the organizational health of the school as determined by the presence of the 
twenty-eight characteristics of Jesuit education, indicated the effectiveness of Fr. García's leadership. Results from both the surveys and interviews indicated that Belen is a very healthy school, thus providing evidence that Fr. García’s leadership has been effective. Further analysis of the factors that have contributed to his effectiveness revealed three predominant themes that have characterized Fr. García's Jesuit leadership and that have significantly contributed to his success and longevity.

The implications of this study raised questions for further research regarding the use of Bolman and Deal's leadership instrument and its application to the study of one particular leader. Analysis of frame use in particular circumstances along with a comparison of self-perception and the perception of others can further the understanding of educational leadership. In addition, the study included the need to further research the use of the two conceptual frameworks within the same study. Similarities between the two frameworks can further the understanding of Jesuit educational leadership.

In conclusion, this study took advantage of two proven conceptual frameworks to determine the factors that have contributed to the success and longevity of the leadership of Fr. García in his role as a Jesuit high school president. Evidence that Fr. García's leadership has access to all four frames as identified by Bolman and Deal (1997) and the presence of the characteristics of Jesuit education verified his success as a Jesuit high school president. 


\section{LIST OF REFERENCES}

Achinstein, B., \& Barrett, A. (2004). (Re)framing classroom contexts: How new teachers and mentors view diverse learners and challenges of practice. Teachers College Record, 106(4), 716-746.

Amabile, T. M. (1997). Motivating creativity in organizations: On doing what you love and loving what you do. California Management Review, 40(1), 39-58.

Ammeter, A. P., Douglas, C., Gardner, W. L., Hochwarter, W. A., \& Ferris, G. R. (2002). Toward a political theory of leadership. The Leadership Quarterly, 13, 751-796.

Argyris, C. (1990). Integrating the individual and the organization. New Brunswick, NJ: Transaction Publishers.

Arrupe, P., S.J. (1981). Our secondary schools, today and tomorrow. In Acta Romana Societatis Iesu, XVIII, 257-276.

Badaracco, J. L., Jr. (1998). The discipline of building character. Harvard Business Review, 76(2), 115-125.

Barr, R., \& Bizar, M. (2001). Conceptualizing leadership in the context of school reform. In R. Barr \& M. Bizar (Eds.), School leadership in times of urban reform. Mahwah, NJ: Lawrence Erlbaum Associates.

Beck, C. (1993). Learning to live the good life: Values in adulthood. Toronto, ON: OISE Press.

Beckner, W. (2004). Ethics for educational leaders. Boston: Pearson Education, Inc.

Belen Jesuit Preparatory School. (2007, September). President's Report. Miami: Author.

Bennis, W. (2003). On becoming a leader (Rev. ed.). Cambridge, MA. Perseus Publishers.

Bennis, W., \& Nanus, B. (1997). Leaders: Strategies for taking charge. New York: Harper Business.

Bensimon, E. M. (1989). The meaning of "good presidential leadership": A frame analysis. Review of Higher Education, 12(2), 107-123.

Berg, B. (2007). Qualitative research methods for the social sciences $\left(6^{\text {th }}\right.$ ed.). Boston: Allyn \& Bacon. 
Berger, J. B. (2002). The influence of the organizational structures of colleges and universities on college student learning. Peabody Journal of Education, 77(3), 4059.

Bolman, L. G., \& Deal, T. E. (1984). Modern approaches to understanding and managing organizations. San Francisco: Jossey-Bass.

Bolman, L. G., \& Deal, T. E. (1991). Leadership and management effectiveness: A multiframe, multi-sector analysis. Human Resource Management, 30(4), 509-534.

Bolman, L. G., \& Deal, T. E. (1992a,). Images of leadership: Your board's leadership style depends on how you see your school. The American School Board Journal, 179(4), 36-39.

Bolman, L. G., \& Deal, T. E. (1992b). Leading and managing: Effects of context, culture, and gender. Educational Administration Quarterly, 28(3), 314-329.

Bolman, L. G., \& Deal, T. E. (1992c). Reframing leadership: The effects of leaders' images of leadership. In K. E. Clark \& M. B. Clark (Eds.), Impact of leadership. Greensboro, NC: Center for Creative Leadership.

Bolman, L. G., \& Deal, T. E. (1997). Reframing organizations: Artistry, choice, and leadership ( $2^{\text {nd }}$ ed.). San Francisco: Jossey-Bass.

Bolman, L. G., \& Deal, T. E. (2002). Leading with soul and spirit: Effective leadership in challenging times boils down to qualities such as focus, passion and integrity. School Administrator, 59(2), 21-26.

Burke, B. F., \& Costello, B. C. (2005). The human side of managing for results. American Review of Public Administration, 35(3), 270-286.

Bush, T., \& Glover, D. (2003, Spring). School leadership: Concepts and evidence. National College for School Leadership.

Carlson, R. V. (1996). Reframing and reform: Perspectives on organization, leadership, and school change. New York: Longman.

Catechism of the Catholic Church. (1994). (United States Catholic Conference, Inc., Trans.). Bloomingdale, OH. (Original work published 1994).

Clark, K. E., \& Clark, M. B. (1992). Introduction. In K. E. Clark \& M. B. Clark (Eds.), Impact of leadership. Greensboro, NC: Center for Creative Leadership.

Codina, G., S.J. (2000). The "modus parisiensis.” In V. J. Duminuco, S.J. (Ed.), The Jesuit Ratio Studiorum: $400^{\text {th }}$ anniversary perspective. New York: Fordham University Press. 
Collins, J. C., \& Porras, J. (1995). Twelve shattered myths. The Healthcare Forum Journal, 38(5), 64-65.

Commission on Research and Development (1994a). Instrument for self-evaluation of Jesuit high schools: Principles and standards. In C. E. Meirose, S.J. (Ed.). Foundations. Washington DC: The Jesuit Secondary Education Association.

Commission on Research and Development (1994b). Profile of the graduate of a Jesuit high school at graduation. In C. E. Meirose, S.J. (Ed.). Foundations. Washington DC: The Jesuit Secondary Education Association.

Constitutions of the Society of Jesus and their complementary norms. (1996). Saint Louis, MO: The Institute of Jesuit Sources.

Cook, S. D. N., \& Yanow, D. (2001). Culture and organizational learning. In J. M. Shafritz \& J. S. Ott (Eds.), Classics of organization theory ( $5^{\text {th }}$ ed.). Fort Worth, TX: Harcourt College Publishers.

Creswell, J. W. (2003). Research design: Qualitative, quantitative, and mixed methods approaches $\left(2^{\text {nd }}\right.$ ed.). Thousand Oaks, CA: Sage.

Creswell, J. W., Clark, V. L. P., Gutmann, M. L., \& Hanson, W. E. (2003). Advanced mixed methods research designs. In A. Tashakkori \& C. Teddlie (Eds.), Handbook of mixed methods in social and behavioral research. Thousand Oaks, CA: Sage.

Daft, R. L. (2008). The leadership experience ( $4^{\text {th }}$ ed.). Mason, OH: Thomson SouthWestern.

Deal, T. E., \& Kennedy, A. A. (1982). Corporate cultures. Reading, MA: AddisonWesley Publishing Company.

de Guibert, J., S.J. (1972). The Jesuits: Their spiritual doctrine and practice. G. E. Ganss, S.J. (Ed.). W. J. Yong, S.J. (Trans.). St. Louis: The Institute of Jesuit Sources.

Dennis, R. S., \& Bocarnea, M. (2005). Development of the servant leadership assessment instrument. Leadership \& Organization Development Journal, 26(7), 600-615.

De Pree, M. (1995). Leadership jazz. In J. Thomas Wren (Ed.), Leader's companion: Insight on leadership through the ages. New York: The Free Press.

DiLiello, T. C., \& Houghton, J. D. (2006). Maximizing organizational leadership capacity for the future: Toward a model of self-leadership, innovation and creativity. Journal of Managerial Psychology, 21(4), 319-337.

Drucker, P. F. (1999). Managing oneself. Harvard Business Review, 77(2), 64-75. 
Ferris, G. R., Treadway, D. C., Perrewé, P. L., Brouer, R. L., Douglas, C., \& Lux, S. (2007). Political skill in organizations. Journal of Management, 33(3), 290-320.

Florida International University. (2005). Regulations for thesis and dissertation preparation manual. Miami: Author.

Fowler, F. C. (2000). Policy studies for educational leaders. Upper Saddle River, NJ: Merrill Prentice Hall.

Friedman, S. D. (2006). Learning to lead in all domains of life. The American Behavioral Scientist, 49, 1270-1297.

Gaskill, F. J., \& Hamer, M., OSF. (2007). Servant-leadership: A new appreciation for the embedded enduring concepts of management in the approach. American Society of Business and Behavioral Sciences, 14(1), 573-577.

Gray, H., S.J. (2000). The experience of Ignatius Loyola: Background to Jesuit education. In V. J. Duminuco, S.J. (Ed.), The Jesuit Ratio Studiorum: $400^{\text {th }}$ anniversary perspective. New York: Fordham University Press.

Green, M. F. (1992). Developing effective leaders: Can it be done? Innovative Higher Education, 17(1), 57-69.

Greenleaf, R. K. (1996). On becoming a servant-leader. D. M. Frick \& L. C. Spears (Eds.). San Francisco: Jossey-Bass.

Hammer, M., \& Champy, J. (1996). Reengineering the corporation: A manifesto for business revolution. New York: Harper Business.

Hersey, P., Blanchard, K. H., \& Johnson, D. E. (1996). Management of organizational behavior: Utilizing human resources $\left(7^{\text {th }}\right.$ ed.). Upper Saddle River, NJ: PrenticeHall.

Howell, W. G. (2005). Besieged: School boards and the future of education politics. Washington DC: Brookings Institution Press.

Hoyle, J. R., \& Slater, R. O. (2001). Love, happiness, and America's schools: The role of educational leadership in the $21^{\text {st }}$ century. Phi Delta Kappan, 82(10), 790-795.

Hughes, R. L., Ginnett, R. C., \& Curphy, G. L. (1995). Power, influence, and influence tactics. In J. Thomas Wren (Ed.), Leader's companion: Insight on leadership through the ages. New York: The Free Press.

International Commission on the Apostolate of Jesuit Education (1994). Go forth and teach: The characteristics of Jesuit education. In C. E. Meirose, S.J. (Ed.). Foundations. Washington DC: The Jesuit Secondary Education Association. 
Israel, M. S., \& Kasper, B. B. (2004). Reframing leadership to create change. The Educational Forum, 69(1), 16-26.

Jesuit Secondary Education Association. (1994). Administrative leadership profile survey: Information about using ALPS. Retrieved September 14, 2007, from http://www.jseacommunities.org/s/342/index.aspx?sid=342\&pgid=14\&cid=80\&gid $=1 \&$

Jesuit Secondary Education Association. (2000). President's job description. Retrieved September 12, 2007, from http://www.jseacommunities.org/s/342/index.aspx?sid=342\&pgid=14\&cid=80\&gid $=1 \&$

Jesuit USA News. (2006, February 8). Education statistics of the Society. Retrieved September 2, 2007, from http://www.companysj.com/sjusa/06-02-08.htm

Kanter, R. M. (1983). The change masters: Innovation for productivity in the American corporation. New York: Simon and Schuster.

Kanter, R. M. (2005). Power failure in management circuits. In J. M. Shafritz, J. S. Ott \& Y. S. Jang (Eds.), Classics of organization theory ( $6^{\text {th }}$ ed.). Belmont, CA: Thomson \& Wadsworth.

Kouzes, J. M., \& Posner, B. Z. (2002). The leadership challenge: How to get extraordinary things done in organizations ( $3^{\text {rd }}$ ed.). San Francisco: Jossey-Bass Publishers.

Leithwood, K., Jantzi, D., \& Steinbach, R. (1999). Changing leadership for changing times. Buckingham: Open University Press.

Lowney, C. (2003). Heroic leadership: Best practices from a 450-year-old company that changed the world. Chicago: Loyola Press.

Lyman, L. L., Ashby, D. E., \& Tripses, J. S. (2005). Leaders who dare: Pushing the boundaries. Lanham, MD: Rowman \& Littlefield Education.

Malen, B., \& Rice, J. K. (2004). A framework for assessing the impact of education reforms on school capacity: Insights from studies of high-stakes accountability initiatives. Educational Policy, 18(5), 631-660.

Manning, K. (2001). Infusing soul into student affairs: Organizational theory and models. New Organizations for Student Services, 95, 27-35.

Marshall, C., \& Scribner, J. D. (1991). It's all political: Inquiry into the micropolitics of education. Education and Urban Society, 23(4), 347-355. 
Maslow, A. H. (1970). Motivation and personality (2 ${ }^{\text {nd }}$ ed.). New York: Harper \& Row, Publishers.

Maslow, A. H. (2001). A theory of human motivation. In J. M. Shafritz \& J. S. Ott (Eds.), Classics of organization theory $\left(5^{\text {th }}\right.$ ed.). Fort Worth, TX: Harcourt College Publishers.

McGregor, D. (1960). The human side of enterprise. New York: McGraw-Hill.

McTighe, J., \& O’Connor, K. (2005). Seven practices for effective learning. Educational Leadership, 63(3), 10-17.

Metts, R. E., S.J. (1995). Ignatius knew. Washington DC: Jesuit Secondary Education Association.

Miller, R. J., \& Rowan, B. (2006). Effects of organic management on student achievement. American Educational Research Journal, 43(2), 219-253.

Miller, S. (2003). Impact of mixed methods and design on inference quality. In A. Tashakkori \& C. Teddlie (Eds.), Handbook of mixed methods in social and behavioral research. Thousand Oaks, CA: Sage.

Mintzberg, H. (2001). The power game and the players. In J. M. Shafritz \& J. S. Ott (Eds.), Classics of organization theory ( $5^{\text {th }}$ ed.). Fort Worth, TX: Harcourt College Publishers.

Morrill, R. L. (2007). Strategic leadership: Integrating strategy and leadership in colleges and universities. Westport, CT: Praeger Publishers.

Morse, J. M. (2003). Principles of mixed methods and multimethod research design. In A. Tashakkori \& C. Teddlie (Eds.), Handbook of mixed methods in social and behavioral research. Thousand Oaks, CA: SAGE Publications.

Mulford, W., Silins, H., \& Leithwood, K. (2004). Educational leadership for organizational learning and improved student outcomes. Studies in Educational Leadership, 3. Retrieved October 4, 2007, from http://www.netlibrary.com.ezproxy.fiu.edu/Details.aspx

Newmann, F. M. (1993). Beyond common sense in educational restructuring: The issues of content and linkage. Educational Researcher, 22(2), 4-13, 22.

Newton, R. R., S.J. (1994). Reflections on the educational principles of the Spiritual Exercises. In C. E. Meirose, S.J. (Ed.). Foundations. Washington DC: The Jesuit Secondary Education Association. 
O’Malley, J. W., S.J. (1993). The first Jesuits. Cambridge, MA: Harvard University Press.

O'Malley, J. W., S.J. (2000). How the first Jesuits became involved in education. In V. J. Duminuco, S.J. (Ed.), The Jesuit Ratio Studiorum: $400^{\text {th }}$ anniversary perspective. New York: Fordham University Press.

O'Reilly, C. A., Chatman, J., \& Caldwell, D. F. (1991). People and organizational culture: A profile comparison approach to assessing person-organization fit. The Academy of Management Journal, 34(3), 487-516.

Padburg, J. W., S.J. (2000). Development of the Ratio Studiorum. In V. J. Duminuco, S.J. (Ed.), The Jesuit Ratio Studiorum: 400 ${ }^{\text {th }}$ anniversary perspective. New York: Fordham University Press.

Pardey, D. (2007). Leadership in turbulent times: Effective leadership during times of organizational change. Strategic HR Review, 6(5), 16-19.

Patton, M. Q. (2002). Qualitative research and evaluation methods ( $3^{\text {rd }}$ ed.). Thousand Oaks, CA: Sage.

Pavur, C., S.J. (2005). Introduction. In The Ratio Studiorum: The official plan for Jesuit education. Claude Pavur, S.J. (Trans.). St. Louis: The Institute of Jesuit Sources.

Pfeffer, J. (1981). Power in organizations. Marshfield, MA: Pitman Publishers.

Pfeffer, J. (1992). Managing with power: Politics and influence in organizations. Boston: Harvard Business School Press.

Pfeffer, J., \& Fong, C. T. (2005). Building organization theory from first principles: The self-enhancement motive and understanding power and influence. Organization Science, 16(4), 372-449.

Pfeffer, J., \& Sutton, R. I. (2006). Hard facts, dangerous half-truths, and total nonsense: Profiting from evidence-based management. Boston: Harvard Business School Press.

Rubin, H., \& Rubin, I. (2005). Qualitative interviewing: The art of hearing data. Thousand Oaks, CA: Sage.

Ruderman, M. N., \& Ernst, C. (2007). Finding yourself: How social identity affects leadership. Leadership in Action, 24(3), 3-7.

Ryan, G. W., \& Bernard, H. R. (2003). Techniques to identify themes. Field Methods, 15(1), 85-109. 
Sáez, J. L., S.J. (2002). Breve historia del colegio de Belén. Santo Domingo, RD: Amigo del Hogar.

Salacuse, J. W. (2006). Leading leaders: How to manage smart, talented, rich, and powerful people. New York: American Management Association.

Saphier, J., King, M., \& D'Auria, J. (2006). 3 strands form strong school leadership. National Staff Development Council, 27(2), 51-59.

Schein, E. H. (2001). Defining organizational culture. In J. M. Shafritz \& J. S. Ott (Eds.), Classics of organization theory $\left(5^{\text {th }}\right.$ ed.). Fort Worth, TX: Harcourt College Publishers.

Schumaker, D. R., \& Sommers, W. A. (2001). Being a successful principal: Riding the wave of change without drowning. Thousand Oaks, CA: Corwin Press.

Sergiovanni, T. J. (2001). The principalship: A reflective practice perspective $\left(4^{\text {th }}\right.$ ed.). Needham Heights, MA: Allyn \& Bacon.

Sergiovanni, T. J. (2005). The virtues of leadership. The Educational Forum, 69, 112123.

Seyfarth, J. T. (2002). Human resources management for effective schools $\left(3^{\text {rd }}\right.$ ed.). Boston: Allyn and Bacon.

Short, P. M., \& Greer, J. T. (2002). Leadership in empowered schools: Themes from innovative efforts. Upper Saddle River, NJ: Merrill Prentice Hall.

Szente, J. (2007). Empowering young children for success in school and in life. Early Childhood Education Journal, 34(6), 449-453.

Tashakkori, A., \& Teddlie, C. (2003). Major issues and controversies in the use of mixed methods in the social and behavioral sciences. In A. Tashakkori \& C. Teddlie (Eds.), Handbook of mixed methods in social and behavioral research. Thousand Oaks, CA: Sage.

Taylor, F. W. (2001). The principles of scientific management. In J. M. Shafritz \& J. S. Ott (Eds.), Classics of organization theory $\left(5^{\text {th }}\right.$ ed.). Fort Worth, TX: Harcourt College Publishers.

Taylor-Bianco, A., \& Schermerhorn, J. Jr. (2006). Self-regulation, strategic leadership and paradox in organizational change. Journal of Organizational Change, 19(4), 457-470.

The Spiritual Exercises of St. Ignatius of Loyola: A translation and commentary by George E. Ganss, S.J. (1992). Saint Louis, MO: The Institute of Jesuit Sources. 
Thompson, M. D. (2000). Gender, leadership orientation, and effectiveness: Testing the theoretical models of Bolman \& Deal and Quinn. Sex Roles, 42(11/12), 969-992.

Thompson, M. D. (2005, Fall/Winter). Organizational climate perception and job element satisfaction: A multi-frame application in a higher education setting. E-Journal of Organizational Learning and Leadership, 4. Retrieved October 2, 2007, from http://www.weleadinlearning.org/mt05.htm

Trice, H. M., \& Beyer, J. M. (2001). The principles of scientific management. In J. M. Shafritz \& J. S. Ott (Eds.), Classics of organization theory $\left(5^{\text {th }} \mathrm{ed}\right.$.). Fort Worth, TX: Harcourt College Publishers.

Tylenda, J. N., S.J. (1998). Jesuit saints and martyrs: Short biographies of the saints, blessed, venerables, and servants of God of the Society of Jesus ( $2^{\text {nd }}$ ed.). Chicago: Loyola Press.

Van Meter, E. J., \& McMinn, C. A. (2001). Measuring a leader. Journal of Staff Development, 22(1), 32-35.

Vecchio, R. P. (2007). Leadership: Understanding the dynamics of power and influence in organizations $\left(2^{\text {nd }}\right.$ ed.). Notre Dame, IN: University of Notre Dame Press.

Wallace, M. (2000). Integrating cultural and political perspectives: The case of school restructuring in England. Educational Administration Quarterly, 36(4), 608-632.

Weber, M. (2001). Bureaucracy. In J. M. Shafritz \& J. S. Ott (Eds.), Classics of organization theory $\left(5^{\text {th }}\right.$ ed.). Fort Worth, TX: Harcourt College Publishers.

White, B. J. (2007). The nature of leadership: Reptiles, mammals, and the challenge of becoming a great leader. New York: American Management Association.

Wildermuth, C., \& Wildermuth, M. (2006). Beyond rule following: Decoding leadership ethics. Industrial and Commercial Training, 38(6), 297-301.

Wirt, F. M., \& Kirst, M. W. (2001). The political dynamics of American education $\left(2^{\text {nd }}\right.$ ed.). Richmond, CA: McCutchan Publishing Corporation.

Yin, R. K. (1981). The case study as a serious research strategy. Knowledge: Creation, Diffusion, Utilization, 3(1), 97-114.

Yin, R. K. (2003). Case study research: Design and methods ( $3^{\text {rd }}$ ed.). In L. Bickman \& D. J. Rog (Eds.), Applied social research methods series: Vol. 5. Thousand Oaks, CA: Sage.

Yukl, G. A. (2002). Leadership in organizations ( $5^{\text {th }}$ ed.). Upper Saddle River, NJ: Prentice Hall. 


\section{Appendix A}

This outline charts the relationship between the spiritual vision of Ignatius of Loyola and the characteristics of Jesuit education. The twenty-eight characteristics in the second column are ordered in reference to their foundation in the Ignatian vision summarized in nine sections in the first column.

\begin{tabular}{|c|c|}
\hline The Ignatian Vision & Jesuit Education \\
\hline $\begin{array}{l}\text { 1. For Ignatius, God is creator and } \\
\text { Lord, Supreme Goodness, the one } \\
\text { reality that is absolute; all other } \\
\text { reality comes from God and has } \\
\text { value only insofar as it leads us to } \\
\text { God. } \\
\text { This God is present in our lives, } \\
\text { "laboring for us" in all things. } \\
\text { He can be discovered through faith } \\
\text { in all natural and human events, in } \\
\text { history as a whole, and especially in } \\
\text { the lived experiences of each } \\
\text { individual person. }\end{array}$ & $\begin{array}{l}\text { 1.1 World affirming } \\
\text { 1.2 The total formation of each } \\
\text { individual within community } \\
\text { 1.3 Religious dimension permeates the } \\
\text { entire education } \\
\text { 1.4 An apostolic instrument } \\
\text { 1.5 The dialogue between faith and } \\
\text { culture }\end{array}$ \\
\hline $\begin{array}{l}\text { 2. Each man or woman is personally } \\
\text { known and loved by God. This love } \\
\text { invites a response which, to be } \\
\text { authentically human, must be an } \\
\text { expression of a rational freedom. } \\
\text { Therefore, in order to respond to the } \\
\text { love of God, each person is called } \\
\text { to be: } \\
\text { - Free to give of oneself, while } \\
\text { accepting responsibility for and } \\
\text { the consequences of one's } \\
\text { actions: free to be faithful; } \\
\text { - Free to work in faith toward that } \\
\text { true happiness which is the } \\
\text { purpose of life: free to labor } \\
\text { with others in the service of the } \\
\text { Kingdom of God for the healing } \\
\text { of creation. }\end{array}$ & $\begin{array}{l}\text { 2.1 Care and concern for each } \\
\text { individual person } \\
\text { 2.2 Activity of students in the learning } \\
\text { process } \\
\text { 2.3 Life-long openness to growth }\end{array}$ \\
\hline
\end{tabular}




\section{Appendix A (cont.)}

\begin{tabular}{|c|c|}
\hline The Ignatian Vision & Jesuit Education \\
\hline $\begin{array}{l}\text { 3. Because of sin, and the effects of } \\
\text { sin, the freedom to respond to } \\
\text { God's love is not automatic. Aided } \\
\text { and strengthened by the redeeming } \\
\text { love of God, we are engaged in an } \\
\text { ongoing struggle to recognize and } \\
\text { work against the obstacles that } \\
\text { block freedom, including the effects } \\
\text { of sinfulness, while developing the } \\
\text { capacities that are necessary for the } \\
\text { existence of true freedom. } \\
\text { a. This freedom requires a genuine } \\
\text { knowledge, love and acceptance } \\
\text { of self, joined to a } \\
\text { determination to be freed from } \\
\text { any excessive attachment to } \\
\text { wealth, fame, health, power, or } \\
\text { even life itself. } \\
\text { True freedom also requires a } \\
\text { realistic knowledge of the } \\
\text { various forces present in the } \\
\text { surrounding world and includes } \\
\text { freedom from distorted } \\
\text { perceptions of reality, warped } \\
\text { values, rigid attitudes or } \\
\text { surrender to narrow ideologies. } \\
\text { To work toward this freedom, } \\
\text { one must learn to recognize and } \\
\text { deal with the influences that can } \\
\text { promote or limit freedom: the } \\
\text { movements within one's own } \\
\text { heart; past experiences of all } \\
\text { types; interactions with other } \\
\text { people; the dynamics of history, } \\
\text { social structures and culture. }\end{array}$ & $\begin{array}{l}\text { 3.1 Value-oriented } \\
\text { 3.2 A realistic knowledge, love, and } \\
\text { acceptance of self } \\
\text { 3.3 A realistic knowledge of the world }\end{array}$ \\
\hline
\end{tabular}




\section{Appendix A (cont.)}

\begin{tabular}{|c|c|}
\hline The Ignatian Vision & Jesuit Education \\
\hline $\begin{array}{l}\text { 4. The world-view of Ignatius is } \\
\text { centered on the historical person of } \\
\text { Jesus. He is the model for human life } \\
\text { because of his total response to the } \\
\text { Father's love, in the service of others. } \\
\text { He shares our human condition and } \\
\text { invites us to follow him, under the } \\
\text { standard of the cross, in loving } \\
\text { response to the Father. } \\
\text { He is alive in our midst, and remains } \\
\text { the Man for others in the service of } \\
\text { God. }\end{array}$ & $\begin{array}{l}\text { 4.1 Proposes Christ as the model of } \\
\text { human life } \\
\text { 4.2 Pastoral care } \\
\text { 4.3 Prayer and worship }\end{array}$ \\
\hline $\begin{array}{l}\text { 5. A loving and free response to God's } \\
\text { love cannot be merely speculative or } \\
\text { theoretical. No matter what the cost, } \\
\text { speculative principles must lead to } \\
\text { decisive action: "love is shown in } \\
\text { deeds". } \\
\text { Ignatius asks for total and active } \\
\text { commitment of men and women who, } \\
\text { to imitate and be more like Christ, } \\
\text { will put their ideals into practice in } \\
\text { the real world of ideas, social } \\
\text { movements, the family, business, } \\
\text { political and legal structures, and } \\
\text { religious activities. }\end{array}$ & $\begin{array}{l}\text { 5.1 Active life commitment } \\
\text { 5.2 Education in the service of the } \\
\text { faith that does justice } \\
\text { 5.3 Men and women for others } \\
\text { 5.4 Manifests a particular concern for } \\
\text { the poor }\end{array}$ \\
\hline $\begin{array}{l}\text { 6. For Ignatius, the response to the call } \\
\text { of Christ is in and through the } \\
\text { Catholic Church, the instrument } \\
\text { through which Christ is sacramentally } \\
\text { present in the world. } \\
\text { Ignatius put the Society of Jesus at } \\
\text { the service of the pope, "to go to any } \\
\text { place whatsoever where he judges it } \\
\text { expedient to send them for the greater } \\
\text { glory of God and the good of souls". }\end{array}$ & $\begin{array}{l}\text { 6.1 An apostolic instrument in service } \\
\text { of the Church } \\
\text { 6.2 Active participation in the Church }\end{array}$ \\
\hline
\end{tabular}


Appendix A (cont.)

\begin{tabular}{|c|c|}
\hline The Ignatian Vision & Jesuit Education \\
\hline $\begin{array}{l}\text { 7. Repeatedly, Ignatius insisted on the } \\
\text { "magis" - the more. His constant } \\
\text { concern was for greater service of } \\
\text { God through a closer following of } \\
\text { Christ, and that concern flowed into } \\
\text { all the apostolic work of the first } \\
\text { companions. The concrete response } \\
\text { to God must be "of greater value". }\end{array}$ & $\begin{array}{l}\text { 7.1 Excellence in formation } \\
7.2 \text { Witness to excellence }\end{array}$ \\
\hline $\begin{array}{l}\text { 8. As Ignatius came to know the love } \\
\text { of God revealed through Christ and } \\
\text { began to respond by giving himself } \\
\text { to the service of the Kingdom of } \\
\text { God, he shared his experience and } \\
\text { attracted companions who became } \\
\text { "friends in the Lord", in the service } \\
\text { of others. } \\
\text { The strength of the community } \\
\text { working in service of the Kingdom } \\
\text { is greater than that of any individual } \\
\text { or group of individuals. }\end{array}$ & $\begin{array}{l}\text { 8.1 Lay-Jesuit collaboration } \\
\text { 8.2 Relies on a spirit of community } \\
\text { among: teaching staff and } \\
\text { administrators; the Jesuit } \\
\text { community; governing boards; } \\
\text { parents; students; former students; } \\
\text { benefactors. } \\
\text { 8.3 Takes place within a school } \\
\text { structure that promotes } \\
\text { community. }\end{array}$ \\
\hline $\begin{array}{l}\text { 9. For Ignatius and for his } \\
\text { companions, decisions were made } \\
\text { on the basis of an ongoing process } \\
\text { of individual and communal } \\
\text { "discernment" done always in a } \\
\text { context of prayer. Through } \\
\text { prayerful reflection on the results of } \\
\text { their activities, the companions } \\
\text { reviewed past decisions and made } \\
\text { adaptations in their methods, in a } \\
\text { constant search for greater service } \\
\text { to God ["magis"]. }\end{array}$ & $\begin{array}{l}\text { 9.1 Adapts means and methods in } \\
\text { order to achieve the purposes of } \\
\text { Jesuit education. } \\
\text { 9.2 The Jesuit "system" of schools } \\
\text { 9.3 Professional training and ongoing } \\
\text { formation }\end{array}$ \\
\hline
\end{tabular}


Appendix B

\section{LEADERSHIP ORIENTATIONS (SELF)}

C 1990, Lee G. Bolman and Terrence E. Deal, all rights reserved

This questionnaire asks you to describe your leadership and management style.

\section{Leader Behaviors}

You are asked to indicate how often each of the items below is true of you.

Please use the following scale in answering each item.

1

Never
2

3

Sometimes
4

5

Always

Occasionally

Often

So, you would answer ' 1 ' for an item that is never true of you, ' 2 ' for one that is occasionally true, ' 3 ' for one that is sometimes true of you, and so on.

Be discriminating! Your results will be more helpful if you think about each item and distinguish the things that you really do all the time from the things that you do seldom or never.

1. Think very clearly and logically.

2. Show high levels of support and concern for others.

3. Have exceptional ability to mobilize people and resources to get things done.

4. ___ Inspire others to do their best.

5.___ Strongly emphasize careful planning and clear time lines.

6.___ Build trust through open and collaborative relationships.

7.___ Am a very skillful and shrewd negotiator.

8. ___ Am highly charismatic.

9.___ Approach problems through logical analysis and careful thinking.

10.___ Show high sensitivity and concern for others' needs and feelings. 


\section{Appendix B (cont.)}

11.____ Am unusually persuasive and influential.

12. Am able to be an inspiration to others.

13.___ Develop and implement clear, logical policies and procedures.

14.___ Foster high levels of participation and involvement in decisions.

15.___ Anticipate and deal adroitly with organizational conflict.

16.___ Am highly imaginative and creative.

17.___ Approach problems with facts and logic.

18.___ Am consistently helpful and responsive to others.

19.___ Am very effective in getting support from people with influence and power.

20. Communicate a strong and challenging sense of vision and mission.

21.___ Set specific, measurable goals and hold people accountable for results.

22. L__ Listen well and am unusually receptive to other people's ideas and input.

23.____ Am politically very sensitive and skillful.

24._See beyond current realities to generate exciting new opportunities.

25._Have extraordinary attention to detail.

26.___ Give personal recognition for work well done.

27.___ Develop alliances to build a strong base of support.

28.___ Generate loyalty and enthusiasm.

29._Strongly believe in clear structure and a chain of command.

30._Am a highly participative manager.

31._Succeed in the face of conflict and opposition.

32. Serve as an influential model of organizational aspirations and values. 


\section{Appendix B (cont.)}

\section{Leadership Style}

For each item, give the number "4" to the phrase that best describes you, " 3 " to the item that is next best, and on down to "1" for the item that is least like you.

1. My strongest skills are:

a. Analytic skills

b. Interpersonal skills

c. Political skills

d. Ability to excite and motivate

2. The best way to describe me is:

a. Technical expert

b. Good listener

c. Skilled negotiator

d. Inspirational leader

3. What has helped me the most to be successful is my ability to:

a. Make good decisions

b. Coach and develop people

c. Build strong alliances and a power base

d. Energize and inspire others

4. What people are most likely to notice about me is my:

a. Attention to detail

b. Concern for people

c. Ability to succeed, in the face of conflict and opposition

d. Charisma. 
Appendix B (cont.)

5. My most important leadership trait is:

a. Clear, logical thinking

b. Caring and support for others

c. Toughness and aggressiveness

d. Imagination and creativity

6. I am best described as:

a. An analyst

b. A humanist

c. A politician

d. A visionary

\section{Overall rating}

Compared to other individuals that you have known with comparable levels of experience and responsibility, how would you rate yourself on:

1. Overall effectiveness as a manager.

$\begin{array}{lllll}1 & 3 & 4 & 5\end{array}$

Bottom 20\% $\quad$ Middle 20\% $\quad$ Top 20\%

2. Overall effectiveness as a leader.

$\begin{array}{lllll}1 & 2 & 3 & 4 & 5\end{array}$

$\begin{array}{lll}\text { Bottom 20\% } & \text { Middle 20\% } 20 \%\end{array}$ 
Appendix C

\section{LEADERSHIP ORIENTATIONS (OTHER)}

(C) 1990, Lee G. Bolman and Terrence E. Deal, all rights reserved

This questionnaire asks you to describe Fr. Marcelino García, S.J. in terms of leadership and management style.

\section{Leader Behaviors}

You are asked to indicate how often each item is true of Fr. Marcelino García.

Please use the following scale in answering each item.

1 2

3

4

5

Never

Sometimes

Always

Occasionally

Often

So, you would answer ' 1 ' for an item that is never true of the person you are describing, ' 2 ' for one that is occasionally true, ' 3 ' for one that is sometimes true, and so on.

Be discriminating! The results will be more helpful to the ratee if you think about each item and distinguish the things that the ratee really does all the time from the things that $\mathrm{s} /$ he does seldom or never.

1. Thinks very clearly and logically.

2.___ Shows high levels of support and concern for others.

3. Shows exceptional ability to mobilize people and resources to get things done.

4. Inspires others to do their best.

5.___ Strongly emphasizes careful planning and clear time lines.

6.___ Builds trust through open and collaborative relationships.

7. Is Is a very skillful and shrewd negotiator.

8. Is highly charismatic.

9.___ Approaches problems through logical analysis and careful thinking.

10.___ Shows high sensitivity and concern for others' needs and feelings. 


\section{Appendix C (cont.)}

11._Is unusually persuasive and influential.

12. Is an inspiration to others.

13. ___ Develops and implements clear, logical policies and procedures.

14. F__ Fosters high levels of participation and involvement in decisions.

15.___ Anticipates and deals adroitly with organizational conflict.

16. Is highly imaginative and creative.

17.___ Approaches problems with facts and logic.

18.___ Is consistently helpful and responsive to others.

19.___ Is very effective in getting support from people with influence and power.

20. Communicates a strong and challenging vision and sense of mission.

21.___ Sets specific, measurable goals and holds people accountable for results.

22. L__ Listens well and is unusually receptive to other people's ideas and input.

23. Is politically very sensitive and skillful.

24.___ Sees beyond current realities to create exciting new opportunities.

25. Has extraordinary attention to detail.

26. ___ Gives personal recognition for work well done.

27.___ Develops alliances to build a strong base of support.

28.___ Generates loyalty and enthusiasm.

29._Strongly believes in clear structure and a chain of command.

30. Is a highly participative manager.

31. Succeeds in the face of conflict and opposition.

32. Serves as an influential model of organizational aspirations and values. 


\section{Appendix C (cont.)}

\section{Leadership Style}

For each item, give the number "4" to the phrase that best describes Fr. García, "3" to the item that is next best, and on down to " 1 " for the item that is least like this person.

1. The individual's strongest skills are:

a. Analytic skills

b. Interpersonal skills

c. Political skills

d. Ability to excite and motivate

2. The best way to describe this person is:

a. Technical expert

b. Good listener

c. Skilled negotiator

d. Inspirational leader

3. What this individual does best is:

a. Make good decisions

b. Coach and develop people

c. Build strong alliances and a power base

d. Energize and inspire others

4. What people are most likely to notice about this person is:

a. Attention to detail

b. Concern for people

c. Ability to succeed, in the face of conflict and opposition

d. Charisma 


\section{Appendix C (cont.)}

5. This individual's most important leadership trait is:

a. Clear, logical thinking

b. Caring and support for others

c. Toughness and aggressiveness

d. Imagination and creativity

6. This person is best described as:

a. An analyst

b. A humanist

c. A politician

d. A visionary

\section{Overall rating}

Compared to other individuals that you have known with comparable levels of experience and responsibility, how would you rate Fr. García on:

1. Overall effectiveness as a manager.

$\begin{array}{lllll}1 & 2 & 3 & 4 & 5\end{array}$

Bottom 20\% $\quad$ Middle 20\% $\quad$ Top 20\%

2. Overall effectiveness as a leader.

$\begin{array}{lllll}1 & 2 & 3 & 4 & 5\end{array}$

$\begin{array}{lll}\text { Bottom 20\% } & \text { Middle 20\% } 20 \%\end{array}$ 


\section{Appendix D}

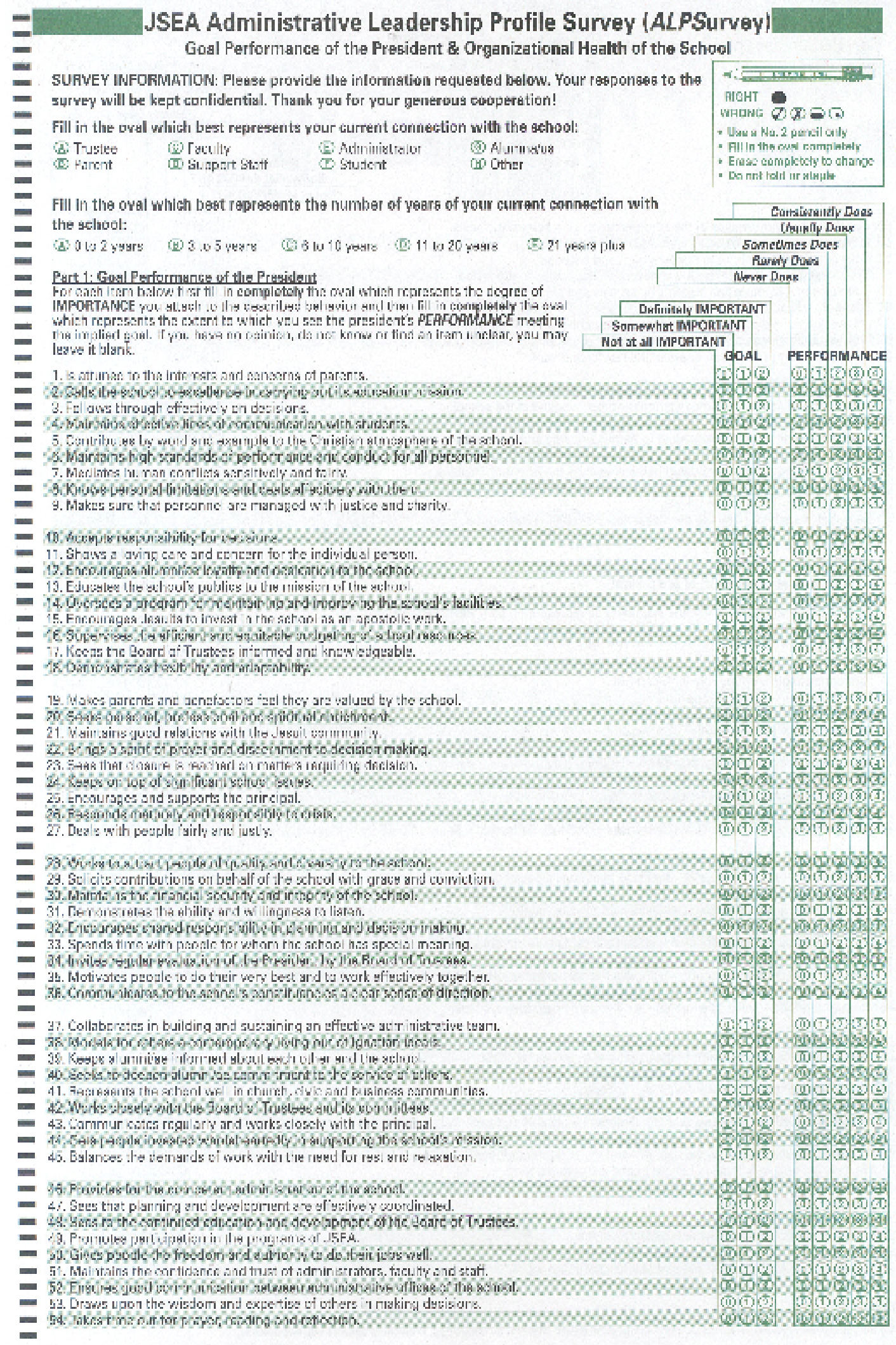




\section{Appendix D (cont.)}

ALPSurvey

Goal Performance of the President (page 2)

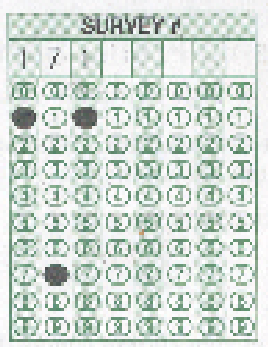

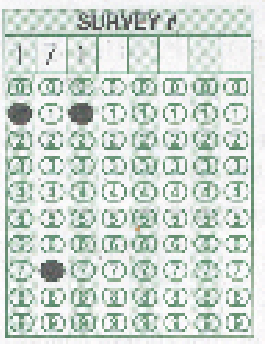

Fo omice
uns : : iny.
Do wo.
numk.

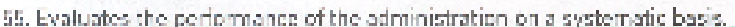

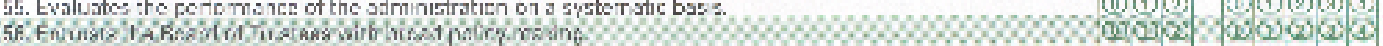

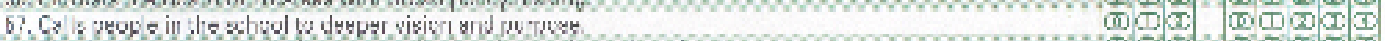

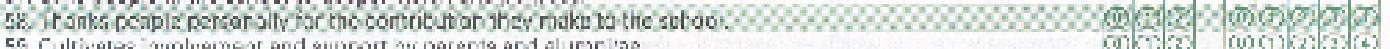

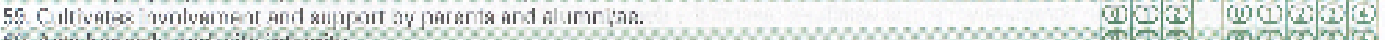

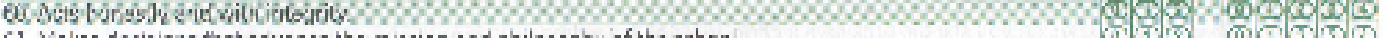

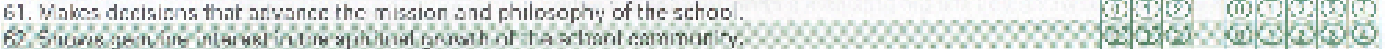

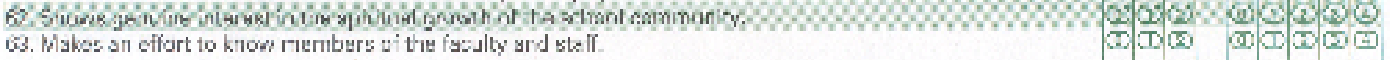

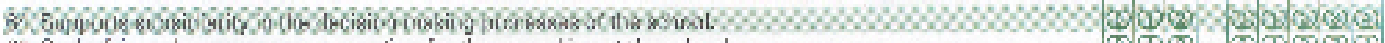

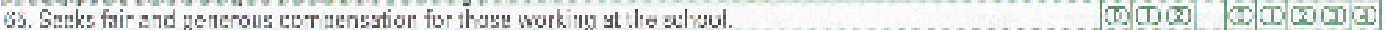

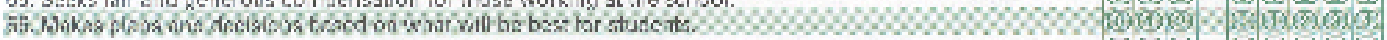

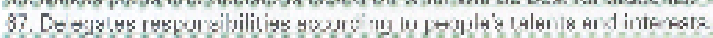

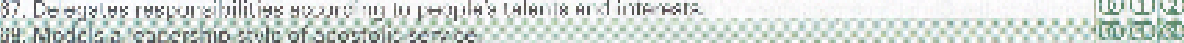

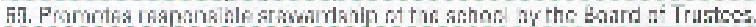

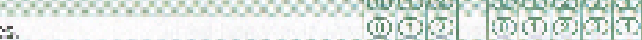

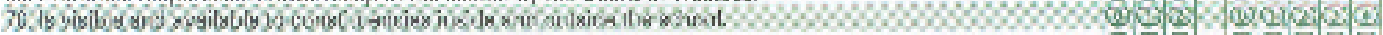

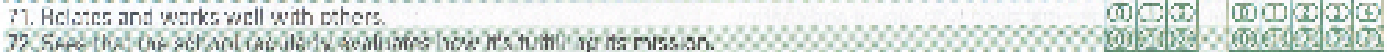

\section{Then}

Past 2: Orgonizational Heslth af the School

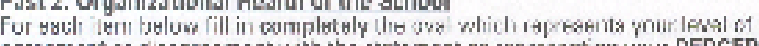

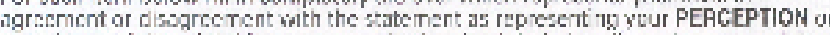

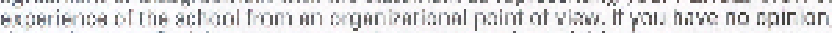
de ot krow or fod the staterne't unz eyr, wou myy leswe it blynk.

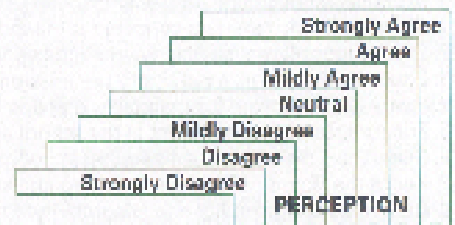

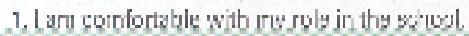

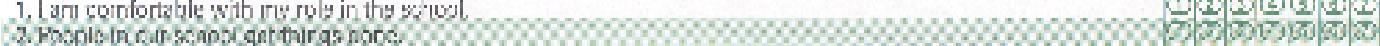

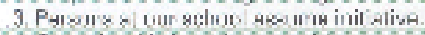

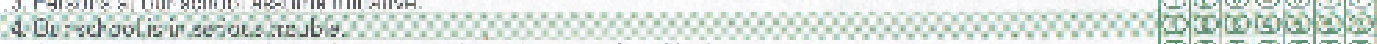

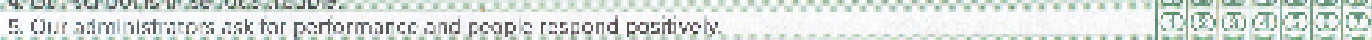

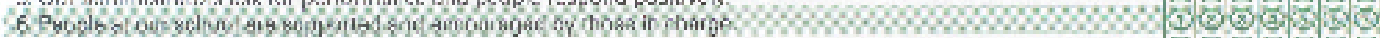

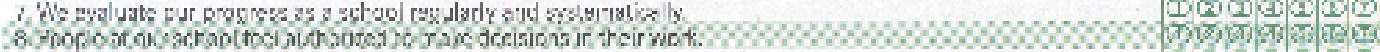

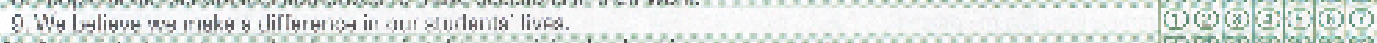

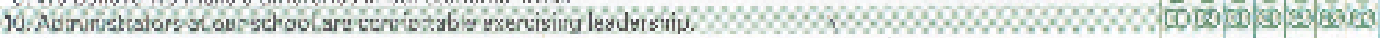

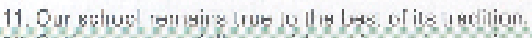

(1) (2) 2 ; (1) (1)

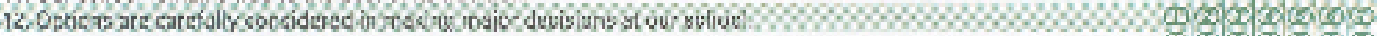

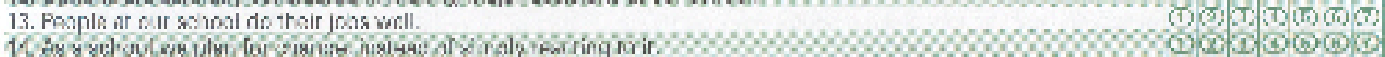

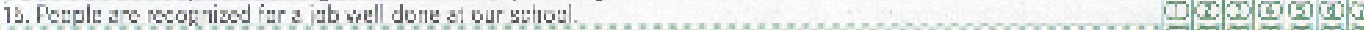

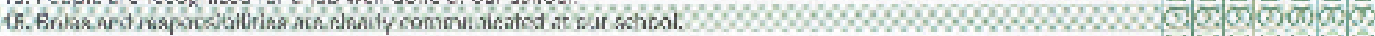

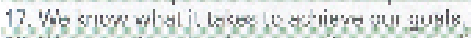

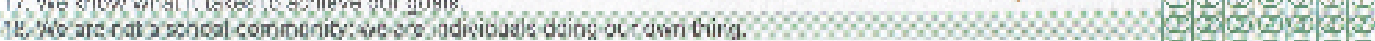

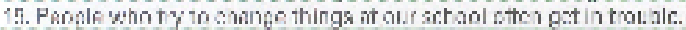

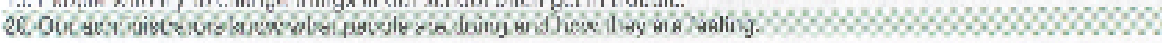

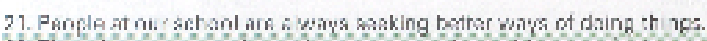

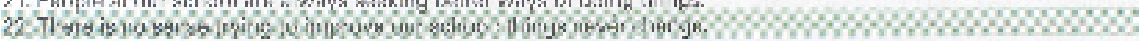

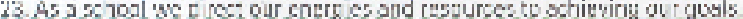

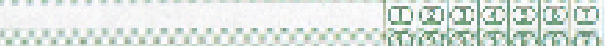

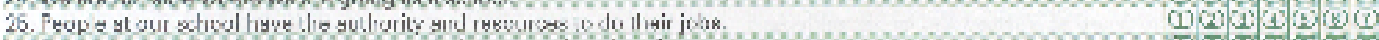

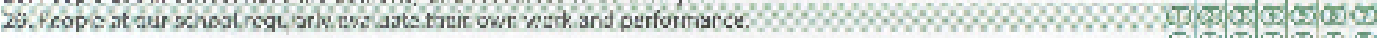

77. Wh have détinita gen 8.69 a sthanl.

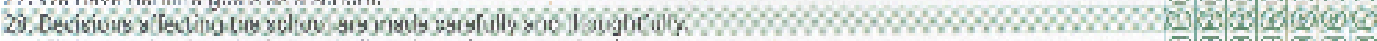

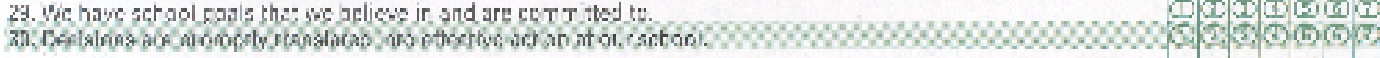

37. Intemal conmunisat on in oL.rachaol is gocd.

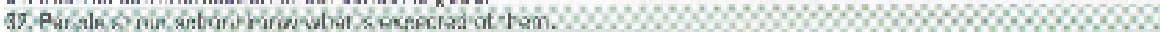

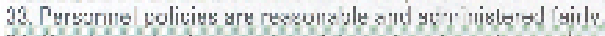

T4 our 


\section{Appendix E}

Semi-structured Interview Guide for Fr. Marcelino García, S.J.

1. What do you consider to be some of the most important responsibilities of a high school president?

2. Tell me about your 25 year tenure as the president of Belen Jesuit Preparatory School?

3. Why do you think you have lasted so long as president?

4. Describe a success. (Repeat until he has no more stories)

a. What are the factors that contributed to that particular success?

b. What have you learned from this success?

5. Describe a challenge. (Repeat until he has no more stories)

a. What are the factors that helped you overcome this challenge?

b. What have you learned from this challenge?

6. Describe the process you use to develop the goals for your administration.

7. What is your relationship between your faculty, staff, and administration?

8. How do you work with each stakeholder community of the school?

9. Belen has a very long and rich tradition, what challenges or opportunities does that present to you as president?

10. Where do you see Belen ten years from now?

11. Describe Jesuit leadership. How is it different than other forms of leadership?

12. Is there anything that you would like to add?

13. Is there anything I should have asked you but didn't? 


\section{Appendix F}

\section{Semi-structured Interview Guide for Secondary Interviews}

1. What do you consider to be some of the most important responsibilities of a high school president?

2. Referring to the years that you have been associated with Fr. Marcelino García, tell me about his presidency.

3. Why do you think that he has lasted so long as president?

4. Describe a success. (Repeat until he/she has no more stories) - What are the factors that contributed to that particular success?

5. Describe a challenge. (Repeat until he/she has no more stories) - What are the factors that contributed to overcoming that challenge?

6. Describe the process Fr. García uses to develop the goals of his administration.

7. Describe his working relationship with the administration/faculty/staff/alumni/parents/Jesuit community. Are they involved in decision-making?

8. How do you see him working with each stakeholder community of the school?

9. Belen has a very long and rich tradition, what challenges or opportunities does that present to Fr. García's administration?

10. Where do you see Belen ten years from now?

11. Describe Jesuit leadership. How is it different than other forms of leadership?

12. Is there anything that you would like to add?

13. Is there anything I should have asked you but didn't? 
Appendix G

Coding Rubric

\begin{tabular}{|c|c|c|c|}
\hline $\begin{array}{l}\text { Data } \\
\text { Analysis } \\
\text { Code }\end{array}$ & $\begin{array}{c}\text { Leadership } \\
\text { Frame }\end{array}$ & Definition & Evidence \\
\hline $\mathrm{ST}$ & Structural & $\begin{array}{l}\text { Structural Frame } \\
\text { encompasses the analytic } \\
\text { and organized dimensions } \\
\text { of leadership. }\end{array}$ & $\begin{array}{l}\text { - Analytic - the ability to } \\
\text { think clearly and logically, } \\
\text { approaching problems } \\
\text { with facts, focused on } \\
\text { details } \\
\text { - Organized - the ability to } \\
\text { develop clear goals, } \\
\text { holding people } \\
\text { accountable }\end{array}$ \\
\hline HR & $\begin{array}{c}\text { Human } \\
\text { Resource }\end{array}$ & $\begin{array}{l}\text { Human Resource Frame } \\
\text { encompasses the } \\
\text { supportive and } \\
\text { participative dimensions } \\
\text { of leadership. }\end{array}$ & $\begin{array}{l}\text { - Supportive - concerned } \\
\text { with and respond to the } \\
\text { feelings of subordinates } \\
\text { - Participative - fosters } \\
\text { participation and } \\
\text { involvement, listens to } \\
\text { new ideas }\end{array}$ \\
\hline $\mathrm{PO}$ & Political & $\begin{array}{l}\text { Political Frame } \\
\text { encompasses the powerful } \\
\text { and adroit dimensions of } \\
\text { leadership. }\end{array}$ & $\begin{array}{l}\text { Powerful - persuasive, } \\
\text { successful at mobilizing } \\
\text { people and resources, } \\
\text { ability to network } \\
\text { - Adroit - skillful, expert } \\
\text { negotiator in moments of } \\
\text { conflict }\end{array}$ \\
\hline SY & Symbolic & $\begin{array}{l}\text { Symbolic Frame } \\
\text { encompasses the } \\
\text { inspirational and } \\
\text { charismatic dimensions of } \\
\text { leadership. }\end{array}$ & $\begin{array}{l}\text { Inspirational - inspires } \\
\text { loyalty and enthusiasm, } \\
\text { communicates vision } \\
\text { - Charismatic - imaginative, } \\
\text { emphasizes culture and } \\
\text { values }\end{array}$ \\
\hline
\end{tabular}


Appendix G (cont.)

\begin{tabular}{|c|c|c|c|}
\hline $\begin{array}{c}\text { Data } \\
\text { Analysis } \\
\text { Code }\end{array}$ & $\begin{array}{c}\text { Jesuit } \\
\text { High School } \\
\text { Leadership }\end{array}$ & Definition & Evidence \\
\hline LD & Leadership & $\begin{array}{l}\text { Leadership is the } \\
\text { ability to communicate } \\
\text { a clear sense of } \\
\text { direction and } \\
\text { encourages adherence } \\
\text { to school mission and } \\
\text { goals. }\end{array}$ & $\begin{array}{l}\text { Vision - communicates } \\
\text { sense of direction, } \\
\text { inspires appreciation of } \\
\text { school goals and mission } \\
\text { - Inspiration - motivates } \\
\text { excellence, cooperation, } \\
\text { commitment, investment }\end{array}$ \\
\hline OG & Open to Growth & $\begin{array}{l}\text { Open to Growth is the } \\
\text { ability to understand } \\
\text { limitations and to } \\
\text { desire personal } \\
\text { development. }\end{array}$ & $\begin{array}{l}\text { - Deals well with personal } \\
\text { limitations } \\
\text { - Flexible - adaptable and } \\
\text { open to change } \\
\text { - Continuous formation - } \\
\text { understand the need for } \\
\text { personal, professional, } \\
\text { and spiritual } \\
\text { development }\end{array}$ \\
\hline $\mathrm{PC}$ & $\begin{array}{l}\text { Professional } \\
\text { Competence }\end{array}$ & $\begin{array}{l}\text { Professional } \\
\text { Competence is the } \\
\text { ability to secure the } \\
\text { well being of the } \\
\text { school. }\end{array}$ & $\begin{array}{l}\text { Proficient - in } \\
\text { administration, } \\
\text { institutional integrity, } \\
\text { and financial well being } \\
\text { of the school } \\
\text { - Coordinator - oversees } \\
\text { planning, development } \\
\text { and public relations }\end{array}$ \\
\hline $\mathrm{LC}$ & $\begin{array}{l}\text { Loving and } \\
\text { Caring }\end{array}$ & $\begin{array}{l}\text { Loving and Caring is } \\
\text { the ability to make } \\
\text { subordinates feel like } \\
\text { valued members of the } \\
\text { community. }\end{array}$ & $\begin{array}{ll}\text { - } & \text { Relates and works well } \\
\text { with others } \\
\text { - Visible - is present and } \\
\text { accessible } \\
\text { - Supportive - helps } \\
\text { people feel they are a } \\
\text { valued member of the } \\
\text { community }\end{array}$ \\
\hline IV & Ignatian Vision & $\begin{array}{l}\text { Ignatian Vision refers } \\
\text { to the adherence to the } \\
\text { characteristics of Jesuit } \\
\text { education. }\end{array}$ & $\begin{array}{l}\text { - Religious - contribute to } \\
\text { the Catholic/Christian } \\
\text { identity of the school } \\
\text { - Value-oriented - } \\
\text { inspires confidence, } \\
\text { trust, acts with integrity }\end{array}$ \\
\hline
\end{tabular}


Appendix G (cont.)

\begin{tabular}{|c|c|c|c|}
\hline $\begin{array}{c}\text { Data } \\
\text { Analysis } \\
\text { Code } \\
\end{array}$ & $\begin{array}{c}\text { Jesuit } \\
\text { High School } \\
\text { Leadership }\end{array}$ & Definition & Evidence \\
\hline IA & In Action & $\begin{array}{l}\text { In Action refers to the } \\
\text { ability to put ideals into } \\
\text { practice. }\end{array}$ & $\begin{array}{l}\text { - Stewardship - promotes } \\
\text { generous service to } \\
\text { others } \\
\text { - Apostolic - motivates } \\
\text { community and social } \\
\text { service }\end{array}$ \\
\hline $\mathrm{CO}$ & Communications & $\begin{array}{l}\text { Communications is the } \\
\text { ability to correspond } \\
\text { effectively with all } \\
\text { school stakeholders. }\end{array}$ & $\begin{array}{l}\text { - Attuned to the interests } \\
\text { and concerns of the } \\
\text { school community } \\
\text { - Contact - in touch with } \\
\text { all school stakeholders }\end{array}$ \\
\hline DM & Decision Making & $\begin{array}{l}\text { Decision Making is the } \\
\text { ability to make sound } \\
\text { decisions. }\end{array}$ & $\begin{array}{l}\text { Planning - encourages } \\
\text { responsible planning } \\
\text { that leads to good } \\
\text { decisions } \\
\text { - Implements - follows } \\
\text { through, holds people } \\
\text { and self accountable } \\
\text { - Delegates - understands } \\
\text { subordinates and } \\
\text { distributes responsibility } \\
\text { appropriately }\end{array}$ \\
\hline
\end{tabular}




\section{Appendix $\mathrm{H}$}

\section{President's Performance in Leadership}
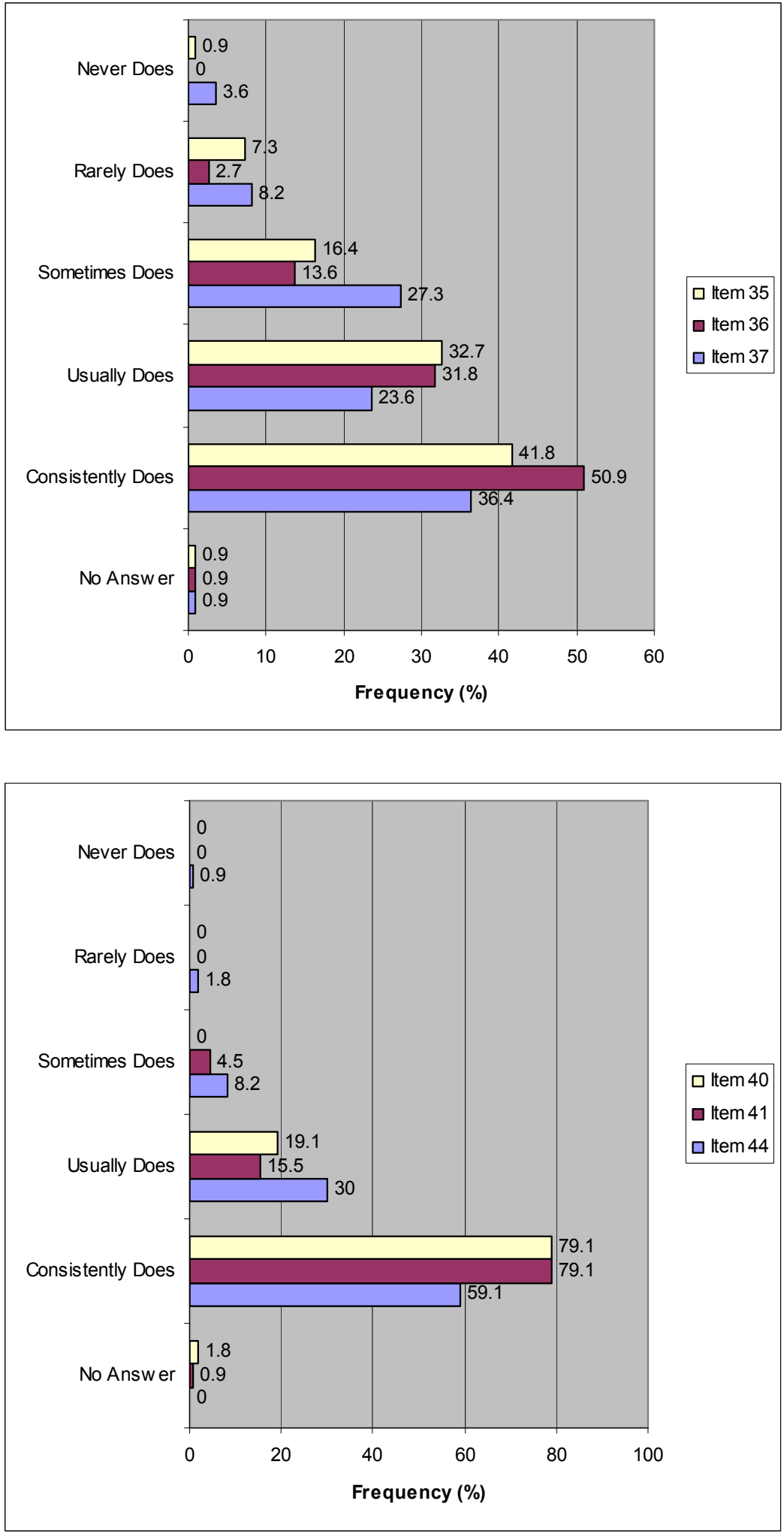


\section{Appendix H (cont.)}

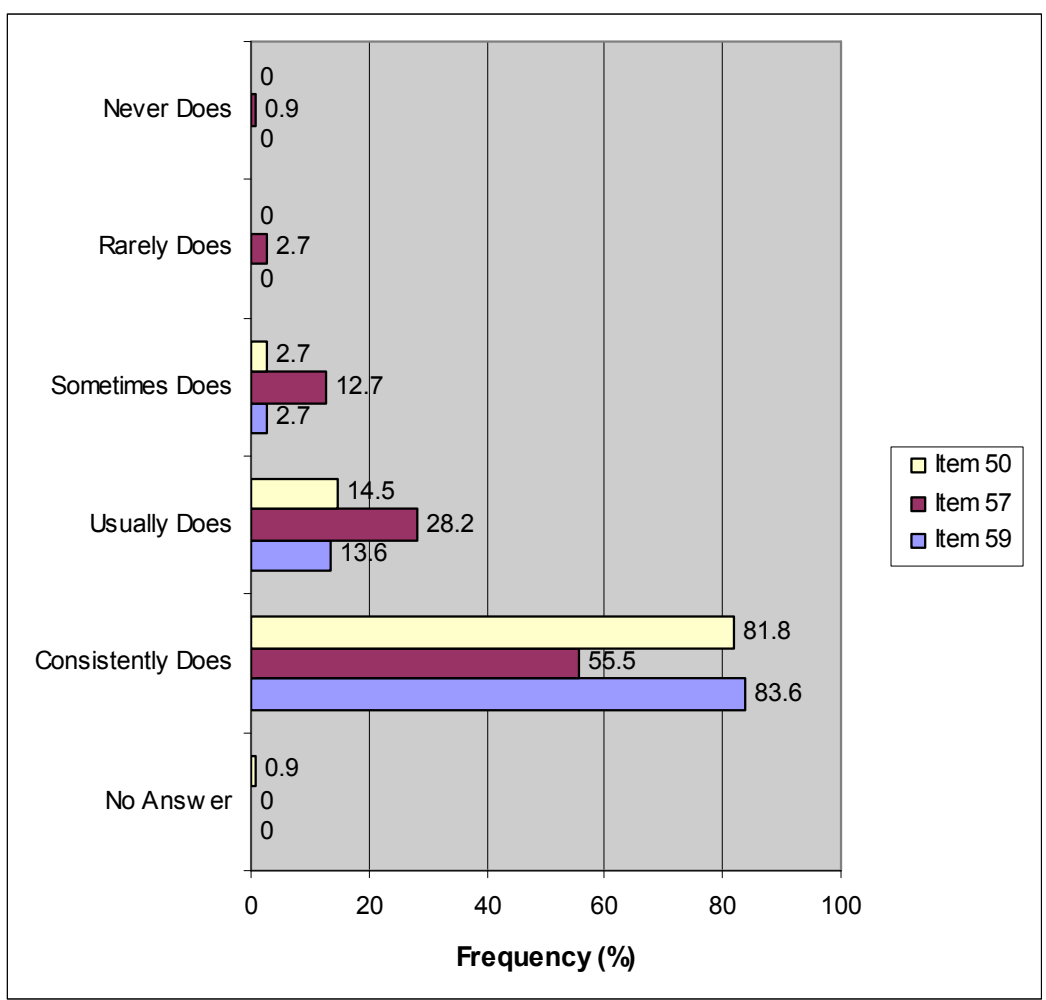

President's Performance in Open to Growth

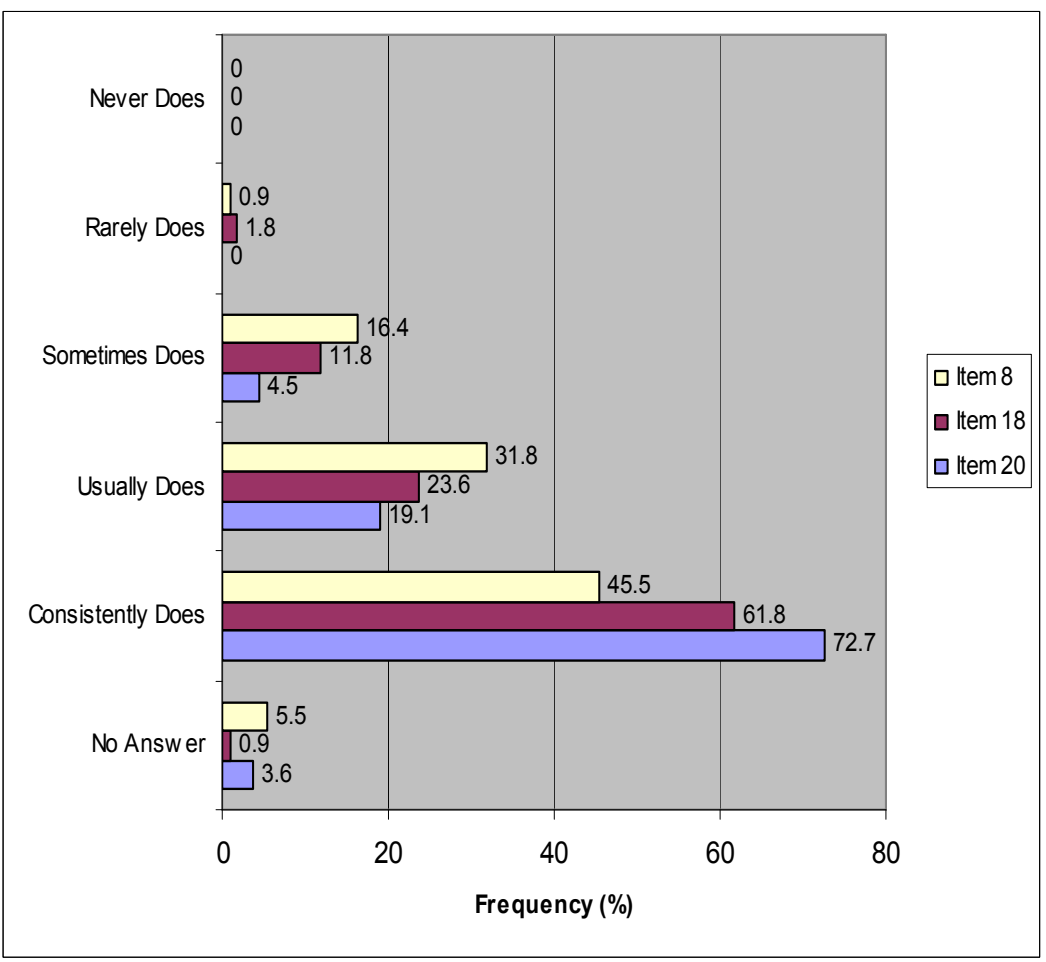




\section{Appendix H (cont.)}
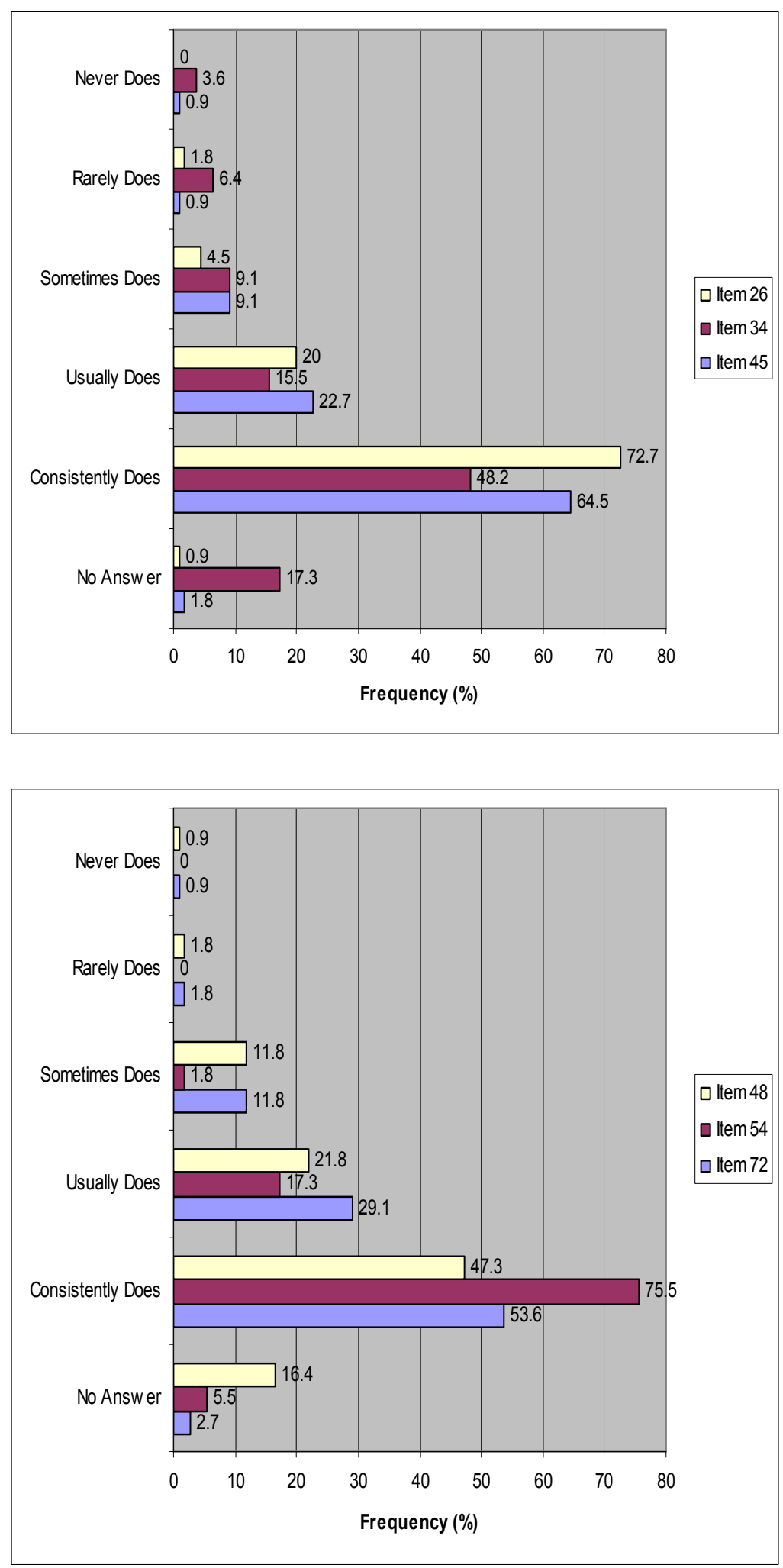


\section{Appendix H (cont.)}

President's Performance in Professional Competence
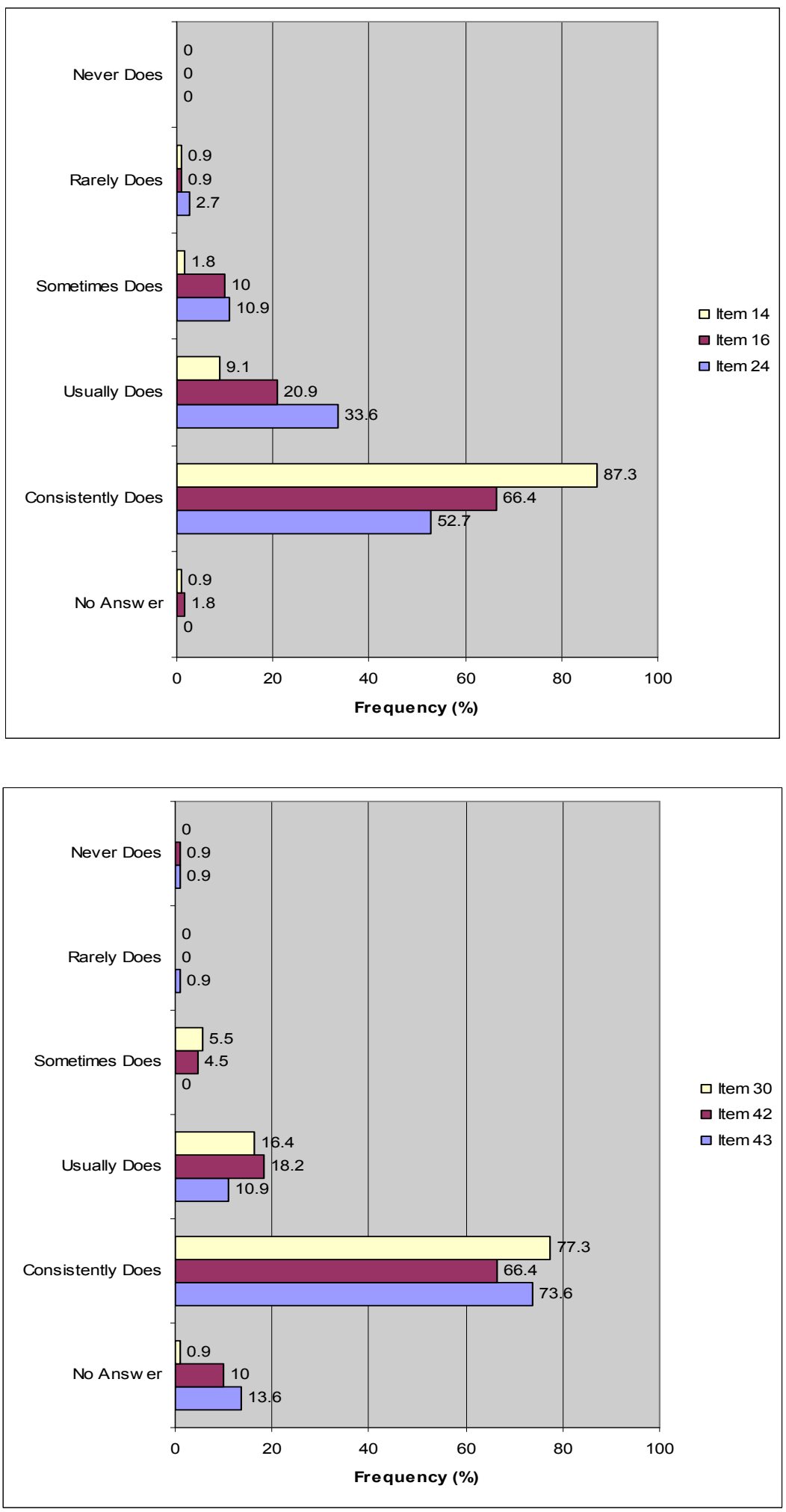
Appendix H (cont.)

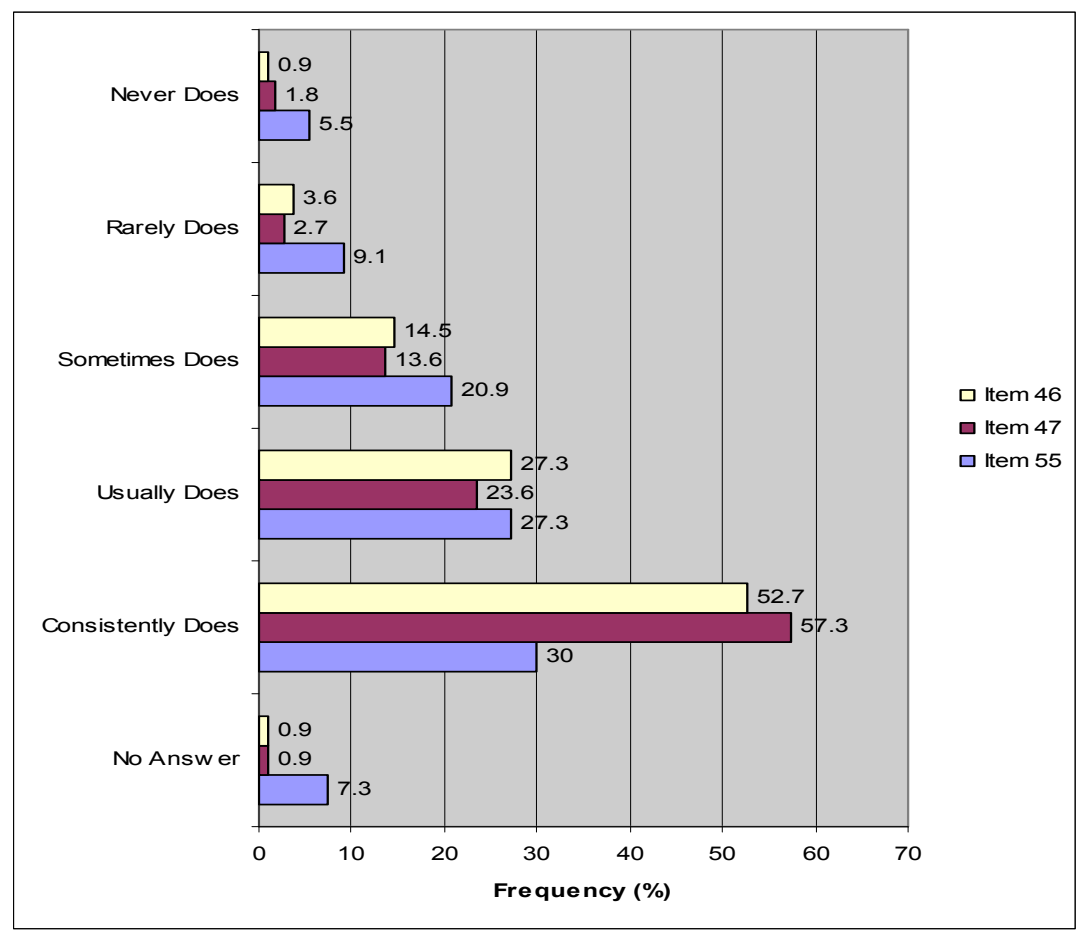

President's Performance in Loving and Caring

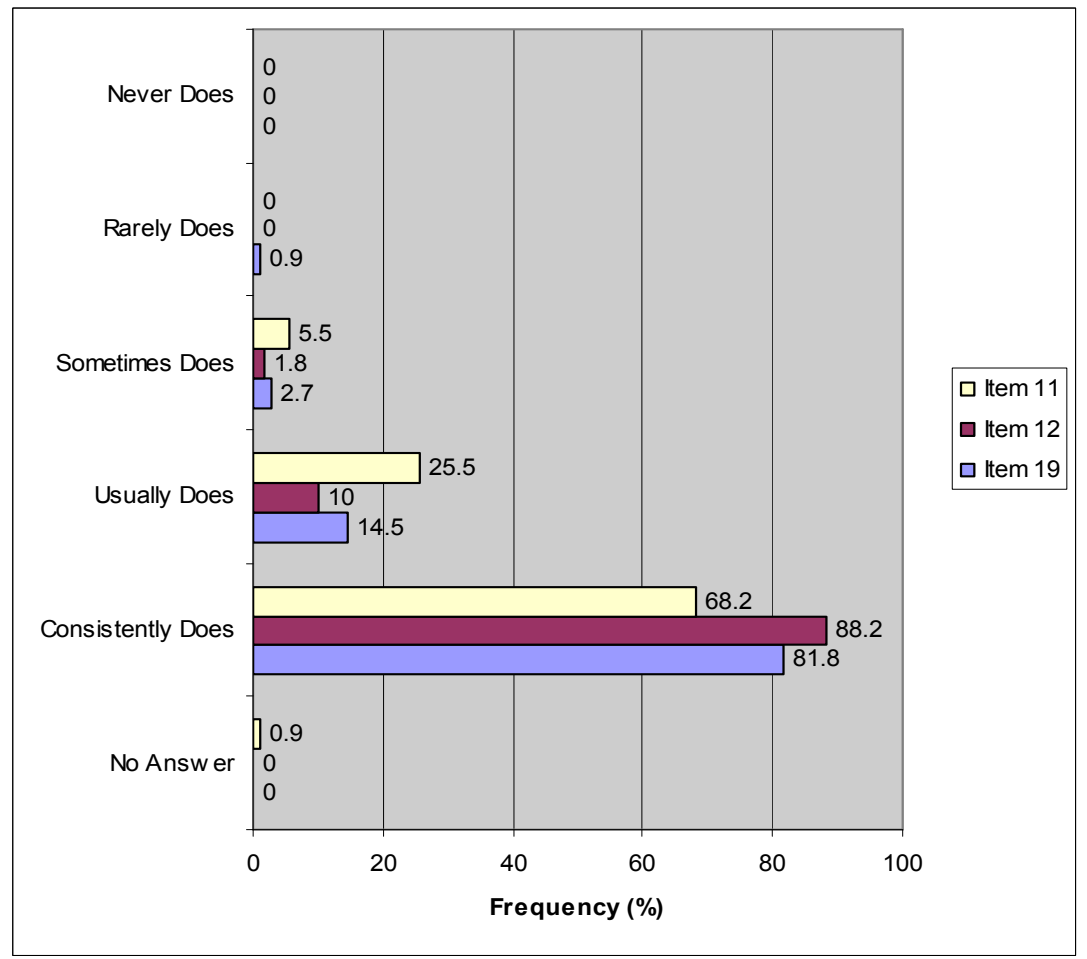




\section{Appendix H (cont.)}
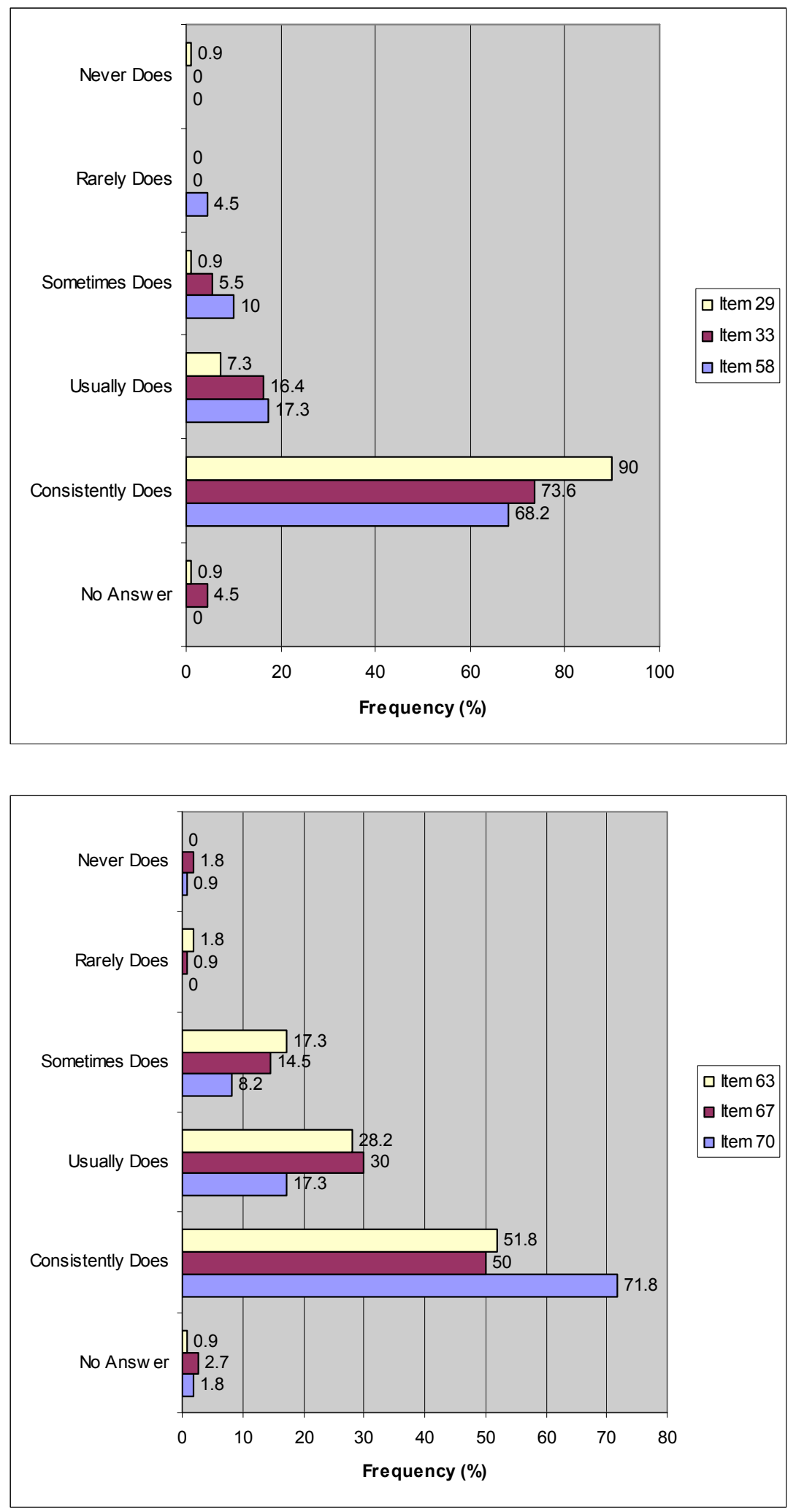


\section{Appendix H (cont.)}

\section{President's Performance in Ignatian Vision}
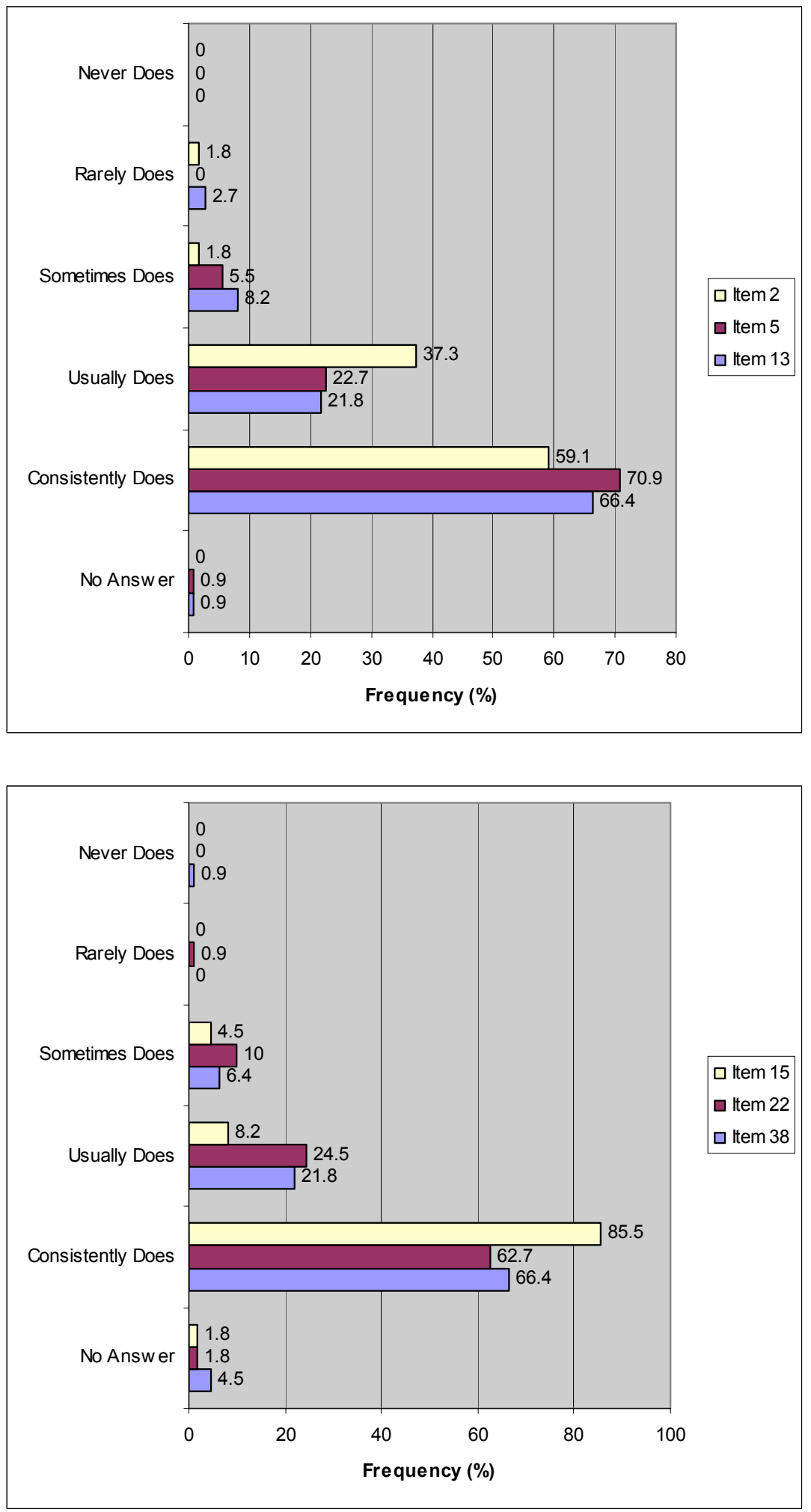


\section{Appendix H (cont.)}

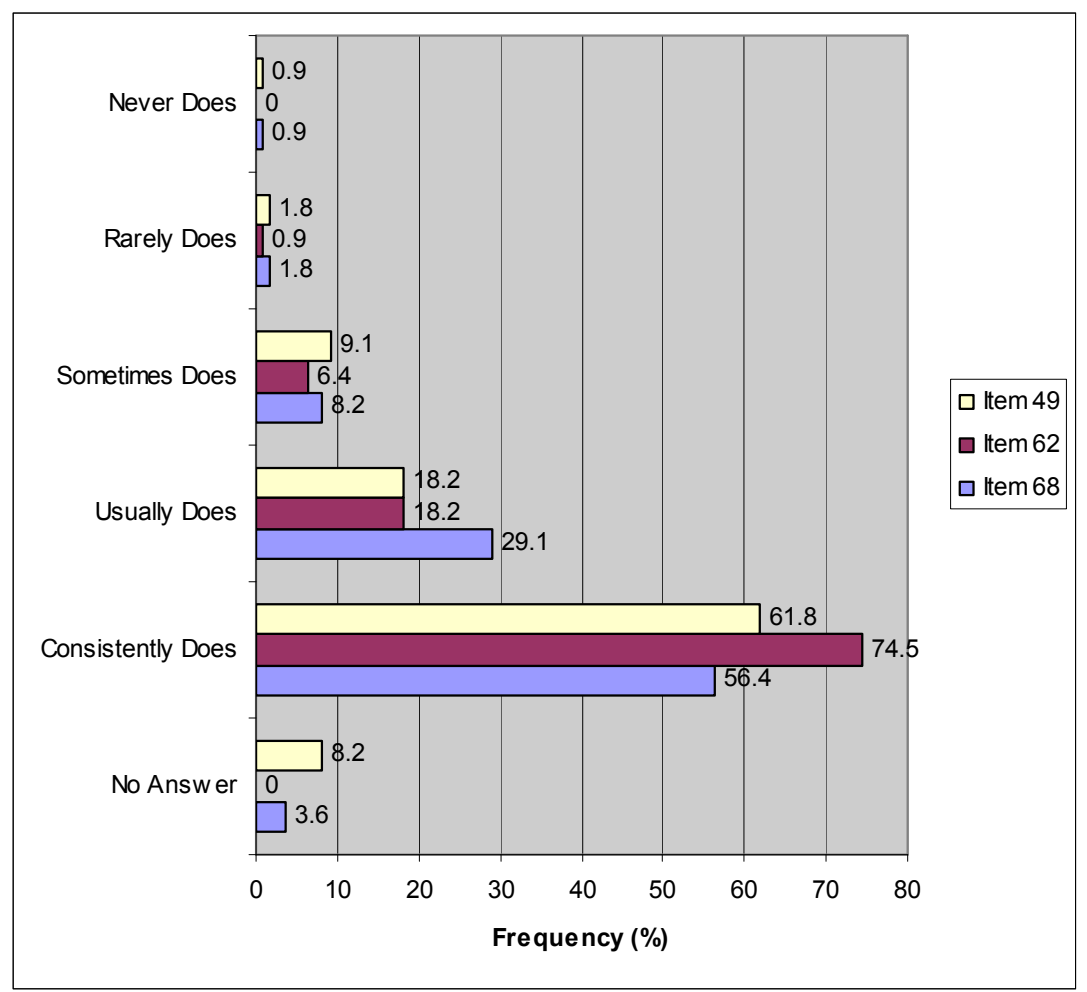

\section{President's Performance in In Action}

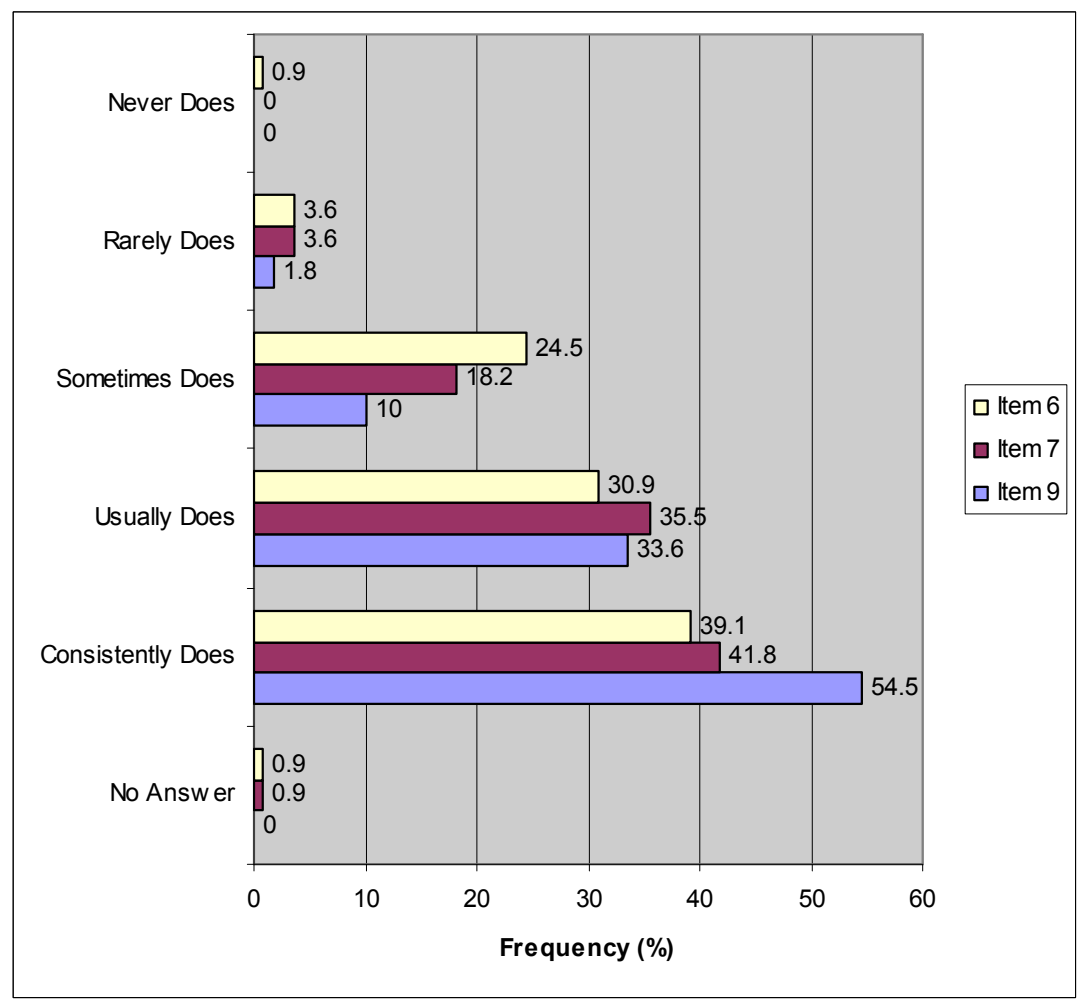




\section{Appendix H (cont.)}
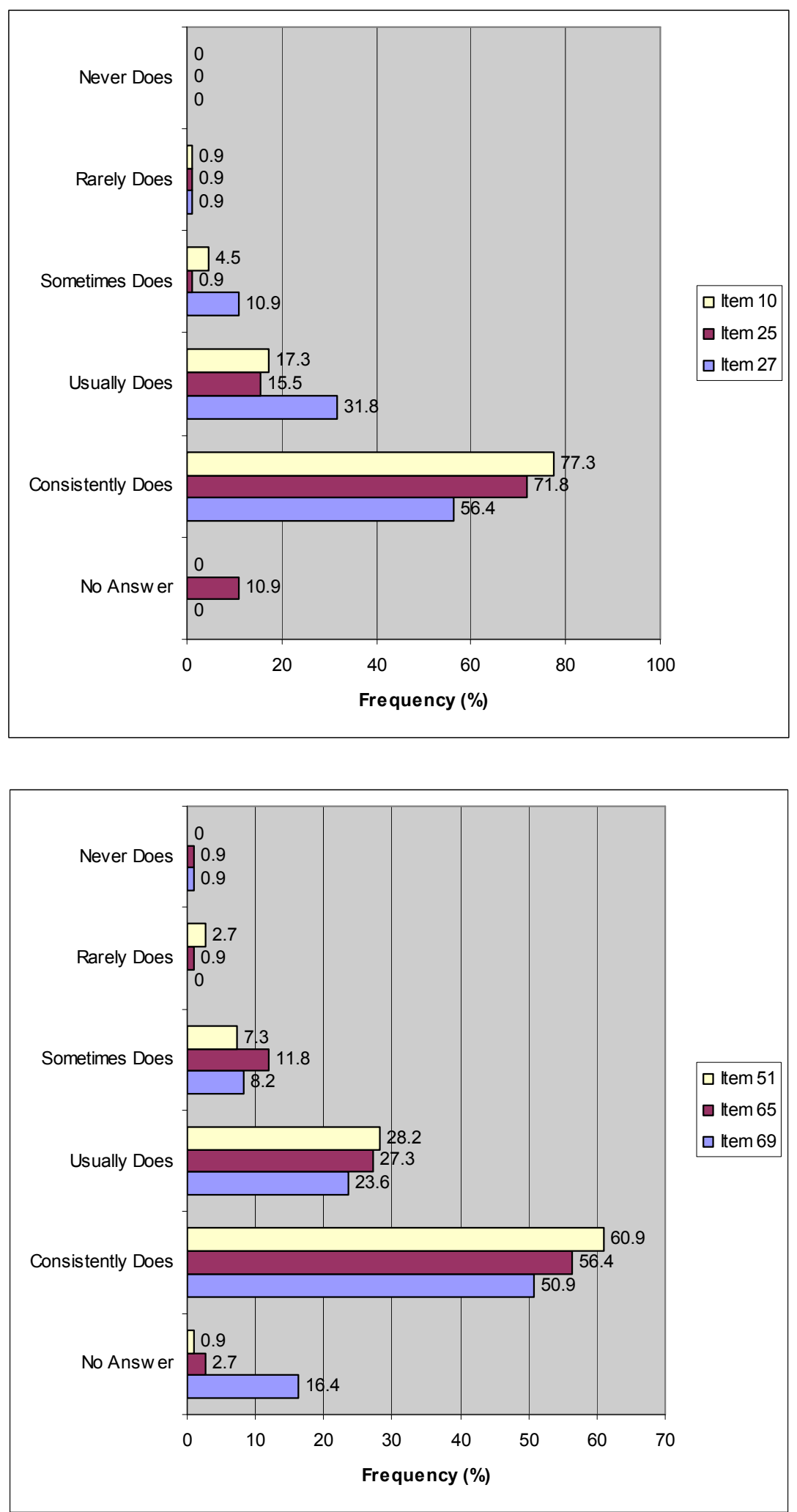


\section{Appendix H (cont.)}

President's Performance in Communications
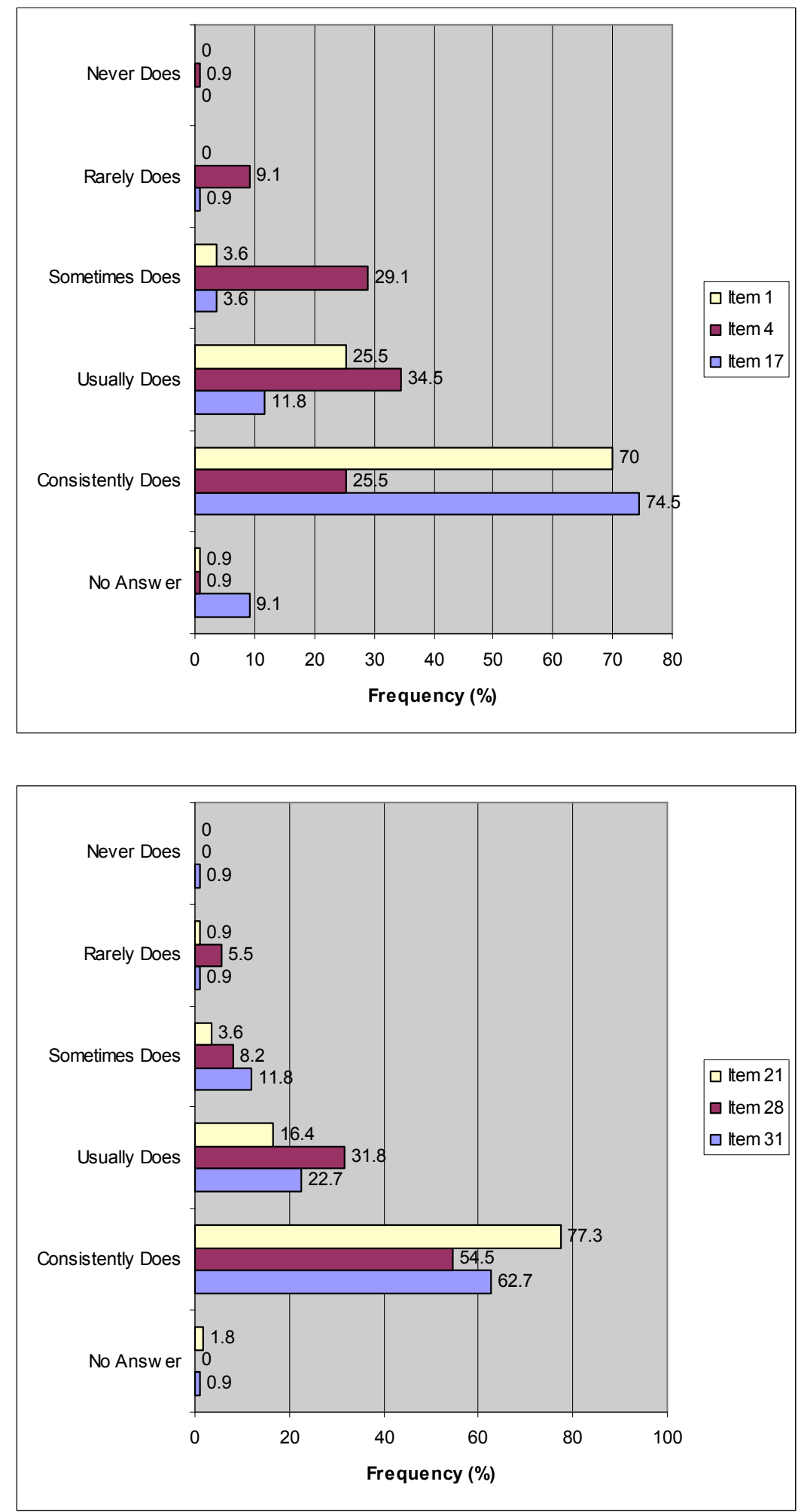


\section{Appendix H (cont.)}

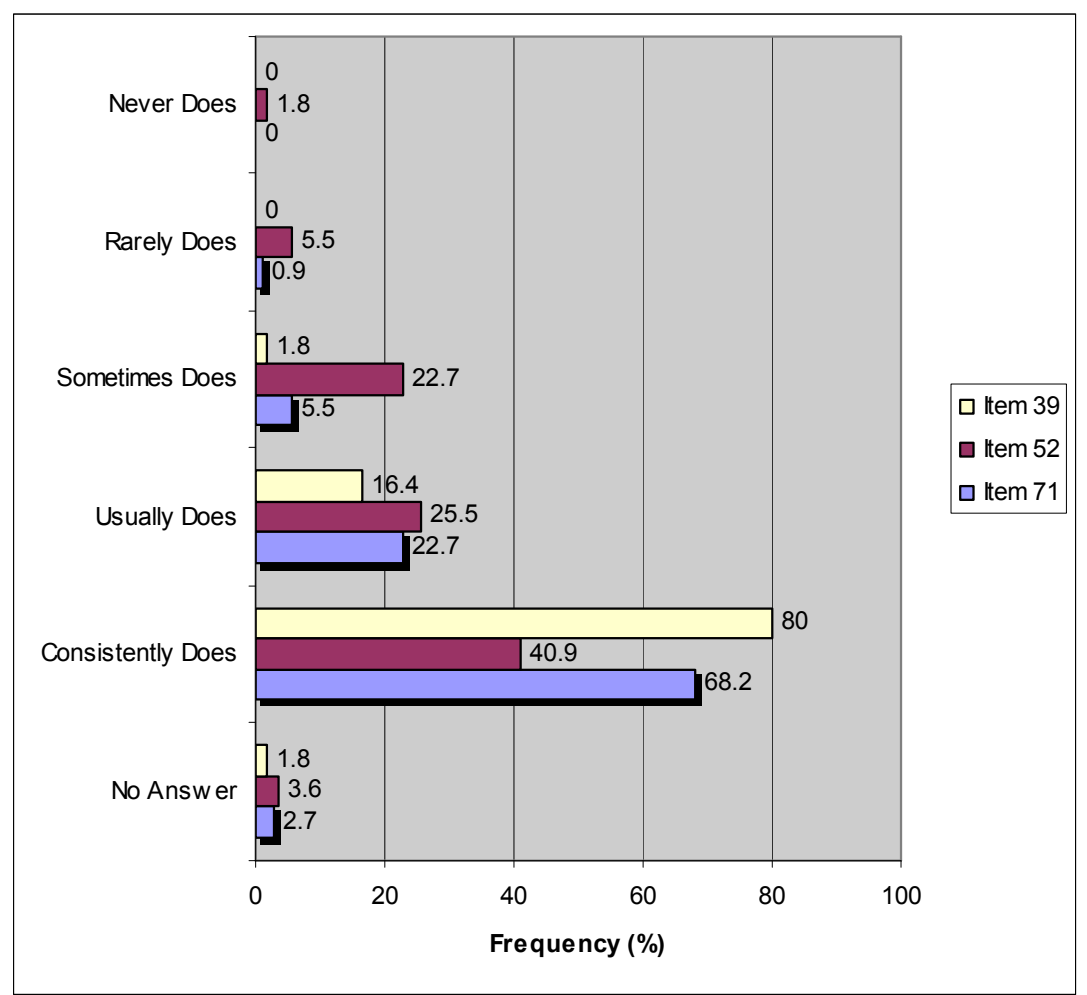

\section{President's Performance in Decision Making}

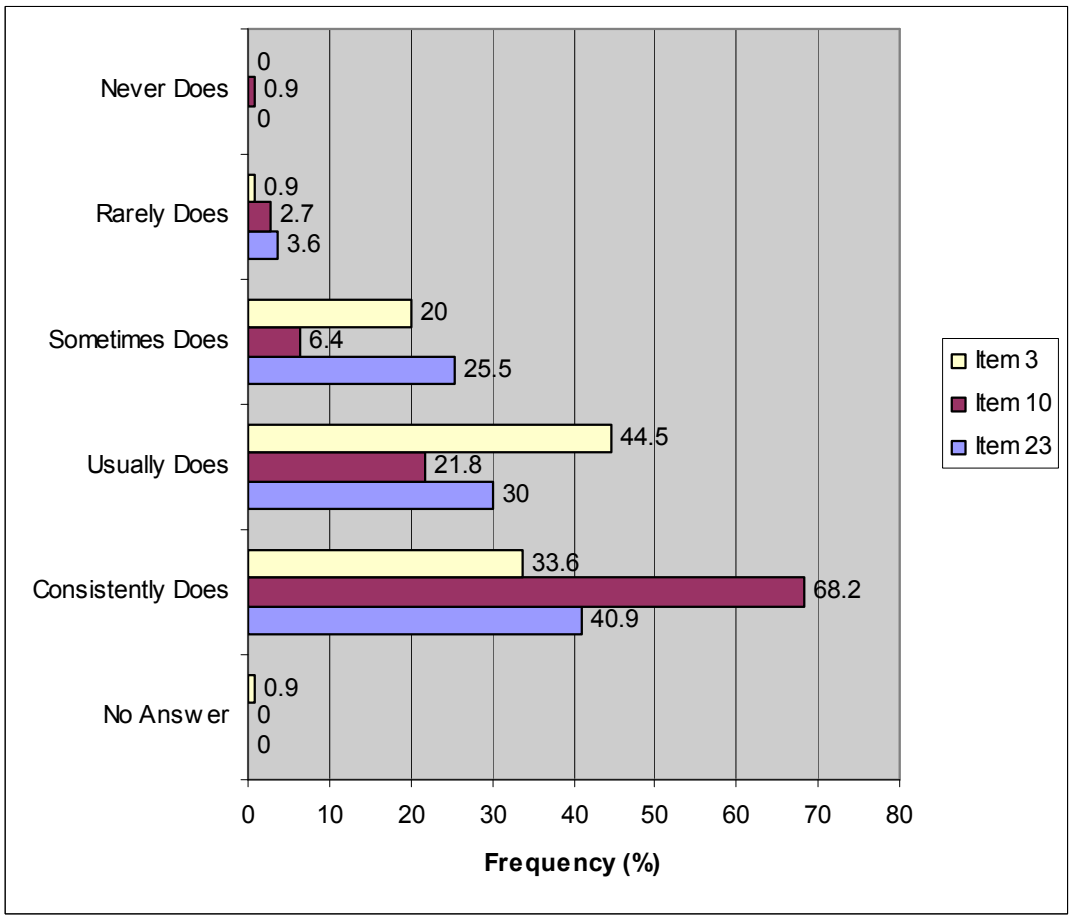




\section{Appendix H (cont.)}
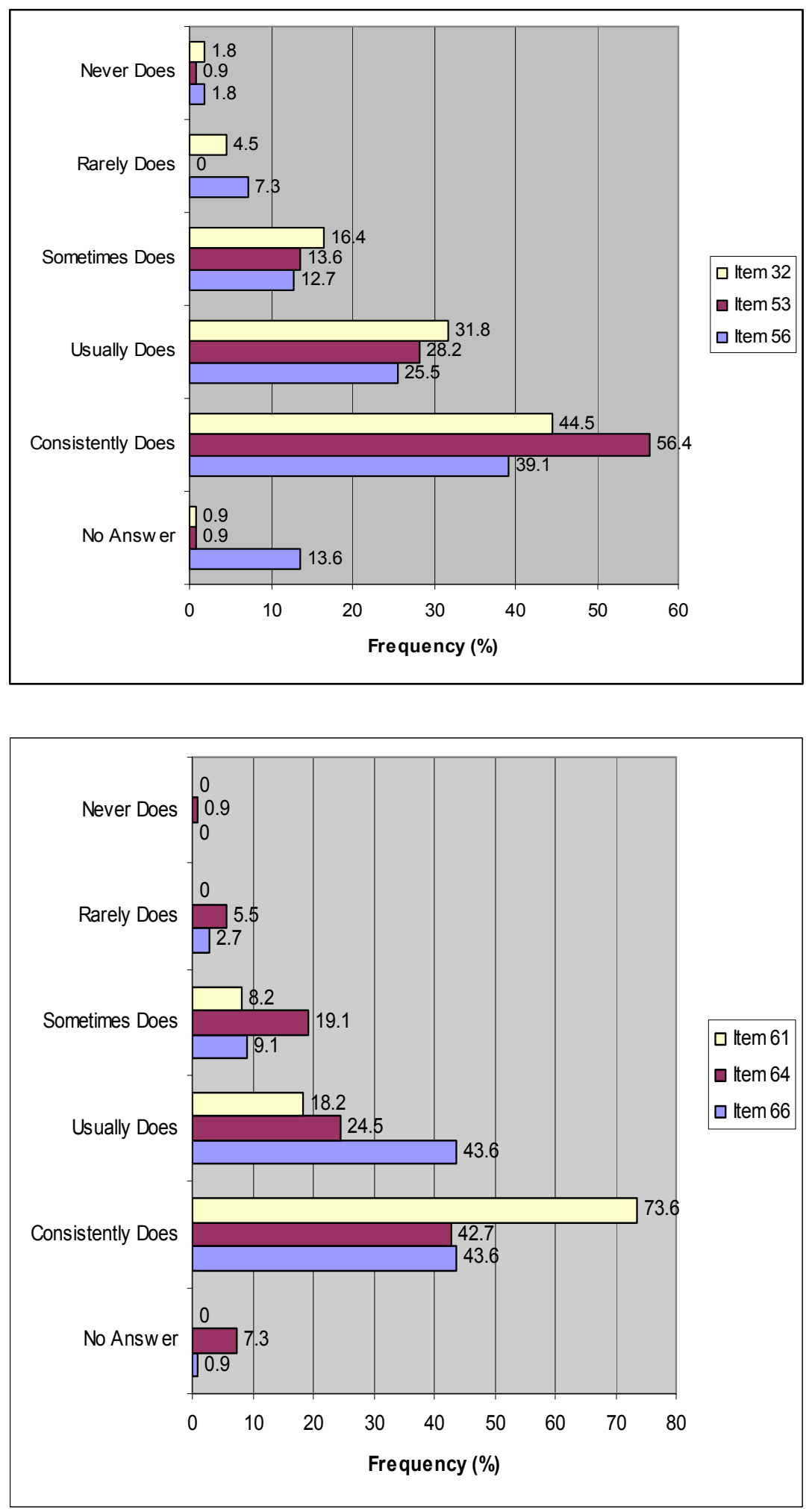


\section{Appendix I}

\section{Leadership}
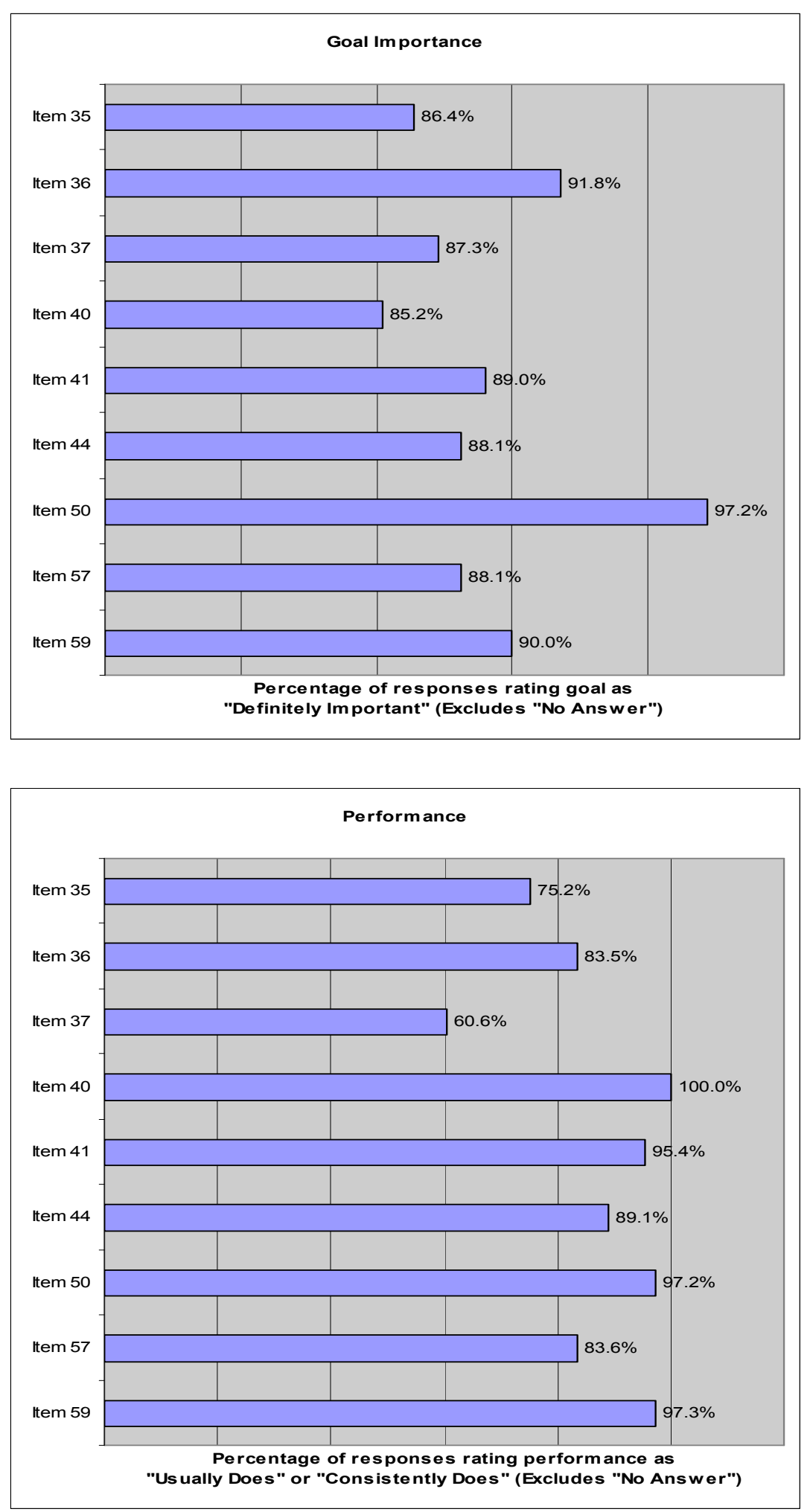


\section{Appendix I (cont.)}

\section{Open to Growth}
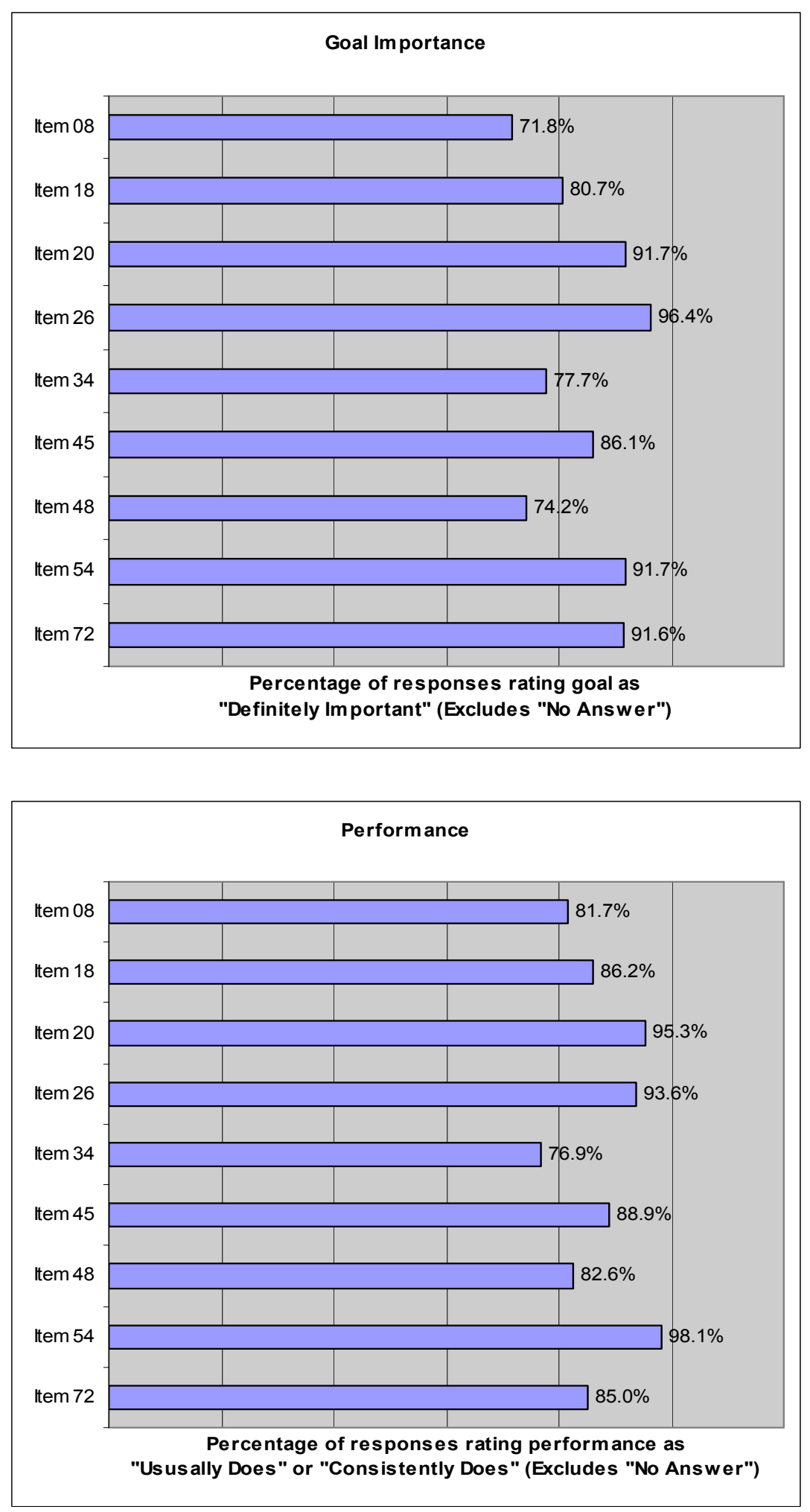


\section{Appendix I (cont.)}

\section{Professional Competence}
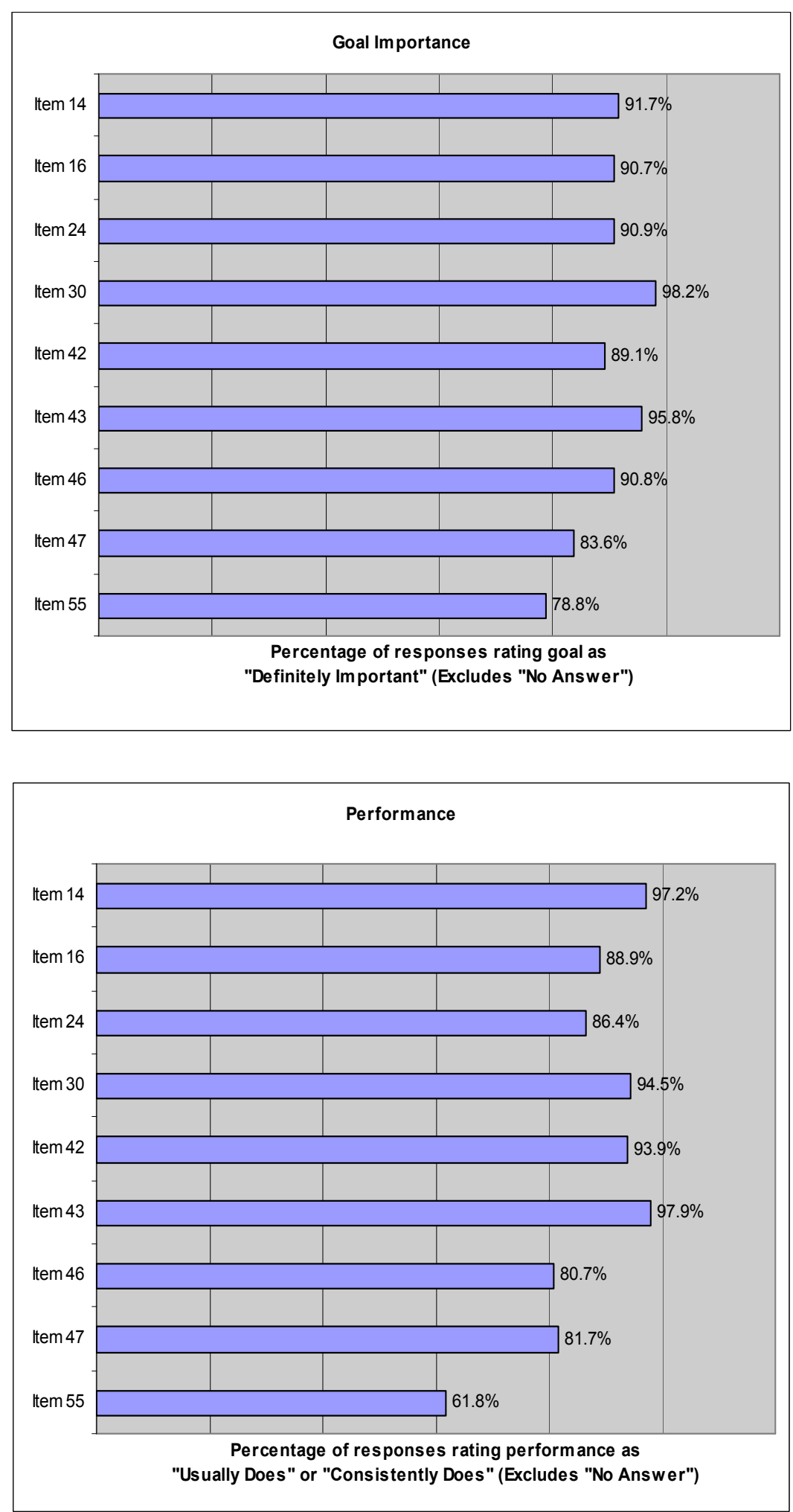


\section{Appendix I (cont.)}

\section{Loving and Caring}
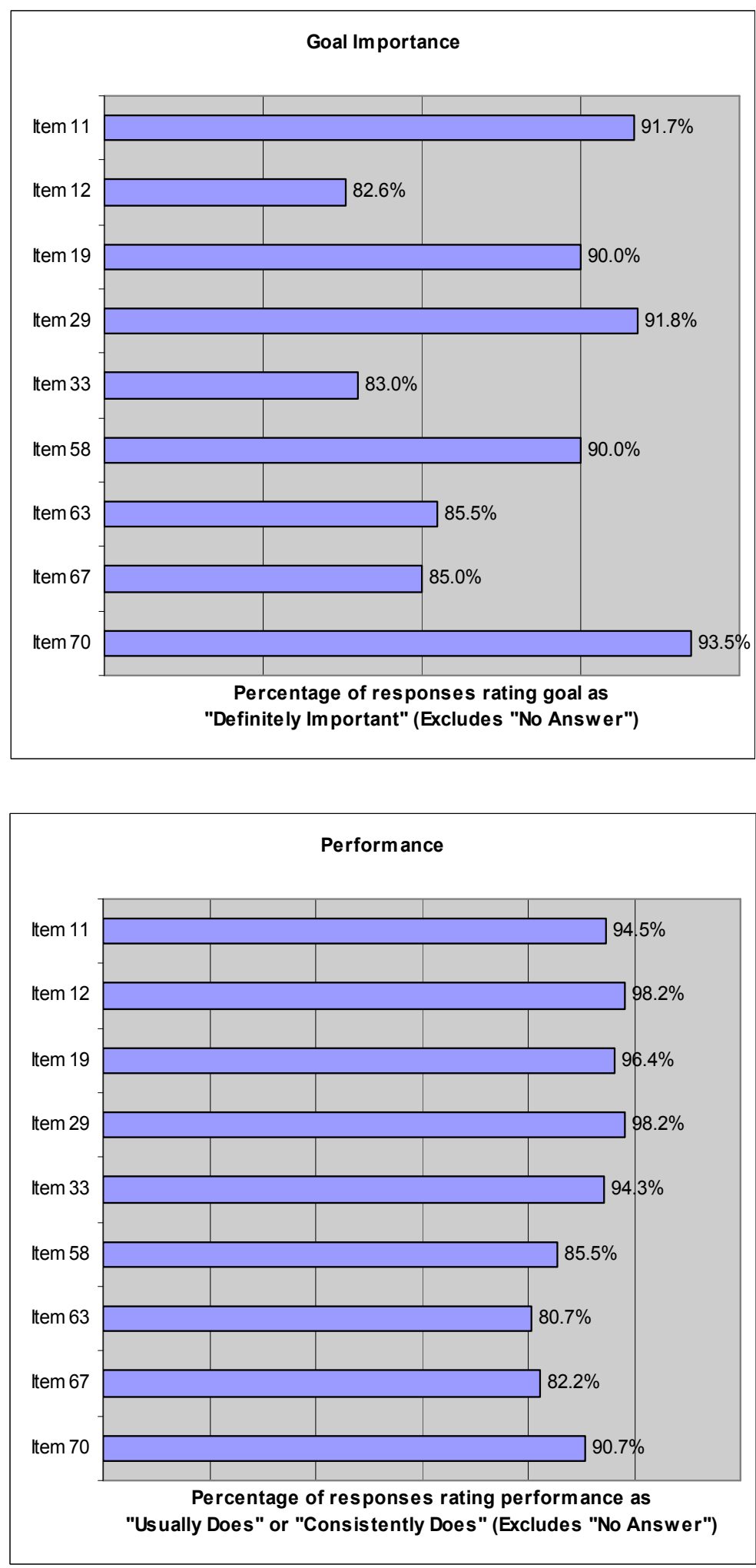


\section{Appendix I (cont.)}

\section{Ignatian Vision}
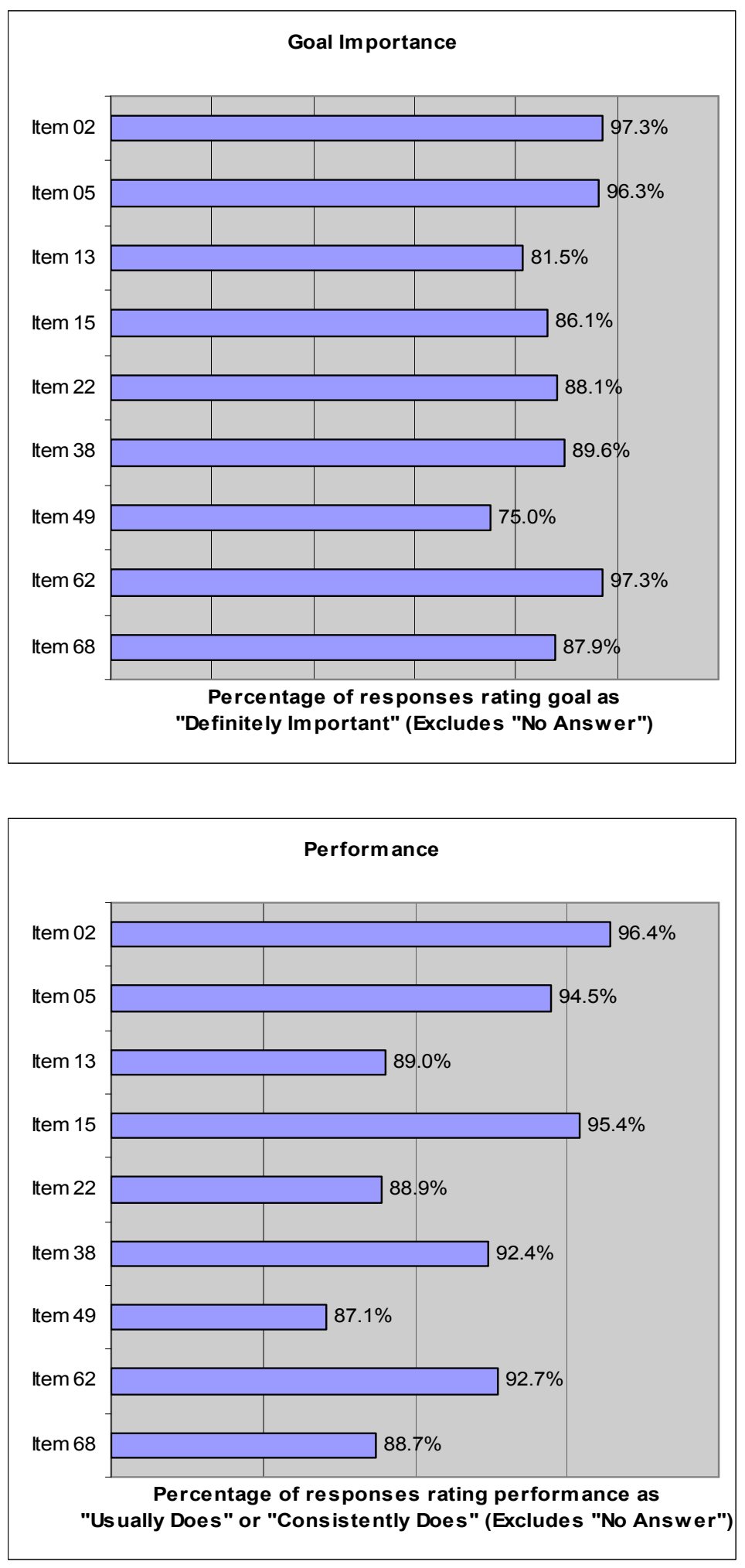


\section{Appendix I (cont.)}

\section{In Action}
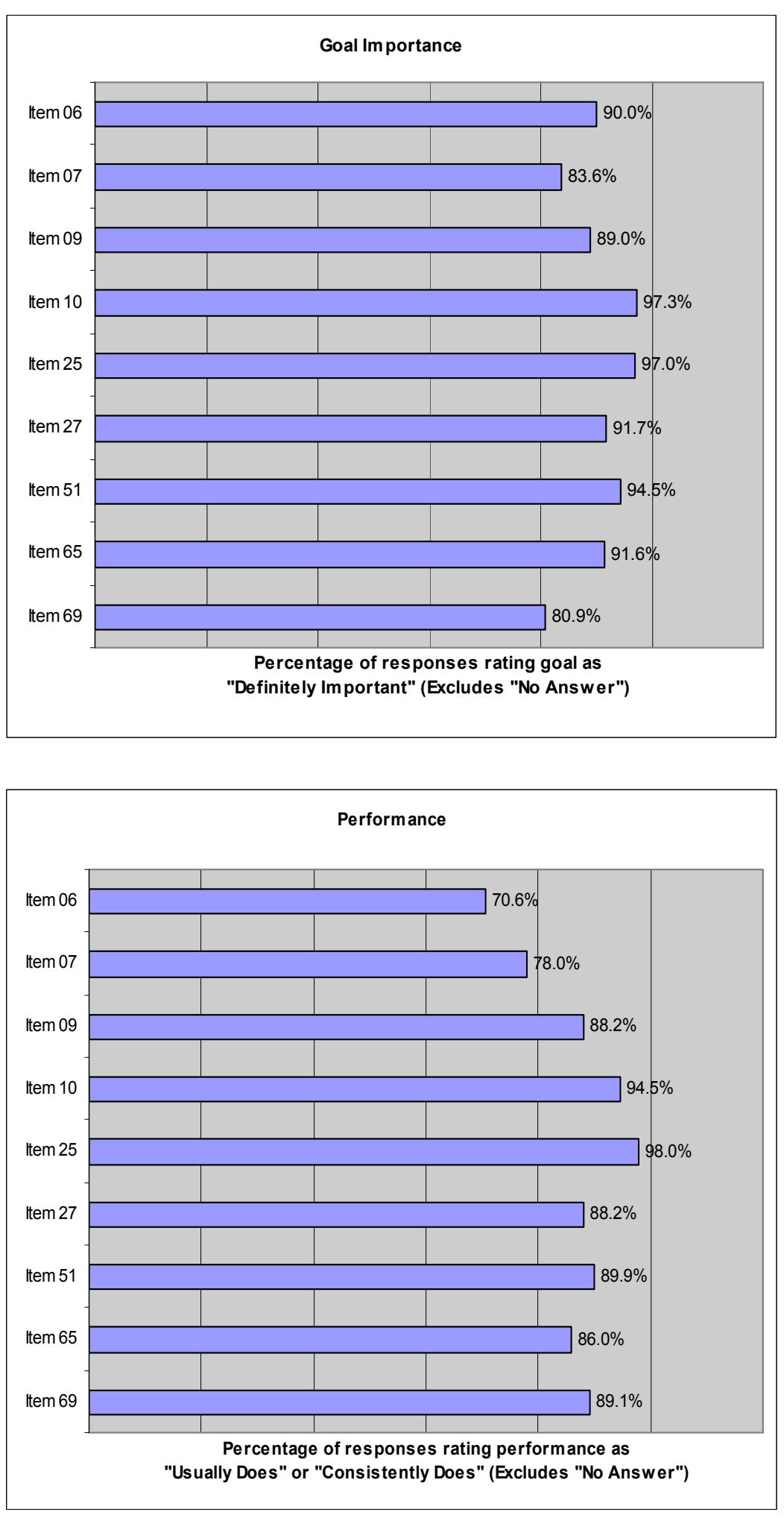


\section{Appendix I (cont.)}

\section{Communications}
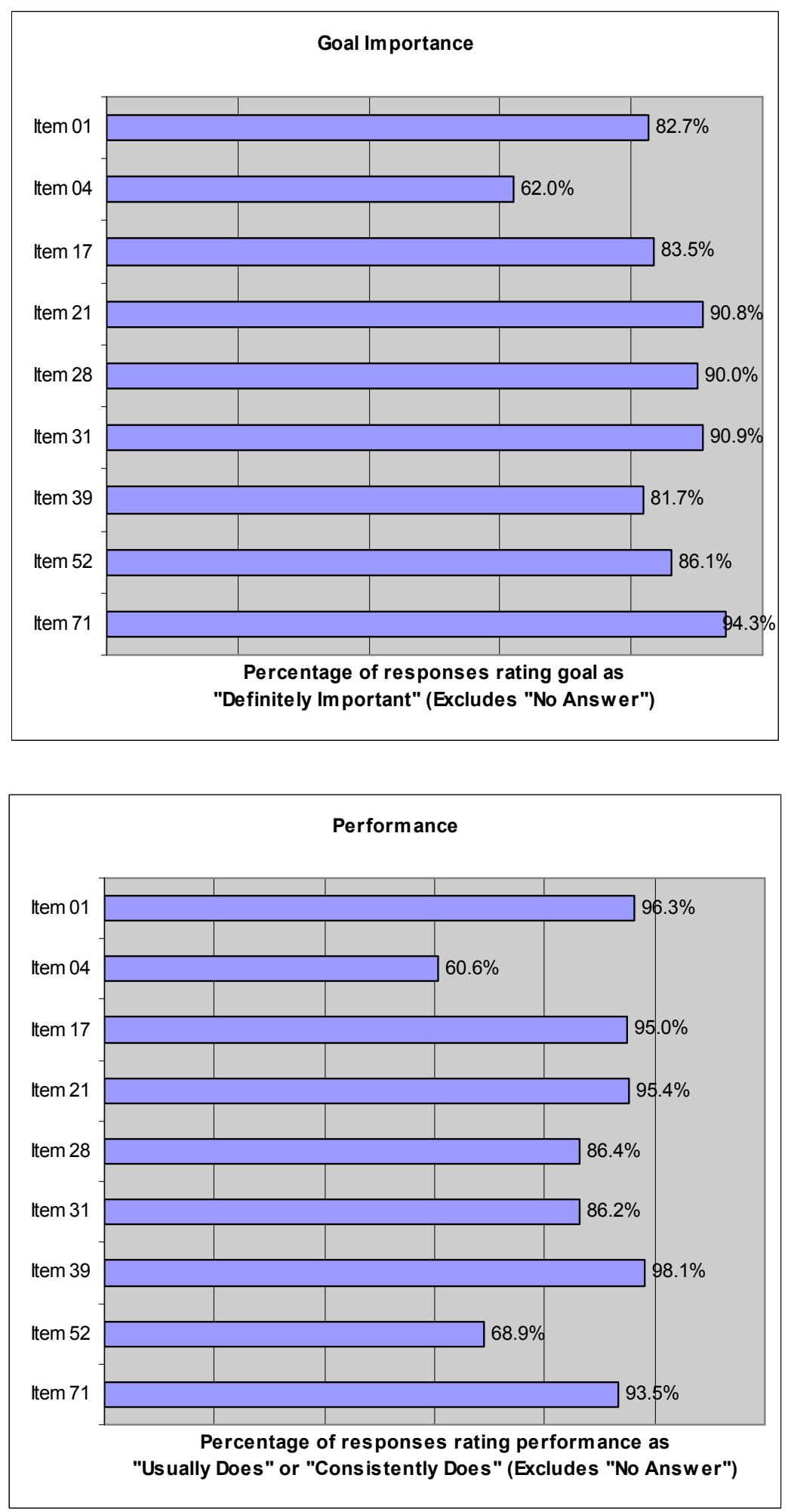


\section{Appendix I (cont.)}

\section{Decision Making}
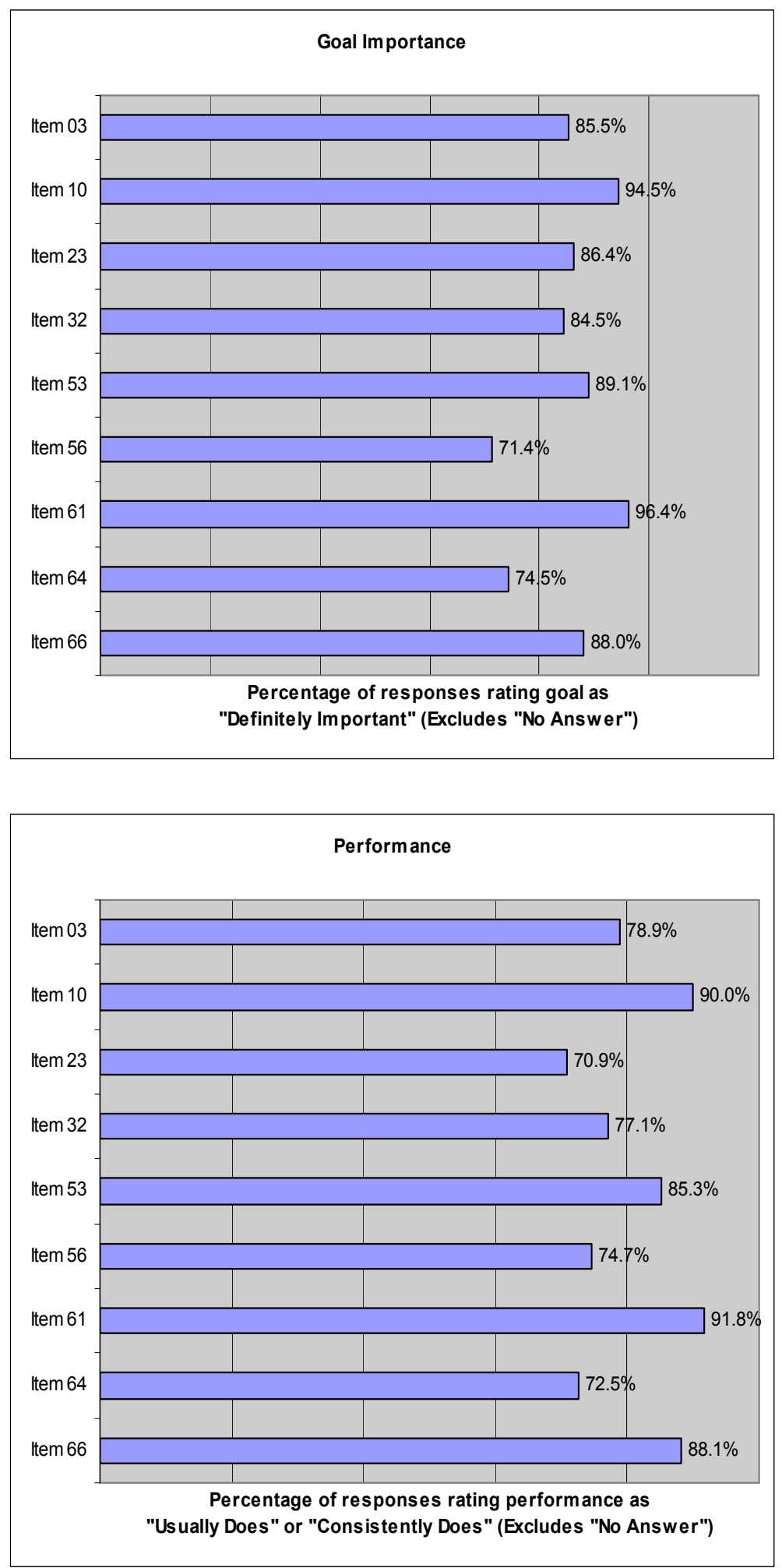


\section{Appendix $\mathbf{J}$}

\section{Line Graphs per Category}
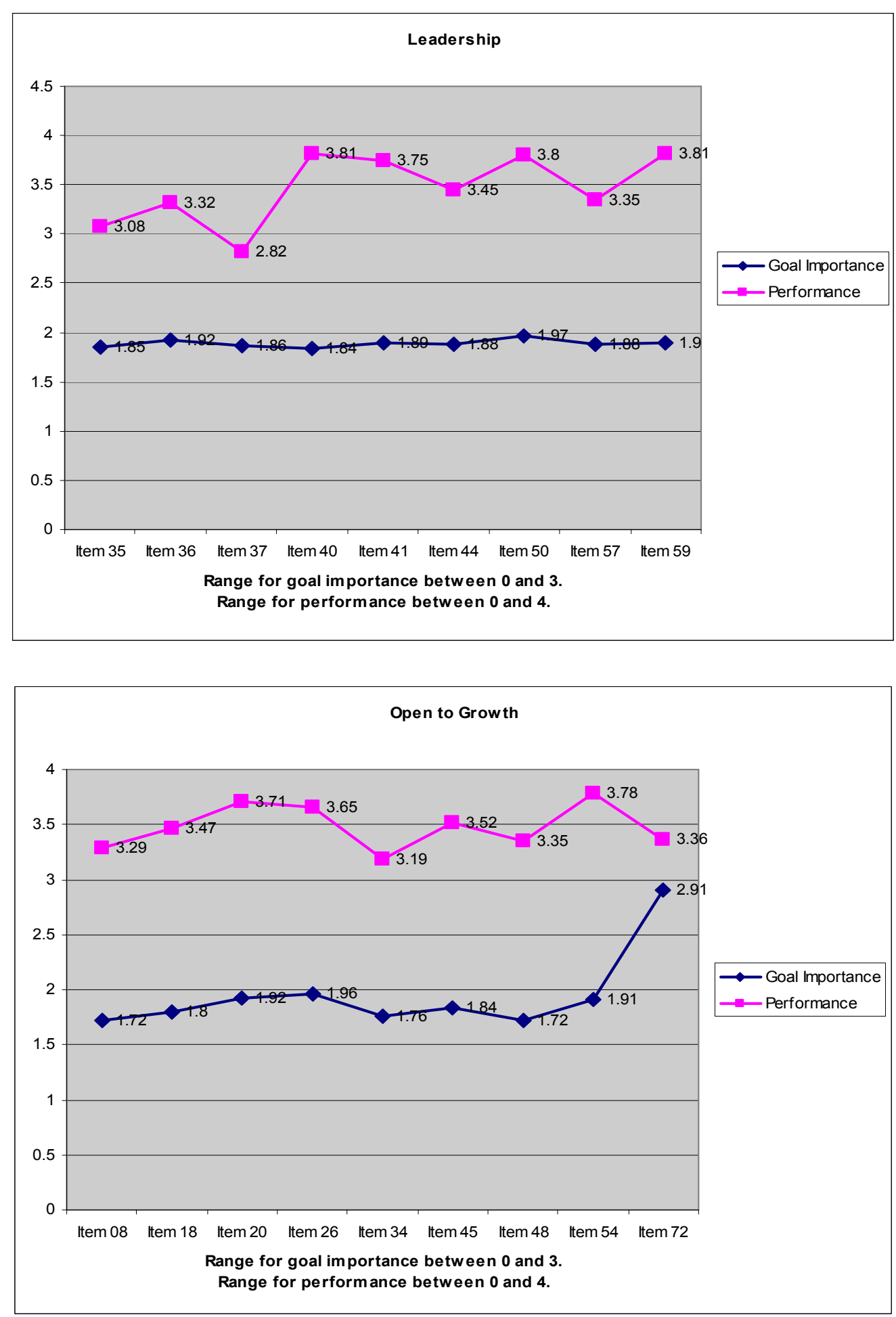
Appendix J (cont.)

\section{Line Graphs per Category}
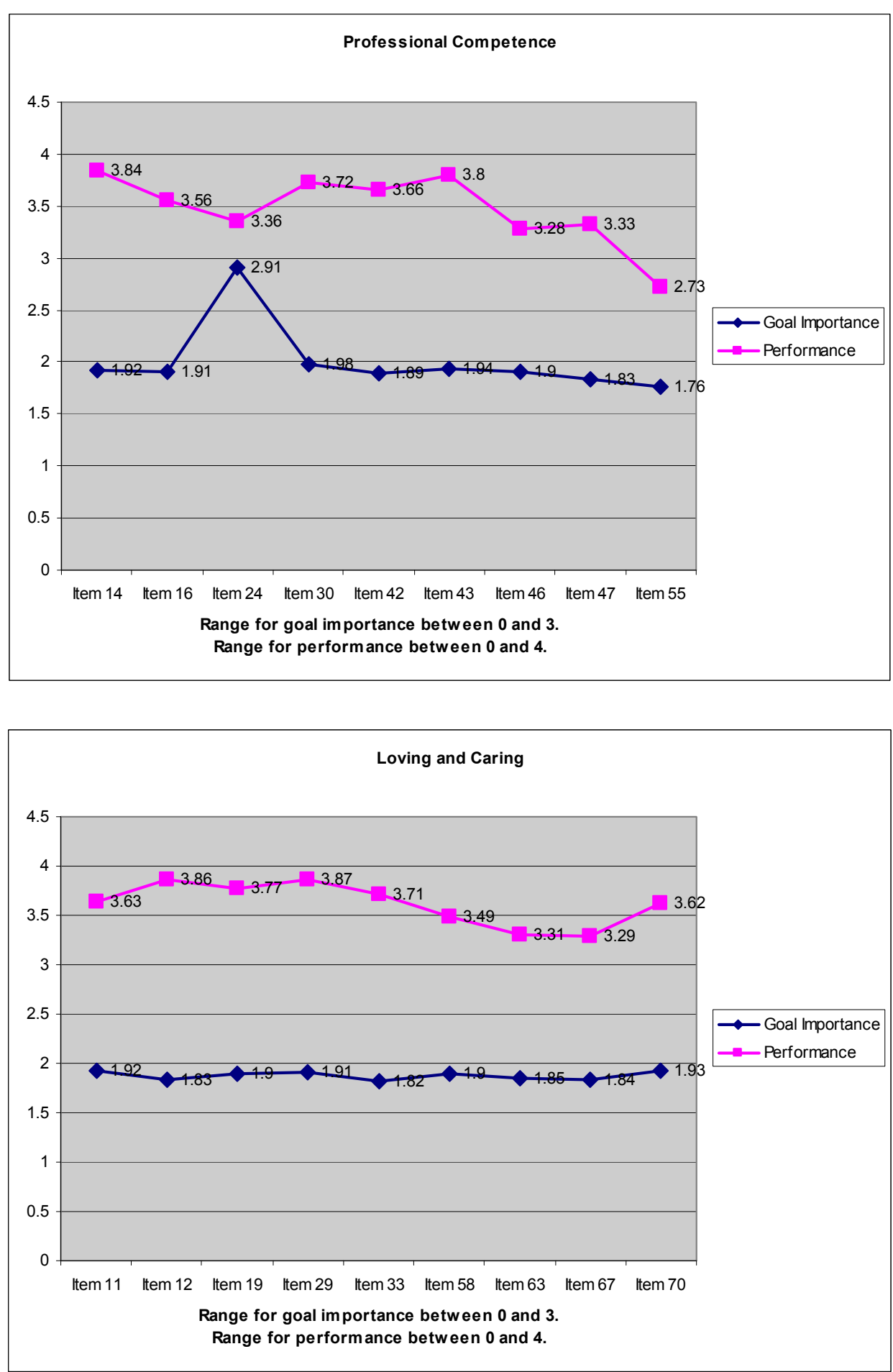
Appendix J (cont.)

\section{Line Graphs per Category}
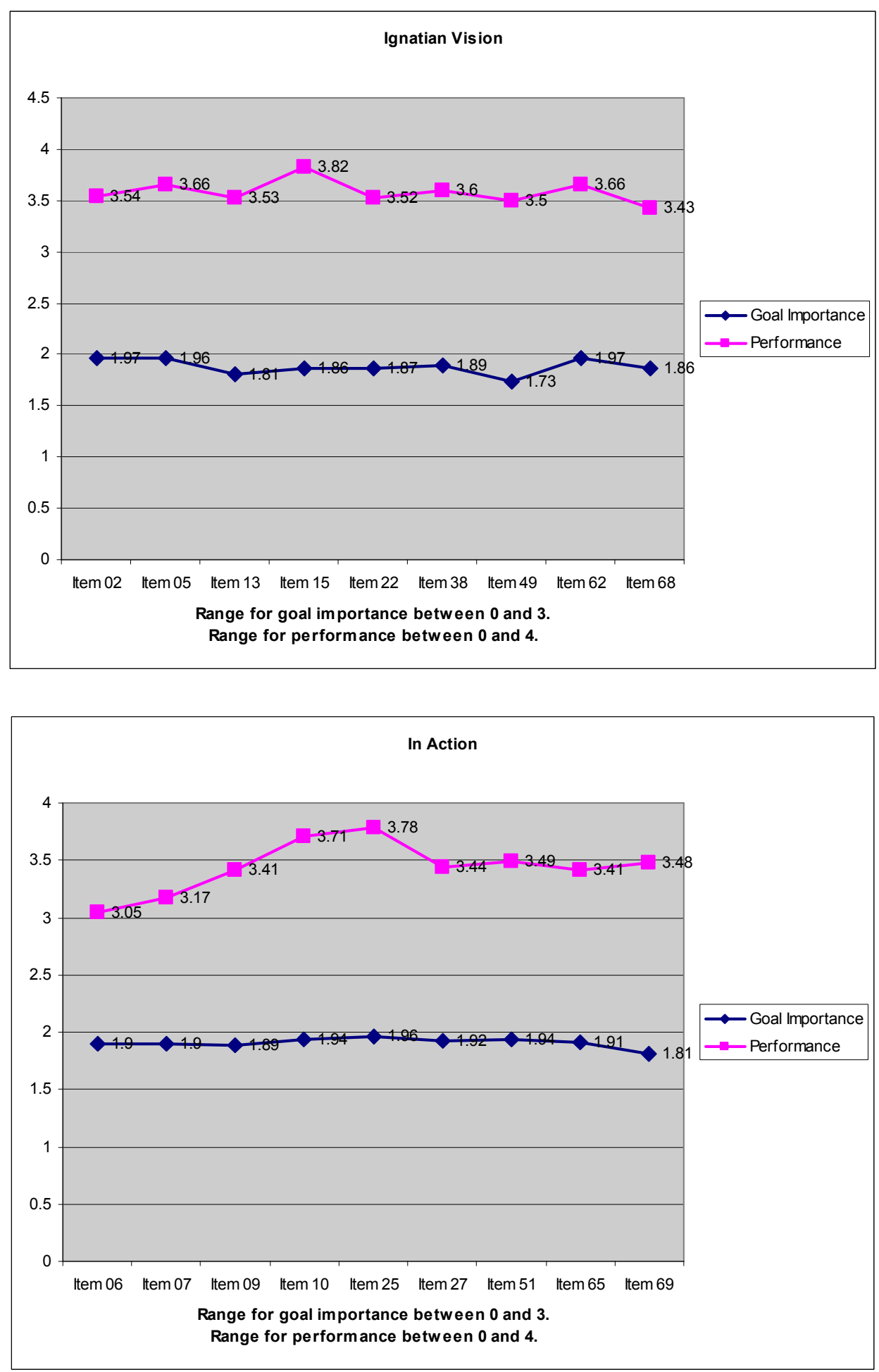
Appendix J (cont.)

\section{Line Graphs per Category}
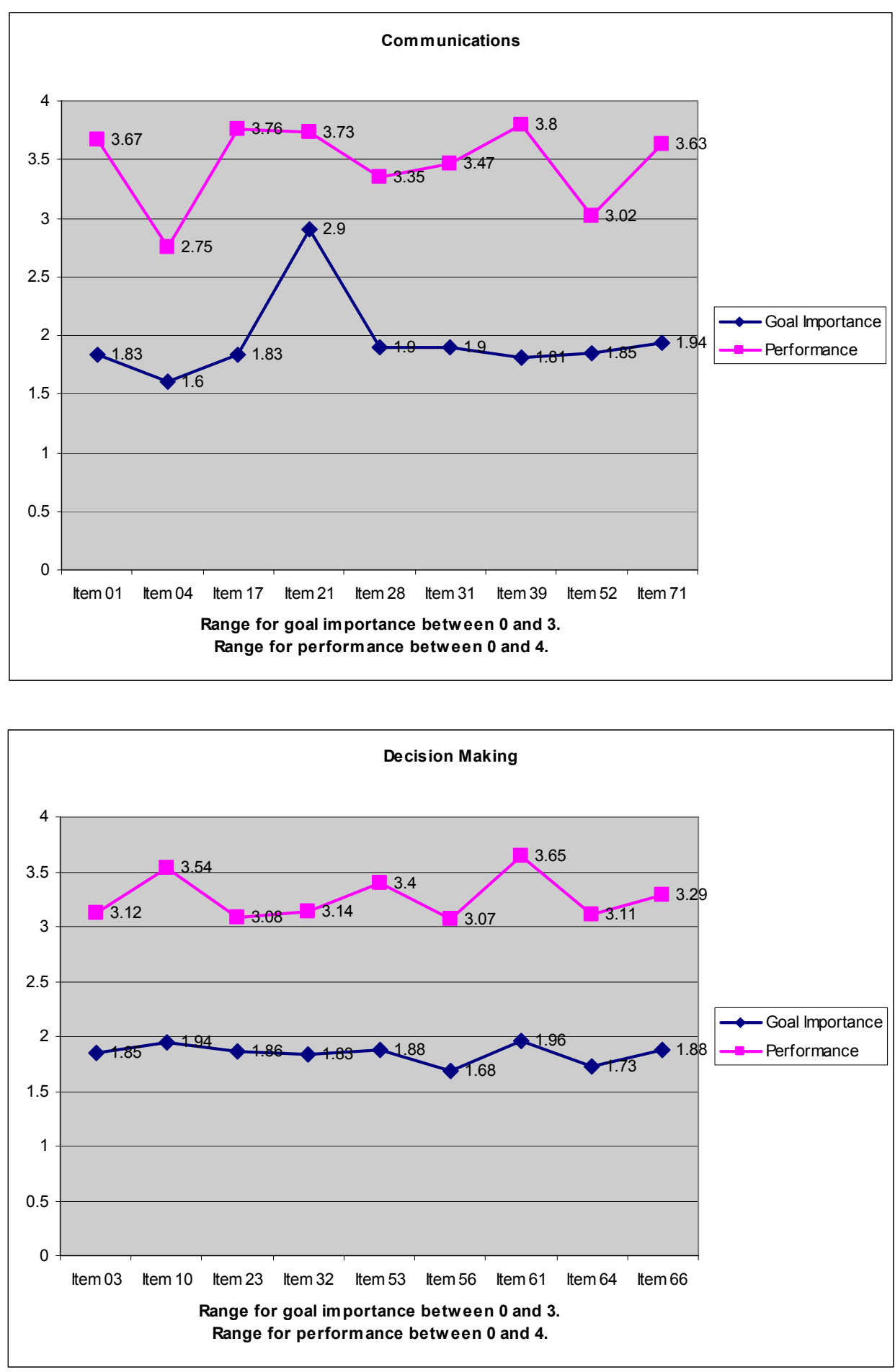


\section{Appendix K}

Organizational Health of the School Charts for Goals
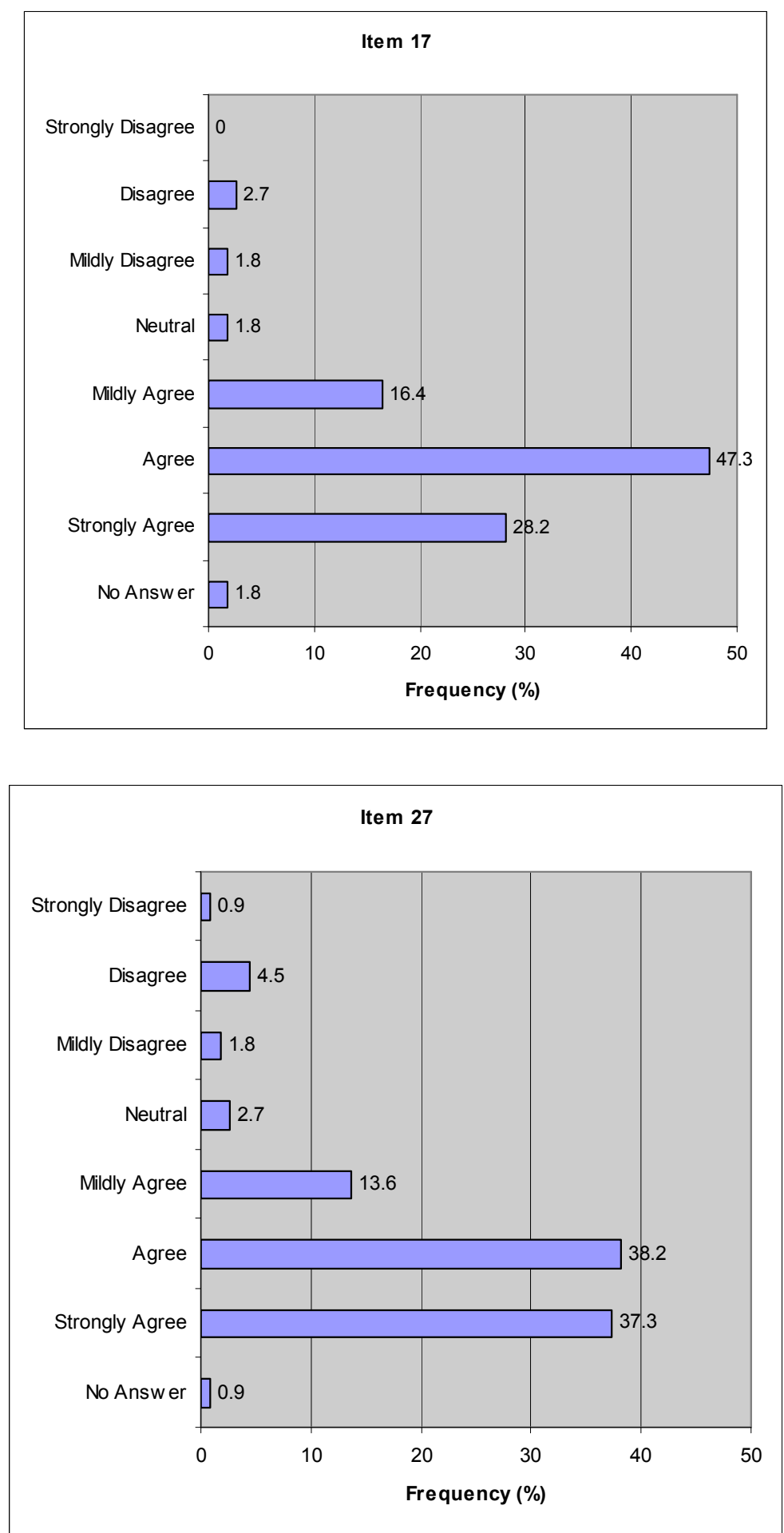


\section{Appendix K (cont.)}

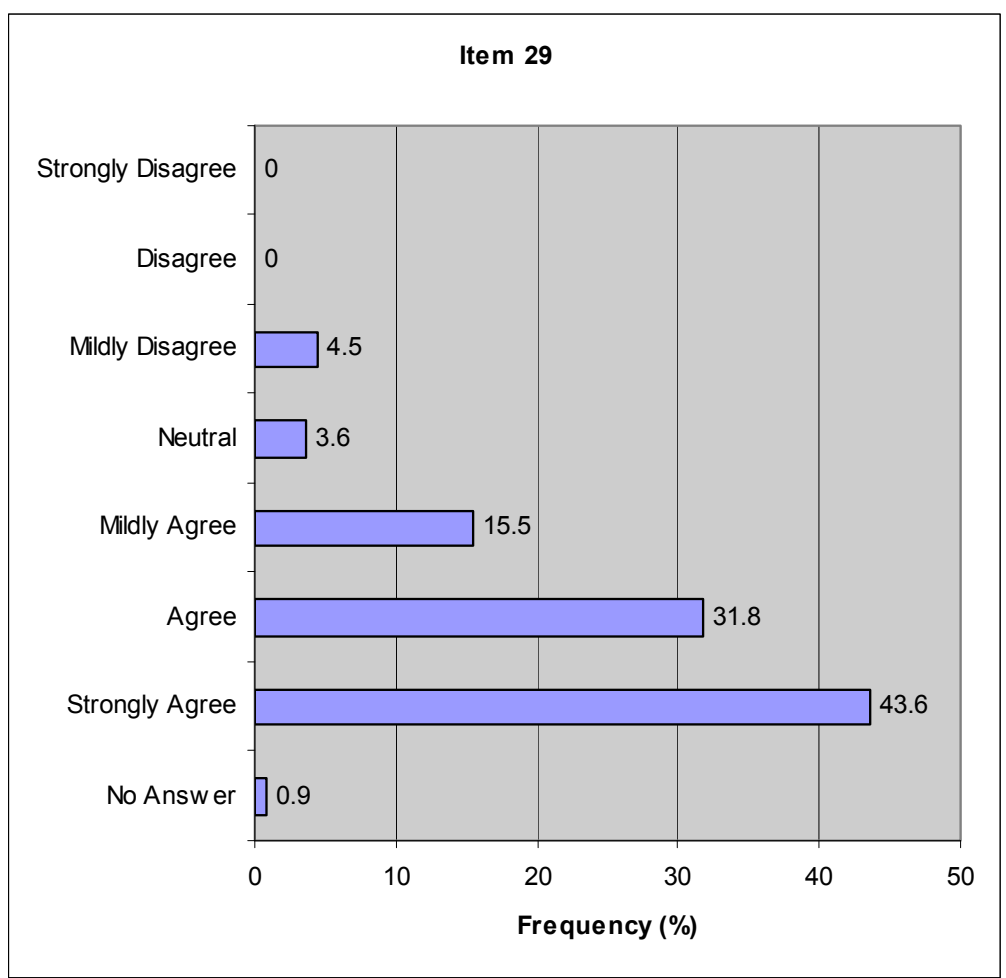

Organizational Health of the School Charts for Roles

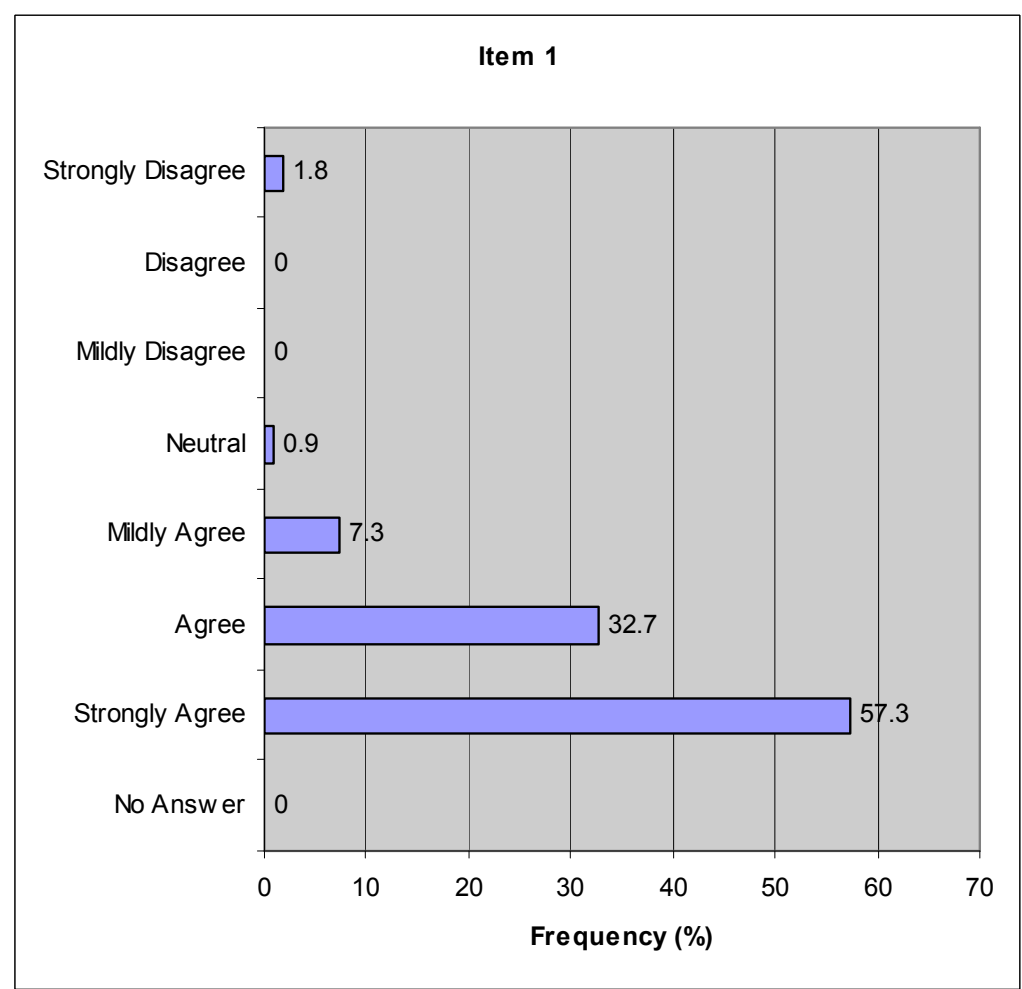




\section{Appendix K (cont.)}
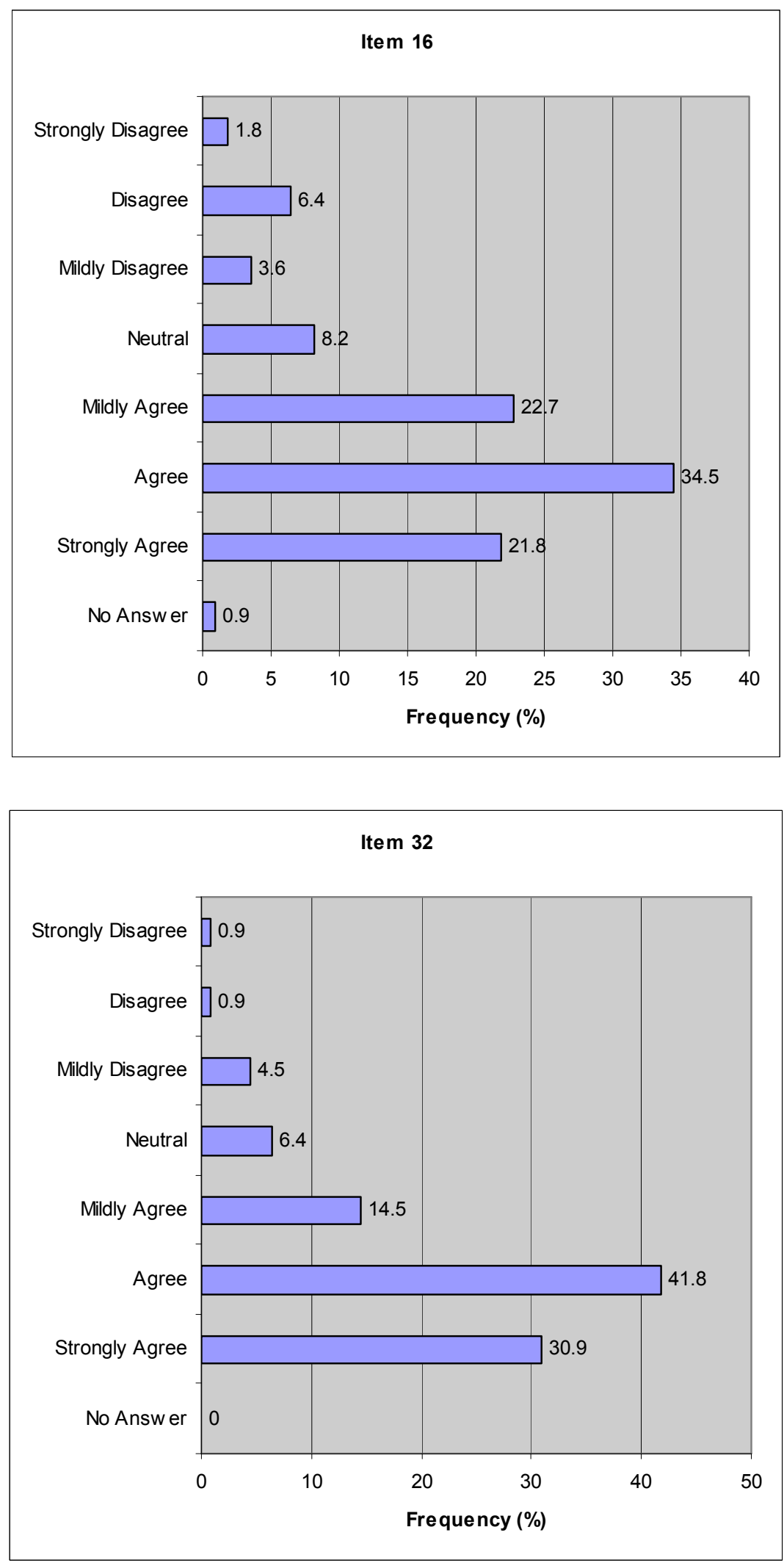


\section{Appendix K (cont.)}

Organizational Health of the School Charts for Leadership
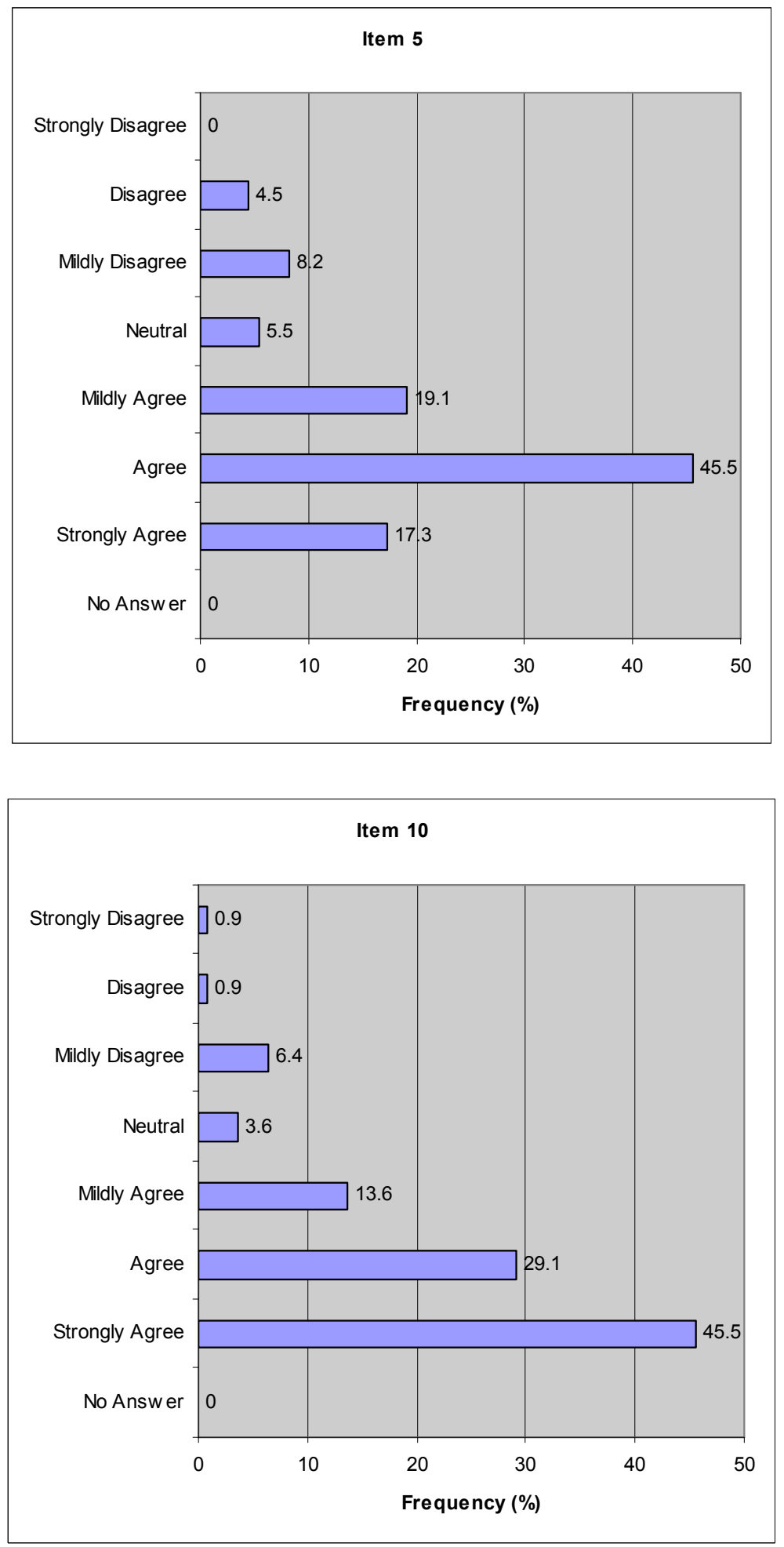


\section{Appendix K (cont.)}

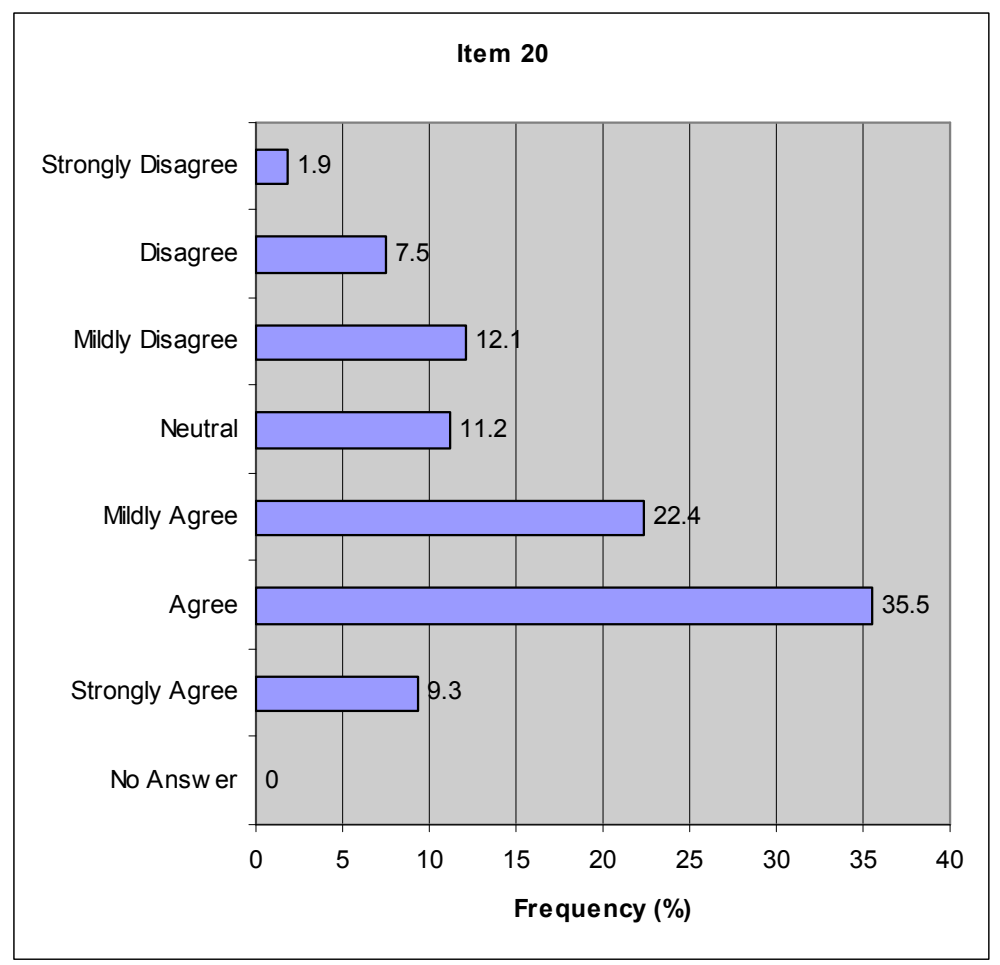

Organizational Health of the School Charts for Efficiency

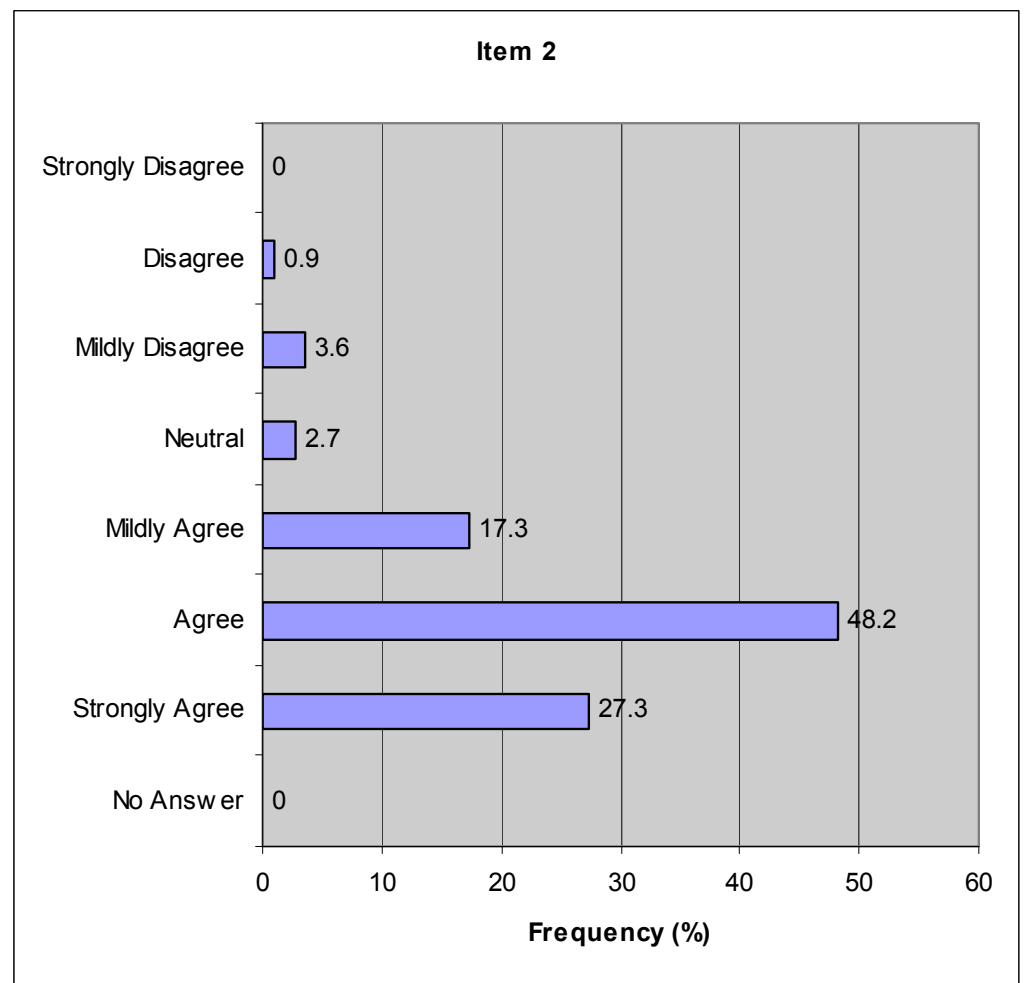




\section{Appendix K (cont.)}
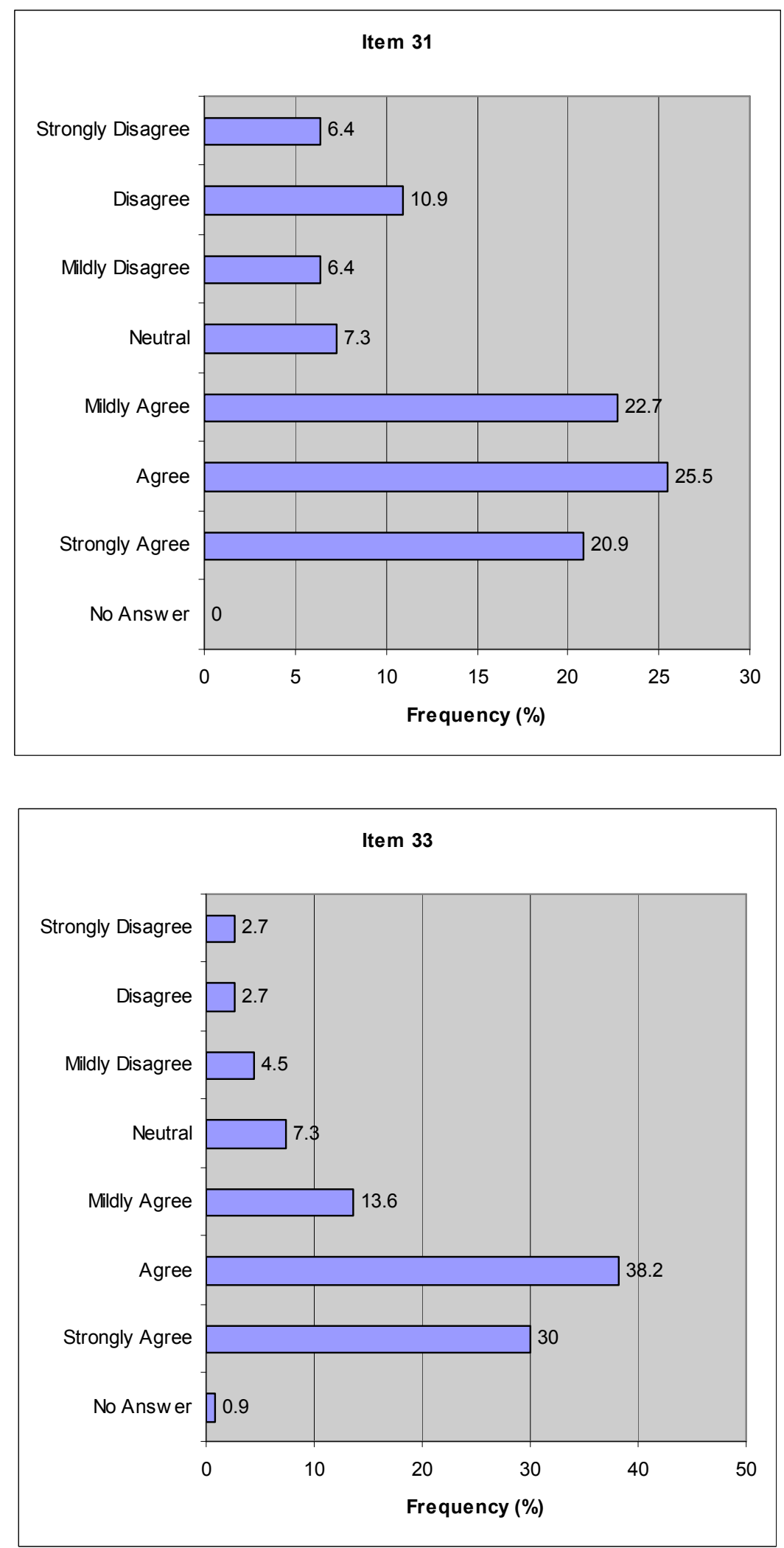


\section{Appendix K (cont.)}

\section{Organizational Health of the School Charts for Consonance}
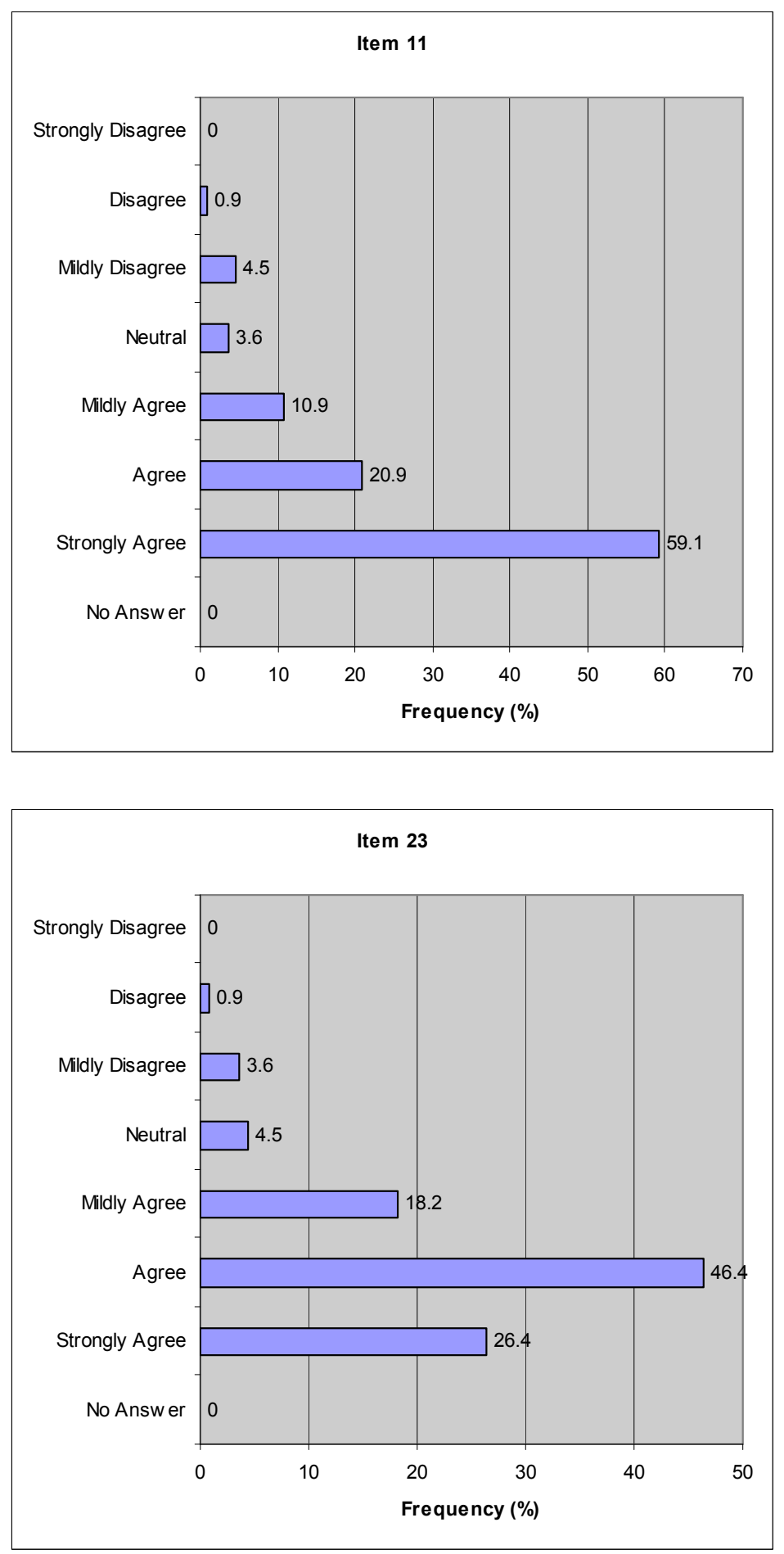


\section{Appendix K (cont.)}

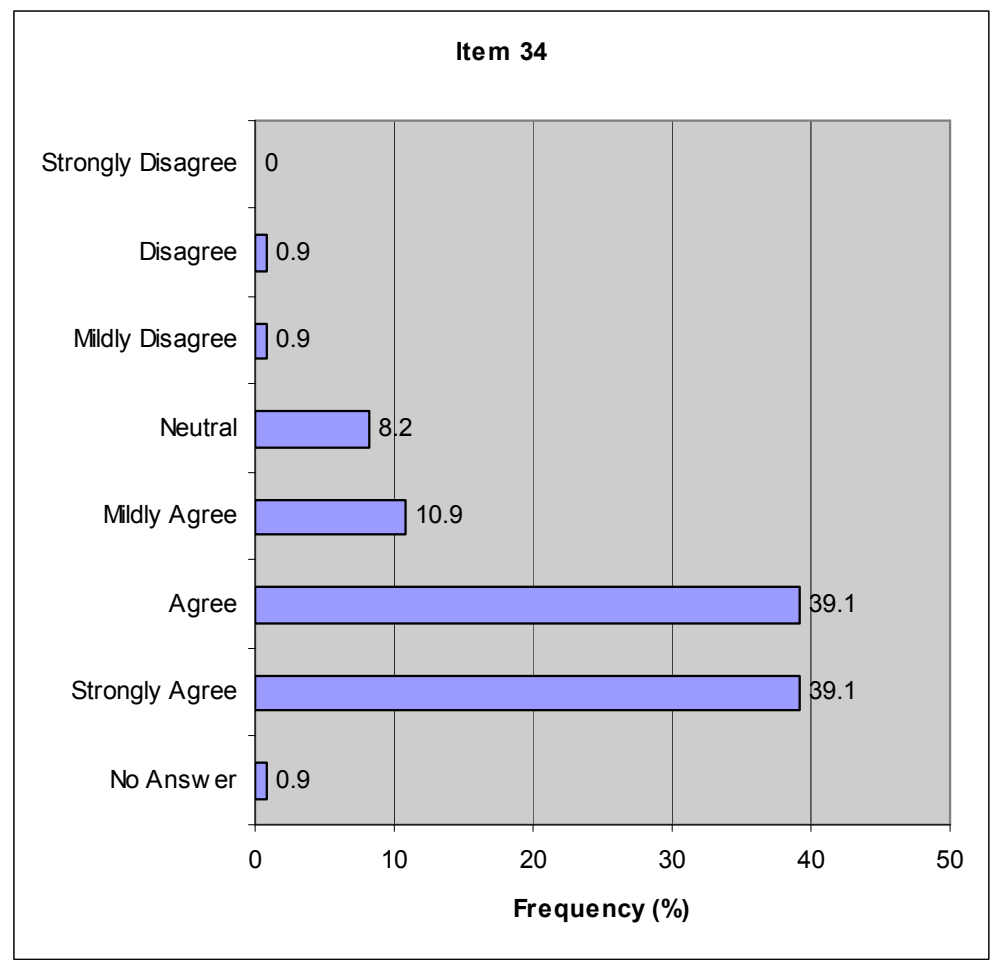

Organizational Health of the School Charts for Proponence

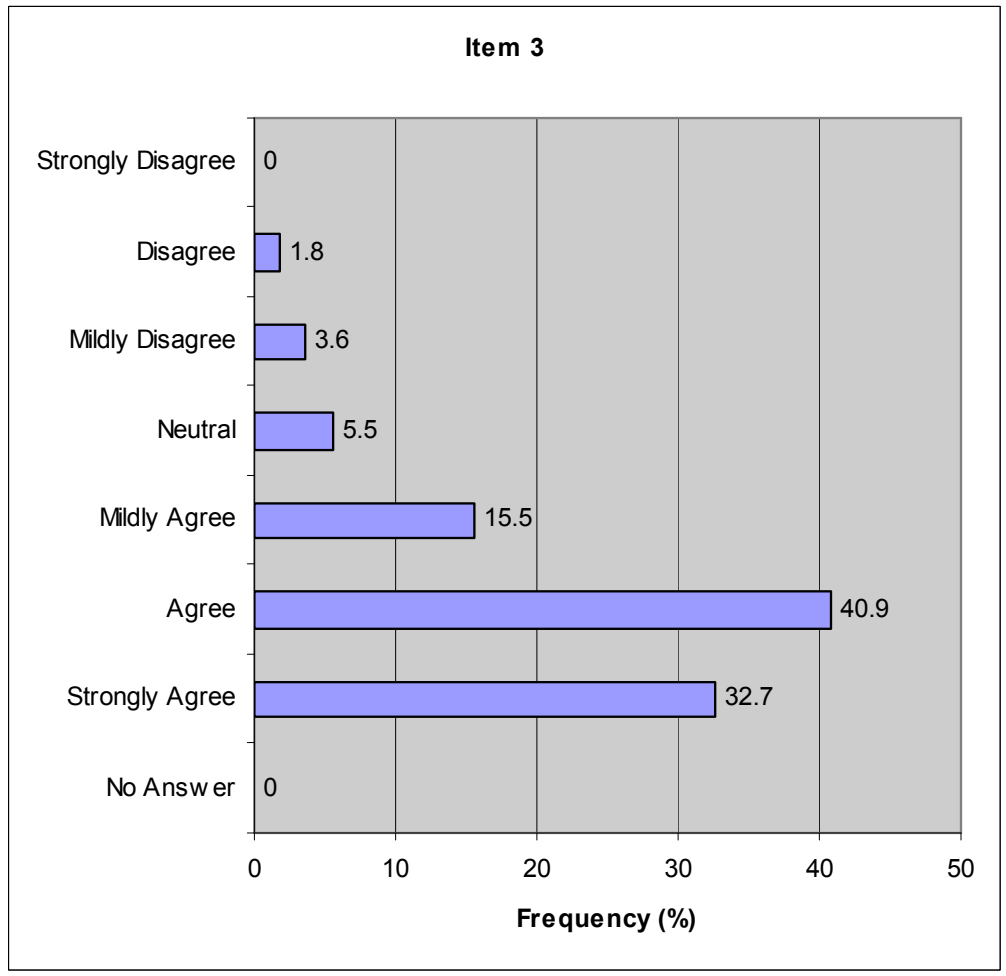




\section{Appendix K (cont.)}
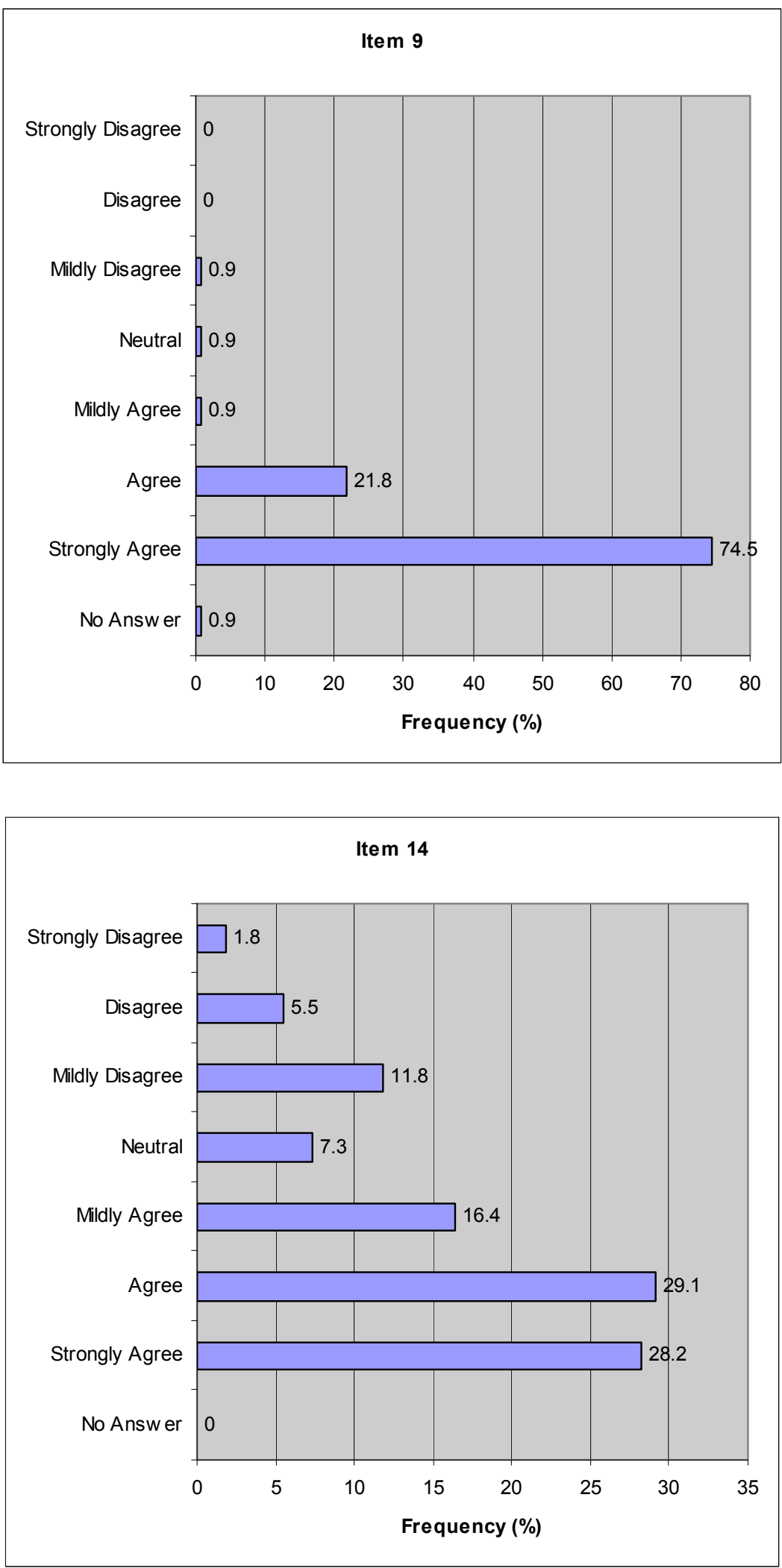
Appendix K (cont.)

Organizational Health of the School Charts for Individual Synergy in Decision Making
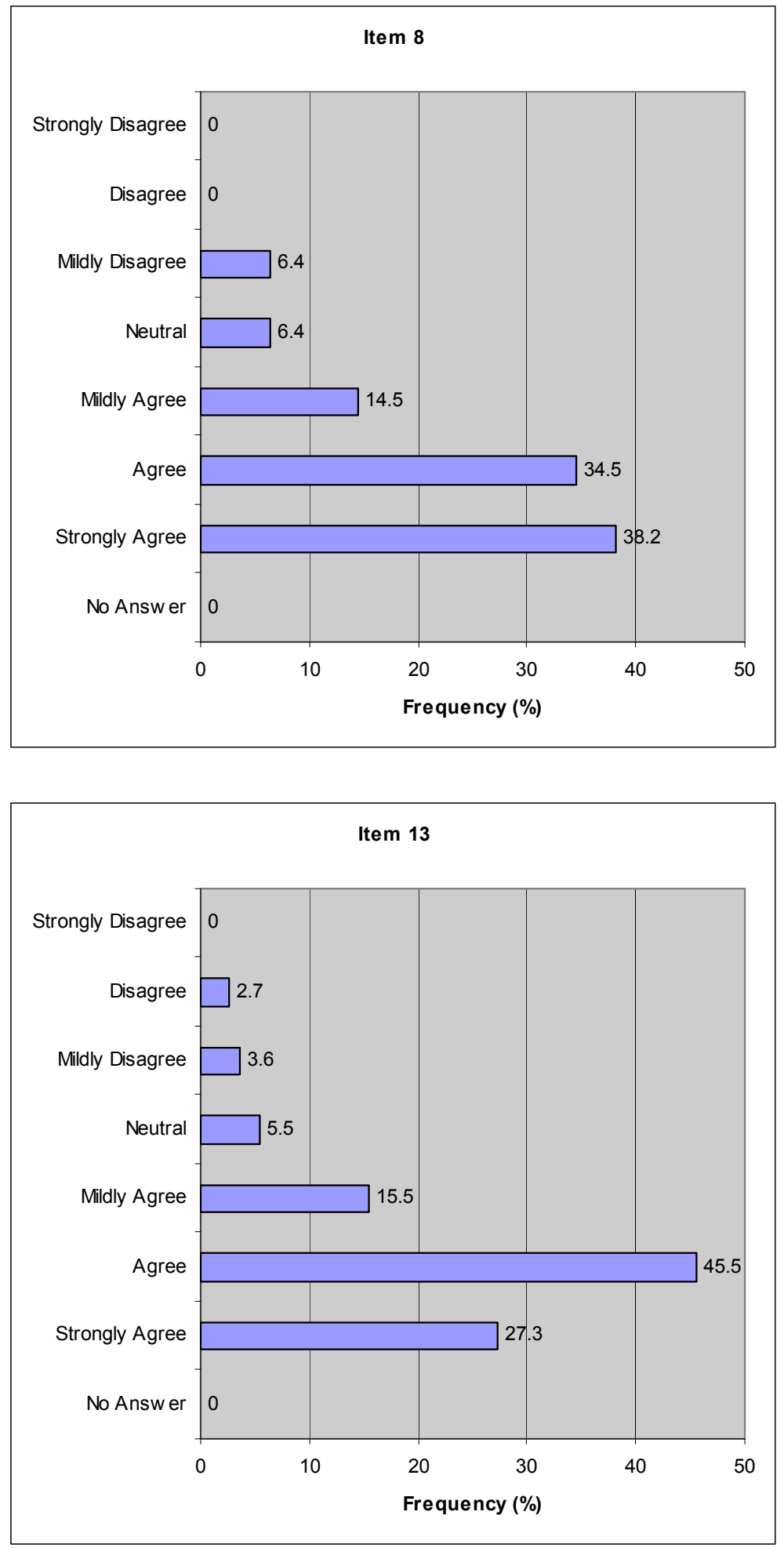
Appendix K (cont.)

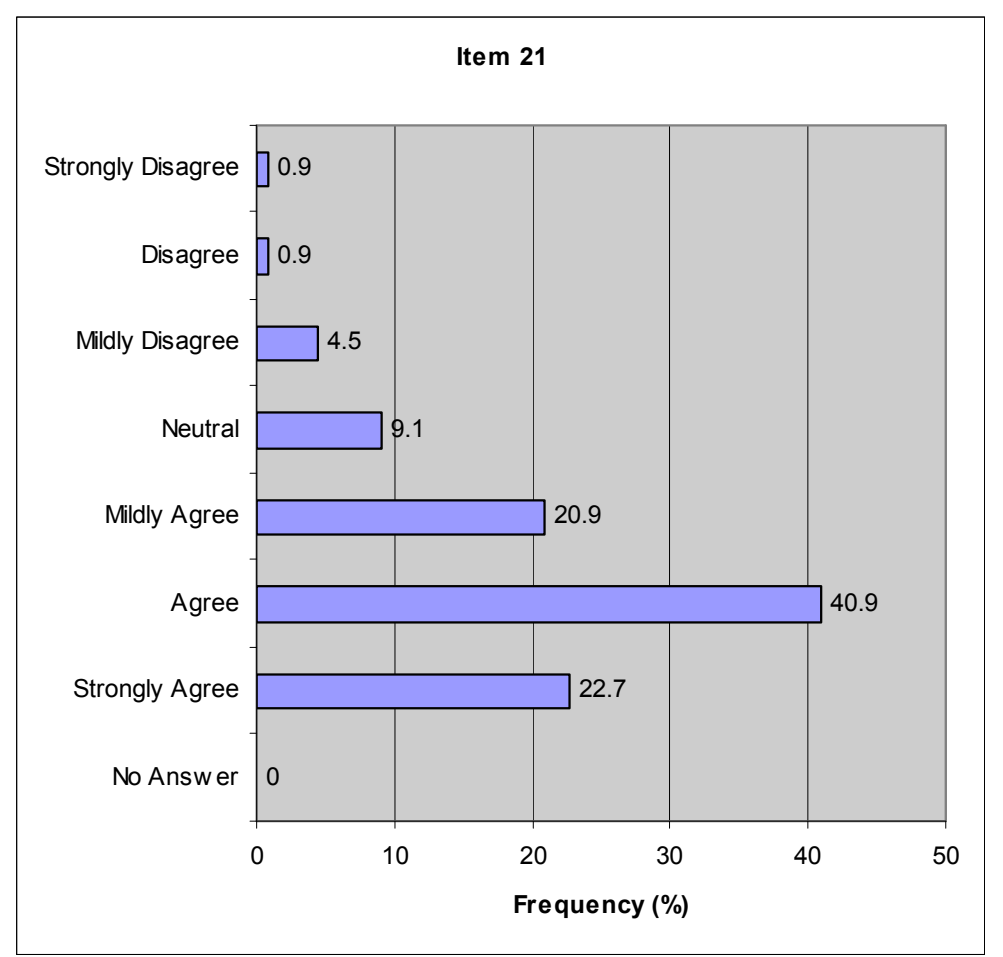

Organizational Health of the School Charts for Individual Synergy in Decision Making

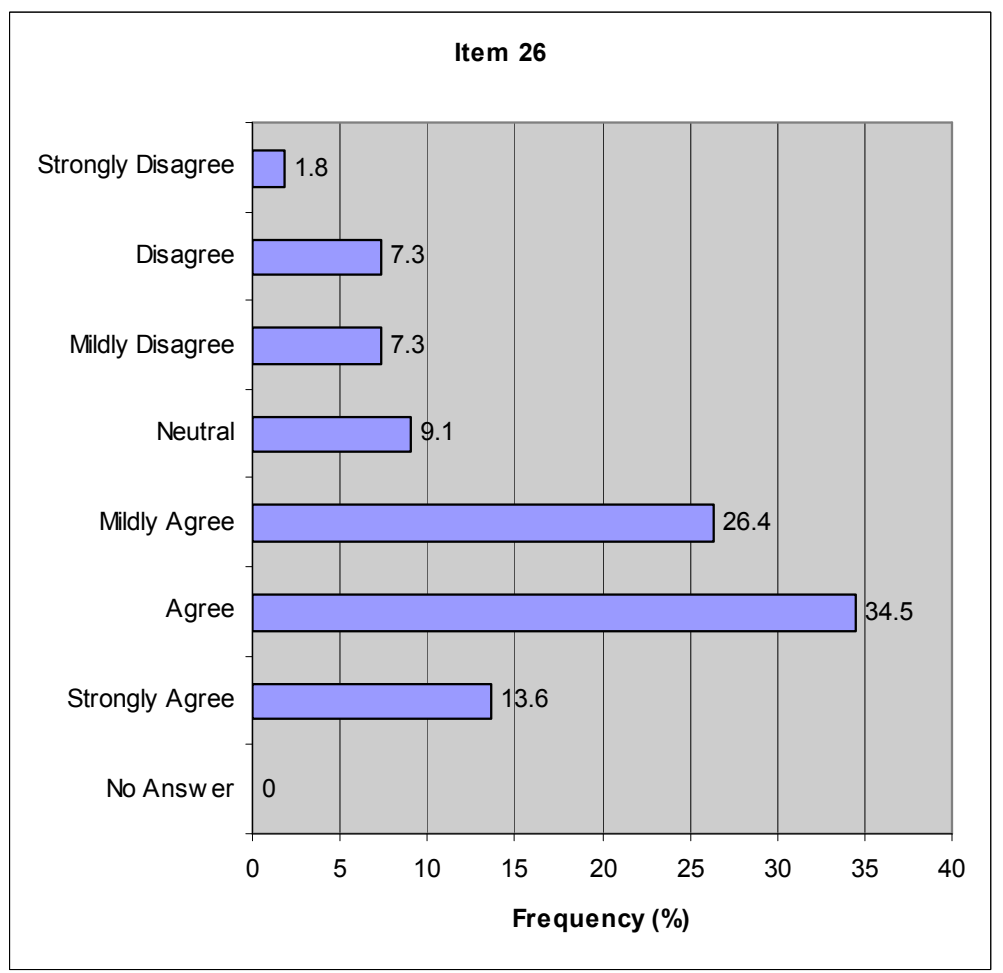


Appendix K (cont.)

Organizational Health of the School Charts for Institutional Synergy in Decision Making
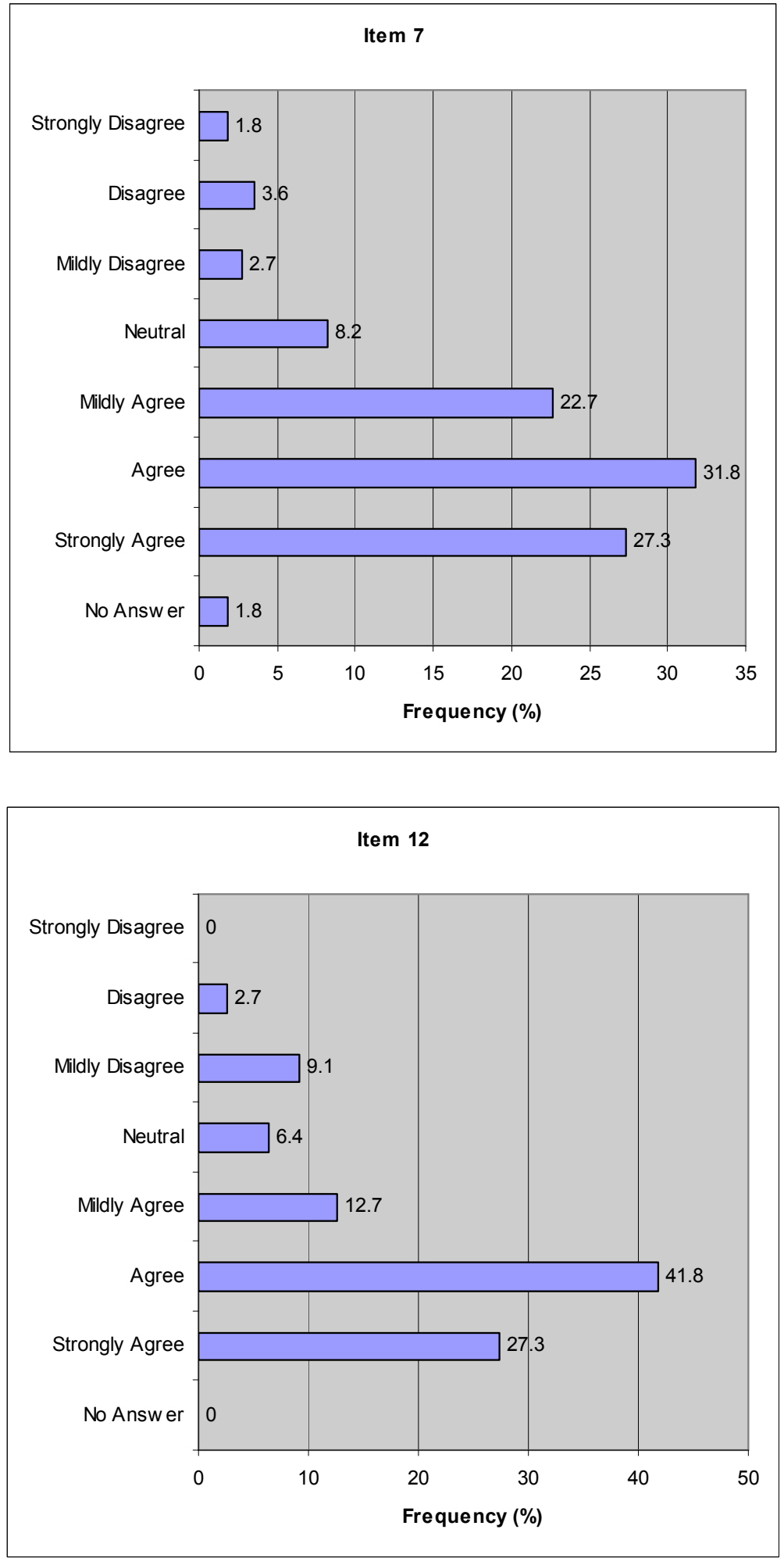


\section{Appendix K (cont.)}

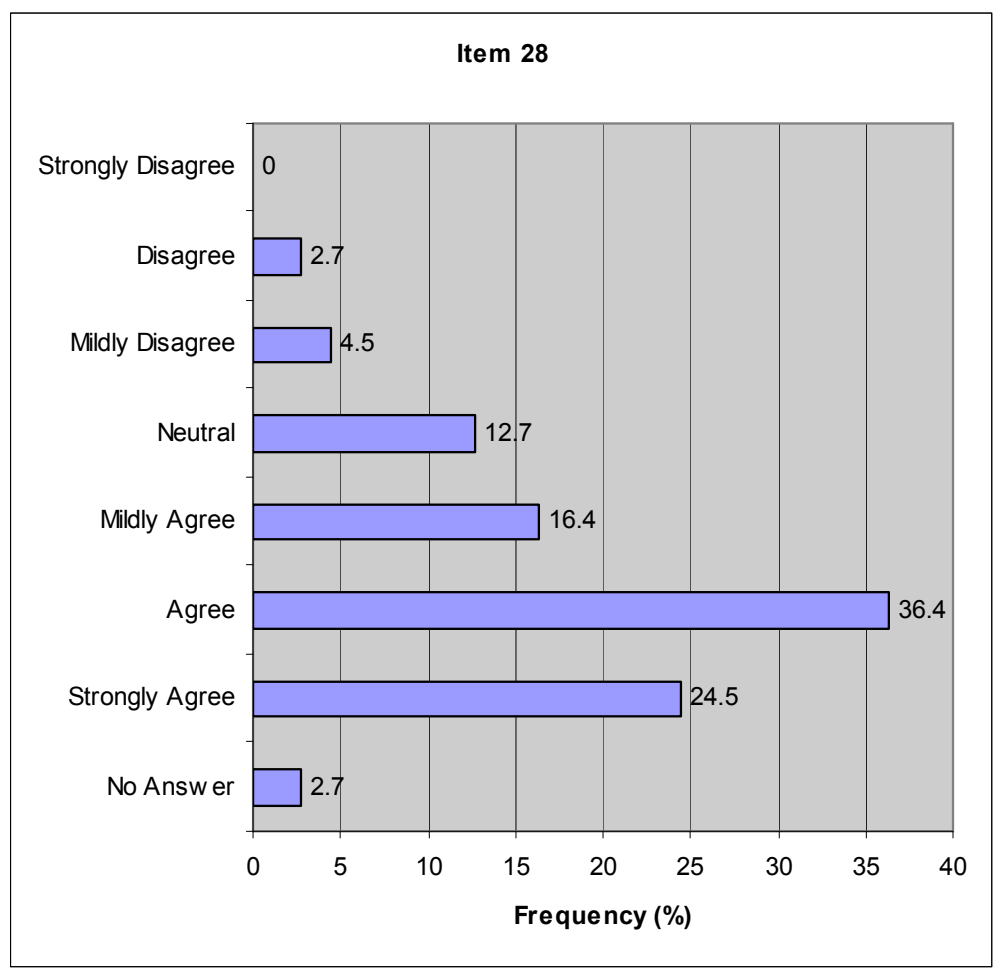

Organizational Health of the School Charts for Institutional Synergy in Decision Making

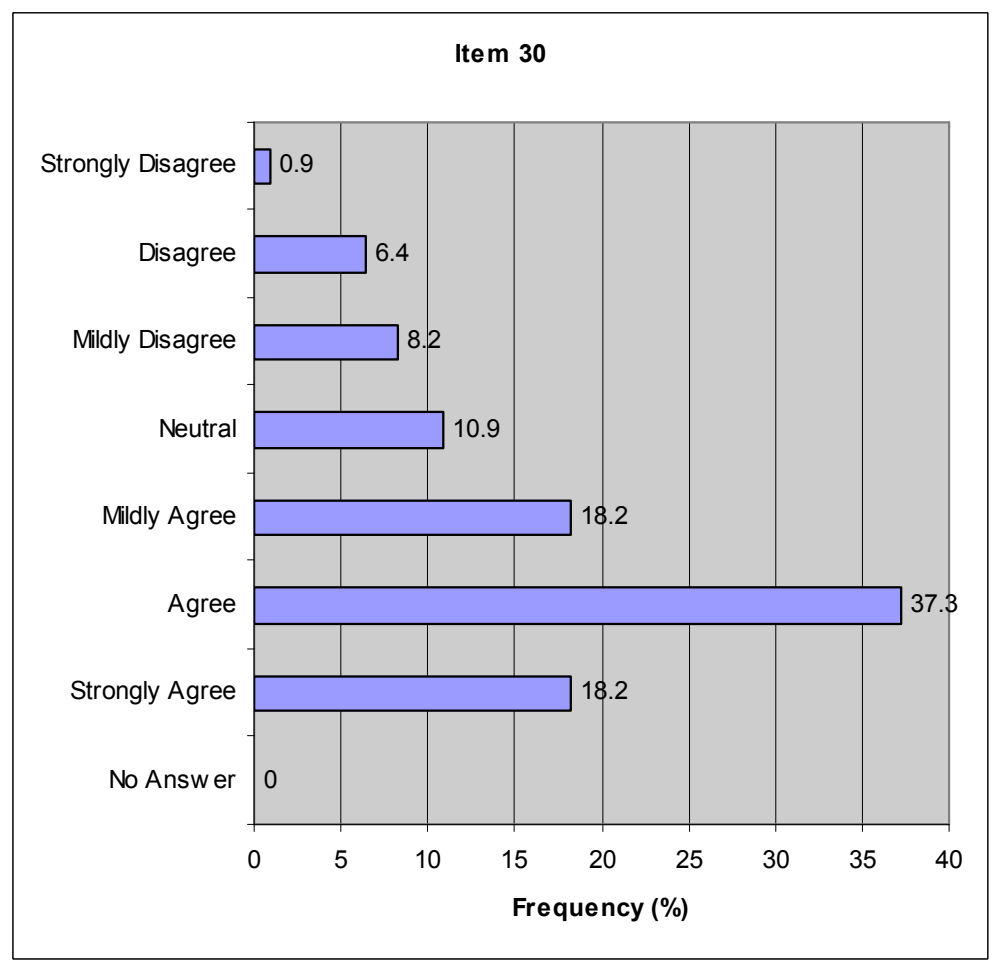




\section{Appendix K (cont.)}

Organizational Health of the School Charts for Support
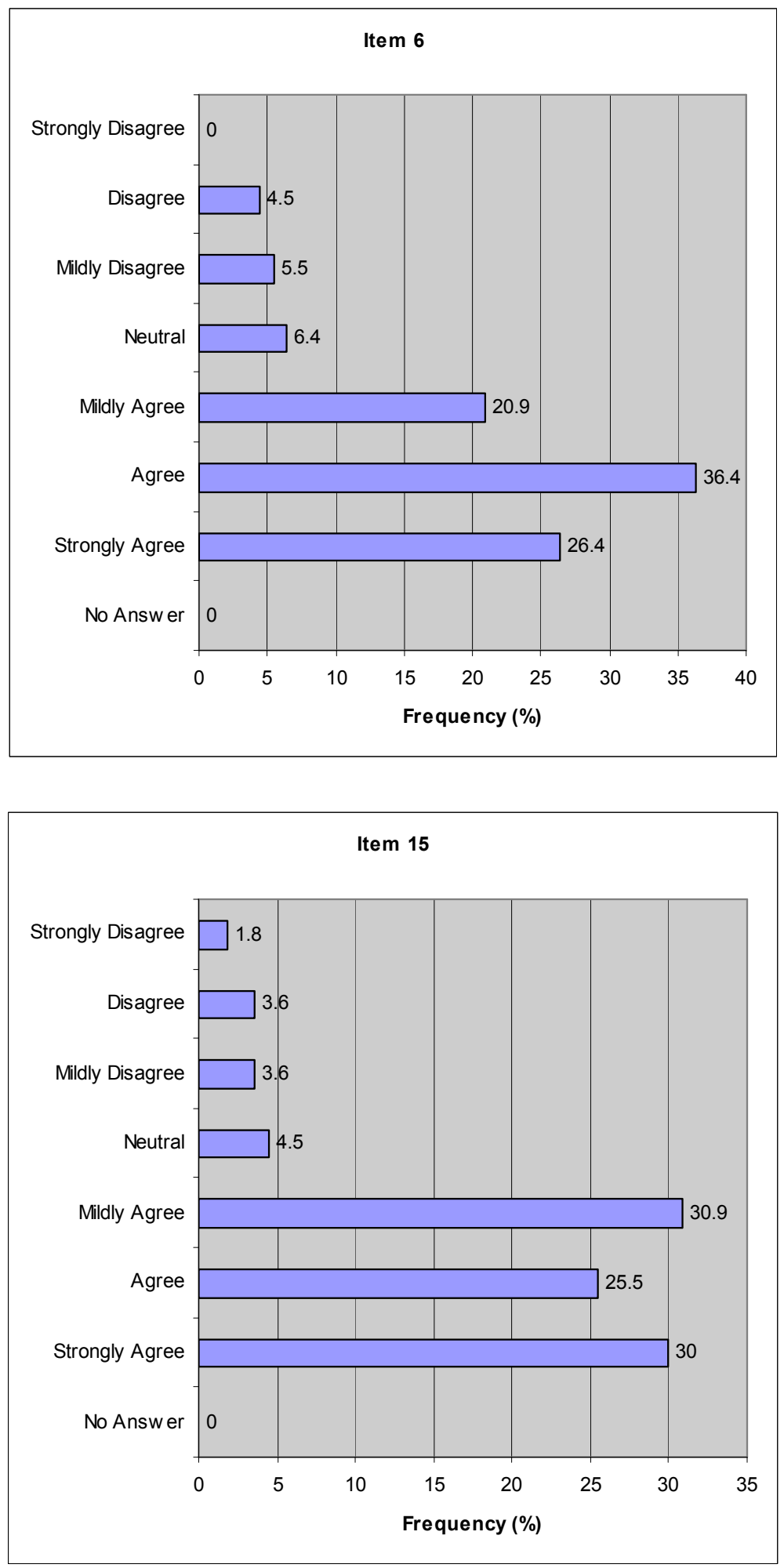


\section{Appendix K (cont.)}

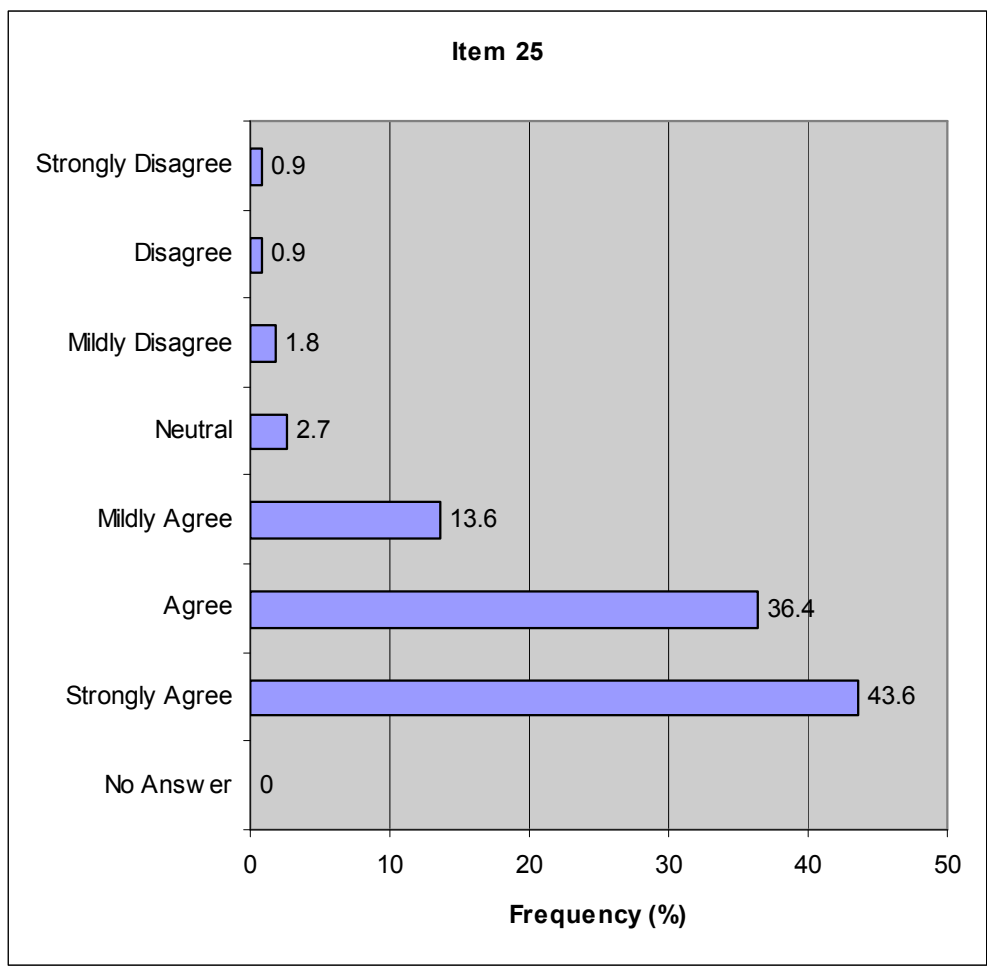

\section{Organizational Health of the School Charts for Attitudinal Outlook}

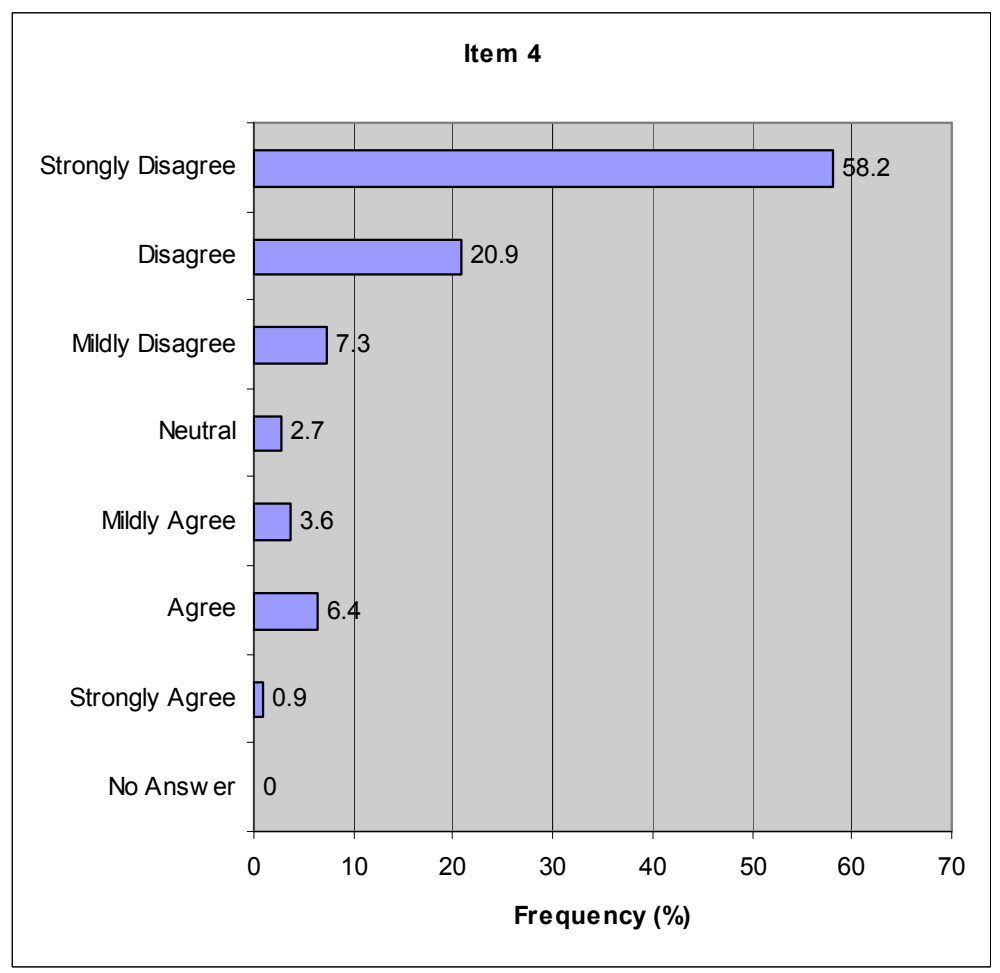


Appendix K (cont.)
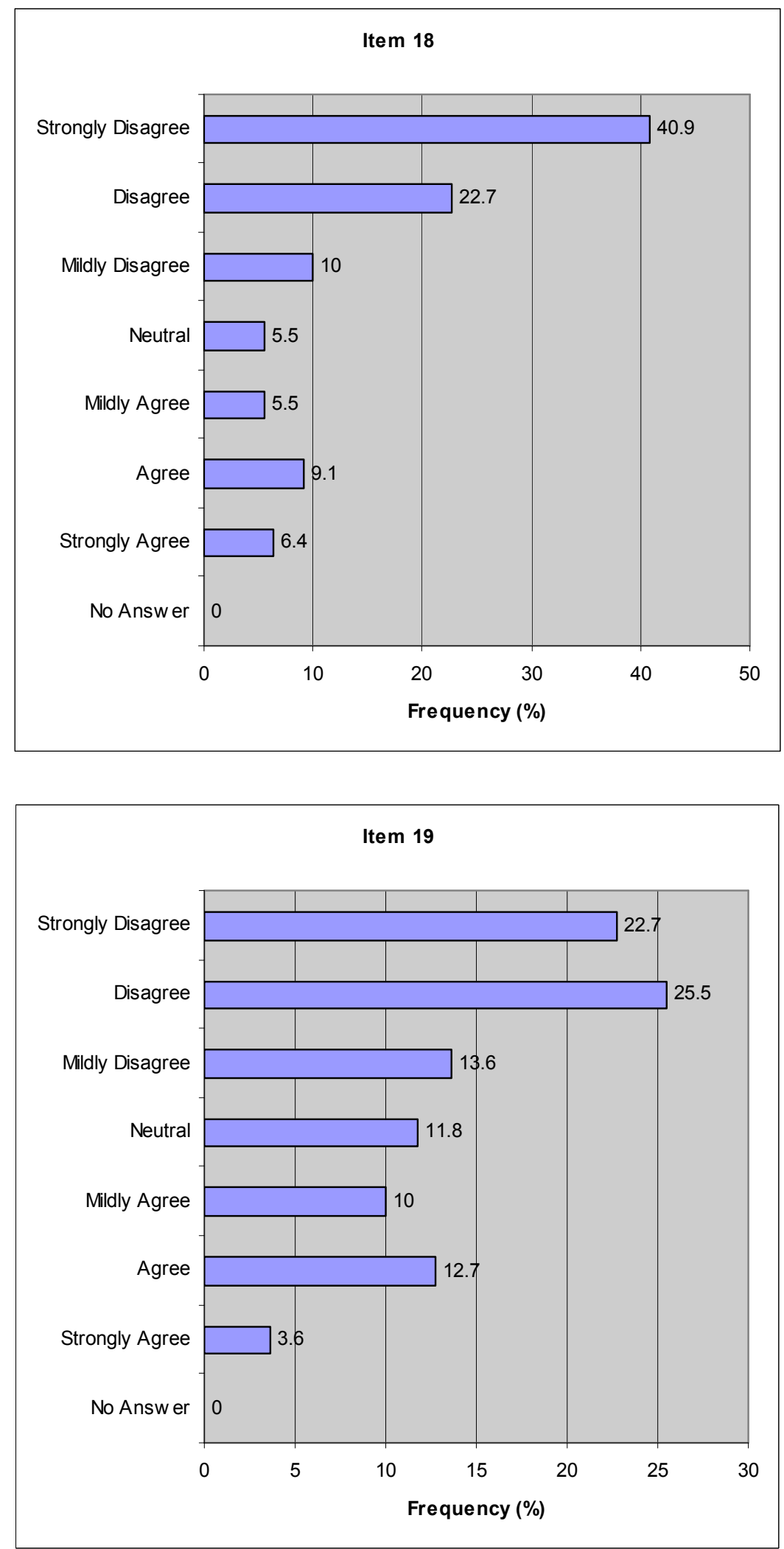


\section{Appendix K (cont.)}

Organizational Health of the School Charts for Attitudinal Outlook
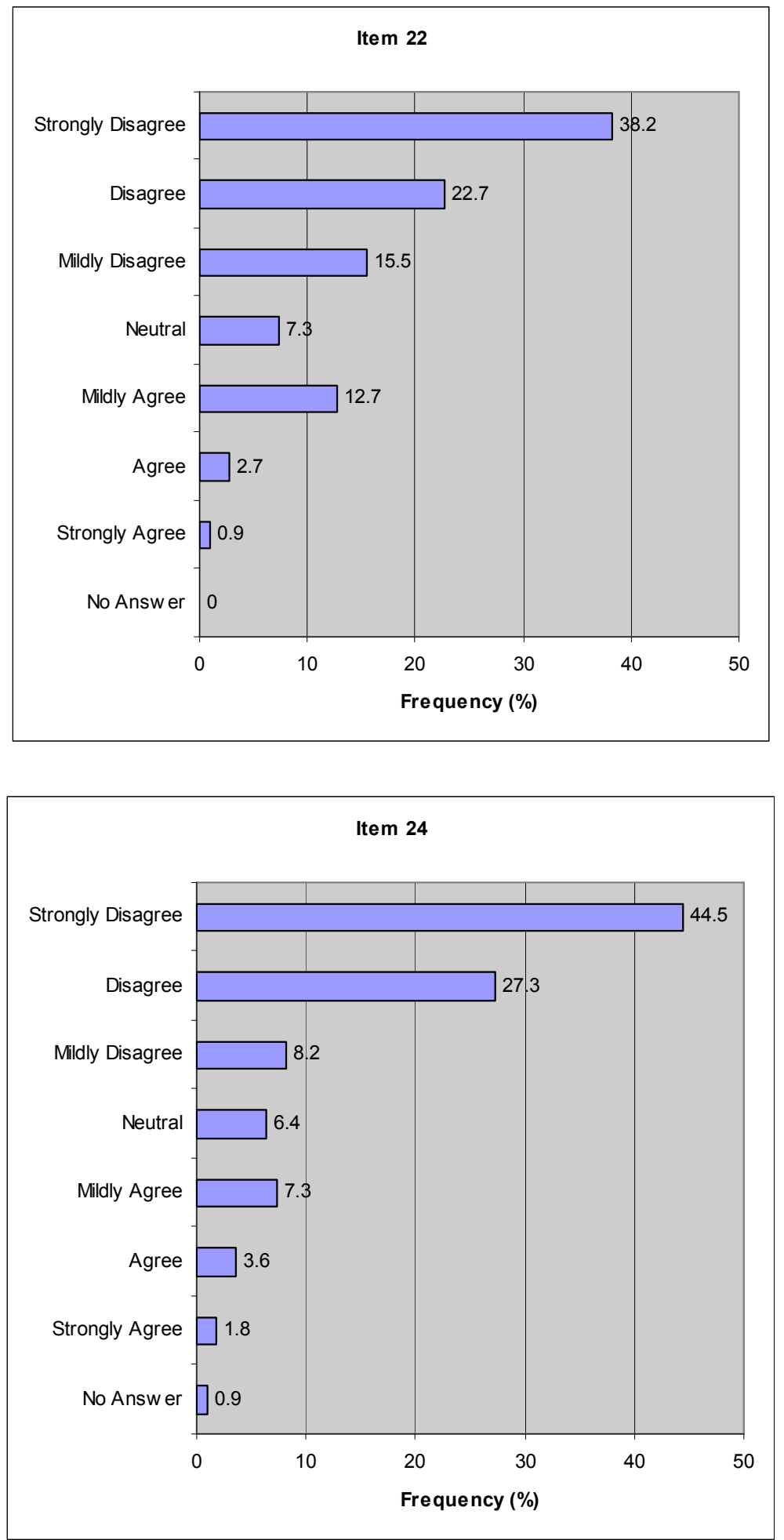


\section{Appendix L}

\section{Organizational Health of the School Charts of Percentage of Responses per Category}
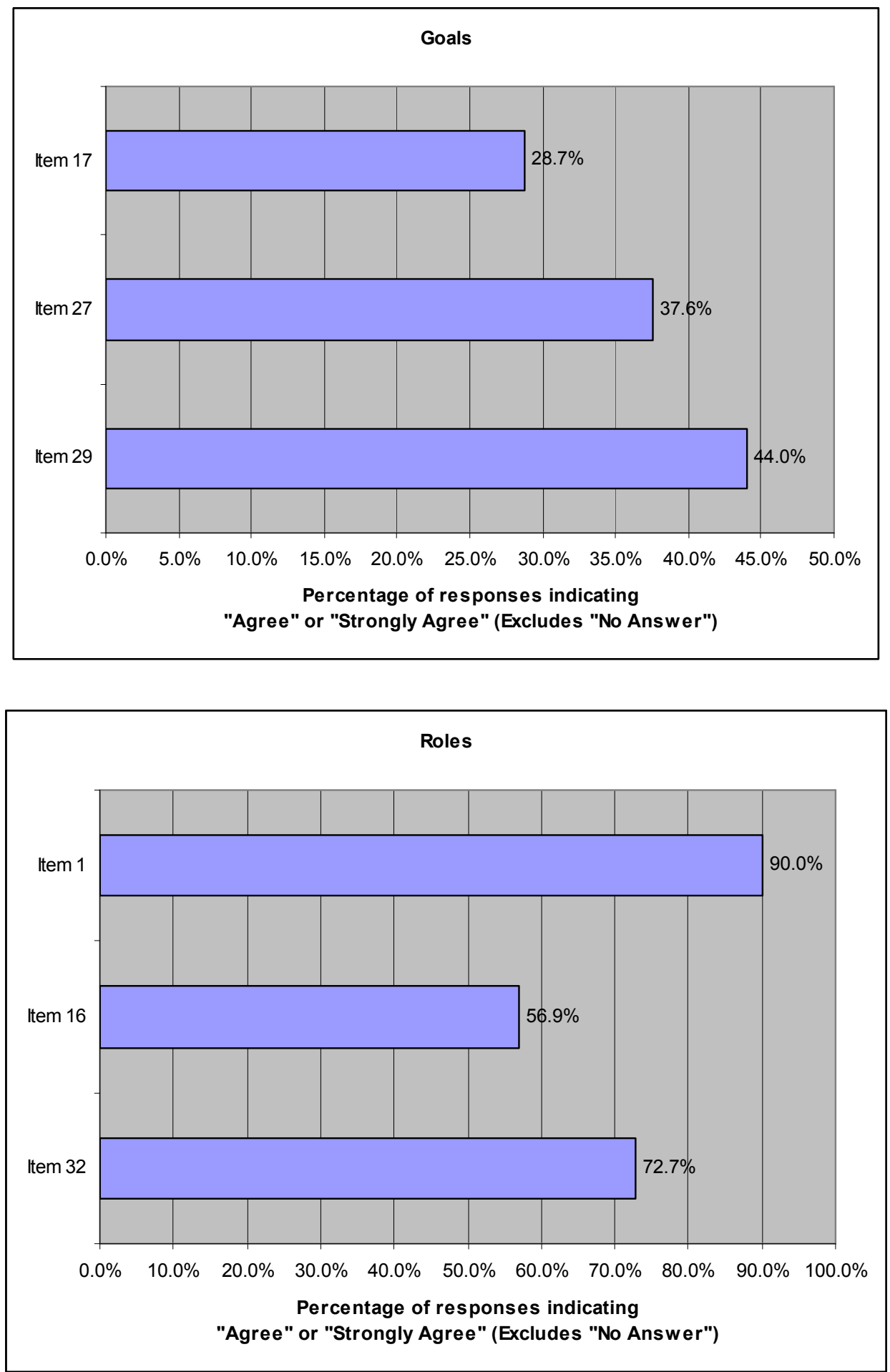
Appendix L (cont.)

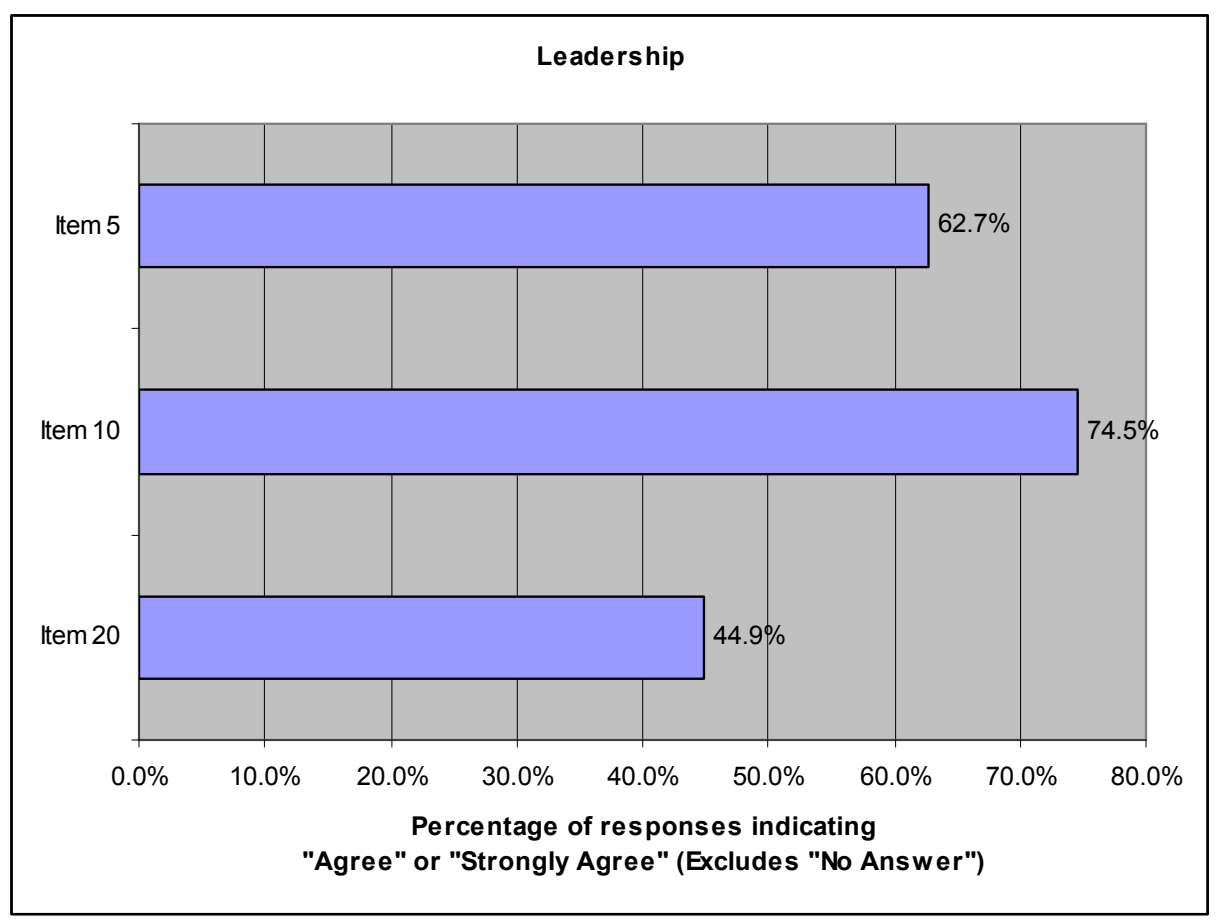

Organizational Health of the School Charts of Percentage of Responses per Category

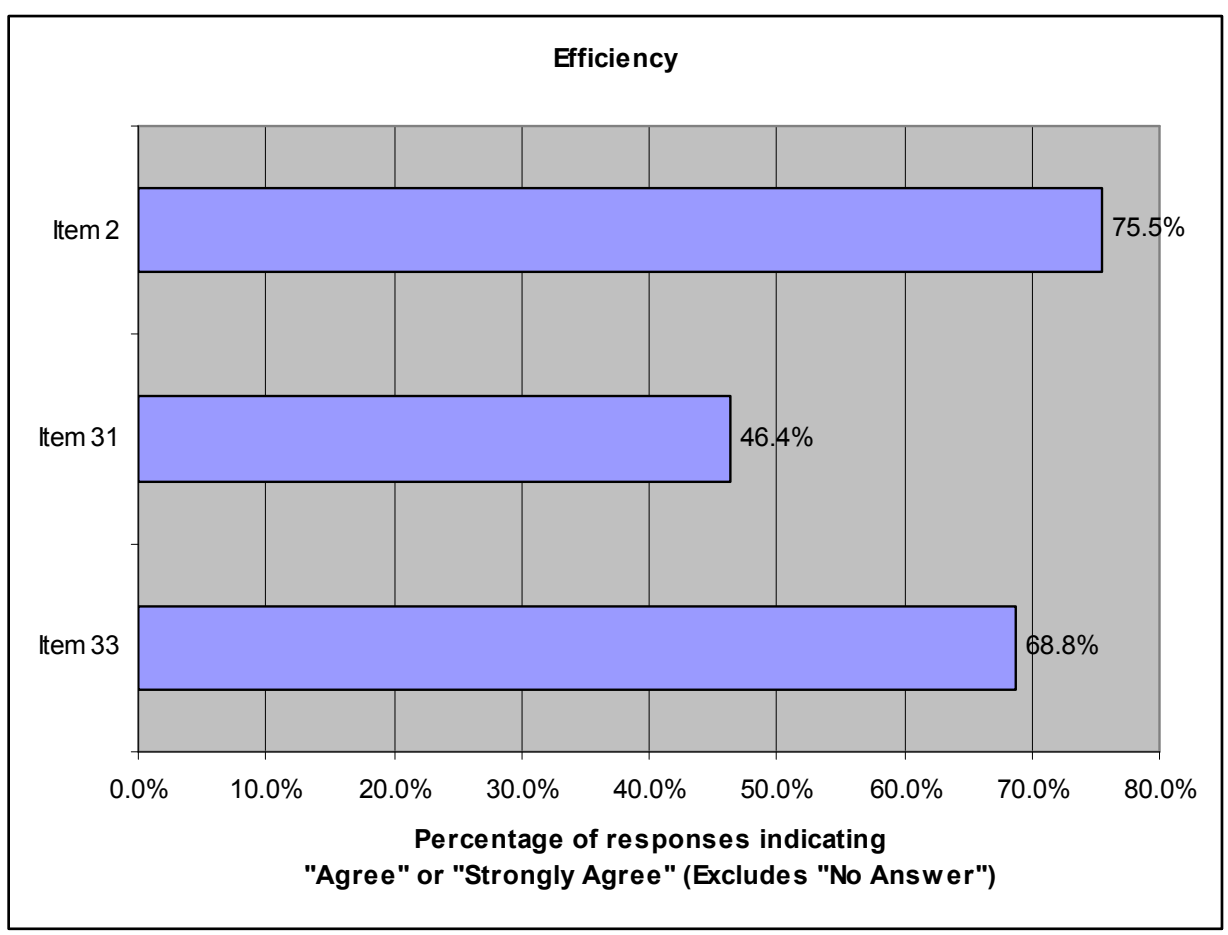


Appendix L (cont.)
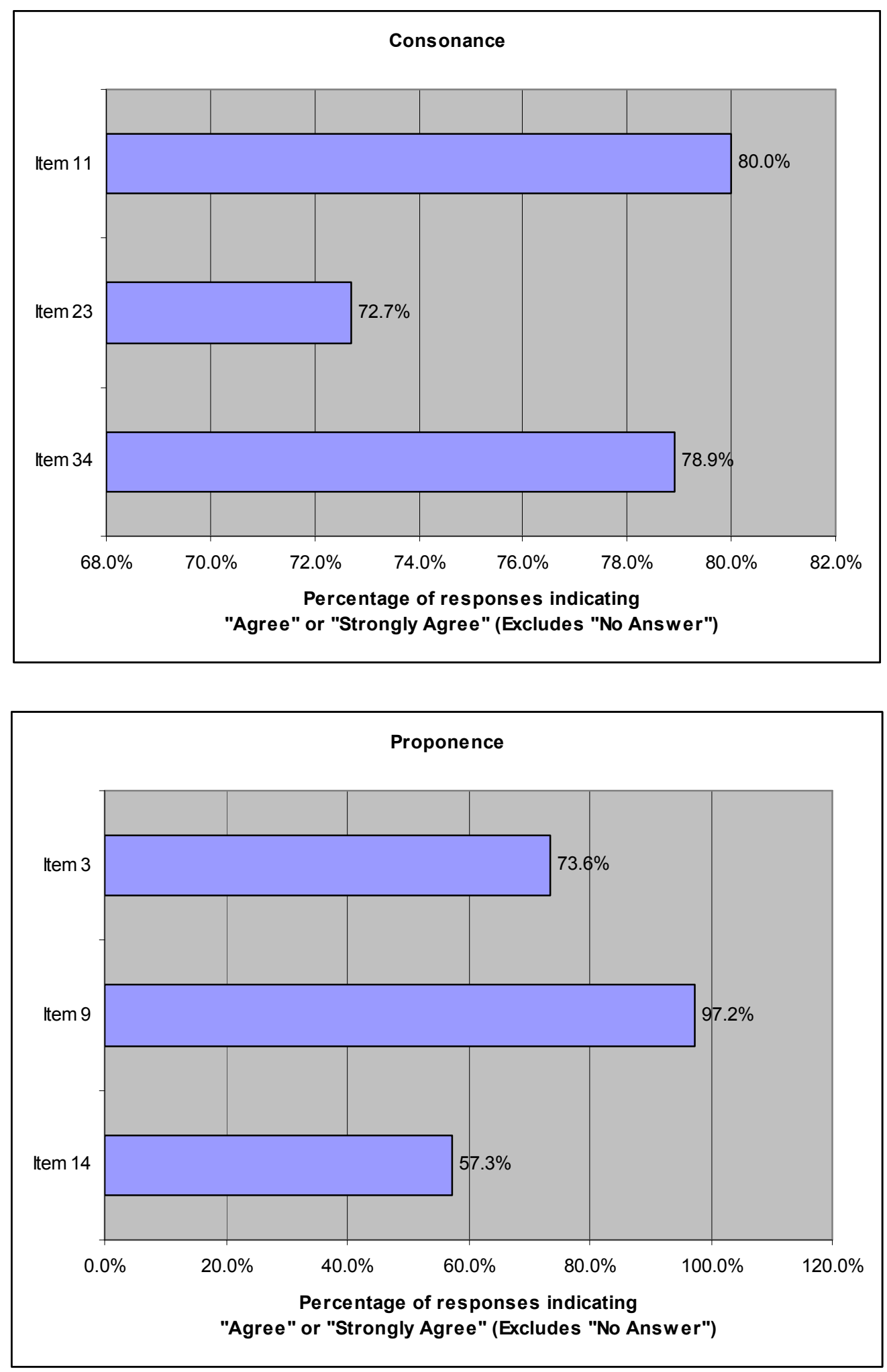
Appendix L (cont.)

Organizational Health of the School Charts of Percentage of Responses per Category
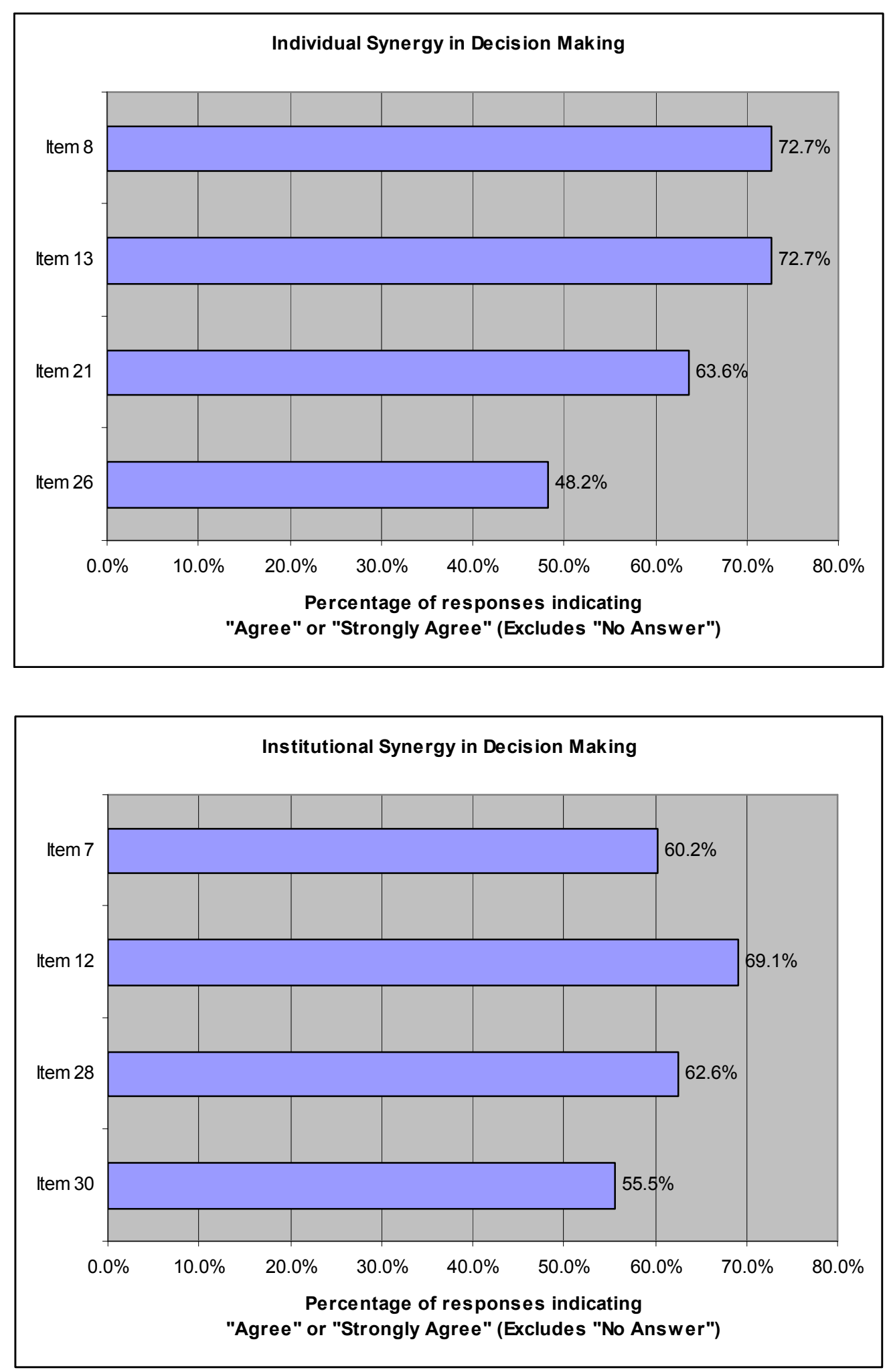
Appendix L (cont.)

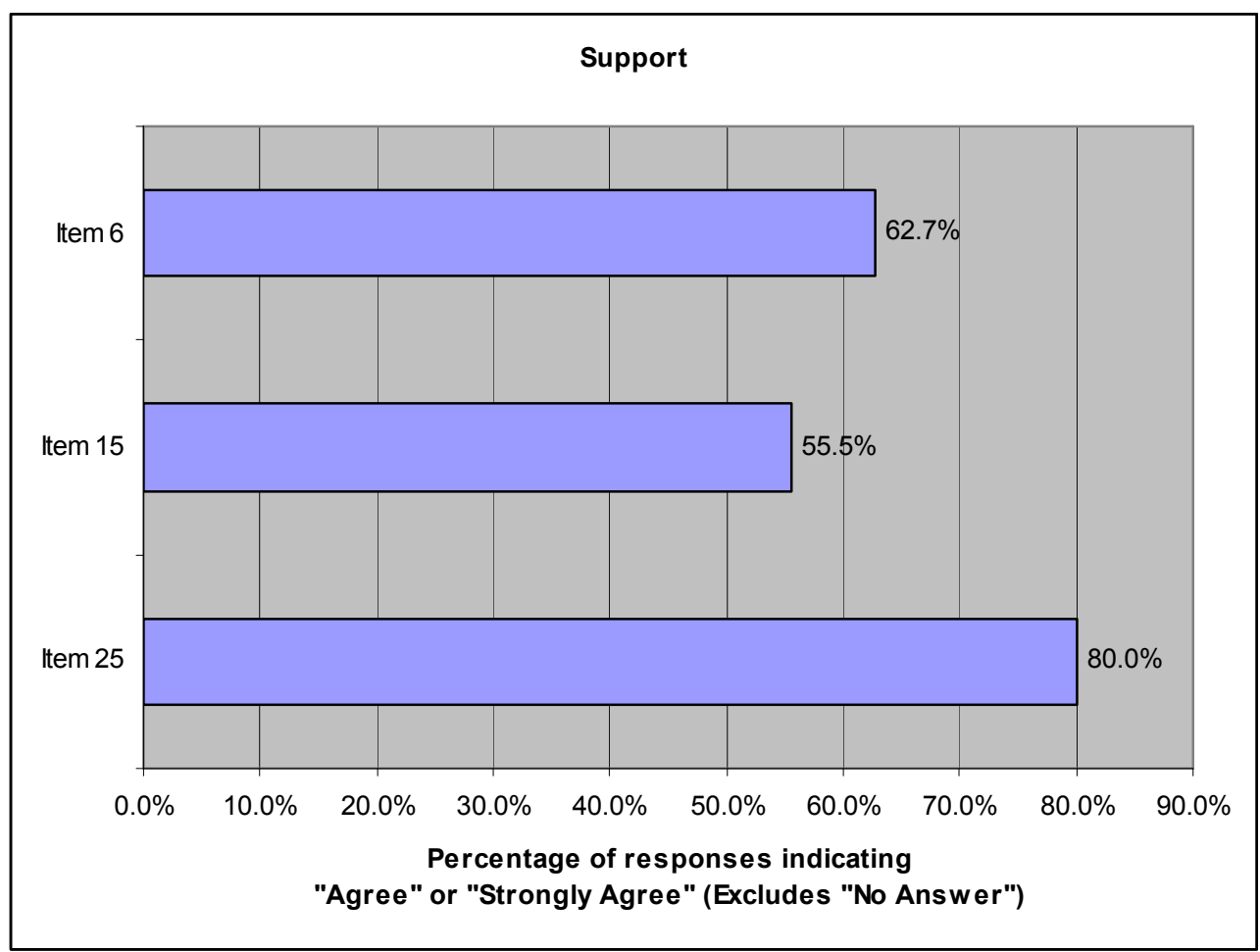

Organizational Health of the School Charts of Percentage of Responses per Category

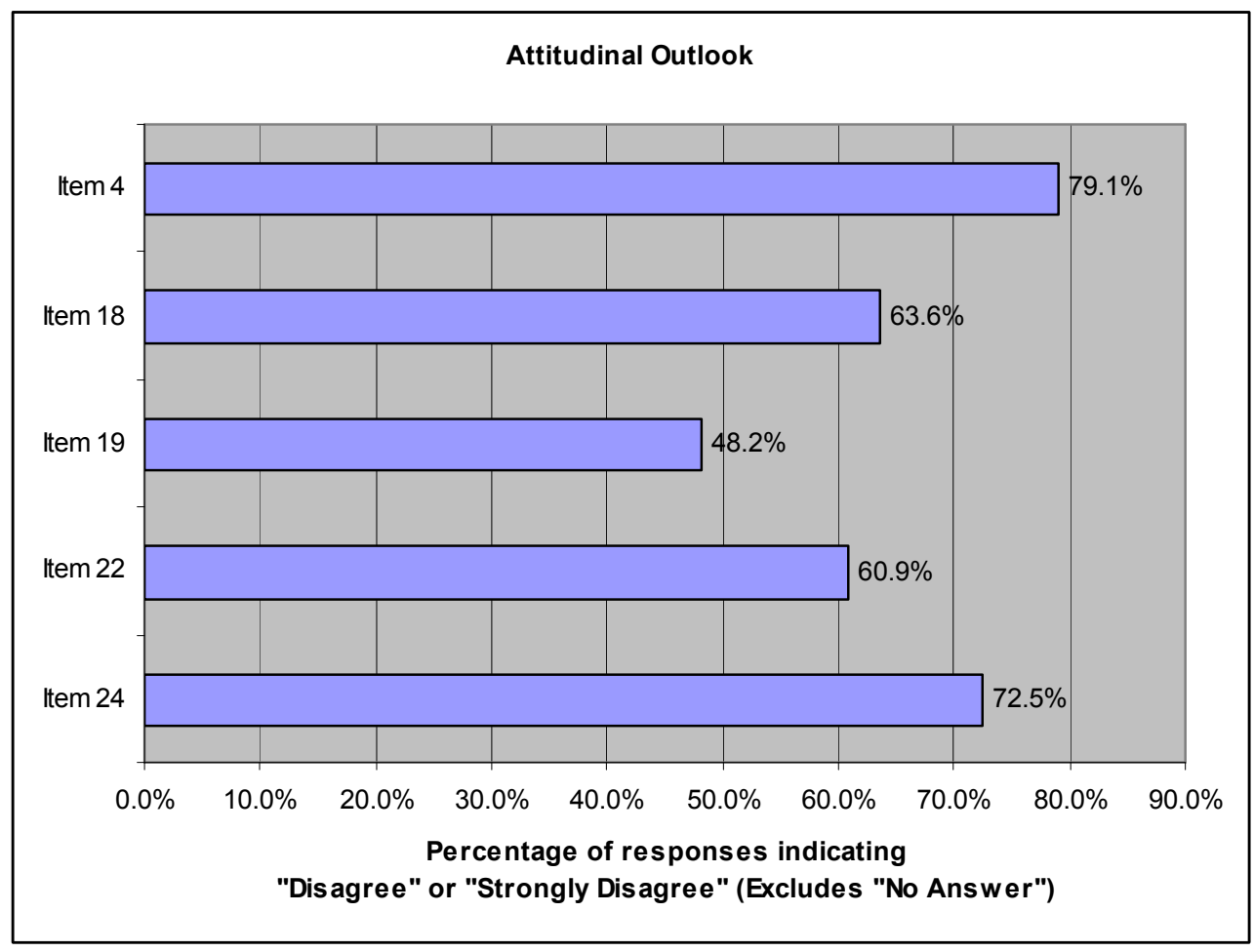


VITA

GUILLERMO M. GARCÍA-TUÑÓN, S.J.

November 26, 1969

1992-1995

1993-1996

1997-1999

2000-2008
Born, Miami, Florida

B.A., History

Florida International University

Miami, Florida

M.A., Philosophy

Fordham University

Bronx, New York

M.S., Education

Fordham University

Bronx, New York

M.Div., Theology

Instituto Santo Inacio

Belo Horizonte, Minas Gerais, Brazil

Philosophy Teacher

Theology Teacher

Belen Jesuit Preparatory School

Miami, FL 